\title{
Gestão do Conhecimento e
}

\section{Inovação}

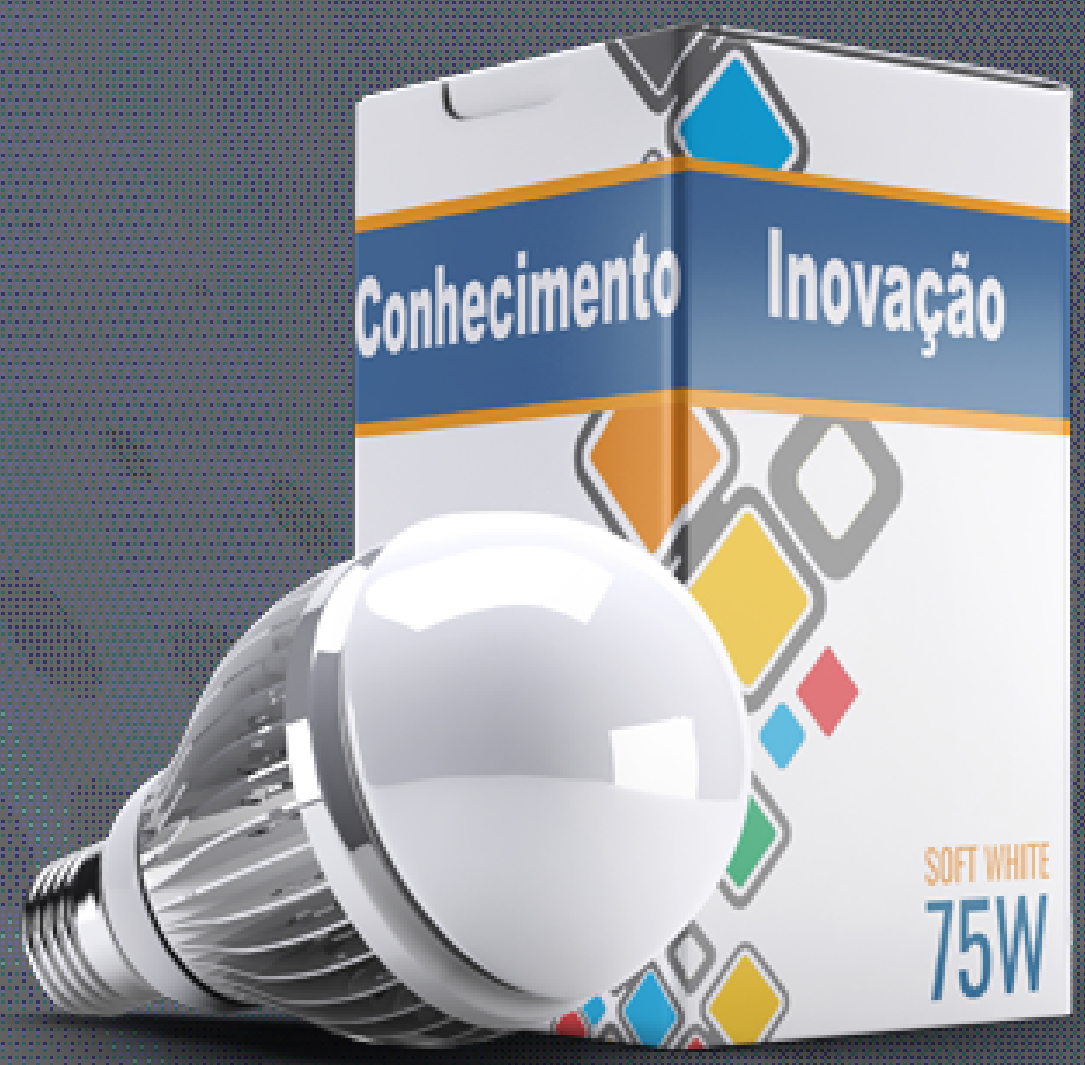

Brenner Lopes

(Organizador)

$\prec$ Editora Poisson 
Brenner Lopes

(organizador)

\title{
Gestão do Conhecimento e
}

\author{
Inovação \\ Volume I
}

1a Edição

Belo Horizonte

Poisson

2017 


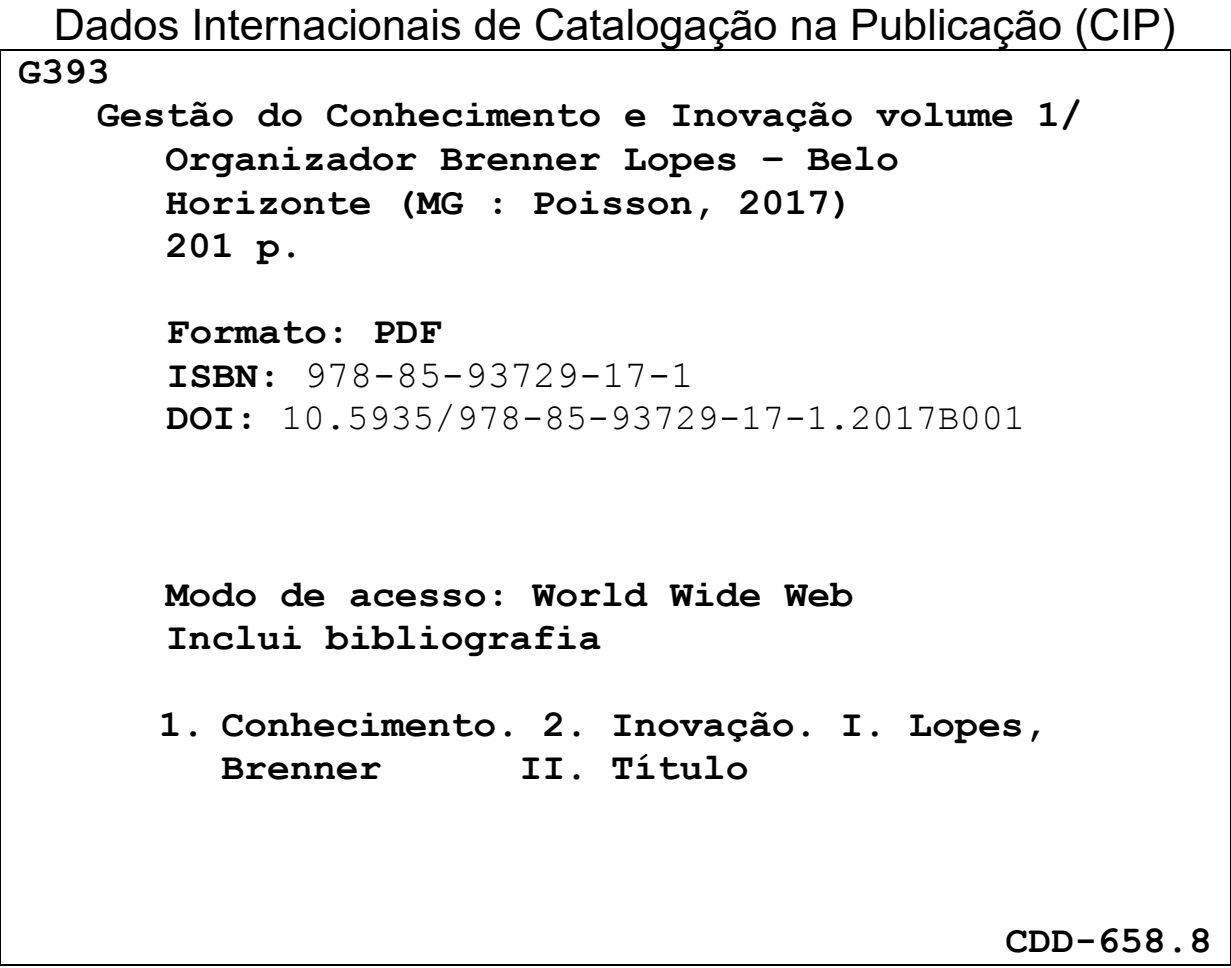

O conteúdo dos artigos e seus dados em sua forma, correção e confiabilidade são de responsabilidade exclusiva dos seus respectivos autores.

$\underline{\text { www.poisson.com.br }}$

contato@poisson.com.br 


\section{APRESENTAÇÃO}

Num momento da história da humanidade no qual o que se sabe vale mais do que o que se tem, e onde os tradicionais fatores de produção (capital, terra e trabalho) parecem não possuir o mesmo grau de relevância de tempos atrás, as palavras do visionário Alvim Toffler em seu instigante livro "A Terceira onda", de 1982, parecem estar mais atuais do que nunca: "pode-se criar mais valor com uma ideia em dez segundos do que com dez mil horas em uma linha de produção". Portanto, nada mais relevante, pertinente e atual do que discutir novas possibilidades e abordagens em gestão do conhecimento e inovação. E é justamente isso o que está proposto nos trabalhos que compõe essa obra.

Trataremos aqui de dois conceitos fundamentais e interligados, duas faces da mesma moeda, que devem ser entendidos dentro de um contexto único e encarados como as molas propulsoras do desenvolvimento de países, territórios, instituições e empresas.

Mas ao adentrarmos nessa seara, onde seremos conduzidos ao longo dos dezesseis capítulos dessa obra, numa viagem só de ida, cabe ressaltarmos dois questionamentos fundamentais.

Primeiro, entendendo que o conhecimento é algo intangível e que está "dentro da cabeça" das pessoas, mesmo que parte dele seja passível de exteriorização e codificação, seria possível efetivamente gerenciá-lo?

Segundo, sendo o processo de inovação uma abordagem que envolve novas ideias e maneiras de ver o mundo e seus problemas, novas tecnologias (não necessariamente apenas tecnologia da informação- TI) e novos conhecimentos, estaríamos falando da necessidade de um processo eminentemente criativo ou mais hermético e sistematizado? 
Para a primeira questão, uma possível resposta é que não há como "gerenciar" o conhecimento; sendo a alternativa, portanto, a criação e gerenciamento de um ambiente que possibilite a transferência, troca, criação e aplicação do conhecimento. Sendo assim, pode o leitor chegar a conclusão de que o termo "gestão do conhecimento" nada mais é do que um eufemismo.

Por sua vez, o processo de inovação, não necessariamente é um processo eminentemente só criativo e nem se desenvolve num ambiente de controle absoluto, onde não haja espaço para os erros. Tais erros podem ser grandes propulsores do processo de aprendizado, geração de conhecimento e inovação.

Com essas reflexões pode-se inferir que o fator mais relevante tanto no contexto da gestão do conhecimento quanto da inovação é a capacidade de se criar um ambiente profícuo, estimulante, com diversidade e liberdade, ao mesmo tempo em que se consiga acompanhar, gerir e propor estágios mais avançados a se galgar.

Métodos, competências, diversidade, estímulo, acompanhamento, gestão, liberdade, multiculturalismo, curiosidade, inconformismo, teoria, prática, novas visões, aceitação dos "erros sinceros". Elementos que permeiam e direcionam todos os capítulos cuidadosamente selecionados para comporem esse primeiro volume de "Gestão do Conhecimento e Inovação".

Um agradecimento aos autores dos capítulos pela cordial parceria e que bons ventos soprem novamente nessa direção! Boa leitura!

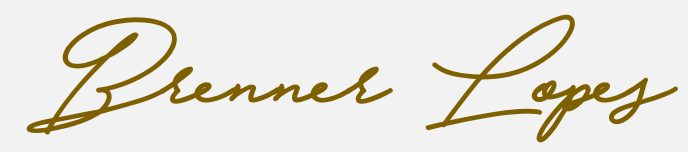




\section{SUMÁRIO}

Capítulo 1: Monitoramento da arquitetura da gestão do conhecimento em indústrias de micro e pequeno porte da região de Sorocaba (Haroldo Lhou Hasegawa, Vidal Dias Da Mota Junior, Ana Cristina Da Costa Piletti, Délvio Venanzi, João Pedro Albino)

Capítulo 2: Mineração de dados aplicada à base de dados do imposto ISS 22 (Alcione Dias Da Silva, Bruno Missi Xavier, Geórgia Regina Rodrigues Gomes, Marcelo Tadeu Monteiro Freitas, Willen Borges Coelho)

Capítulo 3: Sistema integrado de gestão - ERP: fatores que influenciam na implantação de um novo sistema

(Janaina Wohlenberg, Claudio Sonaglio Albano, Michel Stein Barbosa, André Irazoqui De Lima)

Capítulo 4: Exploration e exploitation em instituições de ensino superior 40 (Fernando Ribeiro Dos Santos, Laura Melo Barros Bona Miranda)

Capítulo 5: Desenvolvimento de um modelo para o levantamento das necessidades de capacitação dos servidores técnico- administrativos em educação lotados na pró-reitoria de gestão de pessoas da UFSM (Luciane Ines Matte, Daniel Arruda Coronel)

Capítulo 6: A Gestão da Informação com Foco na Tomada de Decisão de um Gestor Público

(Silvio Luiz De Paula, Tiberius Mariano Medeiros, Antônio De Souza Silva Junior)

Capítulo 7: Percepções dos gerentes de projeto em relação às falhas e barreiras de comunicação

(Marilyn De Souza Cyganczuk, Ricardo Mendes Junior, Jose Eduardo Pecora Jr)

Capítulo 8: Evidenciação das inovações realizadas pelas agroindústrias listadas na ABIOVE

(Pablo De Lima, Fernanda Mosseline Josende Coan, Marcelo Elias Dos Santos) 
Capítulo 9: Análise da base de atendimento de emergência e urgência nas unidades públicas de saúde de campos dos Goytacazes

(Vaneska Tavares Rangel Prestes, Maria Eugenia S.S. Vasconcelos, Geórgia Regina Rodrigues Gomes)

Capítulo 10: Modelagem de processo e priorização de projetos de TI utilizando múltiplos critérios.

(Renata Gomes Cordeiro, Munir De Sá Mussa, Rafael Leite De Freitas, Henrique Rego Monteiro Da Hora, Simone Vasconcelos Silva)

Capítulo 11: Transferência de tecnologia: a cultura como um contributivo aporte teórico à investigação da relação entre os laboratórios públicos de pesquisa e as EBT's

(Daisy Campos Alvim, Valderez Ferreira Fraga)

Capítulo 12: O Processo de Implementação do BPM no Cloud Computing (Rodolfo De Amorim Paulo, Luiz Gabriel Pereira Herzog, Stephany Pereira Dos Santos, Roquemar De Lima Baldam)

Capítulo 13: Inovação no planejamento mestre de produção e operações no ramo alimentício

(Thiago José Barbosa Dantas., Murilo Gonçalves Almeida, Flávio De São Pedro Filho, Carolina Yukari Veludo Watanabe., Tomás Daniel Menendez Rodriguez)

Capítulo 14: As informações contábeis no processo de tomada de decisão nas organizações

(Elias Garcia, Jorge Bidarra)

Capítulo 15: Uso do Sistema de Informação Gerencial para Tomada de Decisões nas organizações

(Elias Garcia, Osmarina Pedro Garcia Garcia, Udo Strassburg)

Capítulo 16: Construção de um Data Warehouse utilizando ferramenta open source no processo de Gestão da Informação Gerencial (Larissa Lourenço Nunes Benck, Simone De Almeida, Emanoély Fernanda Gura Vieira)

\section{Autores}




\section{Bajfitolo1}

\section{MONITORAMENTO DA ARQUITETURA DA GESTÃO DO CONHECIMENTO EM INDÚSTRIAS DE MICRO E PEQUENO PORTE DA REGIÃO DE SOROCABA}

Haroldo Lhou Hasegawa

Vidal Dias da Mota Junior

Ana Cristina da Costa Piletti

Délvio Venanzi

João Pedro Albino

Resumo: O presente projeto estudou a arquitetura da Gestão do Conhecimento (GC) pela realização de um benchmarking, comparando os dados e os resultados da análise de três empresas de Sorocaba de micro e pequeno porte (MPE) pertencente a diferentes ramos de atuação, Metal Mecânico, Construção Civil e Consultoria Empresarial. A escolha das organizações MPE se baseou em estudos realizados pelo SEBRAE (Serviço Brasileiro de Apoio a Micro e Pequenas Empresas) na qual indicaram que as MPE's são as que mais absorvem a mão de obra e também pelo fato destas empresas prestarem serviços e também serem responsáveis pela terceirização da produção. Portanto o fortalecimento destas empresas resulta em um parque industrial competitivo e coeso permitindo o crescimento econômico da região. Dentro deste contexto o estudo permitiu analisar o real posicionamento das organizações com relação à GC, sendo que, todas as empresas analisadas encontravam-se no estado "Priorizar/Selecionar", estado na qual as atividades e processos de GC são pouco difundidos. Por outro lado, a aplicação de treinamentos e uma maior interação das responsabilidades indicou uma sensível melhora na aplicabilidade da GC e ao mesmo tempo mostrou que, segundo a opinião dos entrevistados, a principal barreira para implementação da GC é a falta de patrocínio e metodologias claras e objetivas por parte da alta gestão.

Palavras-chave: Monitoramento; Gestão do Conhecimento 


\section{INTRODUÇÃO}

Atualmente o município de Sorocaba é considerado uma das seis maiores economias do Estado de São Paulo e tem atraído a atenção não só das indústrias, como também, do sistema educacional de nível superior. Tal fato se deve ao seu amplo e crescente parque industrial, destacando se o setor metal-mecânico, somado a forte atuação dos setores de serviços. Este crescimento vem acompanhado pela instalação do Parque Tecnológico e também de novas empresas multinacionais, como a terceira planta brasileira da montadora de automóveis Toyota do Brasil, de novas plantas de multinacionais produtoras de veículos pesados como a Case e a JCB do Brasil e também do centro de manutenção da Embraer o que resulta em um município com um parque industrial moderno e competitivo (SEADE, 2015).

Tal cenário de atração de grandes corporações traz uma expectativa muito grande para as redes de micro, pequenas e médias empresas instaladas na cidade, que pretendem ampliar seus negócios via terceirização e prestação de serviços. Segundo dados da prefeitura de Sorocaba (SEADE, 2015) existem aproximadamente 1800 indústrias inseridas nestas categorias, portanto, diante desta realidade a adoção de novas metodologias e técnicas de administração que impactam diretamente na produtividade e também na lucratividade é de grande importância e dentro deste contexto, a Gestão do Conhecimento (GC), é vista como uma estratégia de negócio que pode trazer ganhos significativos de competitividade para as organizações (SANTOS e NETO, 2008; REIS e MILAN, 2009).

Apesar da importância, a aplicabilidade e investimentos em GC se torna complexo quando se trata de empresas com pouca estrutura financeira, administrativa e tecnológica, ou seja, o caso das micro e pequenas empresas (MPE) não somente de Sorocaba mais de todo o território nacional, sendo que segundo dados divulgados no ano de 2009 pelo SEBRAE (2012), as MPE's representam $98 \%$ de todas as empresas instaladas no Brasil, além de empregar aproximadamente $56 \%$ da mão de obra com carteira assinada (CLT). Logo o fortalecimento destas empresas resulta também na garantia da empregabilidade e também do desenvolvimento econômico.

Por outro lado, a competitividade das MPE's muitas vezes depende exclusivamente do planejamento estratégico baseado apenas no conhecimento técnico e mercadológico do proprietário ou dos gestores da alta gerência, sendo que as estratégias empresariais, normalmente, são de caráter informal, intuitiva e incremental sem que haja uma estratégia definida e documentada (REGGIANI e DALCOL, 2011).

Portanto a mudança da cultura e também da incorporação de modelos de gestão, como por exemplo, a GC, torna-se de fundamental importância para garantir a sobrevivência das empresas MPE's de modo economicamente viável e competitivo, sendo que esta mudança deve ser aplicada de uma forma não muito complexa, que resulte em esforços finaceiros compatíveis e viáveis para que as empresas instaladas em Sorocaba, principalmente as MPES's, possam continuar operando de forma saudável e sustentável.

\section{REFERENCIAL TEÓRICO}

\subsection{INFORMAÇÃO E TECNOLOGIA DA INFORMAÇÃO}

Para Dias e Belluzzo (2003), a informação é um conjunto de dados que podem trazer alguma vantagem e que quando corretamente manuseados resultam em conhecimento. Os dados podem ser entendidos como fatos distintos e pessoais que descreve e relata apenas os fatos que ocorreram. Portanto, a informação pode ser entendida como dados organizados de modo sistemático e significativo, tanto que a mesma pode ser classificada em informação do tipo científico, tecnológico e de estratégia de negócios, sendo que, a correta interpretação e transmissão destas são o ponto de partida para que uma organização passe a operar de um modo mais efetivo. Tal fato é destacado por Takeuchi e Nonaka (1997), uma vez que,"quando existem diferenciais de informações dentro da organização, os membros da organização não conseguem interagir nos mesmos termos retardando a busca de diferentes interpretações das novas informações".

Dentro deste contexto, é possível afirmar, que as informações estão disponíveis na forma de inúmeros tipos de suportes sendo que atualmente o meio digital tem se tornado a principal fonte e também de uso. Portanto o gerenciamento destas depende fortemente de uma estrutura baseada na Tecnologia de Informação ou simplesmente da TI 
(BELTRAME e MAÇADA, 2009; HABERKAMP et al, 2010).

Por outro lado, para Silva et al (2006), a popularização da tecnologia e o avanço da economia digital colocaram a TI no centro do ambiente empresarial, fazendo com que esta exerça papel decisivo na capacidade de muitas empresas competirem. Porém o conceito de TI é muito mais profundo do que simplesmente o processamento de dados, sistemas de informação ou o conjunto de hardware e software, pois também envolve aspectos humanos administrativos e organizacionais (LAURINDO et al, 2001).

Já o debate envolvendo o custo benefício da utilização das ferramentas de $\mathrm{TI}$ persiste desde que a tecnologia de processamento de dados se tornou parte fundamental para auxilio na organização para o gerenciamento de dados e informações. O uso destas tecnologias têm se intensificado na última década com a popularização do uso da internet, queda no preço dos ativos em $\mathrm{Tl}$ e principalmente pelo desenvolvimento de novas tecnologias digitais e aumento nos processo de automação dentro das organizações (BELTRAME e MAÇADA, 2009; ALBERTIN e SANCHEZ, 2009).

Porém é inegável que em um cenário de rápidas mudanças e competição crescente, o conhecimento de como a $\mathrm{TI}$ interage nas organizações configura-se importante, pois tal fato resulta diretamente nas mudanças culturais, assim como, mudanças no comportamento dos interlocutores. Logo o papel a ser desempenhado pela TI pode ser considerado como estratégico, principalmente para auxiliar o desenvolvimento do conhecimento coletivo e do aprendizado contínuo, tornando mais fácil, para as pessoas nas organizações compartilharem problemas, perspectivas, ideias e soluções (PEREIRA, ABREU e REZENDE, 2002).

\subsection{GESTÃO DO CONHECIMENTO}

O conceito de GC, apesar de parecer moderno no início da década de 1980 Parsons (1983), já afirmava que a geração do conhecimento depende fortemente do manuseio e interpretação das informações, ou seja, a informação pode ser definida como um conjunto de dados e fatos que visam trazer alguma vantagem, como por exemplo, a diminuição no tempo de desenvolvimento de projetos ou aumento na eficiência para responder as necessidades do mercado. Logo a informação pode ser entendida como dados organizados de modo significativo podendo ser classificada em três tipos: científico, tecnológico e de estratégia de negócios e a correlação entre eles pode ser observado na Figura 1.

Figura 1 - Relação entre os três principais tipos de informações.

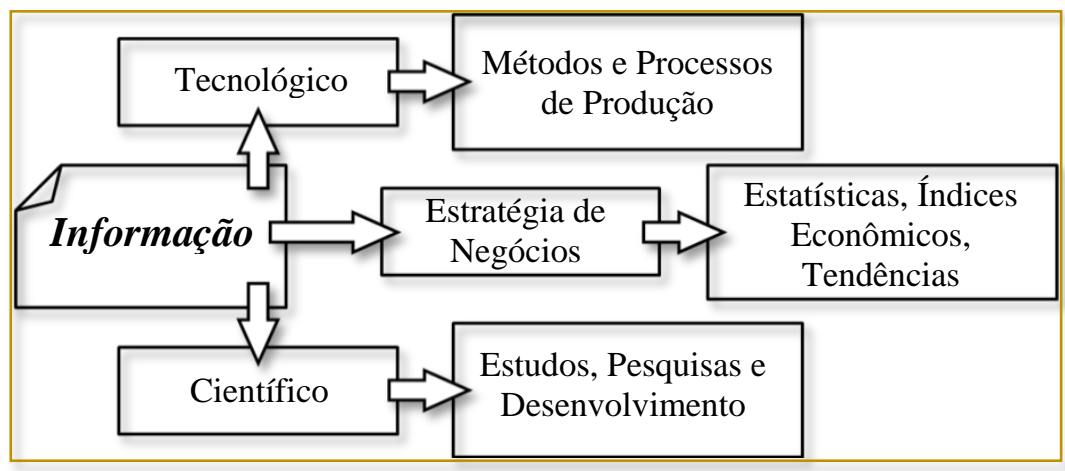

Fonte: Adaptado de Dias e Belluzzo (2003).

Atualmente, a utilização das ferramentas de TI para o gerenciamento e o monitoramento das informações, tornou-se comum dentro das organizações. $O$ setor contábil e administrativos das empresas, assim como as prestadoras de serviços na área econômica e fiscal foram as que mais se beneficiaram com a introdução da TI nas últimas décadas (HABERKAMP et al, 2010; REZENDE e ABREU, 2003; BAIERLE et al, 2011). E ainda, Beltrame e Maçada (2009) afirmam que as empresas brasileiras têm aumentado 
consideravelmente os investimentos em Tecnologias de Informação (TI) visando à automatização de processos e aumento da produtividade, portanto o uso das ferramentas de TI é um requisito obrigatório para que se consiga aplicar a GC.

Pereira, Rezende e Abreu (2002) definem que a geração do conhecimento e a GC ocorre quando as informações são combinadas, comparadas e analisadas por pessoas, auxiliadas ou não pelos recursos da $\mathrm{TI}$, objetivando contribuir com os processos decisórios e estratégicos dentro das organizações. Portanto, o uso e a manipulação das informações e das ferramentas de $\mathrm{TI}$, de maneira adequada e racional, pode levar para a criação e a implantação de processos que gerem, armazenem, gerenciem e disseminem os conhecimentos para resultar na prática da GC.

Já Santos e Neto (2008), afirmam que a grande dificuldade das empresas, nos próximos anos, será a geração de negócios agregados a vantagens competitivas duradouras aliadas a capacidade de inovar, baseado no conhecimento, focando a diferenciação de produtos e processos. É nesse contexto que a Gestão do Conhecimento $(\mathrm{GC})$ se transforma em valioso recurso estratégico segundo Albino, Reinhard e Santana (2009).

Para Canongia et al (2004) e Albino e Reinhard (2009), a GC pode ser sintetizada em um conjunto de processos para promover a circulação das informações tendo como objetivo aumentar o desempenho das organizações gerando conhecimento. Logo a GC pode ser interpretado também como um modelo de negócio novo, emergente e interdisciplinar que tem o conhecimento, que é gerado pelo conjunto de informações pertinentes e de cunho estratégico que teve como origem a filtragem e compilação dos inúmeros dados, como principal componente da estrutura organizacional. Dentro desta abordagem, Takeuchi e Nonaka (1997) ainda classificam o conhecimento como explícito e tácito. O explícito é aquele que pode ser enunciado transcrito por linguagens formais permitindo a transmissão destas para terceiros. Por outro lado, o tácito é aquele intangível, ou seja, é o conhecimento que cada indivíduo incorpora com a sua experiência profissional e pessoal e se caracteriza pelo fato de ser impossível de ser transmitido para outros, logo fica evidente que a capacidade de geração de conhecimento depende fortemente das pessoas e do ambiente de trabalho nas quais estas estão inseridas e também de como elas são estimuladas e incentivadas à criação da GC.

Conforme ilustrado na Figura 2, a prática da GC nas empresas é fruto das mudanças nas quais as organizações vêm desenvolvendo para adequarem suas estratégias de negócios a nova realidade empresarial, sendo que a gestão do conhecimento se apoia em três fundamentos básicos que são as pessoas (Força de Trabalho), a tecnologia da informação e os processos organizacionais (ALBINO, REINHARD e SANTANA, 2009).

Dentro deste contexto, entende-se por processos organizacionais toda a infraestrutura e o organograma de uma organização onde os setores de chefia, gerência e operacional estão divididos, já a infra-estrutura de $\mathrm{TI}$ é todo o maquinário e programas computacionais que auxiliam o desenvolvimento, monitoramento e a manutenção das atividades e por final as pessoas podem ser definidos como a força de trabalho ou os indivíduos dentro de uma organização (ALBINO e REINHARD, 2009). Também é importante que os recursos humanos $(\mathrm{RH})$ tenham conhecimento suficiente para poder gerenciar e manipular as ferramentas de $\mathrm{TI}$ de modo a agregar valor à organização (GONÇALVES; LIMA e COSTA, 2009). 
Figura 2 - Pilares de sustentação da GC.

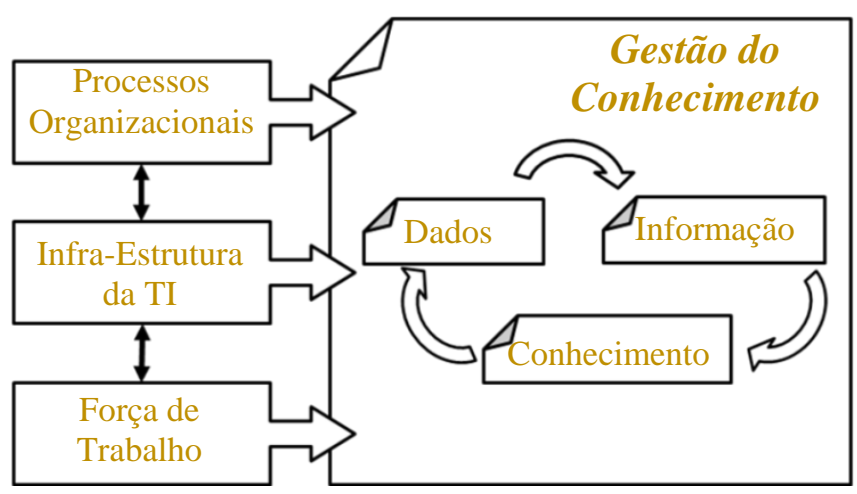

Fonte: Adaptado de Albino, Reinhard e Santana (2009)

Takeuchi e Nonaka (1997), assim como, Pimentel e Albino (2003), destacam que muitas empresas possuem dificuldades tanto financeiras quanto de recursos humanos para a introdução e utilização da GC e também das atividades de inovação e desenvolvimento. Boa parte das "perdas" se dá na forma de circulação desnecessária de material como, por exemplo, fotocópias, papéis e documentos eletrônicos e também, apesar do fácil acesso aos equipamentos e programas de $\mathrm{TI}$ os recursos humanos disponíveis nas organizações não estão devidamente treinados e capacitados para explorar o potencial dos oferecido pela TI.

Portanto é importante a criação de uma ferramenta ou metodologia para avaliar a posição, ou a arquitetura da GC de modo sistemático. Dentro deste contexto o Knowledge Management Audit Tool Brazil (KMAUDITBR) possibilita organizar e mensurar o real posicionamento da organização com relação à GC apoiada pela TI e tomar medidas para melhorar o posicionamento com relação à execução ou a arquitetura da GC e o nível de aplicabilidade dos processos de gerenciamento conforme pontuação descritos no Quadro 1. O KMAUDITBR ainda permite identificar os principais pontos fortes e fracos e a possibilita a realização de um benchmarking entre setores distintos dentro de uma organização e também entre as empresas (ALBINO e REINHARD, 2009; JAGER, 1999).

Quadro 1 - Estado da arquitetura da GC conforme pontuação obtida pelo questionário KMAUDITBR.

\begin{tabular}{lc|c|c|c} 
Faixa de Pontuação & \multicolumn{2}{c}{24 a 48} & 49 a 72 & \multicolumn{2}{c}{73 a 96} & 97 a 120 \\
$\begin{array}{l}\text { Estado da } \\
\text { Arquitetura }\end{array}$ & Estacionário & Inicial & Priorizar/Selecionar & $\begin{array}{c}\text { Refinar/ } \\
\text { Continuar }\end{array}$ \\
\hline
\end{tabular}

Fonte:Albino, Reinhard e Santana (2009)

As características de cada estado podem ser descrito como:

- Estacionário: Estado na qual não existe ou existe uma baixa atividade da GC:

- Inicial: Estado na qual a atividades e processos de GC são pouco difundidas;

- Priorizar/Selecionar: Estado na qual, vários procedimentos está em andamento, porém sem coordenação ou com um projeto coerente e cadenciado;

- Refinar/Continuar: Estágio na qual existe uma ótima relação entre processos de GC e projetos coordenados com uso da TI, necessitando o controle de qualidade para aprimoramento contínuo. 
Esta ferramenta, portanto, também permite auxiliar a avaliação dos Recursos Humanos $(\mathrm{RH})$, ou seja, a força de trabalho. Convém lembrar, de acordo com Becker; Mark e Ulrich (2001), que a imagem da área de $\mathrm{RH}$ transformou-se ao longo do tempo. Tradicionalmente, a área era vista como uma função basicamente administrativa e profissional, hoje, predomina a perspectiva do desempenho superior e que considera o $\mathrm{RH}$ como estratégico e articulado com a alta gestão para garantir padrões de qualidade de excelência.

Para visualizar esse valor econômico advindo de uma gestão estratégica de Recursos Humanos, Guimarães e Campos (2009) consideram a implantação da norma ISO 10015 (Gestão da Qualidade - Diretrizes para Treinamento) editada no Brasil em abril de 2001 pela Associação Brasileira de Normas Técnicas (ABNT), fundamental para garantir que os objetivos da área de $\mathrm{RH}$ estejam de acordo com as estratégias da organização e que o resultado gerado pelo conhecimento produzido pelas pessoas possa ser visualizado no desempenho global da organização. Tal fato se torna importante, pois, de acordo com Guimarães e Campos (2009) estudos informais revelaram que poucas organizações investem no treinamento necessário para explorar a capacidade que a tecnologia oferece. Nesse caso, a aplicação das normas da ISO 10015 poderia permitir essa constatação de forma clara e produtiva, já que abrangeria "o desenvolvimento, implementação, manutenção e melhoria das estratégias e dos métodos de treinamento que afetem a qualidade dos produtos fornecidos por uma organização" (NBR ISO 10015, 2001).

Portanto, a ampliação dos estudos e pesquisas em relação ao retorno sobre investimentos (ROI) em gestão do conhecimento é uma tendência mundial e está diretamente relacionada com os recursos humanos, afinal, o conhecimento não têm qualquer valor organizacional até que seja aplicado a um negócio e consiga agregar valor ao empreendimento, afirmam Albino, Reinhard e Santana (2009). Nesse estudo a ferramenta KMAUDITBR é justamente uma proposta para medir a gestão de conhecimento de uma organização de maneira integrada e holística, considerando inclusive o valor estratégico da área de $\mathrm{RH}$ da organização contribuindo para a constante manutenção e avaliação, permitindo a manutenção da aplicabilidade da GC, como pode ser observado na Figura 3.

Figura 3 - Envolvimento do RH Estratégico na aplicabilidade da GC e a contribuição do KMAUDITBR.

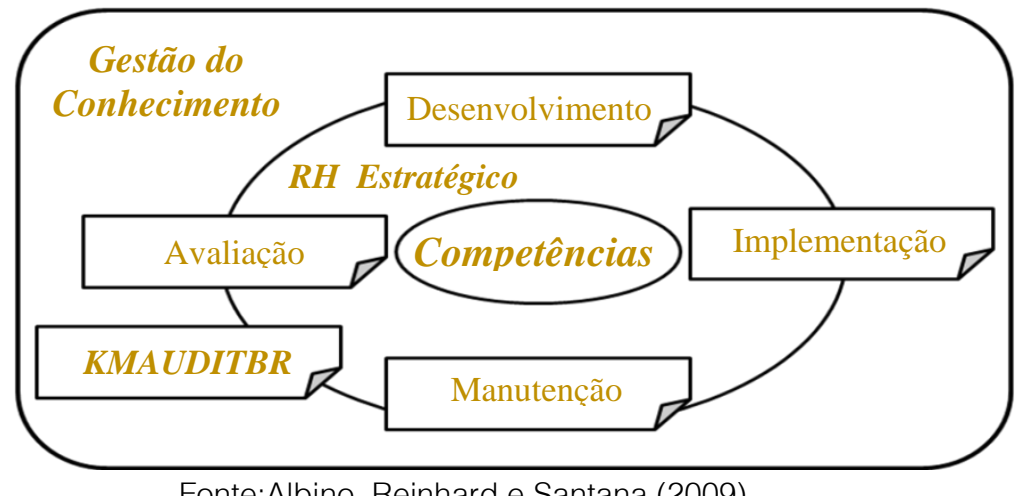

Fonte:Albino, Reinhard e Santana (2009)

\section{METODOLOGIA DE PESQUISA}

O presente trabalho pode ser classificado como uma pesquisa quantitativa, pois em um primeiro momento foi utilizada a técnica de coleta de dados pela aplicação de um questionário visando verificar quais os pontos fortes e fracos e com base neste foi realizado treinamentos. Após 10 meses do treinamento o mesmo questionário foi aplicado e os dados foram tabulados e analisados. Vale salientar que a aplicação do questionário, baseado no modelo criado por Albino e Reinhard (2009), foi submetido ao Comitê de Ética em Pesquisa da Universidade de SorocabaUNISO (Sorocaba-SP) antes de ser aplicado nas organizações. E conforme o parecer da comissão o questionário não necessitou do protocolo, uma vez que é destinado a pessoas jurídicas dentro das empresas. 
O questionário foi aplicado em um grupo formado por 3 indústrias de porte do tipo MPE, obedecendo a classificação adotada pelo SEBRAE-SP, sendo uma no ramo metal mecânico, outra no ramo da construção civil e a terceira no ramo de consultoria industrial. A pesquisa foi realizada no período entre setembro de 2010 a dezembro de $2011 \mathrm{com}$ um enfoque tático e estratégico, uma vez que, estudou apenas o conhecimento dos envolvidos sobre o que se entende por GC e este foi quantificado na forma de uma pontuação contínua classificando cada organização com relação a arquitetura da GC pela adoção do benchmarking antes e depois do treinamento aplicado nas três empresas, e com isso possibilitando comparar o grau de maturidade da arquitetura da GC.

O primeiro questionário foi aplicado em novembro de 2010 e o último em outubro de 2011, sendo que entre este período foi realizado treinamentos e entrevistas informais com os envolvidos em conjunto com o $\mathrm{RH}$ de cada empresa para a elaboração e adoção de metodologias para a incorporação dos conceitos de GC nas atividades diárias dos funcionários. Por final o trabalho não teve como finalidade formular ou elaborar estratégias de negócio, a criação de uma metodologia para implantação da GC, mas sim testar a aplicabilidade da metodologia e estudar principalmente as suas vantagens e limitações.

\section{APRESENTAÇÃO DOS RESULTADOS}

A apresentação dos resultados está dividida, na forma de tabelas e quadros, nos seguintes tópicos: (1) perfil geral das empresas respondentes; (2) número total de respostas correlacionadas com a prática ou não da GC; (3) resultados correlacionados com os ativos de TI e (4) a pontuação média obtida pelos grupos e análise do benchmarking.

A Tabela 1 apresenta o perfil geral das empresas, todas situadas na região de Sorocaba-SP, que participaram deste trabalho de pesquisa.

Tabela 1 - Panorama geral do perfil das empresas pesquisadas.

\begin{tabular}{l|c|c|c|}
\multicolumn{1}{|c|}{ Empresa } & $\begin{array}{c}\text { Total de } \\
\text { Funcionários }\end{array}$ & Âmbito de Atuação & Volume de Negócios (R\$/Ano) \\
Metal Mecânico & 57 & Nacional e Regional & Abaixo de 5 Milhões \\
\hline Construção Civil & 35 & Regional & Abaixo de 5 Milhões \\
\hline Consultoria & 15 & Nacional & Abaixo de 5 Milhões \\
\hline
\end{tabular}

Fonte: Dados da pesquisa

O perfil de cargos ocupados em cada empresa pelos respondentes do questionário é apresentado na Tabela 2, vale salientar que a escolha destes foi de responsabilidade das próprias empresas, sendo que a escolha se deu, em função do cargo baseado na importância estratégica com relação a tomada de decisões e influência direta no modelo de gestão destas organizações.

Tabela 2 - Panorama geral do perfil dos funcionários participantes da pesquisa.

\begin{tabular}{|l|c|c|c|c|c|c|}
\hline \multicolumn{1}{|c|}{ Empresa } & Alta Gerência & $\begin{array}{c}\text { Chefia de } \\
\text { Setor }\end{array}$ & Engenheiro & Administrador & Técnico & Total \\
\hline Metal Mecânico & 3 & 3 & 1 & 1 & 3 & 11 \\
\hline $\begin{array}{l}\text { Construção } \\
\text { Civil }\end{array}$ & 2 & 2 & 3 & 1 & 5 & 13 \\
\hline Consultoria & 3 & 0 & 2 & 0 & 2 & 7 \\
\hline
\end{tabular}

Fonte: Dados da pesquisa 
Já pela Tabela 3 pode ser observado os resultados, aplicado logo no início do processo de pesquisa e após o treinamento e implementação de mudanças, referentes ao conhecimento que os respondentes do questionário possuem com relação à GC.

Tabela 3 - Definição de Gestão do Conhecimento (GC).

\begin{tabular}{|c|c|c|c|c|c|c|}
\hline \multirow{3}{*}{ Qual a Definição da GC? } & \multicolumn{6}{|c|}{ Tipo de Empresa } \\
\hline & \multicolumn{2}{|c|}{ Metal Mecânico } & \multicolumn{2}{|c|}{ Construção Civil } & \multicolumn{2}{|c|}{ Consultoria } \\
\hline & Antes & Depois & Antes & Depois & Antes & Depois \\
\hline $\begin{array}{l}\text { Estratégia de Competição na Era do } \\
\text { Conhecimento }\end{array}$ & 1 & 4 & 1 & 2 & 2 & 0 \\
\hline $\begin{array}{l}\text { Filosofia Corporativa de Gestão das } \\
\text { Informações }\end{array}$ & 1 & 1 & 0 & 6 & 1 & 2 \\
\hline Política para Execução da GC & 0 & 0 & 0 & 0 & 0 & 0 \\
\hline Modelagem de Processos Corporativos & 0 & 5 & 1 & 4 & 0 & 5 \\
\hline Tecnologia que permite a GC & 5 & 1 & 7 & 1 & 3 & 0 \\
\hline Não Sabe & 4 & 0 & 4 & 0 & 1 & 0 \\
\hline Total de Respondentes & 11 & 11 & 13 & 13 & 7 & 7 \\
\hline
\end{tabular}

Fonte: Dados da pesquisa

A Tabela 4 indica 0 total de respostas relativas à questão: $A$ empresa na qual você trabalha pratica a GC? Sendo que é mostrado as respostas antes e depois do treinamento.

Tabela 4 - Respostas referentes a prática ou não da GC nas organizações.

\begin{tabular}{l|c|c|c|c|c|c|c|c|} 
& \multicolumn{9}{c}{ Empresa } \\
A empresa na qual Trabalha Pratica a GC? & \multicolumn{2}{c|}{ Metal Mecânico } & \multicolumn{2}{c|}{ Construção Civil } & \multicolumn{2}{c|}{ Consultoria } \\
& Antes & Depois & Antes & Depois & Antes & Depois \\
\hline Sim & 2 & 0 & 1 & 0 & 2 & 0 \\
\hline Não & 7 & 11 & 12 & 13 & 4 & 7 \\
\hline Não Sabe & 2 & 0 & 0 & 0 & 1 & 0 \\
\hline Total de Respondentes & 11 & 11 & 13 & 13 & 7 & 7 \\
\hline
\end{tabular}

Fonte: Dados da pesquisa

Já a Tabela 5 mostra que, na opinião dos colaboradores, como a utilização da GC pode trazer vantagens competitivas e melhora do rendimento do desempenho de suas organizações, também antes e depois da realização do treinamento. 
Tabela 5 - Resultados ilustrando quais as principais vantagens que a aplicação da GC pode proporcionar em suas respectivas organizações antes e após a realização do treinamento.

\begin{tabular}{|c|c|c|c|c|c|c|}
\hline \multirow{3}{*}{$\begin{array}{l}\text { Qual a Principal vantagem que a GC pode } \\
\text { proporcionar em sua organização? }\end{array}$} & \multicolumn{6}{|c|}{ Empresa } \\
\hline & \multicolumn{2}{|c|}{$\begin{array}{c}\text { Metal } \\
\text { Mecânico }\end{array}$} & \multicolumn{2}{|c|}{$\begin{array}{l}\text { Construção } \\
\text { Civil }\end{array}$} & \multicolumn{2}{|c|}{ Consultoria } \\
\hline & Antes & Depois & Antes & Depois & Antes & Depois \\
\hline Diferenciação em Relação a Demais Empresas & 4 & 0 & 2 & 0 & 4 & 0 \\
\hline $\begin{array}{l}\text { Organização dos Processos e Procedimentos } \\
\text { Operacionais }\end{array}$ & 5 & 2 & 2 & 5 & 2 & 0 \\
\hline Redução de Custo & 2 & 0 & 8 & 0 & 1 & 0 \\
\hline Maior Agilidade na Tomada de Decisões & 0 & 1 & 1 & 4 & 0 & 4 \\
\hline $\begin{array}{l}\text { Maior Aproveitamento das Informações e do } \\
\text { Conhecimento }\end{array}$ & 0 & 8 & 0 & 4 & 0 & 3 \\
\hline Total de Respondentes & 11 & 11 & 13 & 13 & 7 & 7 \\
\hline
\end{tabular}

Fonte: Dados da pesquisa

Por Final, a Tabela 6 representa, na opinião dos entrevistados após a realização do treinamento, quais são as dificuldades que cada uma das organizações enfrentam para a adoção da GC das organizações estudadas.

Tabela 6 - Resultados ilustrando quais as principais dificuldades encontradas para a aplicação da $\mathrm{GC}$ em suas respectivas organizações.

\begin{tabular}{|c|c|c|c|}
\hline \multirow{2}{*}{$\begin{array}{l}\text { Qual a Principal Dificuldade para Impementação da } \\
\qquad \text { GC? }\end{array}$} & \multicolumn{3}{|c|}{ Empresa } \\
\hline & $\begin{array}{l}\text { Metal } \\
\text { Mecânico }\end{array}$ & $\begin{array}{l}\text { Construção } \\
\text { Civil }\end{array}$ & Consultoria \\
\hline Patrocínio da Alta Gestão & 1 & 3 & 0 \\
\hline Falta de Treinamento e Aculturamento & 4 & 8 & 4 \\
\hline Adoção de Incentivos ou Premiações & 0 & 0 & 0 \\
\hline Clareza na Comunicação da Estratégia de Negócios & 6 & 2 & 3 \\
\hline Aquisição de Novas Ferramentas de TI & 0 & 0 & 0 \\
\hline Total de Respondentes & 11 & 13 & 7 \\
\hline
\end{tabular}

Fonte: Dados da pesquisa

O Quadro 2 mostra quais são os cinco principais sistemas ou ferramentas de TI, tabulados em ordem de prioridade de uso, empregadas e utilizadas pelas organizações entrevistadas, vale comentar que esta relação não se alterou antes e depois do treinamento. 
Quadro 2 - Principais recursos, sistemas e ferramentas de TI utilizadas pelas empresas entrevistadas.

\begin{tabular}{|c|c|c|c|}
\hline \multirow{3}{*}{$\begin{array}{l}\text { Ordem de } \\
\text { Prioridade }\end{array}$} & \multicolumn{3}{|c|}{ Tipo de Empresa } \\
\hline & Metal Mecânico & Construção Civil & Consultoria \\
\hline & Ferramenta ou Sistema de TI & $\begin{array}{l}\text { Ferramenta ou Sistema } \\
\text { de TI }\end{array}$ & $\begin{array}{l}\text { Ferramenta ou Sistema de } \\
\mathrm{TI}\end{array}$ \\
\hline 1 & Internet ou Intranet & AUTOCAD & $\begin{array}{lll}\text { e-mail ou } & \text { Correio } \\
\text { Eletrônico } & & \end{array}$ \\
\hline 2 & SOLID WORKS & SOLID WORKS & Internet ou Intranet \\
\hline 3 & GED* & $\begin{array}{ll}\text { e-mail ou Correio } \\
\text { Eletrônico }\end{array}$ & Video/Teleconferência \\
\hline 4 & Fluxo de Trabalho (Workflow) & Internet ou Intranet & GED* \\
\hline 5 & e-mail ou Correio Eletrônico & GED* & Pacote MS Office \\
\hline
\end{tabular}

*Sistemas de Gerenciamento Eletrônico de Documentos

Fonte: Dados da pesquisa

E por final na Figura 4 (a), (b) e (c) pode se observar a evolução da pontuação média, conforme estipulado no Quadro 1, revelando a arquitetura da GC antes e depois da aplicação do treinamento para as empresas metal mecânico, construção civil e de consultoria respectivamente.

Figura 4 - Pontuação obtida pela análise do KMAUDITBR

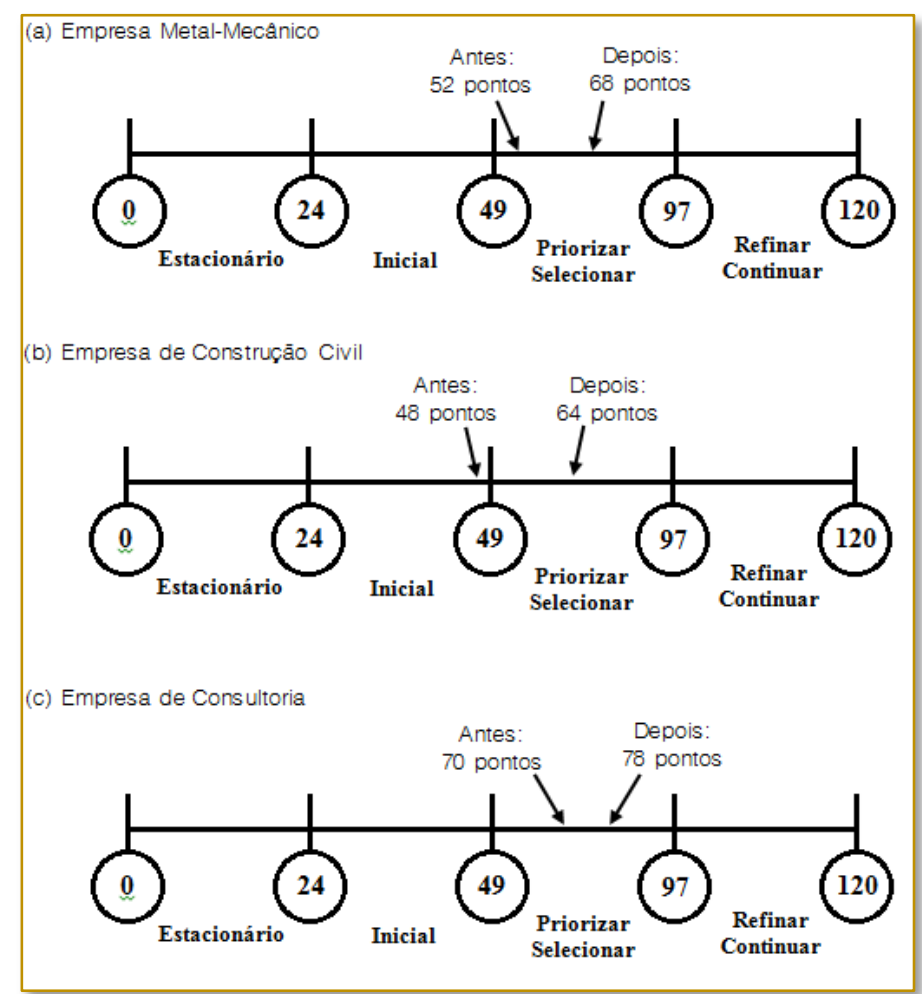

Fonte: Dados da pesquisa 


\section{ANÁLISE DOS RESULTADOS}

A análise do perfil das empresas estudadas mostra que todas se enquadram na categoria das MPE's, segundo classificação do SEBRAE-SP (2012) e são prestadoras de serviço ou terceirizam a produção de grandes empresas multinacionais localizadas na região de Sorocaba. Segundo resultados de entrevistas informais, todos os representantes da alta gerência das empresas afirmaram que a crise econômica de 2008 trouxe dificuldades e também a necessidade da revisão do modelo de negócio, uma vez que, a elevada competitividade cria novos concorrentes e novos desafios.

No entanto, assim como há a necessidade de criar ferramentas e indicadores para verificar a arquitetura da GC de uma organização é preciso, paralelamente e alinhadamente, desenvolver um sistema de mensuração que demonstre, de maneira convincente, o impacto da área de $\mathrm{RH}$ sobre o desempenho da organização, isto é, relacionar a competência das pessoas com os resultados da organização. De acordo com Fleury e Fleury (2004), as competências devem agregar valor econômico para a organização e valor social para o indivíduo, sendo que este está relacionado com a aprendizagem e desenvolvimento das pessoas, portanto são compartilhados e constituem uma rede de conhecimento. Pode-se dizer que a competência só existe num contexto onde ela pode se manifestar e refletir em ação, mobilização de recursos e habilidades, integração de saberes possibilidades de engajamento e incorporação de responsabilidades.

Dentro deste contexto, após a apresentação das vantagens da adoção da GC, as empresas se mostraram interessadas em aplicar este modelo em suas respectivas organizações seja para coordenar e monitorar a produção ou para elevar a autoestima dos colaboradores. O resultado da Tabela 3 mostrou que os entrevistados tiveram uma nítida evolução sobre a definição da GC, uma vez que, a mesma pode ser entendida como um conjunto da organização de dados que são transformados em informações, que resulta em conhecimento, que traga um ganho competitivo a uma organização levando se em consideração as experiências e os conhecimentos tanto da empresa quanto dos indivíduos. Tanto que esta evolução indicou que após o treinamento $100 \%$ dos entrevistados das três empresas afirmam que as organizações na qual trabalham não praticam a GC, conforme resultados apresentados na Tabela 4.

Os resultados da Tabela 5 indicam a capacidade que os entrevistados mostraram em correlacionar as vantagens que a implementação da GC pode trazer em suas organizações, sendo que fica claro a importância do setor de $\mathrm{RH}$ se envolver com mais intensidade com a realização de treinamentos, por exemplo, para que os colaboradores tenham uma melhor compreensão do conceito competitivo da aplicação da GC e também como correlacionar a GC com as estratégias de negócios da empresa.

Já os resultados do Quadro 2 permitem, também, inferir que as organizações possuem instrumentos de TI compatíveis com os seus respectivos modelo de negócios, porém as entrevistas informais mostraram que elas são subutilizadas pois muitos funcionários desconhecem a sua real capacidade operacional e poucos receberam treinamento adequado para a utilização destes sistemas, sendo que a maioria teve como treinamento somente o contato com os sistemas durante os seus cursos técnicos ou superior.

Ainda pelas entrevistas informais, foi diagnosticado que mesmo após o treinamento os funcionários das três empresas acreditam que a aquisição de sistemas avançados de $\mathrm{TI}$, é um fator suficiente para que a organização passe a atuar com mais eficiência sobre a GC. Tal fato é curioso, uma vez que, os próprios entrevistados entram em contradição alegando a falta de treinamento como sendo um dos principais motivos para a não exploração dos recursos da TI.

Portanto, é importante salientar que o papel a ser desempenhado pela $\mathrm{TI}$ pode ser considerado como estratégico, principalmente para auxiliar o desenvolvimento do conhecimento coletivo e do aprendizado contínuo, tornando mais fácil, para as pessoas nas organizações compartilharem problemas, perspectivas, ideias e soluções desde que usuários estejam aptos para extrair o máximo potencial possível destas ferramentas. Este resultado se torna uma informação com elevado valor estratégico para os setores de $\mathrm{RH}$ das empresas elaborem programas de treinamento visando que os colaboradores possam explorar ao máximo potencial 
oferecido pelas ferramentas de TI existentes nas organizações.

Os resultados ilustrados na Figura 4 apresenta a arquitetura da GC das empresas estudadas e mostra que todas tiveram uma evolução, mas ainda se encontram no estado "priorizar/selecionar", ou seja, estado na qual elas possuem ferramentas de TI e um baixo grau de organização da GC e com pouca sinergia entre os pilares de sustentação da GC (processos organizacionais, os recursos humanos e a infra-estrutura da TI). Logo fica evidente a falta de planejamento e a ausência de políticas que levem estas organizações a aproveitarem ao máximo os recursos que a TI oferece para permitir uma GC mais efetiva. Portanto, a realização de treinamentos e atualizações de conhecimento dos colaboradores constantes é de fundamental importância para a maturação e evolução da GC.

Ainda o resultado da Figura 4 (c), indica certa preocupação com a empresa de consultoria, uma vez que, esta foi a que apresentou menor evolução e teoricamente, devido a sua natureza de negócio, deveria ser a empresa com um grau de maturação maior da GC. Tal ponto é outro a ser destacado e analisado pelo $\mathrm{RH}$ desta empresa.

Por final os resultados da Tabela 6, mostra que apesar da boa intenção e pré-disposição para a implementação da GC as empresas ainda pecam num ponto fundamental que é a clareza na troca de informações, alinhamento dos colaboradores com as estratégias de negócio das empresas e a falta ou ausência de treinamento e aculturamento. Este resultado permite afirmar que a comunicação e a falta de interação entre a alta gerência, $\mathrm{RH}$ e o operacional precisa ser executado de modo mais intenso e direto. Logo o KMAUDITBR permitiu inferir que as empresas entrevistadas possuem como maior vantagem uma boa infraestrutura de $\mathrm{Tl}$ e possuem um grau inicial suficiente para iniciar a execução da GC. Por outro lado, as desvantagens são a necessidade de maior interação entre os recursos humnos da empresa, necessidade de atualização e treinamentos e também a necessidade de melhorar a comunicação interna e estabelcimento de metas e objetivos claros e definidos.

\section{CONSIDERAÇÕES FINAIS}

GC pode ser entendida como um conjunto da organização de dados que são transformados em informações, que resulta em conhecimento, que traga um ganho competitivo a uma organização. Para tanto é de fundamental importância o conhecimento tácito dos recursos humanos envolvidos na execução das ações capacidade de combinar diferentes perspectivas para compreender as complexas relações entre o mercado, meio produtivo e a aspiração da empresa. Este monitoramento pode ser realizado por um permanente processo de reformulação dos modelos mentais e mapas cognitivos, para tanto podem ou não ter suporte das facilidades da TI.

Porém como destacado por Guimarães e Campos (2009), esta prática deve ser conduzida e monitorada pelo setor de $\mathrm{RH}$ dentro das organizações. Para que isto ocorra é importante a realização de treinamentos e também o alinhamento das estratégias entre a alta gestão e o operacional para que os resultados gerados pela adoção da GC possam ser mensurados e acompanhados na forma de um indicador de desempenho, logo não é exagero afirmar que a falta de comunicação, ou a troca de informações, entre os vários setores das organizações seja o ponto chave para que a adoção da GC seja mais efetiva.

Portanto pode se concluir que a ferramenta KMAUDITBR se mostrou bastante promissora para estudar as atividades de GC nas organizações, sendo que o ponto forte desta ferramenta está na possibilidade da realização do benchmarking, comparando-se dados entre grupos distintos de organizações e com isto auxiliar o setor de $\mathrm{RH}$ a proporcionar um desenvolvimento contínuo, elevando o grau de competitividade da organização. A aplicação desta metodologia também possibilitou um maior envolvimento dos colaboradores com as estratégias da empresa aumentando o grau de satisfação e motivação dos mesmos com relação à organização na qual trabalham. O ponto fraco da ferramenta é a necessidade de uma leitura atenciosa e cuidadosa para responder as questões e a necessidade de um longo tempo para a compilação e interpretação dos resultados. Tais indicadores mostram que 0 KMAUDITBR ainda necessita de adaptações e melhorias. 
Por final, a importância da realização deste trabalho é o fato das MPEs de Sorocaba estar com baixa eficiência na gestão do conhecimento e isso certamente, poderá contribuir, não somente com $\mathrm{O} R \mathrm{H}$ das empresas, mas também para que as instituições que apoiam e fomentam o setor no município tais como SEBRAE, CIESP, FIESP, Núcleo de Planejamento do Sudoeste
Paulista (NUPLAN), Polo de Desenvolvimento e Inovação (PODI) e a Prefeitura de Sorocaba possam se atentar a esses aspectos para que o parque industrial mecânico do município caminhe no sentido de permanente aperfeiçoamento de suas estratégias de GC utilizando se dos resultados do benchmarking proporcionado pelo KMAUDITBR.

\section{REFERÊNCIAS}

[1] ABREU A.F., MARTINS C.F., PRADA C.A., O papel da Tecnologia da Informação na Condução do Planejamento e Controle da Produção: Um Estudo de Caso, GEPROSGestão da Produção, Operações e Sistemas, v.1,n.1, p.77-88, 2008.

[2] ALBERTIN, A. L.; SANCHEZ, O. P.. A racionalidade limitada das decisões de investimento em tecnologia da informação. RAE revista de administração de empresas, v. 49, n.1, jan.-mar. 2009, pp. 86-106.

[3] ALBINO J.P. , REINHARD N., KMADUITBR: KMADUITBR: Uma Estrutura para Avaliação e Diagnóstico de Gestão de Conhecimento, Revista Gestão Tecnológica, v.05, n.02, p. 6179, 2009.

[4] ALBINO J.P. , REINHARD N., SANTANA S., Uma Ferramenta para Diagnóstico e Avaliação de Sistemas de Gestão de Conhecimento, FACEF Pesquisa, v.12, n.01, p. 5-19, 2009.

[5] BAIERLE. I.C.; FROZZA R.; NARA, E.O.B; KIPPER, L.M.; O ciclo da Produção de Inteligência como Apoio à Estratégia de Tomada de Decisão Organizacional, Revista Produção Online, v.11, n.4, p.1086-1113, 2011;

[6] BECKER, B. E.; MARK, A. H.; ULRICH, D. Gestão Estratégica de Pessoas com "Scorecard". 3. ed. Rio de Janeiro: Campus, 2001.

[7] BERTRAME M.M, MAÇADA A.C.G., Validação de um Instrumento para medir o Valor da Tecnologia da Informação (TI) para as organizações, Organizações em Contexto, Ano 5, n9, p. 1-23, 2009

[8] CANONGIA C., SANTOS D.M., SANTOS M. M., ZACHIEWICS M., Foresight, Inteligência Competitiva e Gestão do Conhecimento: Instrumentos para Gestão do Conhecimento, Gestão \& Produção,v.11, n.2, p. 231-238, 2004.
DIAS, M. M. K., BELLUZZO, R.C.B., Gestão da Informação em Ciência e Tecnologia sob a Ótica do Cliente, 1 ed, EDUSC, p.184, 2003.

[10] FLEURY A.; FLEURY M. T. L. Estratégias Empresariais e formação de competências. 2. ed. São Paulo: Atlas, 2004.

[11] GONÇALVES L. C., LIMA E. P., COSTA S. E. G., Um Estudo sobre a Adoção de Práticas de Gestão do Conhecimento em Organizações Cooperativas, Produção, v.19, n1, p.163-189, 2009.

[12] GUIMARÃES, S.; CAMPOS, J. P. Em busca da eficácia em treinamento. São Paulo: ABTD, 2009.

[13] HABERKAMP A.M., MAÇADA A.C.G, RAIMUNDINI S.L.,BIANCHI M., Impacto dos Investimentos em Tecnologia da Informação (TI) das Variáveis Estratégicas das Empresas Prestadoras de Serviços Contábeis, BASE Revista de Administração e Contabilidade da UNISINOS, v.7, n2, p. 149-161, 2010

[14] JAGER, M. The KMAT: Benchmarking Knowledge Management. Library Management. v.20, n.7, p. 367-372, 1999.

[15] LAURINDO F. J., SHIMIZU T., CARVALHO M.M, RABECHINI R.J., O Papel da Tecnologia da Informação (TI) na Estratégia das Organizações, Gestão e Produção, v8, p.160179, 2001

[16] NBR ISO 10015. Gestão da qualidade Diretrizes para treinamento. Rio de Janeiro: Associação Brasileira de Normas Técnicas, 2001.

[17] PARSONS, G. L. Information technology: a new competitive weapon. Sloan Management Review, v 1, n²5, p. 3-14, Fall 1983.

[18] PEREIRA, R. O.; ABREU, A. E; REZENDE, D. A. Gestão do conhecimento com apoio dos recursos de sistemas de informação e tecnologias emergentes. In: XX ENCONTRO NACIONAL DE ENGENHARIA DE PRODUÇÃO, 20., 2002, São Paulo. Anais... São Paulo: Enegep, 2002. 
[19] PIMENTEL A. C. M., ALBINO J. P., Dificuldades na Aplicação de Gerenciamento de Conhecimento (KM) em Empresas Brasileiras de Médio Porte, In: SIMPÓSIO DE ENGENHARIA DE PRODUÇÃO - SINPEP, X, 2003, Bauru, SP. Anais...Bauru, SP, UNESP, 2003

[20] REGIANNI, G.B.; DALCOL P.R.T.; Uso da Tecnologia de Informação na Indústria de Alimentos e Bebidas: Um modelo de Planejamento para Pequenas e Médias Empresas de Manufatura, Revista Produção Online, v.11, n.4, p.892-920, 2011;

[21] REIS Z.C., MILAN G.S., Gestão do Conhecimento-Um Desafio a Ser Administrado, Revista Produção, v.IX, n.I, p. 74-94, 2009.

[22] REZENDE D.A., ABREU A.F., Tecnologia da Informação aplicada a Sistemas de Informação Empresariais: 0 papel estratégico da informação e dos sistemas de informação nas empresas, 3 ed., Editora Atlas S.A., p. 316, 2003.

[23] SANTOS I. C., NETO J. A., Gestão do Conhecimento em Indústria de Alta Tecnologia, Produção, v.18, n.3, p.569-582, 2008.

[24] SEADE. Dados municipais. Sorocaba. Disponível em: <www.seade.gov.br>. Acesso em 02 mai. de 2015.

[25] SEBRAE Serviço Brasileiro de Apoio às Micro e Pequenas Empresas. Disponível em <http://www.sebrae.com.br>, acesso em 16 mar. 2012.

[26] SILVA E.M., YUE G.K., ROTONDARO R.G., LAURINDO F. J., Gestão da qualidade em serviços de TI: em busca de competitividade, Produção, v.16, n.2, p.329-340, 2006.

[27] TAKEUCHI H., NONAKA I., Criação de Conhecimento na Empresa, Ed. Campus, Rio de Janeiro - RJ, 1997, p.358 


\title{
Bapítulo 2
}

\section{MINERAÇÃO DE DADOS APLICADA À BASE DE DADOS DO TRIBUTO ISS}

\author{
Alcione Dias da Silva \\ Bruno Missi Xavier \\ Geórgia Regina Rodrigues Gomes \\ Marcelo Tadeu Monteiro Freitas \\ Willen Borges Coelho
}

Resumo: No setor governamental, a eficácia no recolhimento de impostos deve ser combinada com a boa utilização dos recursos. Este trabalho identifica informações úteis através da Mineração de Dados, possibilitando um melhor entendimento do que foi recolhido aos cofres públicos, evidenciando principalmente, fraudes contra o tesouro municipal. Tem como objetivo estabelecer uma arquitetura de dados economicamente viável de ser implantada e que sirva como modelo a ser utilizado nas bases de dados de tributos dos muncípios brasileiros. Ainda, utilizar a Mineração de Dados na base de tributos da cidade de Cachoeiro de Itapemirim-ES, especificamente para o tributo ISS (Imposto Sobre Serviços). Para tal foi utilizado o processo de KDD (Knowledge Discovery in Database) como metodologia para viabilizar a Mineração de Dados através do software WEKA (Waikato Environment for Knowledge Analysis). Com o mapeamento obtido através da aplicação dos algoritmos Apriorie $\mathbf{J} 48$ foram reveladas informações relevantes tais como os ramos de atividade mais problemáticos do ponto de vista econômico. Os conceitos utilizados neste artigo poderão ser aplicados no estudo de outros tributos bem como ser úteis no contexto de outros municípios.

Palavras-chave: KDD; ISS; Mineração de dados. 


\section{INTRODUÇÃO}

A Mineração de Dados aplicada a base de dados tributária municipal tem como foco a descoberta de conhecimentos não induzidos sobre o Imposto Sobre Serviços (ISS). Por conhecimentos não induzidos, entendem-se aqueles nos quais não há direcionamento sobre os resultados obtidos.

O ISS tem fundamento no art. 156 inciso IV da Constituição Federal Brasileira de 1988. Neste pode-se encontrar a competência exclusiva do município para instituir o Imposto Sobre Serviços. De acordo com Rodriguez (2008) o vocabulário serviço, que provém do Latim "servitium", exprime a condição de escravidão, servidão, dever de servir. Então não é apenas o desempenho de uma atividade, ou a execução de um trabalho intelectual, ou mesmo de obra material; é dever de executar uma tarefa, ocupar uma função.

Para efeitos tributários, a Constituição Federal não traz conceituação expressa sobre o que são serviços. Há duas concepções básicas economicamente pertinentes à definição fiscal de serviços - uma decorrente dos diversos fatores do processo de produção, e outra decorrente da distinção entre serviços e bens materiais. O conceito fiscal de serviços, assim, define-se pela materialidade, o que o distingue do conceito de bens, uma vez que serviços não podem ser estocados haja vista serem intangíveis.

As ferramentas de análise de dados tradicionais, como $\mathrm{BI}$ (Business Intelligence) e OLAP (Online analytical processing), não são capazes de traçar perfis e relacionamentos não induzidos entre o tributo a ser arrecadado e o contribuinte, havendo forte necessidade de implementar "inteligência computacional" às bases de dados utilizadas pela gestão pública municipal.

Enormes quantidades de dados têm sido sistematicamente coletados e armazenados eletronicamente nas esferas dos governos municipais. Segundo Bothorel, Serrurier e Hurter (2011), a Mineração de Dados visa extrair o máximo de conhecimento a partir de bancos de dados volumosos. Neste contexto, nota-se a necessidade de explorar a base de dados relativa ao lançamento de tributos municipais, aplicando sobre esta o processo de DCBD (Descoberta de Conhecimento em Base de Dados) ou KDD (Knowledge Discovery in Databases).
A partir de grandes quantidades de dados armazenados, de forma automática ou semiautomática podem-se utilizar modelos computacionais para descoberta de conhecimentos. Tal processo foi definido por Fayyad, Piatetsky-shapiro e Smyth (1996), como sendo: “... o processo não trivial de identificação de padrões válidos, novos, potencialmente úteis e compreensíveis, embutidos nos dados". A Mineração de Dados apresenta-se como parte do processo de KDD.

Identificar conhecimentos que possam estar "ocultos", explicitando-os com intuito de oferecer informações analíticas aos governos municipais a fim de aprimorar a aplicação desta importante fonte de receita, identificar possíveis fraudes fiscais e propor um modelo economicamente viável e que sirva como base para aplicação das ferramentas de Mineração de Dados, são os principais objetivos.

Vale ressaltar que apesar da Mineração de Dados ser amplamente utilizada em diversas áreas de interesse, quando se trata de trabalhos relativos ao setor público, percebese uma grande carência.

Alguns trabalhos merecem destaque no setor público, Brown, Cooper e Pidd (2005) utilizaram as técnicas de Mineração de Dados para modernizar a sistemática de funcionamento do imposto de renda de competência da Receita no Reino Unido. No que diz respeito a outro importante tributo municipal, O ISS (Imposto Sobre Serviço), Nascimento et al. (2009) apresentam o GIF, que é um sistema para Gestão e Inteligência Fiscal, identificando possíveis evasões fiscais por meio de técnicas de Mineração de Dados aplicadas sobre a base de dados dos serviços prestados e tomados pelos contribuintes do ISS. Silva et al. (2012) aplicaram as tarefas de associação e classificação para minerar os dados relativos a base de tributos do IPTU, os algoritmos utilizados foram Apriori e J48.

Desta forma o propósito deste estudo é apresentar a técnica de Mineração de Dados para extração de conhecimento sobre a base de dados dos tributos municipais, mais especificamente para o imposto ISS. Este trabalho identifica a metodologia e os algoritmos que melhor se adéquam as características deste estudo, com objetivo de que a base de conhecimento obtida seja útil 
para as atividades voltadas aos anseios dos governos municipais brasileiros.

O presente artigo está estruturado em quatro seções. A Seção 1 contextualiza o imposto ISS, o processo de KDD e trata de uma breve revisão da literatura. $\mathrm{Na}$ Seção 2, é apresentada a metodologia, descrevendo as etapas do KDD e os algoritmos utilizados, na Seção 3 são demonstrados os resultados provenientes da Mineração de Dados aplicada, a Seção 4 discorre sobre as conclusões oriundas dos diversos resultados.

\section{METODOLOGIA}

As técnicas de Mineração de Dados adotadas neste trabalho foram aplicadas à base de dados tributária da Prefeitura Municipal de Cachoeiro de Itapemirim - ES, onde os dados selecionados foram os relativos aos lançamentos tributários do imposto ISS pertinentes ao exercício fiscal de 2011. Por razões de confidencialidade, uma das atividades constantes das análises deste artigo, teve seu nome alterado, passando a ser designada como atividade "XPTO".

\subsection{ARQUITETURA PROPOSTA}

Neste tópico será apresentada a estrutura conceitual para que os dados provenientes da base tributária da Prefeitura Municipal de Cachoeiro de Itapemirim - ES pudessem ser utilizados no processo de KDD. A estrutura mostrada na Figura 1 foi concebida para dar suporte operacional ao modelo a fim de que os dados provenientes da etapa de Mineração de Dados fossem passíveis de visualização e análise pelos gestores e especialistas tributários.

Figura 1 - Arquitetura proposta para mineração da base tributária.

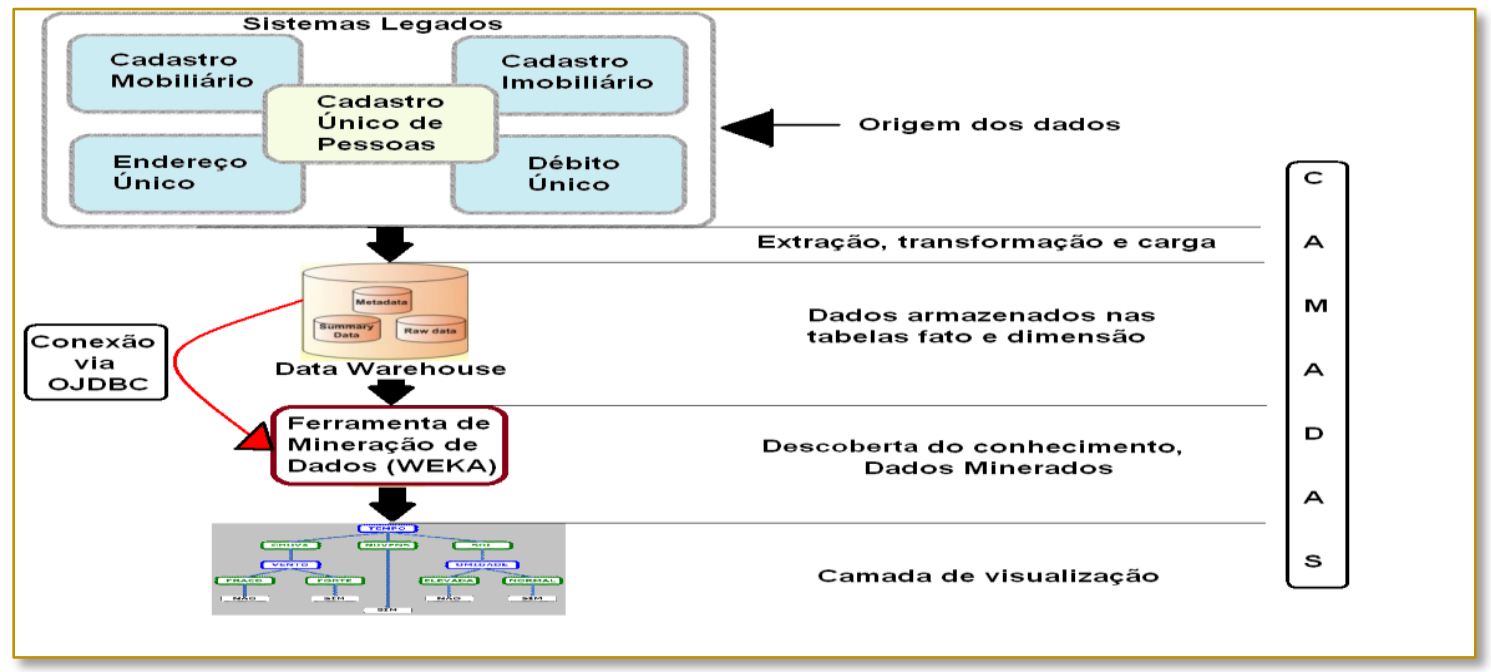

Fonte: Autoria própria

\subsubsection{ORIGEM DOS DADOS}

Esta camada, exposta na Figura 1, representa os sistemas legados aos quais foram fontes de dados para o processo de ETC (Extração Transformação e Carga). Os sistemas, representados na primeira camada da Figura 1 , foram essenciais para que todos os dados necessários fossem obtidos. O sistema de Cadastro Imobiliário fornece os dados relativos às empresas, dando origem aos lançamentos do ISS; O sistema de Endereçamento Único fornece os dados de localização para o Cadastro Mobiliário e
Imobiliário; o sistema de Débito Único armazena os valores relativos aos cálculos do ISS, por fim o sistema de Cadastro Único fornece os dados das pessoas físicas e jurídicas responsáveis pelos créditos tributários lançados.

\subsubsection{EXTRAÇÃO, TRANSFORMAÇÃO E CARGA (ETC)}

Segundo Kimball (2002), a etapa de extração, transformação e carga das fontes de dados, 
representa um dos processos mais importantes para a construção de um DW (Data Warehouse). Esta etapa busca aumentar a qualidade dos dados a serem inseridos no repositório. No presente trabalho, o processo de ETC limitou-se a uma projeção dos dados existentes na base de dados tributária, uma vez que tanto os sistemas legados quanto o DW construído encontramse na mesma instância do SGBD oracle 11G. As etapas de pré-processamento e transformação contidas no KDD serão as responsáveis pelos ajustes dos dados carregados no DW.

\subsubsection{EXTRAÇÃO DO CONHECIMENTO UTILIZANDO WEKA}

Um dos pontos fortes da arquitetura proposta encontra-se na conexão direta da ferramenta de Mineração de Dados WEKA $3.7 \mathrm{com}$ o Data Warehouse, conforme Figura 1. O software de mineração foi conectado ao DW com a utilização do driver jdbc do Oracle(ojdbc 14.jar).

Desta forma pode se conectar o WEKA a bancos de dados OpenSource, bem como a soluções proprietárias semelhantes ao Oracle e Sqlserver, o que permite uma enorme flexibilidade na geração dos conjuntos de dados a serem minerados, uma vez que o trabalhoso processo de geração de arquivos ".arff" do WEKA não mais é necessário.

Outra grande vantagem é que sendo o WEKA uma ferramenta OpenSource que pode ser configurada para acessar bases de dados também OpenSource, o modelo proposto através da Figura 1, apresenta-se como opção poderosa e de baixo custo, podendo ser implementado para auxílio na extração de conhecimento em organizações que tem dificuldades para aquisição de softwares proprietários, em face aos altos custos dessas soluções.

Também é possível importar a biblioteca do WEKA para aplicações Java, aumentando ainda mais o poder de uso deste software, que poderá ser executado diretamente dentro de sistemas de gestão que já estejam em uso pelas corporações.

\subsubsection{ETAPAS DE SELEÇÃO}

Após a disponibilização inicial dos dados através do DW, foi iniciada a etapa de seleção, sendo possível então identificar possíveis problemas de qualidade. Também foi possível formar hipóteses com base na compreensão do domínio da aplicação, obtida através de trabalhos realizados e de entrevistas com especialistas.

Através da análise dos dados do DW, foi possível tomar a decisão sobre quais informações poderiam contribuir para o processo de mineração dos dados do ISS.

Com base nas tabelas fato e dimensão do DW, foram obtidos dinamicamente vários conjuntos de dados (itemsets) a serem utilizados na Mineração de Dados. A composição dinâmica dos vários conjuntos de dados obtidos, deve-se ao fato de que a base de dados do Data Warehouse estava diretamente conectada ao software de mineração WEKA.

Dentre os conjuntos obtidos, destaca-se o conjunto "Arrecadacaolss" que abrange os 34.924 lançamentos do imposto ISS e o conjunto "devedores", que representa os lançamentos ISS que não foram quitados. Todos os conjuntos gerados são referentes ao exercício de 2011.

\subsubsection{ETAPA DE PRÉ-PROCESSAMENTO}

Nesta etapa foi realizada a limpeza de dados, remoção de "ruídos", escolha de estratégias para manipular campos de dados ausentes e a formatação de dados de maneira a adequálos à ferramenta de mineração. Informações de outros lançamentos tributários como os relativos à dívida ativa foram retirados por não fazer parte deste estudo.

Os problemas relativos a dados corrompidos, valores desconhecidos e de integridade referencial, foram tratados minimamente nesta etapa, uma vez que os dados já estavam sendo abordados pelos controles primitivos dos sistemas de informação e pelas constraints de referential integrity, check e not null do banco de dados Oracle, onde os mesmos já se encontravam armazenados.

Alguns atributos precisaram ser manipulados para suprir a ausência de conteúdo. Os atributos "anodebito" e "zona" foram alterados em seu tipo de dados, passando de numérico 
para alfanumérico, dada a restrição de campos numéricos para processamento do algoritmo APRIORI.

Outras conversões foram realizadas dinamicamente através de funções utilizadas nos comandos SQL (Structured Query Language), como a função replace. Para um melhor entendimento, será apresentado na Tabela 1 o conjunto de atributos utilizados e a descrição de seu conteúdo:

Tabela 1 - Principais atributos constantes dos conjuntos de dados minerados.

\begin{tabular}{|c|c|}
\hline Atributo & Descrição \\
\hline bairro & Nome do bairro relativo ao imóvel ou empresa \\
\hline zona & Área geográfica relativa a um Conjunto de bairros \\
\hline anodebito & Ano base de lançamento do imposto \\
\hline valortotal & Valor total do lançamento do imposto \\
\hline situacao & Situação relativa ao pagamento (quitado, não pago, parcelado,...) \\
\hline Setor & $\begin{array}{l}\text { Identifica a localização atual do débito ( DA - dívida ativa / Cl - } \\
\text { cadastro imobiliário / TB - tributação e receitas / TA - taxas avulsas e } \\
\text { FT - fiscalização tributária). }\end{array}$ \\
\hline
\end{tabular}

Fonte: Dados do estudo

\subsubsection{ETAPA DE TRANSFORMAÇÃO}

A etapa de transformação é a etapa que antecede a Mineração de Dados. Foram aplicadas operações que tornaram melhor a visualização dos dados, também foram transformados valores discretos em contínuos a fim de facilitar a sumarização pelos algoritmos utilizados. Alguns atributos necessitaram de ter o tipo de dados alterados para facilitar o uso de algoritmos específicos como o Apriori.

Atributos faltantes também foram contemplados a partir de valores de outros atributos correlacionados, sendo estabelecido um conteúdo apropriado.

$\mathrm{Na}$ sequencia á apresentada algumas situações onde foi necessário realizar transformações nos dados antes da etapa de mineração.

\subsection{TRATAMENTO DO ATRIBUTO "ENDSEQUEN"}

No cadastro de contribuintes municipal, tanto as pessoas físicas quanto as pessoas jurídicas podem ter diversos endereços, como de localização do imóvel ou empresa, endereço para correspondência e endereço externo (fora do município), sendo identificados por um seqüencial vinculado ao código do endereço. A fim de filtrar o produto cartesiano entre a relação de endereços com a relação de pessoas física ou jurídica, foi aplicada uma restrição onde foram trabalhados apenas os endereços de localização.

\subsection{TRATAMENTO DO ATRIBUTO "DEBITIPO"}

Este campo serve para identificar a origem do lançamento tributário, entendendo-se como "origem", o fato gerador do imposto. Foi aplicada a restrição no atributo debitipo a fim de limitar as ocorrências de lançamentos, contemplando apenas o imposto ISS.

\subsection{TRATAMENTO DO ATRIBUTO "SITUACAO"}

O atributo "situação" descreve a situação de pagamento do imposto. Este campo é do tipo alfanumérico, foi populado de acordo com o conteúdo do atributo "debistatus", de tipo numérico, tendo os valores adaptados conforme Tabela 2. 
Tabela 2 - Conteúdo transformado do atributo "situacao".

\begin{tabular}{|l|l|}
\hline De debistatus: & \multicolumn{1}{|c|}{ Para situacao: } \\
\hline 0 & NAO PAGO \\
\hline 1 & PARCELADO \\
\hline 3 & QUITADO \\
\hline 4 & CARNE DIVAT \\
\hline 5 & PARCELADO DIVAT \\
\hline 6 & ANISTIA \\
\hline 7 & CARNE TRIBUTARIO \\
\hline 8 & PARCELADO TRIBUTARIO \\
\hline 9 & CANCELADO \\
\hline
\end{tabular}

Fonte: Dados do estudo

\subsubsection{ETAPA DE MINERAÇÃO DE DADOS, TAREFAS E ALGORITMOS UTILIZADOS.}

\subsubsection{TAREFAS DE ASSOCIAÇÃO}

A tarefa de regras de associação pode ser categorizada como uma Atividade de Mineração de Dados descritiva, que segundo Domingues (2004), consiste na identificação de padrões intrínsecos ao conjunto de dados.

Uma regra de associação caracteriza o quanto a presença de um conjunto de itens nos registros de uma base de dados implica na presença de algum outro conjunto distinto de itens nos mesmos registros (AGRAWAL et al., 1994). Desse modo, pode-se entender que o principal objetivo das regras de associação é encontrar tendências que possam ser usadas para entender e explorar padrões de comportamento dos dados. Por exemplo, explorando o conjunto de dados relacionados aos usuários de cartões de crédito, pode-se observar que $75 \%$ dos clientes que compram acima de $R \$ 5.000,00$, também financiam seu saldo em pagamentos futuros. Assim 75\% nessa regra correspondem à sua confiabilidade.

Uma regra de associação pode ser representada por uma implicação na forma LHS $\rightarrow$ RHS, em que LHS e RHS são, respectivamente, o lado esquerdo (Left Hand Side) e o lado direito (Right Hand Side) da regra, definidos por conjuntos disjuntos de itens.

Para a tarefa de regras de associação são utilizadas medidas de interesse. As mais comuns são as medidas de suporte e confiança conforme estão representadas pelas equações (1) e (2) a seguir (RIBEIRO, 2004).

$$
\begin{array}{cl}
\text { Suporte } & (R)=T x \cup y / T \\
\text { Confiança } & (R)=T x \cup y / T x
\end{array}
$$


Onde: Suporte(R) indica a relevância da regra; Confiança(R) indica a validade da regra; $\mathrm{T}$ indica $\mathrm{O}$ número de transações consideradas; Tx - indica o número de transações que incluem os elementos de $\mathbf{X}$; Txuy indica o número de transações que incluem os elementos de XUY. Os parâmetros de suporte e confiança são indispensáveis na validação da qualidade dos resultados obtidos através das regras de associação utilizadas neste estudo.

\subsection{ALGORITMO APRIORI}

O método de associação APRIORI busca por padrões em um conjunto de dados que contêm itens que estão relacionados à ocorrência de outros itens (GARCIA et al., 2008).

De acordo com Tan et al. (2009), o princípio Apriori utiliza a medida de suporte para podar conjunto de itens candidatos. O algoritmo Apriori minera conjuntos de itens freqüentes para regras de associação booleanas. Ele faz diversas passagens sobre a base de transações para encontrar todos os conjuntos de itens freqüentes, sendo que, em cada um destes passos, primeiro gera um conjunto de itens candidatos, e então percorre a base de dados para determinar se os candidatos satisfazem o suporte mínimo estabelecido.

$\mathrm{Na}$ primeira passagem, o suporte para cada item individual (conjunto-de-1-item) é contado e todos aqueles que satisfazem o suporte mínimo são selecionados. Estes são os conjuntos-de-1-item freqüentes. Na segunda iteração, conjuntos-de-2-itens candidatos são gerados pela junção dos conjuntos-de-1-item freqüentes e seus suportes são determinados pela pesquisa no banco de dados, sendo assim encontrados os conjuntos-de-2-itens freqüentes. $O$ algoritmo prossegue iterativamente, até que o conjunto-de-k-itens freqüente encontrado seja um conjunto vazio.

Este algoritmo usa o princípio de que cada subconjunto de um conjunto de itens freqüente também deve ser freqüente. Esta regra é utilizada para reduzir o número de candidatos a serem comparados com cada transação no banco de dados. Todos os candidatos gerados que contenham algum subconjunto que não seja freqüente são eliminados (PITONI, 2002).

\subsubsection{TAREFA DE CLASSIFICAÇÃO E PREDIÇÃO}

De acordo com Cardoso e Machado (2007), classificação e predição, é o processo de criar modelos (funções) que descrevem e distinguem classes ou conceitos, baseados em dados conhecidos, com o propósito de utilizar esse modelo para predizer a classe de objetos que ainda não foram classificados. $O$ modelo construído baseia-se na análise prévia de um conjunto de dados de amostragem ou de treinamento, contendo objetos corretamente classificados. Como exemplo pode-se citar a classificação de clientes de uma empresa em bom pagadores e inadimplentes.

Em algumas aplicações, o interesse maior está em predizer alguns valores ausentes em seus dados, em vez de descobrir classes de objetos. Neste caso, a tarefa de mineração é denominada predição.

Os dados de entrada da tarefa de classificação são um conjunto de registros. Os registros também são conhecidos como instâncias e são caracterizados por uma dupla $(x, y)$, onde $x$ é o conjunto de atributos e $y \circ$ atributo especial, designado como rótulo da classe. Também conhecido como atributo alvo ou de categorização, este atributo deve ser um atributo discreto (TAN et al., 2009).

\subsection{ALGORITMO DE ÁRVORE DE DECISÃO: $J 48$}

O princípio da árvore de decisão é agrupar as instâncias de forma recursiva, minimizando a entropia (ou seja, a variabilidade das classes) dentro de cada grupo. Para isso, o algoritmo utiliza os valores de atributos em cada nó não folha e deposita as instâncias nos nós folha. Dessa forma, cada nó interno corresponde a uma decisão de classificação, e a leitura e interpretação da árvore são naturais.

A árvore de decisão original exige que todos os valores de atributos sejam de domínio finito e relativamente pequeno (para que o desempenho computacional seja aceitável). No entanto, o algoritmo usado pelo WEKA é o J48, uma versão do tradicional algoritmo de C4.5 que consegue, através da discretização de valores numéricos utilizando heurísticas, processar atributos de qualquer tipo na entrada. No entanto, a árvore não é capaz de realizar regressão e desempenha somente o 
papel de classificador, isto é, o atributo de classe deve ser discreto (RAMISCH; ENGEL, 2009).

Diversos parâmetros permitem ajustar o comportamento da árvore, a maioria diz respeito às heurísticas usadas para podar uma árvore. Um dos parâmetros é o número mínimo de nós em uma folha, que define um critério de parada para o algoritmo. Isso significa que, a partir do momento que uma folha atinge certo número de instâncias, mesmo que ainda exista ruído, ela não será subdividida. Valores altos para esse parâmetro, chamado $M$ no WEKA, geram árvores mais genéricas enquanto valores baixos (próximos de 1) geram árvores com alta precisão.

Após construir a árvore de decisão, um passo de "poda da árvore" pode ser executado para reduzir o tamanho da árvore de decisão. Árvores de decisão que sejam grandes demais são susceptíveis a um fenômeno conhecido como overfitting. A poda ajuda a retirar as ramificações da árvore inicial de uma forma que melhore a capacidade de generalização da árvore de decisão (TAN et al., 2009).

Segundo Ingargiola (2011), a partir de uma árvore de decisão é possível derivar regras. As regras são escritas considerando o trajeto do nodo raiz até uma folha da árvore. Os métodos, árvores de decisão e regras de associação, são geralmente utilizados em conjunto.

Devido ao fato das árvores de decisão tender a crescer muito, de acordo com algumas aplicações, elas são muitas vezes substituídas pelas regras. Isto acontece em virtude das regras poderem ser facilmente modularizadas. Uma regra pode ser compreendida sem que haja a necessidade de se referenciar outras regras.

\section{RESULTADOS E DISCUSSÃO}

\subsection{APLICAÇÃO DAS REGRAS DE ASSOCIAÇÃO}

Para os resultados relativos às regras de associação, o algoritmo APRIORI foi utilizado, com objetivo de extrair informações não sugeridas referente aos dados do ISS.

Nesta análise foi utilizado o conjunto de dados "Arrecadacaolss", onde foram considerados a totalidade dos 34.924 lançamentos do ISS. As medidas de interesse foram estabelecidas com confiança mínima de $60 \%$ e suporte mínimo de $5 \%$ e as principais regras encontradas estão descritas na tabela 3.

Tabela 3 - Regras de associação utilizando os atributos "Bairro", "Zona", "Situacao" e "Descrição da atividade".

\begin{tabular}{|c|c|}
\hline Regra obtida & $\begin{array}{l}\text { Fator de } \\
\text { confiança }\end{array}$ \\
\hline Situacao=QUITADO $\rightarrow$ bairro=SÃO JOAQUIM & 0,89 \\
\hline $\begin{array}{l}\text { 2. Atividade }=\text { TRANSPORTE RODOV. INTERM/EST/INTERN } \\
\text { CARG PESS CONG } \rightarrow \text { Situacao=CARNE DIVAT }\end{array}$ & 0,78 \\
\hline $\begin{array}{l}\text { 3. } \text { Atividade }=\text { BARES, LANCHONETES E CONGENERES } \\
\text { bairro=CENTRO } \rightarrow \text { Situacao }=\text { PARCELADO }\end{array}$ & 0,77 \\
\hline 4. Atividade $=$ HOTELARIA $\rightarrow$ Bairro $=$ CENTRO & 0.75 \\
\hline $\begin{array}{lllll}\text { 5. Situacao }=\text { QUITADO Atividade } & = & \text { COMERCIO } & \text { DE } \\
\text { PRODUTOS TEXTEIS, VESTUARIO } & \text { E } & \text { CALCADOS } & \rightarrow \\
\text { bairro=IBITIQUARA } & & & & \end{array}$ & 0,71 \\
\hline $\begin{array}{l}\text { 6. Atividade }=\text { COMERCIO DE PRODUTOS TEXTEIS, VESTUARIO } \\
\text { E CALCADOS, zona }=801 \rightarrow \text { Bairro=CENTRO }\end{array}$ & 0.70 \\
\hline 7. Situacao=NÃO PAGO Atividade $=X P T O ~ \rightarrow z o n a=601$ & 0,63 \\
\hline
\end{tabular}

Fonte: Dados do estudo 
Após uma seleção das 136 regras de associação encontradas pelo WEKA, as constantes da Tabela 3, foram as que representaram maior relevância quanto aos resultados em face da análise dos especialistas.

A regra número 1 apresenta uma ótima situação de pagamento, com confiança de 89\% para as empresas sediadas no distrito de São Joaquim. A situação positiva de quitação do ISS neste caso, pode ser atribuída ao fato de que este distrito foi agraciado de incentivos fiscais para desenvolvimento do local, que se encontra afastado da área urbana do município de Cachoeiro de Itapemirim, o que reforça o acerto na definição desta política.

A regra número 2, induz que o setor de transportes esteja em crise, visto que está com seus créditos em dívida ativa, o que pode ser explicado pela situação difícil presenciada por uma grande empresa de transportes local. Da mesma forma o setor de bares e lanchonetes também encontra dificuldades e precisa parcelar seus débitos.
A regra número 4 mostra que o setor de hotelaria está essencialmente sediado no centro da cidade. As regras número 5 e 6, apresentam o setor de comércio de produtos têxteis, vestuário e calçados com regularidade de pagamentos com o município e tem suas atividades presentes em dois bairros da região central da cidade.

A regra número 7 , demonstra com $63 \%$ de confiança, que uma das principais atividades econômicas do município, tem situação de pagamento irregular o que agrava a situação financeira da prefeitura.

\subsection{APLICAÇÃO DA ÁRVORE DE DECISÃO}

Também com o algoritmo J48, foram criadas árvores de decisão relativas ao tributo ISS. A seguir são demonstrados os principais resultados provenientes desta descoberta de conhecimento. Na Tabela 4 são apresentados os resultados extraídos do conjunto "Arrecadacaolss" com 34.924 registros processados, relativo ao exercício fiscal de 2011.

Tabela 4 - Classificação das instâncias relacionadas à árvore de decisão da Figura 2.

\begin{tabular}{|c|c|c|}
\hline $\begin{array}{c}\text { Instâncias classificadas } \\
\text { corretamente }\end{array}$ & $\begin{array}{c}\text { Instâncias classificadas } \\
\text { incorretamente }\end{array}$ & $\begin{array}{c}\text { Atributo } \\
\text { Classe }\end{array}$ \\
\hline $69,31 \%$ & $30,69 \%$ & Situacao \\
\hline
\end{tabular}

Fonte: Dados do estudo

Figura 2 - Árvore de decisão do algoritmo $\mathbf{J} 48$ evidencia as atividades e contadores.
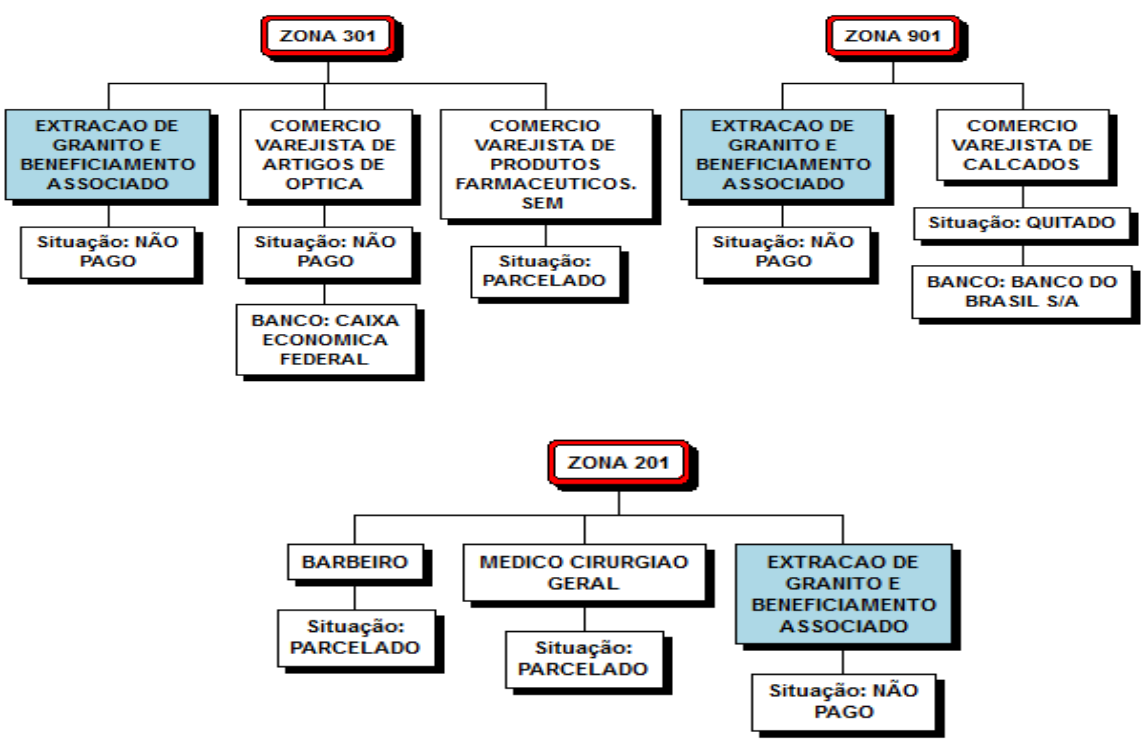

Fonte: Dados do estudo 
Os resultados apresentados na Figura 2 são extremamente reveladores. Ao inserir o atributo "zona" no conjunto de dados processados pelo algoritmo $\mathrm{J48}$, pode-se associar as áreas da cidade onde as empresas da atividade "XPTO" com situação de pagamento irregular se localizam.

Estes resultados reafirmam a regra número 7 da Tabela 3 encontrada pelo algoritmo Apriori, que demonstra a má situação de adimplência deste ramo de atividade no município.

\section{CONSIDERAÇÕES FINAIS}

A importância da exploração das grandes bases de dados existentes nas empresas privadas, também se aplica as corporações públicas. A Mineração de Dados é uma das principais ferramentas a ser utilizada para este fim. As informações obtidas através do algoritmo $\mathrm{J} 48$ pruned tree, que simula uma árvore de decisão, e do algoritmo de associação Apriori, possibilitaram a identificação de regras e análises até então não identificadas pelas ferramentas tradicionais de análise de dados, como: relatórios gerenciais e consultas por ferramentas de $\mathrm{BI}$ (Business Intelligence).

Um dos principais objetivos da mineração é a extração de conhecimentos inesperados e não induzidos. Os resultados demonstraram o acerto da política tributária da prefeitura municipal de Cachoeiro de Itapemirim, em criar um distrito industrial com benefícios fiscais, pois, com $89 \%$ de confiança, as empresas por lá instaladas apresentaram ótima situação de pagamento dos impostos. Outra informação importante evidenciada pelas regras de associação quanto ao ISS, aponta a atividade "XPTO" com situação de pagamento desfavorável.

O algoritmo $\mathrm{J} 48$ evidenciou as zonas da cidade onde as empresas da atividade "XPTO" com situação de pagamento irregular estão localizadas. Tal evidência é bastante relevante, uma vez que a economia da região é muito dependente desta atividade, assim o poder público municipal pode atuar com precisão, a fim de evitar a evasão do ISS por parte deste importante setor produtivo.

A arquitetura proposta no Capítulo 2 provê um modelo economicamente factível a qualquer órgão da gestão pública municipal, uma vez que com o uso das bases de dados existentes e com a inserção de softwares sem custo de licenciamento, é possível construir uma estrutura tecnológica que viabilize a implementação das técnicas de Mineração de Dados, que tanto se fez importante neste estudo aplicado a prefeitura municipal da cidade de Cachoeiro de Itapemirim - ES.

As informações apresentadas trazem conhecimento "novo" não induzido e útil, possibilitando a tomada de decisões com alto índice de acerto e um controle efetivo das políticas de equilíbrio fiscal, o que deve fazer parte do cotidiano da gestão pública. Assim este trabalho, pretende induzir o uso das técnicas de Mineração de Dados no setor público municipal e contribuir para uma fase de maior eficácia na análise de informações.

\section{REFERÊNCIAS}

AGRAWAL, Rakesh; RAMAKRISHNAN, Srikant. Fast Algorithms for mining association rules. International Conference on Very Large Data Bases, Washington, n. , p.487-499, 01 maio 1994.

[2] BOTHOREL, Gwenael; SERRURIER, Mathieu; HURTER, Christophe. Utilisation d'outils de Visual Data Mining pour l'exploration d'un ensemble de règles d'association. Sophia Antipolis, France: Ihm?11, 2011. 4 p.

[3] BROWN, Joyce; COOPER, Ceri; PIDD, Michael. A taxing problem: The complementary use of hard and soft OR in the public sector.
European Journal Of Operational Research, Londres, p. 666-679. 04 jan. 2005.

[4] CARDOSO, Olinda Nogueira Paes; MACHADO, Rosa Teresa Moreira. Gestão do conhecimento usando data mining: estudo de caso na Universidade Federal de Lavras. Revista de Administração Pública Rap, Rio de Janeiro, n. , p.495-528, 01 maio 2007. Bimestral.

[5] DOMINGUES, Marcos Aurélio.Generalização de regras de associação. 2004. $171 \mathrm{f}$. Dissertação (Mestrado) - Curso de Ciências de Computação e Matemática Computacional, Usp, São Carlos, 2004.

[6] FAYYAD, Usama; PIATETSKY-SHAPIRO, Gregory; SMYTH, Padhraic. Knowledge 
Discovery and Data Mining: Towards a Unifying Framework. Portland, Oregon: $\mathrm{Ai}$ Magazine, 1996.

[7] GARCIA, Ederson; VIEIRA, Marina Teresa Pires.MINERAÇÃO DE DADOS USANDO REGRAS DE ASSOCIAÇÃO MULTIRELACIONAL QUANTITATIVA. Piracicaba: 5으 Congresso de Pós-graduação da Unimep, 2008. $96 \mathrm{p}$

[8] INGARGIOLA, G. Building Classification Models: ID3 and C4.5. Disponível em: http://www.cis.temple.edu/ ingargio/cis587/rea dings/id3-c45.html. Acesso em: 13 jul. 2012.

[9] KIMBALL, Ralph. The Data Warehouse Toolkit: Guia Completo para modelagem dimensional. 2. ed. New York: Campus, 2002. $494 \mathrm{p}$.

[10] NASCIMENTO, Francisco Assis M.; LEHNEN, Fernando; MORÉ, Morecy V.; LEIZER, Salomão A. GIF: A Web-based System for Tax Management and Fiscal Intelligence in Municipal Tax Administration. Bogotá, Colômbia: Acm Symposium On Applied Computing, 2009. 7 p.

[11] PITONI, Rafael Moreira. Mineração de Regras de Associação nos Canais de Informação do
Direto. 2002. 61 f. Diplomação (Bacharel) Curso de Ciência da Computação, Departamento de Instituto de Informática, Universidade Federal do Rio Grande do Sul, Porto Alegre, 2002.

[12] RAMISCH, Carlos; ENGEL, Paulo. Algoritmos de aprendizado para avaliação de carros. Porto Alegre: Ufrgs, 2009.

[13] RIBEIRO, M. Mineração de Dados em Múltiplas Tabelas Fato de Data

[14] Warehouse. 131 f. Dissertação (Dissertação de Mestrado) - Departamento de

[15] Computação, Universidade Federal de São Carlos, São Carlos, SP, 2004.

[16] RODRIGUEZ, Luiz Fernando. Manual de Direito Tributário Municipal. Porto Alegre: Andesa, 2008. 405 p.

[17] SILVA, A. D., XAVIER, B. M., GOMES, G. R. R., FREITAS, M. T. M. Mineração de Dados aplicada à base de dados tributária municipal. In: XIX Simpósio de Engenharia de Produção, 2012, Bauru-SP.

[18] TAN, Pan-Ning; STEINBACH, Michael; KUMAR, Vipin. Introdução ao DATAMINING: Mineração de Dados. Rio de Janeiro, Editora Ciência Moderna. 2009. 


\title{
Bapítulo3
}

\section{SISTEMA INTEGRADO DE GESTÃO - ERP: FATORES QUE INFLUENCIAM NA IMPLANTAÇÃO DE UM NOVO SISTEMA}

\author{
Janaina Wohlenberg \\ Claudio Sonaglio Albano \\ Michel Stein Barbosa \\ André Irazoqui de Lima
}

Resumo: A era da tecnologia e da informação norteia as atividades das organizações frente à concorrência globalizada, tornando-se indispensável à utilização de softwares para se obter informações com maior precisão e rapidez auxiliando no processo de tomada de decisão; porém, mesmo sendo considerados indispensáveis à organização, seu processo de implantação apresenta resistências. O presente estudo visa a analisar as mudanças percebidas após a implantação de um Sistema Integrado de Gestão (ERP) em duas organizações, sendo uma atuante no ramo da construção civil e outra no varejo. A pesquisa é descritiva e foi realizada através de um estudo de caso, sendo sua abordagem qualitativa. Para coletar de dados foram realizadas entrevistas estruturadas com questionários contendo respostas abertas e fechadas. Além das análises feitas in loco, as entrevistas utilizam o método TAM (Technology Acceptange Mode). O universo amostral foram os colaboradores que lidam diariamente com os novos sistemas de gestão e os gestores que gerenciam tais sistemas. Após as entrevistas, os dados foram compilados e, juntamente com o relatório da análise in loco, foram traçadas características em comum das vantagens, desvantagens, facilidades e dificuldades no desenvolvimento das atividades cotidianas, por meio da utilização dos novos softwares.

Palavras-chave: ERP; Modelo de aceitação da tecnologia 


\section{INTRODUÇÃO}

As pressões impostas pela competitividade em um mercado globalizado, em que a essência de atuação é regida pelo capitalismo, desencadeia a necessidade de otimização dos recursos por parte das organizações. Com a evolução das linguagens de programação e a popularização dos computadores uma forma de gerar informações rápidas e confiáveis é utilizando-os como ferramenta de suporte à tomada de decisão. Para Morgam (2007), os desafios impostos nas atividades de administrar e organizar em ambientes de mudanças rápidas e constantes são ainda maiores nos dias de hoje.

É neste contexto que os sistemas de informação estão inseridos dentro das empresas, buscando dados históricos e compilando os mesmos com a velocidade de cálculo dos processadores atuais; a fim de, gerar relatórios contendo as informações necessárias ao processo de tomada de decisão e tornando ágil uma atividade que antes era trabalhosa e demorada.

Portanto, o objetivo geral da pesquisa é identificar, através de entrevistas, as vantagens e desvantagens de mudanças de softwares de gestão em duas empresas localizadas na cidade de Bagé, Rio Grande do Sul, bem como, as facilidades e dificuldades para tal implantação. Em um primeiro momento serão discutidos os temas referentes à sustentação teórica do estudo, logo após será descrito o método com o qual a presente pesquisa será realizada, para então, descrever as análises juntamente com os resultados obtidos. Ao final serão apresentadas as considerações finais.

\section{FUNDAMENTAÇÃO TEÓRICA}

\subsection{SISTEMAS DE INFORMAÇÃO}

Falar a respeito de sistemas é fazer uma menção sobre o cotidiano vivenciado dia após dia, em que se faz necessário a utilização de sistemas de transporte, sistema de água e esgoto, sistema de energia elétrica, entre outros. Para tanto, Batista (2006, p. 13) define um sistema como "o conjunto de elementos interdependentes, ou um todo organizado, ou partes que interagem formando um todo unitário e complexo".
Seguindo o preceito proposto pelo autor e comparando com as atividades de uma empresa qualquer, pode-se observar que as organizações atuam como sistemas, ao passo que, possuem elementos de entrada, sendo estes processados e resultando em saídas. Empresas que possuem sistemas mais eficazes também utilizam uma forma de realimentação, a fim de que as saídas do processo possam fornecer a base para novas entradas.

Dispor de informações corretas, no tempo certo é uma necessidade real das organizações frente às pressões impostas pela concorrência, em virtude deste fato, se faz necessário à utilização de Sistemas de Informação (SI), que recebem os dados e os transformam em informações úteis ao usuário final.

Segundo Laudon e Laudon (2007), um sistema de informação é um conjunto de componentes que trabalham juntos, desde a coleta e o processamento de dados brutos até o armazenamento e distribuição de informações, assim, facilitando o planejamento e controle da organização, além de auxiliar no processo decisório da companhia.

Com a utilização de um sistema de informação a empresa consegue transformar dados brutos, os quais, segundo Batista (2006), são representados por um conjunto de elementos que expressam um fato isolado, transformando-os em informações, que segundo o autor são dados organizados e classificados para suprir um objetivo específico.

Stair e Reynolds (2011) descrevem que os sistemas de informação podem ser divididos em: sistemas empresariais básicos, sistemas de automação de escritório, sistemas de informação gerencial, sistemas de suporte a decisão, sistemas de suporte executivo, sistemas integrados de gestão, sistemas especialistas e sistemas de informação geográfica. A presente pesquisa apresenta como foco os sistemas integrados de gestão.

\subsection{SISTEMAS INTEGRADOS DE GESTÃO (ERP)}

Segundo Souza (2000) os sistemas ERP são sistemas de informação integrados adquiridos em pacotes comerciais visando dar suporte à maioria dos setores da empresa 
contemplando suas operações. O ERP é constituído de módulos, existindo comunicação entre os módulos com apenas uma base de dados central. O sistema ERP possui características que os diferem de outros sistemas, dentre essas características podem ser apresentadas: são pacotes comerciais livres, são desenvolvidos a partir de um modelo padrão de processo, são integrados, possuem grande abrangência funcional, apresentam um banco de dados unificado e corporativo, requerem de procedimentos de ajuste a realidade implantada.

Os ERPs apresentam alguns conceitos importantes a serem destacados como a funcionalidade do ERP, ou seja, o conjunto de funções embutidas no sistema, as quais geram o sistema de informação transacional da empresa. Os módulos são conjuntos menores de funções que englobam setores diferentes da empresa e podem ser comprados separadamente, assim, a empresa pode comprar apenas os módulos que necessita ou apresenta interesse. A parametrização, ou seja, através dos parâmetros que existem no ERP a empresa deve adequar seus sistemas para haver compatibilidade (LAUDON; LAUDON, 2007).

A configuração, ou seja, o conjunto de parâmetros após sua definição gerando as opções de funcionamento do ERP. A customização, ou seja, quando algum parâmetro do ERP não pode ser aplicado e então algum profissional ligado a implantação do ERP deve alterar alguma característica do módulo afetado para adequar-se ao sistema da empresa em implantação. A localização, ou seja, quando o ERP é aplicado em países diferentes devem ser adaptadas características como carga tributária, leis, taxas, procedimentos comerciais entre outros e, por fim, a atualização das versões, ou seja, apresentar versões novas corrigindo falhas ou melhorando processos (SOUZA, 2000).

\subsubsection{VANTAGENS COM SISTEMAS DE INFORMAÇÃO}

Em um mercado globalizado é notável que algumas organizações se destaquem mais do que outras. Algumas são líderes de mercado enquanto outras "correm atrás". Isso acontece pelo fato de que, as empresas líderes, apresentam vantagens competitivas com relação às outras, ou por terem acesso a recursos diferenciados, ou por utilizarem mais eficientemente os recursos que possuem.

Segundo Laudon e Laudon (2007) existem quatro tipos de vantagens competitivas:

- Barreiras de entrada que restringem a oferta, ou seja, quando a empresa possui o controle do mercado, seja dona da patente ou tem contrato que excluem os concorrentes.

- Controle da demanda, ou seja, quando o custo de mudança fica muito alto para o consumidor, nesse caso os produtos da empresa líder de mercado apresentam qualidades superiores.

- Economias de escala, empresas buscam reduzir seus custos operacionais fazendo com que custos fixos sirvam como impulsionador para o aumento de produtividade, ou seja, instalações e equipamentos nos quais o capital é investido e precisam estar no local, com ou sem produtividade, podem ser utilizados em maior período de tempo (por doze horas ao invés de oito) que o concorrente, aproveitando oportunidades e reduzindo os custos.

- Eficiência de processos, criação de processos mais eficientes, seja pelo seu funcionamento ou pela aplicação correta de tecnologias.

- Para atingir essas vantagens competitivas, os sistemas de informação e as tecnologias em geral, podem auxiliar as organizações, segundo Laudon e Laudon (2007), através da implantação de, no mínimo, quatro estratégias genéricas, são elas:

- Liderança em custos: os sistemas de informação auxiliam na redução de custos operacionais, assim as empresas, como as do varejo, podem vender seus produtos a preços mais baixos. Um sistema que identifica quais as necessidades de matéria-prima e envia pedidos de orçamento aos fornecedores auxilia na redução do tempo de planejamento das compras e informa ao gestor as necessidades da empresa rapidamente, servindo como facilitador para a tomada de decisão.

- Diferenciação de produto: os sistemas de informação auxiliam na hora de agregar produtos ou valor aos seus produtos, assim uma empresa que vende bens ou serviços pode possuir um cartão de 
crédito próprio para facilitar o pagamento; outro exemplo é o de uma construtora que pode estabelecer um convênio com um banco, realizando simulação de financiamento de seus imóveis para o cliente.

- Foco em nicho de mercado: os sistemas de informação auxiliam na hora de definir qual o nicho de mercado, bem como identificar às necessidades desse mercado a partir do comportamento do consumidor, assim, a empresa pode se diferenciar por atender bem seu nicho de mercado e fidelizar seus clientes.

- Intimidade com o cliente ou fornecedor: os sistemas de informação podem facilitar o contato com clientes e fornecedor, aumentando a capacidade de planejamento desde o curto até o longo prazo, assim, fornecedores e clientes podem saber os prazos para 0 recebimento e entrega de produtos.

Contudo, as vantagens competitivas provenientes da implantação de sistemas de informação podem ganhar força e, consequentemente, as empresas líderes podem aumentar sua liderança, bem como as empresas que não são líderes ou novas empresas podem buscar diferenciação e melhorar sua posição no mercado com o auxílio desses sistemas.

\subsection{DIFICULDADES NA IMPLANTAÇÃO DE SISTEMAS DE INFORMAÇÃO}

Mesmo que os sistemas de informação apresentem-se como um diferencial competitivo, ou meso, como uma grande vantagem operacional, implantar um sistema não se caracteriza como uma tarefa fácil. Segundo Fetzner apud Prado et al. (2010), quando fatores técnicos, sociais, humanos, entre outros interagem entre si, como na implantação de um sistema, podem surgir condições imprevisíveis, dessas condições pode haver modificações na tecnologia e nas pessoas.

O processo de implantação de um sistema de informação segundo Laudon e Laudon (2007) envolve pessoas, tecnologia e a organização. Assim existem barreiras características de cada parte da estrutura. Segundo Prado et al. (2010) as principais dificuldades enfrentadas para implantação de software são:
- Resistência a mudanças internas, principalmente pelo fato de que as pessoas não possuem interesse em mudanças, devido ao medo de não conseguirem utilizar novas ferramentas ou perder seu espaço.

- Despreparo do cliente para o processo de implantação. O cliente acaba sendo penalizado, pois não consegue realizar as operações que costumava realizar com a mesma facilidade, principalmente durante a implantação do novo sistema.

- Imprecisões na especificação do serviço a ser prestado. Inicialmente os serviços passam a não ser tão precisos, tarefas simples podem se tornar bastante complexas se não houver conhecimento sobre o novo sistema implantado.

- Pressões políticas do cliente. O cliente deseja ter o mesmo serviço que possuía anteriormente e exige isso da empresa.

- Excesso de expectativa do cliente. O cliente ao saber que a empresa mudou de sistema espera melhoria nos serviços, o que normalmente não acontece no começo do novo processo.

- Rotatividade de mão de obra. Muitas pessoas preferem não se adaptar à nova realidade, assim há necessidade de contratar novas pessoas interessadas.

- Problemas de infraestrutura. Normalmente como no começo os sistemas demoram a "engrenar" há necessidade de mais estrutura física (computadores, mesas, etc), bem como em determinados casos maquinário mais moderno.

- Diferenças culturais. Dificuldade de determinadas pessoas, ou público, de aceitar características do sistema.

- Excesso de monitoramento do cliente. O cliente fica esperando que os processos funcionem e de certa forma espera uma resposta da empresa, mesmo que já espere um resultado negativo quanto as suas solicitações.

- Problemas de relacionamento, principalmente com fornecedores, onde tarefas simples se tornam mais complexas e os fornecedores exigem que os contratos já firmados sejam executados, porém, barreiras sistêmicas travam os processos.

- Problemas de trabalho em equipe. Conforme as atividades não são executadas a equipe se desgasta e ocorrem problemas internos. 
Esses são exemplos de problemas que podem ocorrer durante a implantação de novos sistemas de informação nas empresas, ressaltando a importância de um planejamento prévio para a implantação do sistema, levando em consideração os aspectos estruturais e, principalmente, os fatores culturais da empresa.

\section{METODOLOGIA}

Quanto à abordagem do problema, o presente estudo utilizar-se-á de pesquisa qualitativa. Segundo Richardson (2008), a diferença entre uma abordagem qualitativa e quantitativa está no modo como os dados são coletados e no tratamento que estes recebem ao serem compilados. Neste caso uma abordagem quantitativa não é adequada devido ao pequeno universo amostral, devido a este fato, os resultados podem ficar distorcidos ao fazer uma análise estatística dos dados; outra característica desta pesquisa é que seu estudo busca compreender a percepção das empresas no processo de mudança, na forma de gerir seus processos.

Para coleta de dados será utilizada a técnica de questionários com perguntas do tipo abertas e fechadas que serão aplicadas em funcionários e gestores de duas empresas situadas na cidade de Bagé, na região da campanha, do estado do Rio Grande do Sul. O questionário será aplicado em entrevistas diretas in loco. A empresa $A$ atua no ramo da construção civil e possui cerca de 104 funcionários e adquiriu um ERP a aproximadamente 16 meses; já a empresa $B$, atua no ramo do varejo e possui cerca de 1000 funcionários distribuídos em 30 filiais e obteve o novo software a cerca de 19 meses. Uma característica comum entre ambas às empresas é que compraram softwares prontos, já comercializados no mercado.

Como método de pesquisa é aplicado o TAM ( Technology Acceptance Model) esse método deriva da Teoria da Ação Intencional (TRA) o qual, segundo Davis et al (1989), apresenta que, um comportamento é fruto de uma intenção, que deriva de atitudes e normas subjetivas em relação ao comportamento visado. As atitudes e normas resultam de crenças e avaliações bem como de crenças normativas e motivação para o comportamento. As crenças, ou seja, as informações que o sujeito tem a respeito do objeto, são a base para formar atitudes. As normas subjetivas auxiliam na formação das intenções, sendo estes, resultantes da percepção o indivíduo com relação à opinião de pessoas as quais considera importante em relação ao fato observado. A intenção é a probabilidade mesmo que subjetiva de um indivíduo comportar-se de determinada maneira.

O modelo TAM complementa-se com uma variável do modelo TPB (Teoria do Comportamento Planejado), o controle percebido sobre o comportamento, sendo esse a percepção do indivíduo sobre sua performance em relação a determinado comportamento. Assim, segundo Davis et al (1989) o modelo TAM busca medidas e conceitos consistentes e válidos para tentar explicar a utilização de sistemas de informação. Assim, o modelo apresenta duas bases teóricas a serem entendidas: a utilidade percebida do sistema e a facilidade de uso percebida no sistema; sendo a primeira, o quanto a pessoa acredita que o uso do sistema pode melhorar seu desempenho no trabalho; e a segunda, o quão livre de esforço a pessoa acredita que um sistema específico seria. Este modelo pode ser visualizado na Figura 1.

Figura 1: Método TAM

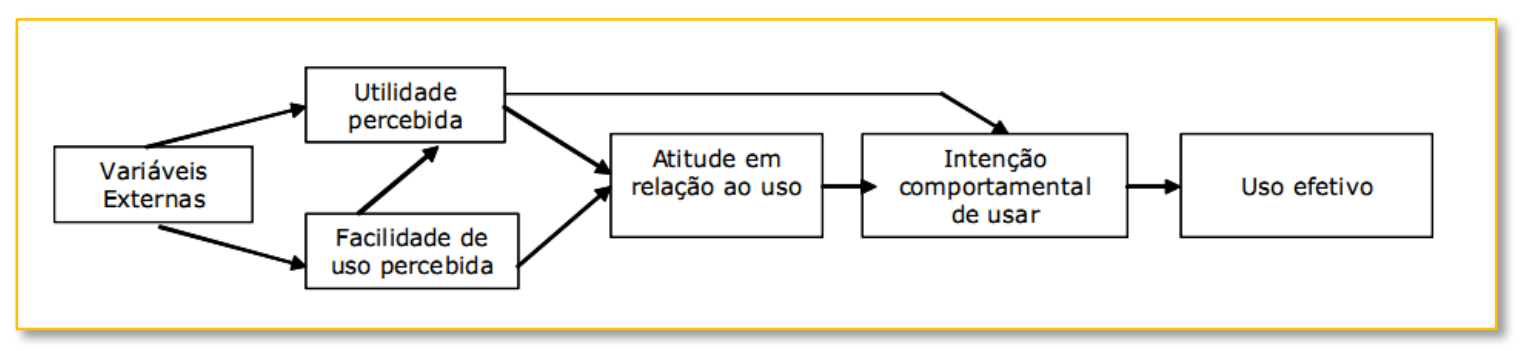

Fonte: Davis et al (1989) 


\section{APLICAÇÃO DO MÉTODO}

Para aplicação do método foi criado um questionário em busca do entendimento de quais seriam as facilidades e dificuldades encontradas no momento de implantação de um sistema, e quais as vantagens e desvantagens percebidas até o momento, em relação ao sistema utilizado anteriormente. Contudo, o questionário foi baseado na busca pelo entendimento da utilidade percebida, da facilidade de utilização, da atitude em relação ao uso e da intenção comportamental em utilizar o sistema, levando em consideração que essas variáveis podem afetar no resultado almejado, essencialmente nas dificuldades de implantação. O questionário é apresentado na Tabela 1 e foi elaborado com base em cinco áreas referentes às aquisições, treinamentos, suporte, manutenção e, por fim, quanto a

avaliação dos usuários nos diversos níveis (operacional, tático e estratégico) que o novo sistema de informação engloba. Devido ambas as empresas terem adquirido um sistema do tipo Enterprise Resource Planning (ERP), de softwares já presentes no mercado, ambas responderão aos mesmos questionamentos.

Tabela 1 - Questionário para análise da implantação do novo SI

\begin{tabular}{|c|c|}
\hline Q1 & Tipo de sistema: Enterprise Resource Planning (ERP) \\
\hline Q2 & Cargo: $\quad$ ( ) Operacional ( ) Tático ( ) Estratégico \\
\hline Q3 & Quanto tempo trabalha na empresa? \\
\hline \multirow[t]{2}{*}{ Q4 } & Participou da implantação do SI? \\
\hline & Quanto às aquisições: \\
\hline Q5 & Houve necessidade de adquirir novos equipamentos? \\
\hline \multirow[t]{2}{*}{ Q6 } & Quais fatores foram mais preponderantes na escolha do sistema? \\
\hline & Quanto ao treinamento: \\
\hline Q7 & Quantas horas de treinamento foram necessárias? \\
\hline Q8 & Treinamento foi suficiente para o tornar apto a usar o sistema? \\
\hline \multirow[t]{2}{*}{ Q9 } & Foi disponibilizado um manual de operações? \\
\hline & Quanto ao suporte: \\
\hline Q10 & Houve algum acompanhamento feito pelo suporte? \\
\hline \multirow[t]{2}{*}{ Q11 } & Qual a disponibilidade do suporte para tirar dúvidas? \\
\hline & Quanto à manutenção: \\
\hline Q12 & Qual a periodicidade que o sistema recebe manutenção? \\
\hline \multirow[t]{2}{*}{ Q13 } & Quando verificado algum bug, como você avalia o tempo de correção do mesmo? \\
\hline & Quanto à avaliação: \\
\hline Q14 & Qual sua percepção sobre o ERP? \\
\hline Q15 & Quais as vantagens? \\
\hline Q16 & Quais desvantagens? \\
\hline Q17 & Ainda utiliza alguma forma de controle paralela ao ERP? \\
\hline Q18 & $\begin{array}{l}\text { Em suma, seu trabalho foi facilitado pelo novo sistema? Você se considera satisfeito } \\
\text { com o desempenho do mesmo? }\end{array}$ \\
\hline
\end{tabular}

Fonte: Autoria própria 
A seguir, serão discutidos os resultados obtidos após a aplicação do questionário nas empresas A e B.

\section{RESULTADOS E DISCUSSÕES}

Por meio das respostas obtidas com a aplicação do questionário, pode ser observado que as crenças individuais de cada colaborador podem dificultar a implantação de um novo sistema, visto que, os indivíduos possuem determinada resistência a mudanças, por associarem novos sistemas e tecnologias a dificuldades de realizarem suas atividades cotidianas.

Quanto às normas subjetivas, verificou-se que estas representam grande influência sobre o nível operacional; pois, quando os gestores demonstram medo em relação ao futuro, a equipe não compra a ideia, e a insegurança toma conta do sistema, por consequência, as pessoas passam a ter mais dificuldade em aprender o novo sistema e criam crenças errôneas em determinados momentos em relação ao ERP.

Com base nos aspectos mencionados, pôde ser percebido que o indivíduo não explora as potencialidades dispostas pelo sistema. Conforme acontecem erros, o mesmo apresenta menor autoestima; além de ser

\section{REFERÊNCIAS}

BATISTA, E. O. Sistemas de Informação: o uso consciente da tecnologia para 0 gerenciamento. São Paulo: Saraiva, 2006.

[2] DAVIS, F. D.; BAGOZZI, R.; WARSHAW, P. R. User Acceptance of Computer Technology: a comparison of two theoretical models. Management Science, v. 35, 1989.

[3] LAUDON, K. C.; LAUDON, K. C. Sistemas de Informação Gerenciais. 7. ed. São Paulo: Prentice Hall, 2007.

[4] MORGAM, G. Imagens da Organização: edição executiva. Tradução: Geni Goldshimidt - São Paulo: Atlas, 2007.

[5] PRADO; E. P. V.; BRITO, B. A. S. Barreiras na Implantação de Sistemas de Informação em necessária a substituição de alguns colaboradores, devido ao fato de que, muitos desses, não se adequam ao novo sistema. Outro fator observado foi quanto à ameaça representada pela nova mão de obra, mais qualificada, frente aos antigos colaboradores, os quais tendem a influenciá-los a aderir resistência ao novo sistema.

Assim, pôde ser observado que a equipe nunca acredita que um novo sistema possa melhorar seu desempenho no trabalho e atribui maior importância às dificuldades a serem enfrentadas durante sua implantação; todavia, após alguns meses de utilização, principalmente nos níveis mais altos (estratégico e tático), é percebida a aceitação do novo sistema, bem como passa a ser compreendido o funcionamento do ERP e suas características, os quais passam a ser identificados como facilitadoras na execução de tarefas rotineiras, reduzindo consideravelmente o esforço empregado; bem como, auxiliam no processo de tomada de decisão, trazendo benefícios a organização frente ao controle interno das atividades, além de promoverem vantagem competitiva frente à concorrência.
Escritórios Contábeis. In: XIII SEMEAD Seminários em Administração, São Paulo, 2010.

[6] RICHARDSON, R. J. Pesquisa Social: métodos e técnicas. 3. ed. São Paulo: Atlas, 2008.

[7] SOUZA, C. A. Sistemas integrados de gestão empresarial: estudos de casos de implementação de sistemas ERP. 306f. Dissertação (Mestrado) - Faculdade de Economia, Administração e Contabilidade, Universidade de São Paulo -FEA/USP, São Paulo, 2000.

[8] STAIR, R. M.; REYNOLDS, G. W. Princípios de Sistemas de Informação. 9. ed. São Paulo: Cengage Learning, 2011. 


\title{
Bapítulo 4
}

\section{EXPLORATION E EXPLOITATION EM INSTITUIÇÕES DE ENSINO SUPERIOR}

\author{
Fernando Ribeiro dos Santos
}

Laura Melo Barros Bona Miranda

Resumo: O objetivo principal desta pesquisa foi analisar os processos de exploraiton e exploitation de conhecimentos mediante uma pesquisa empírica junto a coordenadores de curso de instituições de ensino superior [IES]. A pesquisa nesta área justifica-se por dois importantes pontos: por sua relevância social, pois a informação é, em essência, a matéria-prima do cotidiano do ser humano; e por levar em consideração o modo como estas IES buscam e capturam informações e novos conhecimentos (exploration) ou como as IES catalisam os conhecimentos e informações geradas internamente, através do know-how dos seus funcionários socializados entre todos se baseando em procedimentos e rotinas (exploitation). A pesquisa, considerada qualitativa básica, foi realizada por meio de roteiro, com sete questões abertas sobre o tema e cinco questões para qualificar os respondentes, sendo que sua identificação se manteve confidencial. A coleta de dados foi realizada com o auxilio da plataforma Google docs, onde foi criado o formulário com as questões no qual os respondentes preencheram livremente as respostas às mesmas. Os resultados demonstraram que a maioria das ies possui uma tendência ambidestra, ou seja, estas instituições possuem uma forte orientação para serem explorers e uma forte orientação para, simultaneamente, serem exploiters, conforme Popadiuk (2010).

Palavras-chaves: Exploitation; Exploration; Gestão do conhecimento; Instituições de ensino superior. 


\section{INTRODUÇÃO}

A Gestão do Conhecimento [GC] é um campo de estudo que vem sendo amplamente explorado em diversas áreas, por isso, é necessário fazer uma análise detalhada dos possíveis impactos que possa ter sob diferentes perspectivas. Em particular, as universidades devem ser consideradas como gestoras do conhecimento, por natureza, a considerar três funções importantes, ensino, pesquisa e extensão (FERRER; RíOS, 2006).

Maccari e Rodrigues (2003) afirmam que em GC, um caso singular é o das Instituições de Ensino Superior [IES], pois, de fato, estas organizações lidam tipicamente com 0 conhecimento.

Segundo Hitam, Mahat e Krishnasamy (2008) o conhecimento é o ícone da nova economia e é apresentado como o mais provável fonte de vantagem competitiva. Portanto, a GC é vista como uma inovação com potencial para afetar o conjunto da atividade de uma organização. Estar no negócio de conhecimento, para as IES não é uma exceção a esse imperativo, ainda mais quando há uma longa história de sucesso de IES adotando filosofias de gestão do mundo dos negócios. Em vista do seu papel tradicional na produção, transferência, difusão e manipulação do conhecimento, IES são as principais organizações sócioeconômicas em qualquer sociedade.

O objetivo desta pesquisa consistiu em analisar os processos de exploration e exploitation do conhecimento mediante uma pesquisa empírica junto a Coordenadores de Curso das IES.

E para isto é necessário identificar quais destes procedimentos estão sendo mais explorados nestas organizações, e em quais estavam mais relacionados com os processos de criação e aprimoramentos dos cursos superiores destas instituições.

A pesquisa nesta área justifica-se em duas importantes arenas, a primeira por sua relevância social. A informação é, em essência, a matéria-prima do cotidiano do ser humano, para isso, este ser tem cinco sentidos, que captam as mensagens do ambiente. A informação também deve passar pelo crivo de três núcleos como a cognição, a emoção e as situações (CHOO, 2006).

Num sentido mais acadêmico, a segunda arena, o estudo da Gestão do Conhecimento focado nas atividades de Exploration e Exploitation pode ser feito levando em consideração o modo como a organização busca e captura novas informações e novos conhecimentos (exploration) ou como as organizações catalisam os conhecimentos e informações geradas internamente, baseando-se no know-how dos seus funcionários socializados entre todos por meio de procedimentos e rotinas (exploitation).

\section{GESTÃO DO CONHECIMENTO}

"Em uma economia onde a única certeza é a incerteza, a fonte certa de vantagem competitiva duradoura é o conhecimento" (NONAKA, 2008, p. 39). Para Rowley (2000) muitos argumentam que o conhecimento se tornou a principal ferramenta competitiva para muitas organizações. Drucker (1993) descreveu o conhecimento, ao invés de capital ou o trabalho como o único recurso econômico significativo na sociedade do conhecimento, e Senge (1990) alertou que muitas organizações são incapazes de funcionar como organizações baseadas no conhecimento, porque sofrem de distúrbio de aprendizagem. Liebowitz (2000) argumenta que a GC é o processo de criação de valor de ativos intangíveis de uma organização.

Davenport et al. (1998) categorizaram os projetos de GC por meio da identificação de quatro grandes tipos de objetivos: (1) criar repositórios de conhecimento; (2) melhorar o acesso ao conhecimento, (3) melhorar o ambiente de conhecimento e; (4) gerir o conhecimento como um ativo, valorizando-o.

Sob a perspectiva de Galagan (1997), exemplos de processos de GC são: (1) geração de novos conhecimentos; (2) acesso ao conhecimento a partir de fontes externas; (3) representação do conhecimento em documentos, bases de dados, softwares e assim por diante; (4) incorporação de conhecimento nos processos, produtos ou serviços; (5) transferência de conhecimento existente em torno de uma organização; (6) utilização do conhecimento acessível na tomada de decisões; (7) facilitação do crescimento do conhecimento por meio da cultura e incentivos e; (8) medição do valor dos ativos de conhecimento e o impacto da gestão do conhecimento. 


\section{METODOLOGIA}

Para Caelli (2003) a pesquisa qualitativa deve ser clara em relação a suas escolhas metodológicas e os métodos utilizados. A metodologia reflete as crenças sobre o conhecimento e existência no âmbito filosófico, nos quais a pesquisa está empregada (VAN MANEN, 1998).

A pesquisa, considerada qualitativa básica, foi realizada por meio de roteiro, com sete questões abertas sobre o tema e cinco questões para qualificar os respondentes, sendo que sua identificação se manteve confidencial.

O presente estudo está classificado como um procedimento de pesquisa básico ou genérico, conforme Merriam (1998), este tipo de procedimento busca compreender um fenômeno, uma ação ou procedimento e as diferentes visões e perspectivas abordadas dos envolvidos diretamente, no caso, os coordenadores de curso. A coleta de dados deste tipo de pesquisa é feita na forma de entrevistas, observações, análises documentais. E os achados são descritos em forma de análise, identificando padrões recorrentes e que não podem construir uma teoria.

Justifica-se a escolha do método qualitativo, pois, segundo Vieira (2004), tende-se a utilizar as técnicas de pesquisa qualitativa para a análise de fenômenos vinculados à cultura organizacional.

Os sujeitos de pesquisa foram intencionalmente selecionados (CRESWELL, 2010) inicialmente. Optou-se por iniciar a pesquisa enviando e-mail com o link para acesso ao roteiro de perguntas para coordenadores de cursos superiores conhecidos deste pesquisador. No corpo do e-mail foi solicitado que os mesmos repassassem para seus conhecidos (efeito bola de neve). Cinco e-mails foram passados pelos pesquisadores e foram repassados para conhecidos destes, gerando 14 respondentes.

Os respondentes foram qualificados por meio de cinco questões de múltipla escolha: sexo; idade; formação escolar; tempo no cargo de coordenação; e tipo de IES, conforme se pode observar no Quadro 1:

Quadro 1-Qualificação dos respondentes

\begin{tabular}{|c|c|c|c|c|}
\hline Sexo & Idade & $\begin{array}{c}\text { Formação } \\
\text { escolar }\end{array}$ & $\begin{array}{l}\text { Tempo no cargo de } \\
\text { coordenação }\end{array}$ & Tipo de IES \\
\hline Feminino & mais de 51 anos & Mestrado & mais de 5 anos & Pública \\
\hline Feminino & mais de 51 anos & Mestrado & até 2 anos (incompletos) & Privada \\
\hline Masculino & de 31 a 40 anos & Especialização* & até 2 anos (incompletos) & Pública \\
\hline Feminino & de 31 a 40 anos & Mestrado & até 2 anos (incompletos) & Privada \\
\hline Masculino & mais de 51 anos & Especialização* & mais de 5 anos & Privada \\
\hline Masculino & de 41 a 50 anos & Mestrado & de 3 a 5 anos (incompletos) & Confessional \\
\hline Feminino & de 41 a 50 anos & Doutorado & mais de 5 anos & Privada \\
\hline Masculino & mais de 51 anos & Mestrado & mais de 5 anos & Privada \\
\hline Masculino & mais de 51 anos & Doutorado & até 2 anos (incompletos) & Privada \\
\hline Masculino & mais de 51 anos & Mestrado & de 3 a 5 anos (incompletos) & Privada \\
\hline Feminino & de 31 a 40 anos & Mestrado & mais de 5 anos & Privada \\
\hline Masculino & de 41 a 50 anos & Mestrado & mais de 5 anos & Privada \\
\hline Feminino & mais de 51 anos & Mestrado & mais de 5 anos & Privada \\
\hline Masculino & de 31 a 40 anos & Especialização* & de 3 a 5 anos (incompletos) & Pública \\
\hline
\end{tabular}


A coleta de dados foi realizada com o auxilio da plataforma Google Docs, onde foi criado o formulário com as questões no qual os respondentes preencheram livremente as respostas às mesmas, disponível por meio do endereço eletrônico:

https://spreadsheets0.google.com/spreadshe et/viewform?formkey=dEV4QXE3WFBmeEhFCl hoR04xLVB1bnc6MQ.

As sete questões abertas foram as seguintes:

a) Como e em qual momento, em sua rotina de trabalho, você desenvolve novas ideias?

b) Para este desenvolvimento, você utiliza quais fontes?

c) Como se dá a utilização e o compartilhamento do conhecimento já existente?

d) Como você vê o processo de inovação nesta IES para novos cursos?

e) Como você vê o processo de inovação nesta IES para adaptação e/ou adequação dos cursos atuais?

f) Em sua opinião, o que é mais importante: o aproveitamento do conhecimento interno (melhorar a eficiência, a execução, as rotinas) ou a busca de conhecimento externo (experimentação, novas descobertas, inovação)?

g) Esta IES participa de alguma rede de relacionamentos? Com quais tipos de parceiros?

O tempo da coleta iniciou-se a partir do envio do primeiro e-mail que aconteceu dia 07/10/2011 e outro confirmatório dia 10/10/2011 para reafirmar a importância da pesquisa para os respondentes. As primeiras respostas ocorreram no dia 09/10 e o recebimento da última resposta que ocorreu dia 27/10, totalizando 20 dias de pesquisa.

Segundo Myers (1997) os dados são analisados buscando-se a essência dos fenômenos - no caso o entendimento global de um fenômeno do ponto de vista dos participantes no seu contexto social e institucional particular.
Para Flores (1994) há diversas estratégias para análise de dados qualitativos: agrupamento, contagem, passar do particular para o geral, inclusão, subordinação, ordenação, coocorrência, covariação e causalidade.

Os sistemas de categorias utilizadas em uma pesquisa podem estabelecer-se a priori ou a posteriori (a partir dos próprios dados) (FLORES, 1994) e neste estudo, utilizou-se a categorização a posteriori.

\section{APRESENTAÇÃO DE ANÁLISE DOS RESULTADOS}

A análise dos dados foi realizada essencialmente com base na interpretação das respostas dadas. A pesquisa qualitativa cumpriu a função de discriminar os casos extremos que foram apontados separadamente. A pequena quantidade de respondentes (apenas 14) não permite realizar inferências estatísticas, bem como pelo fato do formulário conter perguntas abertas, mas por tratar-se de uma amostra intencional focada nas pessoas mais qualificadas para a exploração do tema, a análise do conteúdo das suas respostas passa a ter significância.

Esta pesquisa teve um caráter qualitativo e seu objetivo foi analisar como são feitos os processos de Exploration e Exploitation em Instituições de Ensino Superior. Conforme foi exposto no tópico de metodologia e métodos, esta análise contempla sete questões abertas. É importante frisar que os entrevistados não obtiveram recomendações a respeito das perguntas e nem como proceder em suas respostas.

Por conta desta liberdade, muitas das respostas não estavam com o mesmo nível, pois alguns respondentes foram mais abrangentes, outros mais sucintos, e existiram até mesmo, respostas que estavam fora do contexto, mas que foram consideradas por trazerem informações importantes para a pesquisa.

Analisar é buscar elementos e associações (STAKE, 2011) e é isto o que se pretende demonstrar a seguir.

A análise está divida de acordo com estas respostas, e segue nos próximos parágrafos. 
a) Como e em qual momento, em sua rotina de trabalho, você desenvolve novas ideias?

Os respondentes não obtiveram informações do conteúdo da pesquisa, nem quais seus objetivos, muito menos o significado dos termos Exploration e Exploitation. Esta primeira questão foi feita com intuito de descobrir como os entrevistados desenvolviam novas ideias, e em qual momento do seu trabalho isto era mais evidenciado.

A maioria das respostas também trouxe a motivação para o desenvolvimento de novas ideias, o que para a pesquisa é muito importante. As principais motivações são: melhorias nos processos, enfrentamento de novas e inesperadas situações, e a introdução de novos produtos e serviços.

Dentre todas as respostas, uma chamou a atenção pelo fato de destoar das outras.

Nela o entrevistado diz: "As demandas diárias que aparecem para um coordenador de curso, praticamente não the permite desenvolver novas ideias". Nesta fala fica claro, para o entrevistado, que suas rotinas e atribuições vão de encontro com o desenvolvimento de novas ideias.

Nooteboom e Gilsing (2002) caracterizam Exploitation como um processo que possui redes densamente conectadas, com rotinas sedimentadas e aprofundadas. Ou seja, atribuições e obrigações. No entanto existe uma necessidade de que as organizações ao mesmo tempo desenvolvam as capacidades de explorar conhecimentos externos (Exploration).

Nesta resposta, o entrevistado mostra claramente a dificuldade constante que as organizações possuem em coordenar estes dois processos, chamada de ambidestria organizacional (TUSHAMAN; O'REILLY, 1996).

Este desafio tem sido cada vez mais crucial acompanhado por uma onda contínua de atividades gerenciais e pressões institucionais para o processo de gestão e controle (BENNER; TUSHMAN, 2003).

Em resposta à pergunta de como os entrevistados conseguem melhorar seus conhecimentos e adquirir novos dentro da sua rotina de trabalho, um entrevistado respondeu de acordo com as horas em que ele mais trabalha esta competência (entre 05h00 e 06h00), vários responderam "pela manhâ", enquanto outro respondeu: "No estado de semiconsciência, entre o sono e o despertar, é a altura em que os problemas melhor se delimitam e em que melhores ideias e melhores soluções me ocorrem" o que denota que para boa parte dos entrevistados o início da jornada de trabalho é o momento ideal, pois ainda não estão assoberbados com a rotina. Apenas um frisou que isto ocorre durante todo o dia.

Em relação a esta resposta, dois entrevistados indicam que o processo de desenvolvimento de novos conhecimentos acontece em reuniões de colegiado, e outro na confecção de projetos.

Portanto nesta resposta a maioria dos entrevistados conseguiu respondê-la satisfatoriamente, de acordo com a teoria, mesmo não obtendo orientações a respeito do formulário.

b) Para este desenvolvimento, você utiliza quais fontes?

Esta questão obteve um consenso por parte dos entrevistados em suas respostas. Uma justificativa para isto consiste no ambiente em que todos estão inseridos. Apesar de estarem em IES diferentes, todos possuem a mesma função, coordenar cursos, e de alguma forma estão expostos às mesmas influências.

Como fonte de novos conhecimentos, estas pessoas utilizam a discussão com os professores de seus cursos; a experiência e a vivência adquiridas em outras situações e em outras instituições; fontes bibliográficas, como revistas, livros, artigos acadêmicos, dissertações e teses; pesquisas na Internet, como cita o entrevistado que utiliza o Google como exemplo de novas tecnologias.

Sendo assim, neste tipo de empresa estas fontes de informação e obtenção de conhecimento, são utilizadas em todas as organizações pesquisadas.

c) Como se dá a utilização e o compartilhamento do conhecimento já existente?

Como na questão anterior, as respostas se mostraram equilibradas em nível de resultados. Podemos dividir as respostas em duas categorias: compartilhamento de conhecimentos de forma tácita e 
compartilhamento de conhecimentos de forma explícita (POLAYNI, 1965).

De forma tácita, incluem-se as repostas que englobam o compartilhamento através de troca de experiências, envio de sugestões, troca de informações. Todas estas ações oferecem resultados, mas que não são mensurados, pelo fato de não serem documentadas, e estarem incorporadas somente em algumas pessoas que tiveram contato com estas informações de quaisquer maneiras, também não estabelecida.

De forma explícita, enquadram-se as respostas, nas quais, de alguma forma o compartilhamento do conhecimento é formal, documentado, incorporado à rotina e medido através de níveis de desempenho. Este compartilhamento se dá por meio de reuniões, publicações de artigos e circulares. Um dos entrevistados em sua fala exemplifica este tipo de compartilhamento: "Publicando artigos acadêmicos para disseminação formal da informação e utilizando ferramentas colaborativas para construção do conhecimento".

Todavia, pode-se perceber, segundo Benner e Tushman (2002) que estas formas de compartilhamento podem ser classificadas como exploration ou exploitation.

Formas de compartilhamento tácitas acontecem, segundo estes autores, em ambientes mais favoráveis a exploração de conhecimentos externos, relativos a processos de exploration. Em contrário, formas de compartilhamento explícito acontecem em ambientes mais propensos para a atividade de exploitation.

Portanto, destas IES analisadas, apesar de estarem imersas no mesmo ambiente, muitas conseguem promover processos diferentes. Algumas estão trabalhando mais com processos de aprimoramento de conhecimentos internos e outras com processos de busca de conhecimentos externos.

\section{d) Como você vê o processo de inovação nesta IES para novos cursos?}

Esta questão foi inserida para demonstrar como é feito o processo da criação e aprimoramento de novos cursos (que são os produtos das IES). Pelas respostas encontradas, verifica-se que este tipo de empresa está num ambiente de média concorrência. Segundo Benner e Tushman (2002), neste tipo de ambiente, as organizações operam mais com processos de exploitation. Pois a concorrência não é alta a nível tecnológico, e a inovação é um processo muito burocrático neste setor, pois ela é regulamentada pelo Ministério da Educação MEC.

Vale frisar que a média concorrência também se dá, na visão dos respondentes, pois algumas das IES são públicas, o que descaracteriza esta concorrência ou a preocupação com a mesma.

A maioria das respostas traz a informação que a inovação é limitada, atrelada a mão de obra existente. Ou seja, neste setor, para haver inovação no oferecimento de cursos superiores, é necessários que já exista no mercado consumidor demanda e mão de obra para repassar seus conhecimentos.

Outro limitante da inovação são os projetos pedagógicos dos cursos, que já foram feitos tempos atrás, estão defasados com a realidade do mercado, mas que não podem ser modificados, sem a autorização do MEC.

Para analisar esta questão procurou-se relacionar as principais respostas dadas, com o processo correspondente:

Quadro 2 - Exemplos de Exploitation e Exploration retirados das falas dos respondentes

\begin{tabular}{|c|c|}
\hline Exploitation & Exploration \\
\hline "Inovação limitada à mão de obra" & "Inovação para atender o mercado" \\
\hline $\begin{array}{l}\text { "Aprimoramento de cursos já existentes } \\
\text { (novas disciplinas e linguagens)" }\end{array}$ & $\begin{array}{l}\text { "Inovação através de parcerias com } \\
\text { entidades de inovação" }\end{array}$ \\
\hline
\end{tabular}

Fonte: Elaboração própria

Como na questão anterior, estas Instituições estão promovendo processos diferentes internos e externos. Apesar da forte regulação, existem organizações que 
conseguem desenvolver seus conhecimentos internos através de parcerias, e procurando responder e surpreender a expectativa do mercado.

Outras estão apenas se adequando à burocracia e aos procedimentos legais para funcionar, e procuram desenvolver e aprimorar somente os cursos existentes. e) Como você vê o processo de inovação nesta IES para adaptação e/ou adequação dos cursos atuais?

Em resposta a esta questão, observa-se que há diferenças gritantes: tanto entre públicas e privadas, como entre públicas e públicas e entre privadas e privadas, conforme se pode observar no Quadro 03 em que alguns trechos de respostas foram destacados.

Quadro 3 - Postura inovadora/conservadora

\begin{tabular}{|c|c|c|}
\hline & Inovam & Não inovam \\
\hline Públicas & $\begin{array}{l}\text { "Vejo de forma muito } \\
\text { favorável." }\end{array}$ & $\begin{array}{l}\text { "Limitado e medroso. A IES } \\
\text { parece pouco interessada em } \\
\text { inovar." }\end{array}$ \\
\hline Privadas/Confessionais & $\begin{array}{l}\text { "... a partir de demandas } \\
\text { mercadológicas." } \\
\text { "Em constante revisão, em } \\
\text { função das necessidades do } \\
\text { contexto." } \\
\text { "É uma preocupação } \\
\text { constante." }\end{array}$ & $\begin{array}{l}\text { "O processo está totalmente } \\
\text { desalinhado com as } \\
\text { demandas de mercado." } \\
\text { "Não há inovação." }\end{array}$ \\
\hline
\end{tabular}

Fonte: Elaboração própria

As respostas também apontam para dificuldades, tais como a burocracia envolvida no processo, bem como em relação às pessoas envolvidas: "pautado basicamente pela opinião de colegas com pouca experiência prática e sem consultar o setor produtivo que absorverá a mão de obra" (pública).

Vale ressaltar também que muitas respostas a esta questão remetiam à questão anterior (questão d).

f) Em sua opinião, o que é mais importante: o aproveitamento do conhecimento interno (melhorar a eficiência, a execução, as rotinas) ou a busca de conhecimento externo (experimentação, novas descobertas, inovação)?

"Acredito que o equilibrio entre as duas tendências é a melhor resposta" e "As duas opções são importantes e necessárias" são duas, entre as diversas frases das respostas, que espelham a concordância da grande maioria dos entrevistados. Apenas dois respondentes apontaram caminhos diferentes, ambos de IES privadas:
"Conhecimento interno, a cultura da organização é o diamante da instituição" e "Esta questão está intimamente ligada à cultura organizacional da empresa. No caso, o aproveitamento do conhecimento interno". Um dos respondentes, também de uma IES privada apontou um meio caminho: "Ainda estamos no conhecimento interno, mas acho que no futuro próximo usaremos o externo".

Estes posicionamentos apontam para uma tendência ambidestra na maioria das organizações. Quando a empresa possui uma forte orientação para serem explorers e uma forte orientação para, simultaneamente, serem exploiters, são definidas como ambidestras, conforme Popadiuk (2010).

g) Esta IES participa de alguma rede de relacionamentos? Com quais tipos de parceiros?

Nesta questão também se encontrou diversidade de respostas, desde as que participam de redes de relacionamentos diversos; casos em que não há participação alguma (três privadas); e casos em que afirmam desconhecer (uma pública e uma 
privada). Das que afirmam participar, há vários tipos de relacionamentos e parceiros, conforme se pode notar a seguir.

"Esta IES está dentro de um grupo que possui mais duas IES em outro Estado" (privada). "Sim, desde Associação Comercial, entidades de classe, etc." (privada). "[...] com empresas portuárias e retroportuárias, Companhia Docas do Estado de São Paulo, Capitania dos Portos, Prefeitura Municipal de Santos, [...] Universidade Católica do Chile e o Porto de Roterdã, na Holanda, [...] CIEE, SEBRAE e diversas empresas" (privada). "Participamos das redes do Centro Paula Souza e do Inova Paula Souza, [...] atuamos juntamente com entidades de classes na Associação Comercial de Santos" (pública). "Tem uma gama enorme de parceiros dentro e fora do país" (confessional). "Facebook, twitter" (privada).

\section{LIMITAÇÕES}

Em primeiro lugar pode-se afirmar que a falta de pré-teste do formulário de coleta de dados é um fator limitante, que ficou evidenciado, inclusive, pelo entendimento diverso que alguns respondentes tiveram com relação a algumas questões. Outro limitante foi o fato de que não se pesquisou outras fontes de evidências, tais como Documentos, o que proporcionaria mais qualidade e credibilidade à pesquisa.

Um ponto limitante evidenciado foi a amostragem pequena (apenas 14 entrevistados). Suas respostas, que foram analisadas, podem não corresponder com a realidade do ambiente de pesquisa.

Também se pode apontar como limitação o fato de que as respostas não foram coletadas por meio de entrevista o que poderia ter enriquecido as respostas. A escolha pelo método de coleta de dados por meio de formulário se deu tanto pela dificuldade de acesso aos respondentes, como por dificuldades de agenda dos mesmos e destes pesquisadores.

\section{CONSIDERAÇÕEES FINAIS}

Este estudo teve a motivação de analisar como são feitos os processos de Exploration e Exploitation do Conhecimento em Instituições de Ensino Superior, e para isto foram entrevistados 14 coordenadores de cursos de IES entre privadas e públicas.

As questões de pesquisa procuravam identificar quais destes processos eram mais evidentes na fala destes entrevistados, e quais estavam mais relacionados com os processos de criação e aprimoramentos dos cursos superiores destas instituições.

Os resultados demonstraram que a maioria das IES possui uma tendência ambidestra, ou seja, estas instituições possuem uma forte orientação para serem explorers e uma forte orientação para, simultaneamente, serem exploiters, conforme Popadiuk (2010).

Outro ponto importante desta pesquisa foi identificar a diferenciação entre os posicionamentos mercadológicos entre as Instituições Públicas e Privadas. Nas privadas as inovações estão constantemente ligadas com as necessidades do mercado, enquanto as públicas estão mais relacionadas com as diretrizes do Ministério da Educação, ou seja, a inovação não parte da demanda dos mercados nas quais estão inseridas e sim das normas do MEC

Estes resultados comprovam que independente da maneira, sendo exploration ou exploitation, as organizações devem inovar ou morrer, e sua capacidade de aprender, adaptar e mudar torna-se uma competência essencial para a sobrevivência. As forças da tecnologia, a globalização e a economia do conhecimento estão criando uma revolução que está forçando as organizações a procurar novas formas de se reinventar (ROWLEY, 2000)

O diferencial das pesquisas qualitativas é a interação com os entrevistados, e a possibilidade de perceber e analisar detalhes nas falas de cada um, que revelam as emoções que estes sentem com relação ao assunto da pesquisa.Entretanto, é importante ressaltar que os resultados desta pesquisa, apesar de não permitirem generalizações, apontam para caminhos a serem observados, nos quais outras pesquisas possam ser feitas, com a finalidade de aprofundar estas descobertas. 


\section{REFERÊNCIAS}

[1] BENNER, M. J.; TUSHMAN, M. L. Exploitation, exploration, and process management: The productivity dilemma revisited. Academy of Management Review, 28(2): 238-256, 2003.

[2] CAELLI, K.; RAY, L.; MILL, J.; "Clear as Mud": toward greater clarity in generic qualitative researh. International Journal of qualitative methods, vol 2, 2003.

[3] CHOO, Chun Wei. A organização do conhecimento. 2. ed. São Paulo: SENAC, 2003.

[4] CRESWELL, John W. Projeto de Pesquisa: métodos qualitativo, quantitativo e misto. 3. ed. Porto Alegre: Artmed, 2010.

[5] DAVENPORT, Thomas. H., DE LONG, David W.; BEERS, Michael C. Successful knowledge management projects. Sloan Management Review, v. 39, n. 2, Winter, pp. 43-57, 1998.

[6] DRUCKER, Peter F. Landmarks of Tomorrow: A Report on the New "Post-Modern" World. New York, NY: Harper Colophon Books, 1959.

[7] FERRER, Julian; RÍOS, Manriquez. Knowledge management in higher education: a conceptual analysis. Munich Personal RePEc Archive MPRA Paper No. 2622, October (2006) posted 07. November 2007/02:37. Disponível em: <http://mpra.ub.uni-muenchen.de/2622/>. Acesso: em 02 out. 2011.

[8] FLORES, Javier Gil. Análisis de Datos Cualitativos: aplicaciones a la investigación educativa. Barcelona, PPU, 1994.

[9] GALAGAN, Patricia A. Smart companies (knowledge management). Training and Development. v. 51, n. 12, December, pp. 205. 1997.

[10] HITAM, Mizan B.; MAHAT, Sabariah Hj; KRISHNASAMY Rajasegaran. The Tacit Knowledge Dimension for Knowledge Management in Higher Education Organizations. Social and Management Research Journal - SMRJ. v. 5. n. 1. June, 2008.

[11] LIEBOWITZ, J. Building organizatinal intelligence. Boca Raton, FL: CRC Press, 2000.

[12] MACCARI, Émerson A.; RODRIGUES, Leonel C. Gestão do Conhecimento em Instituições de Ensino Superior. In: Revista de Negócios, Blumenau, v. 8, n. 2, p. 79-94, 2003. Disponível em: <http://proxy.furb.br/ojs/index.php/rn/article/vie wFile/318/304>. Acesso em: 02 out. 2011.

[13] MYERS, M. D., Qualitative Research in Information Systems. MIS Quarterly. V.21, n.2, pp. 241-242, June, 1997.

[14] MERRIAM, S. B. What is qualitative research? $\mathrm{In}$ :__. Qualitative research and case study: applications in education. San Francisco: Jossey-Bass, 1998.

[15] MERRIAM, S. B. Qualitative research in practice: examples for discussions and analysis. San Francisco: Jossey-Bass, 2002.

[16] NONAKA, Ikujiro. A Empresa Criadora de Conhecimento. In: TAKEUCHI, Hirotaka; NONAKA, Ikujiro. Gestão do Conhecimento. Porto Alegre, Bookman, 2008.

[17] NOOTEBOOM, Bart; GILSING, Victor. Coevolution of routines: exploration \& exploitation in the multimedia industry.. Conference 'Empirical Research on Routines in Business and Economics, Odensee, Denmark, 2002.

[18] PATTON, M. Qualitative research and evaluation methods. 3. ed. Thousand Oaks: Sage, 2002.

[19] POLANYI, Michael. The structure of consciouness. Brain, 1965. Vol. LXXXVIII, pp. 799-810, 1965.

[20] POPADIUK, Silvio. Escala de Orientação para Exploration-Exploitation do Conhecimento em Empresas Brasileiras. XXXIV Encontro da ANPAD, EnANPAD. Anais. Rio de Janeiro: EnANPAD, 2010.

[21] ROWLEY, J. Is higher education ready for knowledge management? International Journal of Educational Management, 14(7), 325-333. Emerald Group Publishing Ltd. 2000. Disponível em: <http://hdl.handle.net/2173/91722>. Acesso em: 09 abr. 2011.

[22] SENGE, Peter M. The Fifth Discipline: The Art and Practice of the Learning Organisation. New York, NY: Doubleday Currency, 1990.

[23] STAKE, Robert E. Pesquisa qualitativa: estudando como as coisas funcionam. Porto Alegre: Penso, 2011.

[24] VAN MANEN, M. Researching lived experience: Human science for an action sensitive pedagogy. The Althouse Press, Londres, Canadá, 1998. 
[25] VIEIRA, Marcelo M. F. Por uma boa pesquisa (qualitativa) em administração. In: VIEIRA, Marcelo M. F.; ZOUAIN, Deborah M. (Orgs.). Pesquisa qualitativa em administração. Rio de Janeiro: FGV, 2004.
[26] TUSHMAN, M., L.; O'REILLY, C. Ambidextrous organizations: Managing evolutionary and revolutionary change. California Management Review, v. 38, n. 4, sum. 1996. 


\section{Bapítulo 5}

\section{DESENVOLVIMENTO DE UM MODELO PARA O LEVANTAMENTO DAS NECESSIDADES DE CAPACITAÇÃO DOS SERVIDORES TÉCNICO-ADMINISTRATIVOS EM EDUCAÇÃO LOTADOS NA PRÓ-REITORIA DE GESTÃO DE PESSOAS DA UFSM}

\section{Luciane Inês Matte}

Daniel Arruda Coronel

Resumo: Este trabalho teve por objetivo identificar quais os critérios balizadores dos cursos de capacitação da PROGEP/UFSM, bem como verificar quais os programas de capacitação são oferecidos para os servidores, identificar a forma como vem sendo gerida a política de capacitação, e ainda, identificar quais os cursos de capacitação que mais atendam às demandas dos servidores. Neste sentido, o presente estudo procurou desenvolver um novo modelo de levantamento das necessidades de capacitação (LNC) dos servidores lotados na PROGEP/UFSM. Para tanto buscou identificar quais os fatores que definem a oferta dos cursos de capacitação. A coleta dos dados foi feita através de aplicação de questionário, entrevista com os gestores da PROGEP e das observações in loco. Os resultados evidenciam que a UFSM segue as diretrizes do LNC, mas reconhece que existem várias lacunas no que se refere aos cursos de capacitação ofertados. Os servidores avaliaram bem a instituição, mas apontaram uma distribuição ineficiente de informações. De outra maneira reconhecem que a UFSM tem uma boa capacidade de prover produtos e serviços adequados no mercado em que atua. Com relação aos cursos de capacitação, aqueles que mais atendem as demandas dos servidores da PROGEP são respectivamente língua portuguesa e redação oficial, qualidade no atendimento e administração pública, pois apresentaram as maiores médias.

Palavras-chave: capacitação de servidores; levantamento das necessidades 


\section{INTRODUÇÃO}

A gestão de pessoas ganhou destaque a partir da década de 1980 e, com isso, passou a enfrentar uma série de desafios do ponto de vista ambiental e organizacional, decorrentes da globalização da economia, da evolução dos meios de comunicação, do desenvolvimento tecnológico, da competitividade e de uma série de outros fatores. A partir da mudança no contexto interno e no meio ambiente das organizações públicas e privadas, ocorre, então, a renovação do modelo de gestão, especialmente no que se refere à gestão de pessoas, decorrente da necessidade de sobrevivência no ambiente de atuação.

Na Administração Pública, a gestão de pessoas é o planejamento, a organização, a direção e o controle das atividades desenvolvidas nas áreas de seleção, orientação, avaliação, capacitação e qualificação do quadro de servidores dos órgãos públicos (BERGUE, 2010). Devido ao processo de mudanças constantes, que caminha em direção a um modelo organizacional mais ágil e eficiente, buscando atender às necessidades da sociedade, o diferencial de uma organização passa pelo modo com que esta desenvolve seu potencial humano intelectual, sendo este um ponto imprescindível para o alcance do sucesso de sua missão.

Nesse sentido, a organização deve voltar seus esforços para as atividades de desenvolvimento de pessoas, para que o processo de interação indivíduo-organização e vice-versa tenha sucesso e, dessa forma, possa atingir aos objetivos a que se propõe. Para que ocorra o crescimento da organização, é necessário que ela possua profissionais qualificados e integrados, cabendo à área de treinamento e desenvolvimento mapear esse caminho.

A qualidade do serviço público e o alcance de um desempenho estatal mais efetivo tornaram-se assim, um dos grandes desafios da administração pública. Este cenário exige dos governantes a adoção de ações inovadoras na gestão do setor público, uma vez que a mudança de perfil do Estado exige o atendimento de demandas por competência, de gestão de mudanças, de riscos e de inovação (WILHELM, 2013).

A preocupação com a gestão de pessoas representa uma questão estratégica nas organizações, uma vez que os trabalhadores vêm aumentando significativamente seus níveis de educação e aspirações, ao mesmo tempo em que o trabalho passa a ter um papel central em suas vidas. Nesse sentido, é possível afirmar que os indivíduos organizacionais realizam-se pessoalmente sendo criativos e aprendendo constantemente. Corroborando tal ideia, Levy (2001) explica que a capacitação tem um enorme papel a cumprir no sentido de reposicionar o setor público, sem falar na motivação que a mesma pode promover.

Embora, haja extensa literatura dedicada à gestão e à capacitação de pessoas nas empresas, poucas obras tomam como foco as especificidades desse tema na administração pública. Existem diversas ações de capacitação em todo o país, mas elas ainda não são coordenadas e limitam-se a políticas de governo, e não se referem a Políticas Públicas de capacitação dos servidores, o que tornariam as ações perenes, contínuas e objetivas (AMARAL, 2010).

$\mathrm{Na}$ Administração Pública, é preciso encontrar alternativas de desenvolvimento dos recursos humanos presentes, adequar os indivíduos à tecnologia em desenvolvimento, criar mecanismos capazes de retê-los na organização, estimular mudanças organizacionais e, ao mesmo tempo, dar suporte a tais mudanças.

Portanto, o desenvolvimento de um modelo de levantamento das necessidades de capacitação, que permita a flexibilização das organizações frente às constantes exigências do ambiente interno e externo, em que estão inseridas é um dos principais objetivos do gestor de pessoas, preocupado com a contínua qualificação e capacitação de seus servidores.

O desenvolvimento dos servidores técnicoadministrativos em educação na UFSM é dividido em cursos de capacitação e qualificação. Os cursos de qualificação compreendem o processo de aprendizagem baseado em ações de educação formal em 
nível fundamental, médio, médio/ técnico, graduação e pós-graduação (especialização, mestrado e doutorado) por meio dos quais o servidor adquire conhecimentos e habilidades, tendo em vista o planejamento institucional e o desenvolvimento na carreira. Os cursos de capacitação, por outro lado, são constituídos por ações de ensino/aprendizagem que visam atualizar, aprofundar conhecimentos e complementar a formação profissional do servidor, com o objetivo de torná-lo apto a desenvolver suas atividades, tendo em vista as inovações conceituais, metodológicas e tecnológicas do mercado.

Diante desse contexto, este trabalho busca identificar os critérios balizadores dos cursos de capacitação da PROGEP/UFSM, verificar quais os programas de capacitação oferecidos para os servidores técnicoadministrativos em educação da PROGEP/UFSM, identificar a forma com que vem sendo gerida a política de capacitação dos servidores técnico-administrativos em educação, considerando a realidade institucional; e identificar os cursos de capacitação que mais atendam às demandas de anseios dos servidores técnicoadministrativos em educação da PROGEP/UFSM.

O trabalho está dividido em cinco seções. $\mathrm{Na}$ segunda seção consta o referencial teórico, que está subdividido em gestão de pessoas na administração pública, capacitação na gestão de pessoas e capacitação de pessoas na PROGEP - UFSM; A terceira seção resume os procedimentos metodológicos adotados; $\mathrm{Na}$ quarta seção são apresentados os resultados da pesquisa e finalmente; e a quinta seção traz as considerações finais.

\section{REFERENCIAL TEÓRICO}

\subsection{GESTÃO DE PESSOAS NA ADMINISTRAÇÃO PÚBLICA}

O padrão de uso da mão de obra predominante no Brasil até o final da década de 1960 baseava-se no forte autoritarismo, amplo emprego de pessoal não-qualificado, desempenhando tarefas altamente parcelizadas, alta taxa de rotatividade, bem como a adoção de complexas estruturas de cargos e salários, voltadas para estabelecer a divisão do coletivo operário e o controle sobre os trabalhadores. A profunda transformação começou a ocorrer a partir da década de 1970, pois este padrão, baseado no modelo da organização taylorista de processo de trabalho, começou a entrar em crise antes mesmo do início do processo de reestruturação produtiva do final da década de 1970. Tal crise se deu em função do contexto de início de recessão econômica, do ressurgimento do movimento operário, onde os sindicatos começaram a pressionar as empresas no sentido de assegurar maiores benefícios aos trabalhadores, exigindo segurança e condições de trabalho especiais e a abertura política.

Desde o fim da década de 1970, a conjuntura do mercado e suas implicações para a organização do trabalho fizeram surgir outra função de recursos humanos, ligada aos setores operacionais e voltada diretamente para a gestão dos processos de mudança e para a melhoria dos níveis de desempenho e produtividade. Sem as raízes tradicionais, esta nova função, nem sempre bem definida, passou a apropriar-se de conceitos e recursos pouco usados e até desconhecidos de sua antecessora. Embora os rótulos sejam diferentes de organização para organização, esta nova função de recursos humanos, geralmente está associada às áreas de qualidade ou a programas corporativos de mudança organizacional. Convive, geralmente, com algum grau de conflito com a função tradicional, agora diminuída em importância (WOOD JR., 2000).

A gestão de pessoas se configura, portanto, em uma área ou departamento da organização que se ocupa com um conjunto de atividades relacionadas às pessoas. Não há organização sem pessoas. A expressão gestão de pessoas coloca em evidência, em ação e em foco, as pessoas; significa que elas deixaram de ser apenas recurso produtivo para ser valorizadas quanto à vontade, ao saber, à intuição, à criatividade e à subjetividade (RIBEIRO, 2007).

A gestão de pessoas não pode ser segmentada das demais áreas que envolvem a Administração Pública, visto que ela carece de planejamento para desenvolver não apenas a parte burocrática que lhe cabe, mas também para articular sistemas de desenvolvimento e capacitação dos 
servidores, assegurando, desse modo, aperfeiçoamento na qualidade de trabalho e no atendimento à população. Assim, ela envolve várias ações previamente planejadas das necessidades entre a organização e as pessoas. O objetivo do sistema de gestão de pessoas é auxiliar as organizações a desenvolver competências diferenciadas e conquistar consistentemente um desempenho melhor, o crescimento e desenvolvimento da organização e das pessoas que nela trabalham (GEMELLI; FILIPPIN, 2010).

\subsection{CAPACITAÇÃO NA GESTÃO DE PESSOAS}

A moderna doutrina de gestão de pessoas indica, de forma uníssona, que a capacitação é uma das molas mestras para a consecução dos objetivos da instituição, seja esta pública ou privada. A ideia de capacitação de pessoas no setor público se originou da constatação da inércia e, por vezes, inoperância da máquina pública, que culminou na consolidação do princípio da eficiência no art. 37 da Constituição Federal, com a redação dada pela Emenda Constitucional de $n^{\circ} 19$, de 4 de junho de 1998.

A capacitação tem um enorme papel a cumprir no sentido de reposicionar o setor público, sem falar na motivação que a capacitação pode promover. Acrescenta-se que, em termos de política de $\mathrm{RH}, \mathrm{a}$ capacitação tem um espaço decisivo no serviço público, assim como em outras organizações, porque, de fato, o Estado é uma das maiores organizações existentes neste país dotada de uma pluralidade de funções que estão se transformando continuamente; o que demanda um processo de recapacitação e requalificação no mesmo ritmo, tendo em vista as grandes transformações que vêm ocorrendo na sociedade do conhecimento (LEVY, 2001).

Nesse sentido, devido à importância da qual se reveste a capacitação de pessoas, tanto para a organização, quanto para o próprio servidor, e considerando que este trabalho tem por objetivo verificar quais os critérios que definem a oferta de cursos de capacitação, assim como a forma pela qual é sistematizado o processo de capacitação de servidores na UFSM, a abordagem a seguir será feita destacando as ações e o papel da PROGEP, que é a unidade responsável pela implantação e organização dos programas de capacitação.

\subsection{CAPACITAÇÃO DE PESSOAS NA PROGEP - UFSM}

A gestão de pessoas na UFSM teve, em 18 de dezembro de 1996, o início de uma nova era na administração de recursos humanos na instituição. A proposta de reestruturação do Departamento de Pessoal em Pró-Reitoria de Recursos Humanos foi aprovada pelo Conselho Universitário com base na Resolução no 28. Assim, observou-se o foco da gestão de pessoas, que passou a exercer, além dos processos legais e burocráticos, várias ações voltadas para o desenvolvimento humano. Dessa forma, a própria estrutura organizacional passou a dar suporte aos processos de capacitação, desenvolvimento, qualificação, qualidade de vida, saúde e segurança dos servidores, promovendo a valorização do ser humano e a adequação nas condições de trabalho. Em 2012, a PróReitoria de Recursos Humanos passou a ser denominada de Pró-Reitoria de Gestão de Pessoas, conforme reestruturação aprovada com a Resolução no 029/2013, devido à necessidade de adaptação às novas mudanças e à atuação e importância estratégica da área de gestão de pessoas (UFSM, 2013).

Na PROGEP, está inserido o Núcleo de Educação e Desenvolvimento (NED), o qual é responsável pelo processo de capacitação dos servidores docentes e técnicoadministrativos em educação em educação da UFSM.

De acordo com suas atribuições, a PROGEP deve proporcionar e estimular a capacitação de seus servidores. As ações de capacitação visam o desenvolvimento do quadro funcional de forma permanente, adequando os servidores ao novo perfil requerido pelo setor público, buscando sempre a melhoria na qualidade dos serviços prestados à comunidade universitária e à comunidade em geral, observando sempre a racionalização e a efetividade dos investimentos com treinamento. 
A capacitação de pessoas dentro da PROGEP, atende às políticas e às diretrizes para o desenvolvimento de pessoal da Administração Pública federal, previstas pelo Decreto no. 5.707, de 23 de fevereiro de 2006 e o Decreto 5.825, de 29 de junho de 2006, que estabelece as diretrizes para elaboração do Plano de Desenvolvimento dos Integrantes do Plano de Carreira dos Cargos TécnicoAdministrativos em educação, além de desenvolver ações no sentido de valorizar o servidor por meio de mecanismos de profissionalização e responsabilização, capacitando-os para o exercício do papel de orientador e estimulador do desenvolvimento e desempenho dos servidores. A capacitação tem por objetivo contemplar a ampliação dos conhecimentos, das capacidades e das habilidades necessárias ao desempenho do servidor em seu ambiente de trabalho.

\section{METODOLOGIA}

Pretendeu-se, com este estudo, construir um novo instrumento para verificar as necessidades e prioridades de atividades de capacitação de servidores, lotados na PROGEP-UFSM.

Desta forma, este estudo foi realizado em etapas. Inicialmente, foi realizado o levantamento bibliográfico através da revisão literária, em fontes secundárias, por meio de pesquisa em livros, revistas, artigos científicos, pesquisas na internet em sites especializados sobre o tema em questão, bem como da legislação pertinente ao assunto, visando a uma melhor compreensão do assunto. Nessa fase da pesquisa, o material coletado foi analisado e serviu para o embasamento teórico sobre o tema proposto, bem como forneceu subsídios para o desenvolvimento da análise dos dados e a redação final da pesquisa.

A segunda etapa contemplou a formulação e aplicação de questionários, que serviram de base para o levantamento das necessidades de capacitação dos servidores lotados na PROGEP-UFSM. Esses questionários foram construídos de forma categorizada, visando à análise organizacional, análise de tarefas e análise individual propostas por McGehee e Thayer (1961).
Além do questionário, foi realizada uma entrevista com a Pró-Reitora de Gestão de Pessoas e a Pró-Reitora Adjunta, visando captar informações e identificar qual a percepção dos mesmos acerca da política de gestão de pessoas na UFSM no que se refere aos programas de capacitação dos servidores técnico-administrativos em educação lotados na PROGEP.

Para o presente estudo, a coleta dos dados foi feita por meio da aplicação de questionários, entrevista e observações in loco na PROGEP. Responderam aos questionários todos os servidores técnicoadministrativos em educação lotados na mesma, bem como os coordenadores e as chefias dos núcleos que compõem as Coordenadorias, representando um total de 84 servidores.

O questionário foi dividido em três partes: a) Aplicado à organização: composto de 17 perguntas, com o objetivo de realizar o diagnóstico da organização, buscando coletar a percepção dos membros da organização, sobre os pontos fortes e fracos da mesma. b) Aplicado à tarefa: composto de 9 perguntas, visando obter informações sobre o tipo de comportamento que os empregados devem apresentar para o desempenho adequado das respectivas tarefas, bem como conhecimentos, habilidades e atividades requeridas; e c) Aplicado ao indivíduo: composto de 21 questões, sendo as 7 primeiras, referentes aos dados pessoais e 0 perfil dos servidores e as outras 14 questões nas quais foi utilizado uma escala do tipo Likert, visando a identificar quais as carências de capacitação. Para o diagnóstico do indivíduo, esse questionário buscou coletar dados que possibilitem determinar as habilidades e atitudes que devam ser desenvolvidas no servidor para que ele possa desempenhar adequadamente as suas funções.

Para testar a confiabilidade da consistência interna das questões, foi feita correlação utilizando o coeficiente Alfha de Cronbach. Esse coeficiente mede a correlação entre respostas em um questionário através da análise das respostas dadas pelos respondentes, apresentando uma correlação média entre as perguntas. 
Além disso, foram calculados e analisados a Média e o Desvio Padrão. A Média é representada pela soma de todas as observações da variável $\mathrm{X}$, dividida pelo número de elementos do conjunto de dados. De forma geral, a Média pode ser definida como a medida de posição mais importante, vez que constitui uma medida de posição central dos dados. O desvio padrão descreve a dispersão da variabilidade dos valores da distribuição da amostra a partir da média, e é, talvez o índice mais valioso da dispersão (HAIR, 2005).

Os dados coletados a partir dos questionários respondidos foram ordenados e classificados em uma distribuição de frequência.

A análise dos dados quantitativos foi realizada através do software SPSS - Statistical Package for the Social Sciences, na sua versão 21. O SPSS é utilizado para fazer testes estatísticos, tais como os testes da correlação, multicolinearidade, e de hipóteses, bem como contagens de frequência, ordenamento de dados, reorganização de informações, e serve também como um mecanismo de entrada dos dados, com rótulos para pequenas entradas.

\section{ANÁLISE E DISCUSSÃO DOS RESULTADOS}

\subsection{ENTREVISTAS}

Através das entrevistas, foi possível verificar que os gestores entendem ser de extrema importância a capacitação dos servidores, tendo em vista que a área de gestão de pessoas é estratégica e a capacitação pode ser considerada sua diretriz fundamental. A capacitação se faz necessária, visto que o conhecimento é mutável, necessitando de uma educação continuada para o bom desempenho das funções, além de ser uma forma de valorizar os TAES.

O Programa de Capacitação existente na instituição atualmente, segundo os entrevistados segue o diagnóstico obtido através do Levantamento das Necessidades de Capacitação. No entanto, os gestores reconhecem que ainda existem lacunas no Programa de Capacitação, que precisam ser resolvidos, como por exemplo, a falta de cursos de capacitação para os gestores da instituição. Por se tratar de uma instituição de ensino, existem gestores que são da área acadêmica e que ainda não possuem a competência gerencial, o conhecimento na área jurídica e de pessoal, ocasionando em alguns casos, conflitos por falta de habilidade e conhecimento para atuar como gestor.

\subsection{AVALIAÇÃO DA ORGANIZAÇÃO}

Com relação ao questionário realizou-se o teste de confiabilidade das respostas, utilizando para tanto o coeficiente Alpha de Cronbach, para o qual se obteve um índice de 0,961. Este índice, de acordo com os valores propostos por Pestana e Gageiro (2003), representa um padrão de confiabilidade muito bom.

Inicialmente foi aplicado o questionário, composto de 17 perguntas, nas quais foi utilizada uma escala do tipo Likert, com o objetivo de realizar o diagnóstico da organização, buscando coletar a percepção dos TAES, sobre os pontos fortes e fracos da mesma. Da mesma forma, procurou efetuar a análise dos princípios e metas institucionais, que identifica no ambiente interno os fatores que facilitam ou dificultam o desempenho atual da instituição, na visão dos servidores, segundo uma escala de 1 a 5 , onde 1 representava discordo fortemente e 5 concordo fortemente.

A partir dos dados coletados, de uma maneira geral a percepção dos servidores TécnicoAdministrativos em Educação (TAES) referente aos aspectos pesquisados é de que a organização está apresentando um desempenho bastante satisfatório nos pontos abordados, com uma grande prevalência de pontos fortes, principalmente no que se refere a capacidade de a organização prover produtos e serviços adequados ao mercado em que atua. Esta variável foi aquela que atingiu a maior média $(3,76)$, o que representa que a maioria dos servidores concorda que a organização é capaz de prover produtos e serviços adequados ao mercado em que atua. Assim, é considerado um ponto forte da instituição. Ainda figura entre as variáveis com maior credibilidade segundo a percepção dos servidores TAES, aquela que afirma que existem na instituição valores, crenças e normas que norteiam positivamente as decisões e ações da organização, com uma 
média de 3,56. A variável que questionou a existência de mecanismos de avaliação de desempenho que possibilitem a orientação das tomada de decisão, avaliação e desempenho dos processos e indivíduos, obteve a concordância de $80,6 \%$ dos servidores, com uma média de 3,52, o que demonstra que é um ponto forte da instituição. Com relação aos pontos fracos da instituição, de acordo com a pesquisa realizada, a ocorrência de distribuição eficiente de informações relevantes à organização em seus processos operacionais e de melhoria da organização obteve o menor índice de concordância, atingindo uma média de 2,74. Assim, infere-se que a instituição precisa melhorar a gestão da informação. Outra carência evidenciada pela pesquisa diz respeito ao sistema de informação da organização capaz de suportar o fluxo de informação gerencial. De acordo com o resultado, ela obteve baixa concordância, evidenciando ser este um ponto fraco da instituição com uma média de 2,79 e um desvio padrão de 0,920. Deste modo, é perceptível que os pontos fracos da instituição se referem à distribuição ineficiente de informações relevantes e ao sistema de informação insuficiente para suporte do fluxo de informação geral da organização.

Outro ponto fraco da instituição se refere a existência de infraestrutura organizacional, física, material e humana para a condução dos processos operacionais e para a condução de melhorias na organização. Esta variável aparece também como uma carência da instituição, sendo que apresenta uma média de 2,97, o que evidencia que se a instituição precisa melhorar a infraestrutura organizacional, física, material e humana.
A partir dos níveis de concordância observados, é possível afirmar que a maioria dos servidores pesquisados se mostrou satisfeita no desempenho de suas tarefas. No entanto, o índice de insatisfação (16,7\%) quando questionados sobre como se sentem em relação ao conteúdo da sua tarefa $(6,1 \%$ dos servidores se sentindo bastante insatisfeitos e 10,6\% se sentindo insatisfeitos), representa um possível subaproveitamento da capacidade dos servidores. Este é um ponto a ser considerado, visto que a pesquisa trouxe um índice de insatisfação considerável no que se refere ao conteúdo da tarefa executada. Ainda, a maioria dos servidores entende haver duplicidade de tarefas no setor em que atua, com 59,1\% de concordância.A duplicidade das tarefas ocasiona desperdício de recursos e, por conseguinte, uma ineficácia no serviço público.

De outro modo, a partir deste estudo fica evidenciado que os TAES possuem tempo disponível para planejar a suas tarefas e assim imprimir eficácia e eficiência nos serviços prestados, visto que $57,6 \%$ dos servidores afirmaram que tem disponibilidade de tempo para efetuar o planejamento das tarefas a ser executadas.

Quanto a intensidade das tarefas que executam, o que se verifica é que a maioria dos servidores considera média a intensidade, no que se refere a utilização de suas habilidades e competências pessoais para executá-las, com um percentual de $62,1 \%$. Em outra variável a maioria dos servidores considera que, de acordo com a sua formação profissional, a tarefa que exerce é pouco motivadora( $45,5 \%)$ ou desmotivadora (9\%), conforme é possível observar no quadro a seguir:

\subsection{ANÁLISE DA TAREFA}

Quadro 1: Análise da tarefa.

\begin{tabular}{|l|c|c|c|}
\hline \multicolumn{1}{|c|}{ Variável } & $\begin{array}{c}\text { Grau de } \\
\text { Concordância (\%) }\end{array}$ & $\begin{array}{c}\text { Média } \\
\text { Padrão }\end{array}$ & $\begin{array}{c}\text { Desvio } \\
\text { Padrã }\end{array}$ \\
\hline $\begin{array}{l}\text { 6- Considerando a sua formação } \\
\text { profissional, a tarefa que você exerce } \\
\text { atualmente é: }\end{array}$ & $45,545,59$ & 1,64 & 0,648 \\
\hline
\end{tabular}

Fonte: Elaborado pelos autores. 
Isto vem corroborar ainda mais a ideia do subaproveitamento da capacidade dos servidores, já verificado nas variáveis anteriores.

\subsection{AVALIAÇÃO DAS HABILIDADES E ATITUDES INDIVIDUAIS}

$\mathrm{Na}$ terceira parte da pesquisa, foram elencados vários cursos, subdivididos em Áreas para que os servidores apontassem dentro destes, quais os cursos que julgam mais importantes para a sua capacitação e desenvolvimento da carreira.
De um modo geral, foi possível constatar a partir dos resultados deste estudo, que os cursos que mais despertam o interesse dos servidores foram os de Línguas - Inglês, Línguas - Língua Portuguesa e Redação Oficial, Gestão de Pessoas - Relações Interpessoais, Humanas e de Trabalho, Gestão de Pessoas - Qualidade no Atendimento e Gestão de Pessoas Administração Pública e na área de Direito Noções de Direito na Administração Pública.

Quadro 2: Relação dos cursos solicitados pelos servidores.

\begin{tabular}{|l|c|c|}
\multicolumn{1}{|c|}{ Área/Curso } & Média & $\begin{array}{c}\text { Desvio } \\
\text { Padrão }\end{array}$ \\
\hline $\begin{array}{l}\text { Gestão de Pessoas/Relações Interpessoais, Humanas } \\
\text { e de Trabalho }\end{array}$ & 4,41 & 0,723 \\
\hline Gestão de Pessoas/Qualidade no Atendimento & 4,42 & 0,703 \\
\hline Gestão de Pessoas/Administração Pública & 4,42 & 0,725 \\
\hline Direito/ Noções de Direito na Administração Pública & 4,12 & 0,795 \\
\hline Línguas/ Língua Portuguesa e Redação Oficial & 4,48 & 0,638 \\
\hline Línguas/ Inglês & 3,97 & 0,992 \\
\hline
\end{tabular}

Fonte: Elaborado pelos autores.

\section{CONCLUSÕES}

De uma maneira geral a Política de Capacitação existente na Universidade Federal de Santa Maria (UFSM) apresenta um desempenho satisfatório na visão dos técnicoadministrativos em educação e está adequada aos interesses dos servidores, considerando que o Programa de Capacitação busca contemplar as demandas apresentadas no Levantamento das Necessidades de Capacitação.

No entanto, de acordo com este estudo foi possível identificar alguns pontos em que a instituição apresenta falhas e precisa melhorar, segundo os TAES. Inicialmente foi apontada como ponto fraco, a distribuição de informações relevantes à organização em seus processos operacionais e de melhoria. Também foi diagnosticado que na percepção dos TAES, o sistema de informação da organização é insuficiente para suportar o fluxo de informação gerencial. Deste modo, é perceptível que os pontos fracos da instituição se referem essencialmente à distribuição ineficiente de informações relevantes e ao sistema de informação insuficiente.

A capacidade de a organização prover produtos e serviços adequados ao mercado em que atua pode ser considerado um ponto forte da instituição, segundo a pesquisa realizada. Ainda merece destaque, como ponto positivo a existência de valores, crenças e normas que norteiam positivamente as decisões e ações da organização, além da existência de mecanismos de avaliação de 
desempenho que possibilitem a orientação das tomada de decisão, avaliação e desempenho dos processos e indivíduos.

A partir do questionário aplicado, das entrevistas realizadas e das observações in loco, é possível perceber que há avanços significativos relacionados ao Programa de Capacitação da UFSM. No entanto, a carência de cursos em algumas áreas é consenso na gestão da PROGEP, a qual reconhece a existência de lacunas no Plano atual. A ausência de cursos de capacitação para gestores, cursos na área jurídica, trabalho em equipe, departamento de pessoal e atualização permanente foram apontados pelos gestores.

Com relação ao curso de formação/capacitação de gestores foi esclarecido que este se faz extremamente necessário, pois muitos servidores que hoje ocupam cargos de gestão, por serem da área acadêmica, não possuem a competência gerencial necessária para o bom desempenho das suas funções, ocasionando por vezes, conflitos com seus subordinados pela falta desta capacidade de gerenciar e resolver conflitos. Entretanto, de acordo com as entrevistas realizadas, poucos gestores externam esta necessidade de formação gerencial.

A necessidade de diversificação na área dos cursos de capacitação e na forma como estes são ofertados também é uma meta apontada pela gestão atual. Devido à estrutura multi campi da UFSM, a oferta de cursos na modalidade a distancia é extremamente necessária, além de investimentos para a modernização e inovação necessários para a oferta destes cursos.

Ao longo desta pesquisa verificou-se que o tema capacitação quando aplicado ao serviço público ainda é um tema pouco explorado pela literatura, de maneira a se configurar como uma opção ou sugestão para pesquisas e publicações futuras, com diversas temáticas a serem exploradas, visando o enriquecimento da literatura a respeito deste tema tão importante e atual.

Como principal contribuição, pode-se destacar que o objetivo a que este estudo se propôs foi satisfeito uma vez que propiciou fazer uma análise geral da PROGEP, ficando evidenciado quais são os pontos em que a instituição precisa melhorar, além daqueles em que ela tem um desempenho bastante satisfatório. Ainda, evidenciou quais os aspectos em relação aos servidores precisam ser revistos para que estes contribuam cada vez mais para a eficiência e eficácia da UFSM.

As contribuições deste estudo para o tema ficaram limitadas à Pró-Reitoria de Gestão de Pessoas da UFSM e a categoria dos servidores técnico-administrativos em educação, não sendo possível, portanto, conhecer a realidade da UFSM como um todo. Outra limitação se refere à impossibilidade de realizar comparações com outros trabalhos desta natureza, pelo fato de não haver publicações de pesquisas com a mesma perspectiva do presente estudo. Ainda como limitações é importante destacar a resistência de alguns servidores TAES para responder ao questionário utilizado nesta pesquisa, o que diminuiu um pouco a quantidade da amostra, mas não comprometeu o resultado da pesquisa.

A proposta de desenvolvimento de um modelo de Levantamento das Necessidades de Capacitação, também se configura em uma contribuição deste estudo, pois este modelo é mais abrangente em comparação ao LNC utilizado atualmente e traz um panorama geral do quadro de servidores, podendo ser utilizado inclusive como uma importante ferramenta gerencial, na medida em que, fornece o perfil dos servidores lotados na unidade, o que possibilita um planejamento mais adequado das ações de capacitação, a curto e longo prazo.

\section{REFERÊNCIAS}

[1] AMARAL, H.K. Gestão de Pessoas: bases teóricas e experiências no setor público. Brasília: ENAP, 2010.
BeRGue, S. T. Gestão de Pessoas em Organizações Públicas. Caxias do Sul: Educs, 2010.

BRASIL. Presidência da República. Decreto $n$. 5.707, de 23 de fevereiro de 2006. Institui a Política e as Diretrizes para o Desenvolvimento 
de Pessoal da administração pública federal direta, autárquica e fundacional, e regulamenta dispositivos da Lei no 8.112, de 11 de dezembro de 1990

[4] BRASIL. Presidência da República. Decreto $n$. 5.825, de 29 de junho de 2006. Estabelece as diretrizes para a elaboração do Plano de Desenvolvimento dos Integrantes do Plano de Carreira dos Cargos Técnico-administrativos em educação, instituído pela Lei no 11.091 , de 12 de janeiro de 2005.

[5] GEMELLI, I.M.P.G.; FILIPPIM, E.S. Gestão de Pessoas na Administração Pública: o Desafio dos Municípios. Revista de Administração, Contabilidade e Economia. RACE, Unoesc, v. 9, n. 1-2, p. 153-180, jan./dez.

[6] HAIR, J. R. et al. Fundamentos de Métodos de pesquisa em Administração. Tradução: Lene Belon Ribeiro. Porto Alegre: Bookman, 2005. 2010.

[7] LEVY, E. Teleconferência para apresentar o Sistema de Acompanhamento de Capacitação - SIFAC. Ministério do Planejamento,
Orçamento e Gestão, Brasília, 17.12.200114h. (Evelyn Levy - Secretaria de Gestão do MOG - Governo Federal).

[8] MCGEHEE, W., \& THAYER, P. W. Training in business and industry. New York: Wiley.1961.PESTANA, M.H.; GAGEIRO, J.N. Análise de dados para as ciências sociais. Lisboa: Edições Silabo, 2003.

[9] RIBEIRO, E.I.B. Gestão de pessoas. Associação Educacional Leonardo da Vinci (Asselvi). Indaial: Asselvi, 2007.

[10] UNIVERSIDADE FEDERAL DE SANTA MARIA. Pró-Reitoria de Gestão de Pessoas. Disponível em: http://coral.ufsm.br/progep/estrutura.php. Acesso em: 28 set. 2013.

[11] WILHELM, E.M. de S. A capacitação dos servidores públicos nas instituições federais de ensino superior no Estado do Paraná. Curitiba /PR, 2013.

[12] WOOD Jr, T.(coord.). Mudança organizacional: aprofundando temas atuais em administração de empresas. 2 ed. São Paulo: Atlas, 2000. 


\section{Bapítulo 6}

\section{A GESTÃO DA INFORMAÇÃO COM FOCO NA TOMADA DE DECISÃO DE UM GESTOR PÚBLICO}

Silvio Luiz de Paula

Tiberius Mariano Medeiros

Antônio de Souza Silva Junior

Resumo: Este trabalho apresenta uma análise de como as gerências táticas, numa instituição pública estadual, localizada no nordeste brasileiro, organizam as informações disponibilizadas ao seu gerente do nível estratégico que, por sua vez, utiliza esses insumos para tomada de decisão gerencial. Para alcançar este objetivo de pesquisa estudou-se a gestão da informação com imersão maior em fluxos e qualidade da informação, administração pública e o processo de tomada de decisão. Trata-se de um estudo de caso, de natureza exploratória com investigações empíricas e abordagem qualitativa. Como instrumento de coleta de dados, utilizou-se a observação participante e dois tipos de roteiros de entrevistas estruturadas, que foram aplicados com os gerentes estratégico e tático. Em seus resultados, a pesquisa revela que o fluxo informacional adotado contém problemas em determinadas etapas, porém as informações repassadas pelas gerências são, em sua maioria, qualificadas através de atributos trazidos por Sordi (2008) e atendem as expectativas do gerente estratégico.

Palavras-chave: Gestão da Informação. Qualidade da Informação. Tomada de Decisão. Administração Pública 


\section{INTRODUÇÃO}

A Gestão da Informação é uma ciência nova, principalmente em território brasileiro, não tendo, portanto, todo o seu potencial trabalhado nas organizações, sejam elas privadas ou públicas. Neste estudo de caso, o foco é nas organizações públicas; mais precisamente em uma de abrangência estadual que está localizada no nordeste brasileiro. O ponto de interesse deste estudo é nas informações que são disponibilizadas pelas gerentes táticas desta instituição para o seu superior, o gerente estratégico.

Tais informações, segundo McGee e Prusak (1994, p. 25), "não se limita a dados coletados. [...] Informações são dados coletados, organizados, ordenados, aos quais são atribuídos significados e contextos". E, ainda de acordo com os autores, essas citadas etapas devem ser seguidas por profissionais da informação especializados, pois implica diretamente numa decisão, garantindo que seja mais assertiva, trazendo melhores resultados por parte dos tomadores de decisões.

As informações por si só não representam melhores escolhas por parte de um gerente. É necessário que haja o compartilhamento de informações entre setores da organização, passando por profissionais que saibam o que fazer com ela. Para Davenport (2002, p. 173) esse gerenciamento da informação é "um conjunto estruturado de atividades que incluem o modo como as empresas obtêm, distribuem e usam a informação e o conhecimento", ou seja, numa perspectiva prática para o estudo em pauta, este acaba sendo o papel das próprias gerências dentro da organização estudada, no suporte ao seu gestor imediato.

Contudo, pelo motivo das gerentes táticas não serem devidamente capacitadas, a administração da informação é feita com base prioritariamente em suas experiências, e visam garantir novos caminhos para instituição, com as melhores escolhas. Agindo, portanto, sempre visando os melhores benefícios para a sociedade, principal interessada dessas organizações governamentais.

\section{REFERENCIAL TEÓRICO}

\subsection{GESTÃO DA INFORMAÇÃO}

Para Le Coadic (1996) a informação é um conhecimento que está inscrito, seja sob a forma escrita, oral ou audiovisual. A informação, portanto, deve trazer consigo um elemento de sentido e que leve um significado ao ser transmitido por meio de uma mensagem inscrita em um suporte espacial-temporal: impresso, sinal elétrico, onda sonora, etc. E essa inscrição é feita devido a "um sistema de signos (a linguagem), signo este que é um elemento da linguagem que associa o significante a um significado: signo alfabético, palavra, sinal de pontuação" (LE COADIC, 1996, p. 5). Em relação ao seu significante perante um indivíduo, Choo (2003) tem uma abordagem interessante em sua obra, se voltando a uma concepção mais relacionada ao valor da informação.

Com o passar dos anos, a informação se tornou insumo essencial para as estratégias empresariais, fazendo com que viesse a surgir uma grande necessidade das organizações coordenarem a crescente demanda por este elemento. $O$ grande aumento de dados que circula pelo mundo precisava ser gerido de forma mais inteligente e organizada. Foi então que em meados do século XX a Gestão da Informação passou a ser mais fortemente estudada e difundida.

Uma das primeiras vezes que a Gestão da Informação foi tratada de forma mais significativa, foi através de Vanevar Bush, um dos precursores da moderna Gestão. E, segundo Barbosa (2008), ele tentou tornar consolidada a ideia de gerir a informação através de algo concreto.

Dias e Beluzzo (2003, p. 65) referendam que a Gestão da Informação é:

um conjunto de conceitos, princípios, métodos e técnicas utilizadas na prática administrativa e colocadas em execução pela liderança de um serviço de informação [...] para atingir a missão e os objetivos fixados.

E para trazer à realidade deste trabalho devese considerar o uso da informação como instrumento de gestão na Sociedade da Informação. Nesse contexto, Leitão (1993) 
pontua a importância de se ter sempre informações atualizadas e mecanismos que façam por onde elas alcancem tão rápido quanto possível ao gerente responsável de uma instituição.

No entanto, a informação por si só pode não ser relevante ao administrador que precisa tomar de decisões. Existe a necessidade de que chegue o produto de informação até o tomador de decisão, e tal produto é caracterizado, segundo Gonçalves, Gouveia e Petinari (2008), por informações estruturadas que estão focadas em um alvo/objetivo e somente depois de direcionadas que passam a ser consideradas produtos, para então poder alcançar o seu sentido natural de garantir maior grau de certeza na tomada de decisão.

Independente se a empresa é pública ou privada, ou se tem fins lucrativos ou não, os produtos de informação precisam estar no formato certo na hora certa para quem necessita. Com isso, subentende-se que o produto de informação é simplesmente a informação que passa por tratamento e convertida em conhecimento estratégico fazendo com que a instituição melhore sua eficiência em decisões planejadas e com cada vez menos risco de falhas.

Para tanto, é preciso que os produtos informacionais permeiem as vias da organização de forma eficiente, e para isso é necessário haver uma gestão de informação atuante pelos profissionais de informação, e o principal modo para que a execução aconteça de forma orientada e controlada, é utilizando fluxos de informação.

Para que a gestão da informação seja atuante, além de pessoal capacitado, é preciso que sejam pré-definidos processos e etapas padronizadas em estruturas, onde os fluxos de informações sejam responsáveis.

E para contextualizar às organizações, foco do presente trabalho, McGee e Prusak (1994, p. 5) trazem que "a criação, captação, organização, distribuição, interpretação e comercialização da informação são processos essenciais" para organizações que desejam ter um mínimo de foco na gestão da informação. Porém, para resultados mais aprimorados em relação ao processo de gerir insumos informacionais, é preciso também se voltar para a gestão da informação além do universo organizacional, focando nela como elemento da ciência da informação, ciência essa que a traz como objeto da gestão, considerando a informação responsável pela ativação do conhecimento de forma objetiva e dinâmica para o processo da tomada de decisão.

$\mathrm{Na}$ literatura, é possível encontrar diversos modelos de gestão de fluxos de informação, que são estudados mais a fundo pelas organizações de acordo com suas características.

Smit e Barreto (2002) reconhecem três fluxos básicos de informação: interno (Seleção, Entrada, Classificação, Armazenamento e Recuperação e Uso da Informação), o segundo, onde há a transformação da informação em conhecimento, e, por último, a criação da informação com fatos, ideais e imagens que o autor transmuta de sua mente para uma inscrição de informação.

Lesca e Almeida (1994) apresentam, dividido em três fases, o seu modelo com fluxo informacional de uma organização. Neste modelo, os fluxos de informações são divididos em: Etapa 1 - Fluxo da informação advindo de fora da organização e utilizado pela mesma; Etapa 2 - Fluxo da informação produzido e destinado à própria organização; Etapa 3 - Fluxo da informação produzido pela organização e destinada ao mercado externo da organização. Sejam clientes, fornecedores e até concorrentes.

O modelo idealizado por Davenport (2002) contém quatro estágios que a informação deve percorrer para seu melhor gerenciamento. A determinação das exigências é o pontapé inicial e, segundo Davenport (2002), é o mais difícil pois os profissionais da organização devem perceber em que contexto a informação está inserida. Sendo assim, é imprescindível que o profissional não seja alheio à função, para que assim possa determinar melhor a informação que seu gerente necessita. A segunda etapa, a da obtenção, deve acontecer de forma ininterrupta e é subdivida em três fases: exploração, classificação e formatação e estruturação das informações. $\mathrm{Na}$ terceira etapa, é onde ocorre a busca e distribuição da informação através da organização, permeando os níveis hierárquicos. Se os outros estágios estiverem funcionando corretamente, essa etapa tende a ser mais eficiente. Por último, a utilização da informação é referente à aplicação dela pelos usuários da organização, sendo que a forma que o agente procura, absorve e digere a 
informação está ligado diretamente dos meandros da mente humana, de acordo com Davenport (2002).

O próximo modelo de gerenciamento da informação abordado é o de McGee e Prusak (1994), onde os autores também separam os fluxos em 4 fases. A primeira fase é a mais importante e possui três características capitais: 1. Variedade de informação; 2. Os agentes responsáveis pela informação devem conhecer as fontes de informação que contém as melhores informações (MCGEE; PRUSAK, 1994) e; 3. Coleta/entrada de informações, que deverá capturar os dados de forma sistemática de sua origem. Classificação/armazenamento e tratamento/apresentação de informação são tarefas fundidas e transformadas em uma. A seguinte, desenvolvimento de produtos e serviços de informação, tem-se a possibilidade do usuário contribuir para o processo.

A última etapa do processo de gerenciamento de informação de McGee e Prusak, denominada de distribuição e disseminação da informação, tem como ponto principal o alcance do serviço/produto informacional dos membros participantes de todo o processo, e que levam seu conhecimento e sua perspectiva para os indivíduos-chaves.

O quinto e último modelo, o de Beal (2004), é separado em sete passos. A primeira tarefa do modelo de Beal (2004, p. 30) consiste na identificação das necessidades e requisitos de informação, "fundamental para que possam ser desenvolvidos produtos informacionais orientados especificamente para cada grupo e necessidade". A segunda tarefa é a obtenção das informações, onde Beal (2004, p. 30) diz que "são desenvolvidas as atividades de criação, recepção e captura de informação". A terceira tarefa é a de tratamento da informação, onde se faz o tratamento devido da informação, para que seja aproveitado de forma correta pelos usuários (BEAL, 2004). Na tarefa de distribuição, onde a informação será direcionada para onde há necessidade seguindo o caminho interno (membros da organização) ou externo (ex.: fornecedores). O uso é a quinta tarefa, e para Beal (2004) é a mais importante de todo o processo, não devendo ser desprezada pela organização. 0 armazenamento, penúltima tarefa, é o momento de "uso e reuso dentro da organização" (BEAL, 2004, p. 31). A última tarefa do modelo, o descarte da informação, é onde toda e qualquer informação que não é mais desejada pela organização é excluída dos arquivos, melhorando a gestão da informação, segundo Beal (2004).

Todos os modelos de fluxos acima citados podem ser utilizados em uma organização, porém talvez seja preciso adaptação, de acordo com as necessidades de cada realidade vivida pela instituição, alterando, adicionando ou até excluindo etapas.

Para este estudo, o modelo de fluxo apresentado por Davenport (2002) foi o escolhido para aprofundamento por se adequar melhor às necessidades da organização estudada sem que se façam grandes alterações no formato proposto por ele.

Com o fluxo definido e funcionando é possível garantir que os atores trabalhem em prol da "fluidez" da informação, fazendo com que ela alcance todas as vias de interesse da organização. Porém, para que esse insumo informacional seja realmente utilizado para tomadas de decisões coerentes, é necessário que possua o mínimo de qualidade aceitável pela corporação. Os atributos que garantem tal qualidade são tratados a seguir, abordando os conceitos de qualidade, tratando das dimensões e características de uma informação qualificada.

\subsection{QUALIDADE DA INFORMAÇÃO}

Com relação à qualidade da informação, é necessário distinguir e discutir os atributos e dimensões da informação que a qualificam. Entretanto, estes podem ser relacionados, em razão da avaliação daqueles que a utilizam como subsídio. Segundo Paim, Nehmy e Guimarães (1996, p. 112):

A qualidade da informação constitui-se num conceito problemático. [...] não há consenso na literatura sobre definições teóricas e operacionais da qualidade da informação. Há uma alusão recorrente entre autores interessados no tema de que as definições de qualidade de informação são ambíguas, vagas ou subjetivas.

Uma informação de qualidade é difícil de ser conceituada, mesmo que por profissionais 
que precisam dela o tempo todo para tomadas de decisões nas corporações e, de acordo com Amaral e Sousa (2011), autores como Casanova (1990), Schwuchow (1990), Oleto (2006) e Sordi (2008) apresentam percepções similares em relação à dificuldade e, portanto, mensurar as dimensões e os atributos da informação.
Sendo assim, toma-se como exemplo Huang, Lee e Wang (1999 apud AMARAL e SOUSA, 2011) que elegeram 15 dimensões de avaliação da informação, sendo estas divididas em quatro categorias (quadro 1), a seguir expostas:

Quadro 1: Categorias das dimensões da qualidade da informação.

\begin{tabular}{|c|c|}
\hline Categorias & Características \\
\hline Qualidade Intrínseca & $\begin{array}{l}\text { Está diretamente ligada ao quanto a informação está } \\
\text { alcançando o seu objetivo; sanando a necessidade } \\
\text { informacional. A credibilidade e a segurança que passam ao se } \\
\text { deparar com a mesma, são critérios levados em consideração. }\end{array}$ \\
\hline $\begin{array}{l}\text { Qualidade } \\
\text { Acessibilidade }\end{array}$ & $\begin{array}{l}\text { Analisada através do quão acessível e segura está a } \\
\text { informação disponibilizada para determinado público-alvo. Por } \\
\text { exemplo: quais os níveis de segurança dos recursos guardados } \\
\text { e quando/por quem podem ser acessados? }\end{array}$ \\
\hline Qualidade Contextı & $\begin{array}{l}\text { Garantida quando a informação é tida como relevante em } \\
\text { determinado contexto, trazendo valor agregado para quem a } \\
\text { consulta dentro de tempo um otimizado no que se refere ao } \\
\text { acesso }\end{array}$ \\
\hline $\begin{array}{l}\text { Qualidade } \\
\text { Representacional }\end{array}$ & $\begin{array}{l}\text { Caucionada quando há a fácil interpretação, consistência e } \\
\text { representação dentro de um perfil esperado. }\end{array}$ \\
\hline
\end{tabular}

Fonte: adaptado de Huang, Lee e Wang (1999 apud AMARAL e SOUSA, 2011).

De acordo com Sordi e Meireles (2011), em relação às dimensões da informação incluídas nessas categorias, pode-se afirmar que estas são, por vezes, confundidas entre si, pois possuem aspectos semelhantes e que se complementam. O que significa dizer que não se podem avaliar tais dimensões de forma separada, sem que haja um diálogo correlacionando-as.
Todas as dimensões possuem características que thes são peculiares e ajudam na identificação das mesmas, garantindo possibilidade de análise e avaliação do ator envolvido no processo de julgamento relacionado à qualidade informacional. Segundo Sordi (2008), as dimensões da qualidade estão dispostas da seguinte forma: 
Quadro 2: Dimensões e características da informação.

\begin{tabular}{|c|c|}
\hline Dimensões & Caracaterísticas \\
\hline Abrangência/escopo & $\begin{array}{l}\text { Quando a informação está completa e concisa. Não deve } \\
\text { conter informações desnecessárias para os interessados. }\end{array}$ \\
\hline Integridade & $\begin{array}{l}\text { Essa dimensão visa que a informação deve estar acessível } \\
\text { na íntegra e sem alterações por terceiros, sem autorização } \\
\text { prévia. }\end{array}$ \\
\hline Acurácia/veracidade & $\begin{array}{l}\text { Preza pela fidedignidade do que está representando. Sem } \\
\text { que qualquer inverdade esteja contida no seu conteúdo. }\end{array}$ \\
\hline Confidencialidade/privacidade & $\begin{array}{l}\text { Consiste que a informação deve ser acessada apenas pelas } \\
\text { pessoas autorizadas. }\end{array}$ \\
\hline Disponibilidade & $\begin{array}{l}\text { A informação precisa estar disponível no momento que as } \\
\text { pessoas autorizadas necessitarem, independente do suporte } \\
\text { que elas estão alocadas. }\end{array}$ \\
\hline Atualidade & $\begin{array}{l}\text { Garante que a informação deve ser atualizada de acordo } \\
\text { com a necessidade do público atendido por ela. }\end{array}$ \\
\hline Ineditismo/raridade & $\begin{array}{l}\text { A informação com essa dimensão é rara e/ou original para o } \\
\text { público atendido pela mesma. }\end{array}$ \\
\hline Contextualização & $\begin{array}{l}\text { Essa dimensão está atrelada ao quanto à informação é } \\
\text { atraente para o interlocutor. }\end{array}$ \\
\hline Precisão & $\begin{array}{l}\text { A informação deve estar pronta para uso, sem necessidade } \\
\text { de tratamento. }\end{array}$ \\
\hline Confiabilidade & $\begin{array}{l}\text { A informação advém de uma fonte confiável e garante } \\
\text { dignidade diante do público interessado. }\end{array}$ \\
\hline Originalidade & $\begin{array}{l}\text { Quando a informação é autêntica e original, independente do } \\
\text { papel a ela destinado. }\end{array}$ \\
\hline Existência & $\begin{array}{l}\text { É necessário que a informação esteja constante em suportes } \\
\text { disponíveis para acesso. }\end{array}$ \\
\hline $\begin{array}{l}\text { Pertinência/agregação } \\
\text { valor }\end{array}$ & $\begin{array}{l}\text { É preciso que a informação seja interessante para o público- } \\
\text { alvo. }\end{array}$ \\
\hline Identidade & $\begin{array}{l}\text { A denominação da informação precisa representar com } \\
\text { fidelidade seu conteúdo. }\end{array}$ \\
\hline Audiência & $\begin{array}{l}\text { Essa dimensão preza que a informação deve ser acessada } \\
\text { pelos interessados na mesma. }\end{array}$ \\
\hline
\end{tabular}

Fonte: adaptado de Sordi (2008).

Apesar de conhecidas e especificadas, as dimensões da informação não são identificadas facilmente, conforme ratificam Sordi, Meireles e Grijo (2008). Para eles, são, em essência, informações a respeito de uma informação. Ou seja, é preciso que alguém consiga discernir essas metainformações para conseguir verificar o quão qualificada é uma informação. É neste papel de consultor que um profissional da informação pode atuar nas organizações, averiguando de forma embasada todos os aspectos que garantem a qualidade do recurso e, consequentemente, garantindo maior eficiência nas tomadas de decisões de um executivo. O próximo intertítulo tratará da administração de uma forma geral, trazendo conceitos com breve histórico e depois será dado um enfoque maior no tema da administração pública. 


\subsection{ADMINISTRAÇÃO PÚBLICA}

A organização objeto deste estudo faz parte do organograma administrativo de um estado do nordeste brasileiro e está subordinada às leis que regem o seu funcionamento enquanto órgão público. Ela enquanto ente do Estado tem como sua atividade fim o atendimento às demandas sociais dos cidadãos. Como qualquer instituição pública, suas regras e direcionamentos são parametrizados a partir da Administração Pública.

Já para Di Pietro (2005, p. 59) a expressão Administração Pública pode ter o sentido objetivo ou subjetivo. Sendo o primeiro descrito como o que:

abrange as atividades exercidas pelas pessoas jurídicas, órgãos e agentes incumbidos de atender concretamente às necessidades coletivas; corresponde à função administrativa, atribuída preferencialmente aos órgãos do Poder Executivo [...] podendo ser definida como atividade concreta e imediata que 0 Estado desenvolve, sob o regime jurídico de direito público, para consecução dos interesses coletivos.

E o sentido subjetivo é definido por ela como "conjunto de órgãos e de pessoas jurídicas aos quais a lei atribui o exercício da função administrativa do Estado" (DI PIETRO, 2005, p. 61). Pereira e Silva (2011) expõem que o contexto sociopolítico nas organizações públicas é um componente complexo, uma vez que o setor público está mais sujeito às legislações, normas e outras especificidades que o diferenciam do setor privado. Enquanto o setor privado está apto a fazer o que não vai de encontro às leis, o setor público deve apenas se ater ao que está em legislação vigente.

Com as contribuições dos autores infere-se que os interesses do Estado são coletivos e públicos, e que a natureza da Administração procede exclusivamente de leis, conforme o que estão constantes na Constituição de 1988 e na Emenda Constitucional no 19, que é onde está previsto que a administração pública direta e indireta de qualquer dos Poder seja federal, dos Estados, do Distrito Federal e dos municípios obedecerá aos princípios da legalidade, moralidade, impessoalidade e publicidade e eficiência.
Para garantir o atendimento das normas impostas pela Constituição Federal e das necessidades advindas da sociedade, é necessário que cada órgão público seja regido por administradores capazes de coordenar, apoiando-se em estruturas de forma que garanta o bom andamento dos processos, com coordenação, eficiência e eficácia.

Uma das formas de garantir o sucesso de uma instituição minimamente organizada é que seja baseada em hierarquias, como rege conceitos da administração. E Sobral e Peci (2013) tratam disso em vossa obra, onde expõem que os administradores podem ser classificados pelo nível hierárquico, dependendo da função que ocupa dentro da organização. Estes níveis são separados nas seguintes categorias: estratégico, tático ou operacional.

Os servidores públicos apesar de não serem considerados perante a sociedade como inovadores em suas atividades, têm a oportunidade de atuação em qualquer um dos níveis acima expostos, oferecendo ferramentas e serviços que potencializem os produtos de informação que permeiam a instituição, fazendo com que melhores subsídios sejam trabalhados pelos atores da estrutura.

Cândido, Valentim e Contani (2005) pontuam que a falta de uma estrutura organizacional bem definida e sensivelmente atenta à gestão da informação impede a sinergia dentro da instituição, quer seja pelo excesso, pela falta de informação e/ou pelo acesso de forma inadequada. Portanto, se faz necessário que esses profissionais façam com que os setores se relacionem da forma mais assertiva possível, diminuindo as incertezas através de fluxos/processos bem elaborados com base nas necessidades coletivas, respeitando cada peculiaridade existente nos departamentos, que são caracterizadas pelas suas tarefas e/ou culturais organizacionais. Garantindo por consequência um melhor desempenho nos serviços prestados à sociedade através de decisões feitas por administradores públicos em diversos setores das organizações públicas da esfera municipal, estadual ou federal.

Por fim, é sabido que administrativamente uma organização carece de fluxos de informação definidos, onde são garantidos que os processos e produtos informacionais dotados de atributos de qualidade que 
permeiem as vias institucionais chegando a tomadores de decisões. A seguir serão tratados de conceitos e alguns modelos referentes à tomada de decisão, com ênfase no ambiente organizacional.

\subsection{TOMADA DE DECISÃO}

A tomada de decisão é uma das mais importantes e constantes funções de um profissional que atua na função de gerente, além de delegar tarefas e gerir conflitos das mais diversas naturezas. Esse processo pode se dar desde um impulso, que levam segundos ou uma análise aprofundada da situação e do contexto em que se encontra o indivíduo, que pode acarretar em dias, meses ou até anos.

Alguns estudiosos trazem modelos que explicam como se dá o processo de tomada de decisão nas organizações através de indivíduos, como Laudon e Laudon (2011), que trazem um modelo racional de comportamento, defendendo a ideia de que as pessoas empenham-se em cálculos consistentes e racionais. Segundo eles, o tomador de decisão identifica um objetivo, ordena todas as ações de forma que possam ajudar a atingir tal objetivo, e então, escolhe a que mais terá contribuição para o sucesso.

Porém, existem autores que vão de encontro a esse modelo, considerando que nem sempre é possível que o sujeito consiga focar num único objetivo e, racionalmente, organize suas ações premeditando uma escolha que trará consequências unicamente positivas.

Enquanto problemas estruturados, com questões bem determinadas e precisas, podem ser mais bem atacados pensando-se primeiro nos estágios lógicos, outros, que requerem soluções inusitadas e criativas, podem ser melhor resolvidos por um lampejo de intuição.

No caso da instituição de estudo, o gerente necessita diariamente tomar decisões que impactam tanto num futuro próximo quanto distante, ou seja, lida com a forma imediatista e a premeditada da ação decisória, tendo que fazer escolhas baseadas em experiências e/ou informações consolidadas, que são angariadas na rotina de trabalho.

Choo (2003) considerando a administração e a teoria organizacional da atualidade categoriza arenas referentes à criação e uso da informação como papel estratégico no crescimento e na adaptação da empresa.

Na primeira, a organização usa a informação para dar sentido às mudanças do ambiente externo (política, economia, etc.). Para Choo (2003) é preciso grande atenção das empresas que vivem num mercado dinâmico, por conta de sua dependência com o ambiente no qual está inserida, pois estar um passo a frente é garantir vantagem competitiva. Esse campo apesar de não condizer muito com o perfil de uma organização pública, precisa ser considerada, pois também está em um ambiente passível de mudanças, principalmente políticas e legais.

O segundo campo é aquele em que a organização cria, organiza e processa a informação de modo a gerar conhecimentos através da aprendizagem, garantindo à organização o desenvolvimento de melhorias nos processos interno a ela, tentando evitar que as experiências fiquem concentradas apenas em indivíduos ou unidades de trabalho (CHOO, 2003).

O terceiro campo, mais importante em relação ao presente trabalho é a do uso estratégico da informação em organizações que buscam e avaliam informações de modo a tomar decisões. Teoricamente, toda decisão deve ser tomada de forma racional, com base em informações completas sobre os objetivos da empresa, alternativas plausíveis, prováveis resultados dessas alternativas e importância desses resultados para a organização. Já na prática, a racionalidade na hora de decidir vai de encontro com interesses de sócios, barganhas, negociações em cursos, etc. (CHOO, 2003).

No caso de uma instituição pública, ainda pode ser adicionada como barreira as questões políticas, que são incisivamente mais atuantes quando comparadas às empresas privadas. Choo (2003), completa que os três campos de uso da informação: criar significado, construir conhecimento e tomar decisões são interligadas e podem acontecer simultaneamente, se alimentando uma da outra, mutuamente, produzindo fluxos de informação.

Sobral e Peci (2013) citam que o processo de tomada de decisão é contínuo para um administrador, e por mais simples que uma decisão seja, ela segue seis etapas até que o ciclo se renove, pois as fases de 
monitoramento e feedback de uma decisão tomada sempre geram novas escolhas. De acordo com os autores as fases são: identificação da situação, diagnóstico da situação, desenvolvimento de alternativas, avaliação de alternativas, seleção e implementação, monitoramento e feedback.

O processo proposto parte da premissa de que todos os gerentes tomam decisões seguindo rigorosamente as seis etapas acima aludidas, porém na prática isso não é recorrente nem prático. As causas são muitas, e dentre elas se destacam a falta de tempo e as limitações racionais do humano por trás da decisão.

Para driblar a limitação natural, os tomadores de decisão, na prática, simplificam o modelo racional de tomada de decisão, uma vez que consideram as características essenciais do problema, mas não incluem todas as suas. Diante disso, é considerado o conceito da solução satisfatória, onde o administrador não busca todas as alternativas possíveis para o caso e simplesmente escolhe àquela que satisfaz, mesmo que superficialmente, a necessidade atual, deixando de lado opções que trariam mais benefícios, porém com maiores dificuldades de implementação.

No caso das gerências estudadas não é diferente. Há a necessidade de sempre percorrer os caminhos mais curtos, com menores probabilidades de erros possíveis, diminuindo por vezes as beneficies que uma decisão de maior estudo e análise pode propor.

\section{PROCEDIMENTO METODOLÓGICO}

O trabalho foi elaborado com base em uma pesquisa de abordagem qualitativa, ou seja, àquela que não se preocupa com representatividade numérica, mas sim com o aprofundamento da compreensão de um grupo social, de uma organização, etc. Esse tipo de abordagem se volta basicamente a aspectos que não são quantificáveis, preocupando-se com a compreensão e dinâmica das relações entre os indivíduos (GOLDENBERG, 1997).

A pesquisa se deu de forma exploratória com investigações empíricas, que tem como característica a formulação de respostas para questões ou problemas. Para esse tipo de estudo, uma variedade de procedimentos de coleta de dados pode ser utilizada, e, para o presente trabalho foram utilizadas entrevistas e observação participante (LAKATOS; MARCONI, 2003).

Quanto aos fins, foi usada a técnica de análise descritiva neste trabalho, pois tem por objetivo descrever completamente o fenômeno, que aliada à estratégia de investigação de estudo de caso único foram importantes para as apreciações empíricas e teóricas, garantindo descrições qualitativas e acumulação de informações detalhadas como as obtidas por intermédio da observação participante (LAKATOS; MARCONI, 2003).

A coleta de dados aconteceu de duas formas: entrevistas estruturadas e observação participante. A primeira etapa do processo de coleta, a entrevista, é "um procedimento utilizado na investigação social, para a coleta de dados ou para ajudar no diagnóstico ou no tratamento de um problema social" (LAKATOS; MARCONI, 2003, p. 195). Em relação aos tipos existentes, Boni e Quaresma (2005, p. 72 ) trazem que as mais utilizadas para ciências sociais é "a entrevista estruturada, semi-estruturada [sic], aberta, entrevistas com grupos focais, história de vida e também a entrevista projetiva". Para este estudo, as entrevistas foram estruturadas e dirigidas ao Gerente Estratégico (GE) e suas duas Gerentes Táticas (GT 1 e GT 2), no mês de julho de 2015 e as entrevistas tiveram duração de aproximadamente 15 minutos cada.

O GE é do gênero masculino, possui idade entre 50-60 anos, tem 35 anos de funcionalismo público, sendo desses, 5 no cargo atual e possui o título acadêmico de mestre profissional. A GT 1, gênero feminino, também tem entre 50-60 anos, sendo 20 anos como funcionária pública estadual e 1 ano na função que exerce atualmente. Tendo especializações na área de educação. A GT 2, gênero feminino, tem idade entre 45-50 anos, 5 anos na atual função e 18 anos de estatutária. Recentemente concluiu o mestrado profissional.

Os atores supracitados também foram objetos de estudo através da observação participante, que se caracteriza pela participação real do pesquisador com o grupo objeto de estudo, se incorporando e confundindo-se com ele. Fica tão próximo quanto um membro do grupo que está estudando e participa das atividades normais deste. Em geral, esse passo é subdivido em natural e artificial, onde o natural é quando o 
observador pertence à mesma comunidade ou grupo que investiga; e o artificial quando observador integra-se ao grupo com a finalidade de obter informações (LAKATOS; MARCONI, 2003). Sendo o tipo natural, o utilizado para a presente pesquisa, pois o autor é integrante do quadro de pessoal da instituição estudada.

Para esta pesquisa, utilizou-se a análise de conteúdo, que é uma técnica de análise das comunicações, que interpreta o que foi dito nas entrevistas ou observado pelo pesquisador (SILVA; FOSSÁ, 2015).

Bardin (1977) comenta que a análise de conteúdo tem como finalidade esclarecer a especificidade e o campo de ação da análise.

Para este estudo foi realizada a categorização das perguntas e respostas das entrevistas feitas, de forma que aglutinassem os grupos de acordo com os objetivos específicos, a fim de analisar melhor os resultados obtidos.

A instituição do estudo é um órgão público estadual de administração direta do Poder Executivo Estadual, que está localizada na região nordeste do Brasil e tem por finalidade e competência garantir o acesso da população ao ensino médio; garantir a manutenção da Rede Pública Estadual de Ensino; supervisionar instituições públicas e privadas de ensino profissional em seu estado, incluindo a Educação a Distância; desenvolver programas permanentes de melhoria da qualidade do ensino e da capacitação do quadro da educação do estado, além de formular, implementar, acompanhar e avaliar as políticas estaduais de educação profissional de nível técnico, articulado ao projeto de desenvolvimento regional e local; articular e interagir com outros órgãos e entidades envolvidos com educação profissional.
Sua estrutura de pessoal conta com aproximadamente cem colaboradores e o recorte do organograma focando na parte hierarquicamente superior da organização. As duas gerências táticas são do mesmo nível e respondem diretamente à gerência estratégica.

\section{ANÁLISE E DISCUSSÃO DOS RESULTADOS}

\subsection{OS TIPOS DE INFORMAÇÕES QUE CIRCULAM DOS NIIVEIS TÁTICOS PARA O NÍVEL ESTRATÉGICO}

Referente ao mapeamento dos tipos de informações recebidas pelo nível tático e a identificação dos tipos de informações requeridas pelo nível estratégico, a pesquisa contou com a observação participante e as entrevistas direcionadas aos três interlocutores, que contaram com perguntas que aludiam a solução dessas questões. As perguntas se referiam à quais as principais informações que são disponibilizadas do gerente tático para o estratégico: como são recebidas pelo nível tático e como precisam ser apresentadas ao seu superior.

Os pontos abordados pelas GT 1 e GT 2 são, em geral, semelhantes. Apesar de apresentarem peculiaridades inerentes a cada função desempenhada, elas informaram cerca de cinco tipos de informações que são voltadas para o contexto das unidades escolares espalhadas por toda jurisdição de atuação do órgão e que consideram serem as mais requisitadas pelo GE na rotina de trabalho. A seguir, o quadro traz uma representação das abordagens mais significativas:

Quadro 3: Principais informações disponibilizadas pelas GT.

\begin{tabular}{lll|} 
& & Quantitativo de profissionais nas escolas \\
& Quantitativo de estudantes \\
\hline Principais tipos de informações & Informações referentes aos desempenhos dos gestores \\
disponibilizadas pelas GT & escolares \\
\hline & $\begin{array}{l}\text { Informações referentes à evolução da quantidade de escolas } \\
\text { pelo estado }\end{array}$ \\
\hline
\end{tabular}

Fonte: elaborado pelo autor. 
O GE apresenta que as informações mais requisitadas por ele vão desde as questões administrativas, como demanda por professores e quantidade de estudantes quanto no nível de desempenho, verificando rotineiramente os desempenhos dos estudantes nos diversos índices de avaliações de nível estadual e nacional. Por exemplo: o Índice de Desenvolvimento da Educação Básica e as aprovações em Universidades públicas e particulares. Conforme quadro a seguir:

Quadro 4: Principais informações requisitadas pelo GE.

\begin{tabular}{ll} 
& Quantitativo de profissionais nas escolas \\
\cline { 2 - 2 } $\begin{array}{l}\text { Principais tipos de informações } \\
\text { requeridas pelo GE }\end{array}$ & $\begin{array}{l}\text { Informações referentes aos desempenhos de estudantes em } \\
\text { avaliações internas, externas e em vestibulares de } \\
\text { Universidades públicas e particulares }\end{array}$ \\
\hline
\end{tabular}

Fonte: elaborado pelo autor.

É possível notar diferenças entre os resultados apresentados nos quadros acima, principalmente no que se refere ao estudo focado nos estudantes em relação às suas aprovações, onde o GE considera focar. Entretanto, de acordo com os resultados obtidos através da observação participante e das respostas dadas nas entrevistas (em questões posteriores), essas informações requeridas pelo GE acabam sendo atendidas pelas GT de forma periódica e pontual. Abstraiu-se também que devido às suas experiências nos cargos e as rotinas de reuniões frequentes com o gerente, acabam por garantir que tais informações sejam repassadas de forma satisfatória.

\subsection{AS CARACTERÍSTICAS DOS PRODUTOS DE INFORMAÇÃO}

Visando descrever os produtos de informação no nível tático e estratégico, tanto a observação participante quanto as entrevistas se voltaram tanto à identificação dos produtos de informação que conscientemente são necessitados pelo GE quanto aos produtos de informação que são disponibilizados pela GT 1 e GT 2.

Através das respostas dadas pelos entrevistados, verificou-se que os produtos de informação são apresentados em diversos suportes, sempre atendendo as especificidades de cada demanda.

Para a GT 1, as informações são muitas vezes repassadas de forma oral quando há visitas de monitoramento nas unidades escolares. E são recebidas em planilhas quando "retiradas de um sistema de informação ou requeridas nesse modelo à escola através de e-mail ou ofício" (entrevista concedida em julho de 2015). Normalmente, esse tipo de suporte é o utilizado para quantidade de materiais administrativos, por exemplo, e são filtradas e reorganizadas antes de apresentadas ao GE. No caso de informações que precisam ser apresentadas pelo GE a terceiros, a GT 1 informa que esses produtos são construídos em forma de "relatórios redigidos por técnicos educacionais da gerência e revisados antes de seguir para o superior" (entrevista concedida em julho de 2015).

A GT 2 segue a mesma linha da GT 1 , focando sempre em muitos diálogos acerca dos dados de sua gerência. Porém, sua atenção é voltada majoritariamente em respostas através de notas técnicas e e-mails, pois acredita que as suas "informações são sempre repassadas a terceiros e precisam estar um produto melhor elaborado" (entrevista concedida em julho de 2015).

Já o GE (entrevista concedida em julho de 2015) entende que suas necessidades informacionais são supridas de forma verbal em sua maioria das vezes, porém diz que:

é importante frisar a importância de apresentação em slides quando há a necessidade de apresentar resultados para o Secretário de Educação ou até mesmo divulgar as ações e desempenhos da instituição em outros órgãos de dentro do estado ou a nível nacional.

O Gerente por fim ressalta que planilhas e relatórios escritos são utilizados na rotina de trabalho, a fim de melhor entendimento dos 
dados apresentados por suas gerentes táticas.

\subsection{O FLUXO INFORMACIONAL E AS DIFICULDADES}

Com o propósito de apresentar o fluxo informacional do nível tático ao estratégico e detectar os pontos do processo que dificultam o fluxo informacional, a observação participante contou com um olhar investigativo e através de experiências pôde tornar possível montar o fluxo de informação que percorre a organização desde as gerências táticas até ao gerente estratégico. Não obstante, as perguntas realizadas nas entrevistas foram imprescindíveis para identificação das barreiras e dos gargalos enfrentados pelo fluxo.

Conforme considerado no capítulo referente a fluxos de informação, será utilizado o modelo de Davenport (2002) por se enquadrar melhor na realidade da organização estudada, de acordo com a observação dos fluxos de informações predefinidos e utilizados no momento do estudo.

O modelo de Davenport (2002) conta com quatro etapas: Determinação de Exigências, Obtenção, Distribuição e Utilização. A seguir, será analisada cada uma dessas fases, de acordo com o contexto da organização estudada.

A etapa de Determinação de Exigências é caracterizada pela escolha que as GT fazem em relação à quais informações que melhor vão satisfazer o requerente, que, para este estudo, é o GE. Esse primeiro passo é considerado tranquilo por parte dos interessados, muito por causa da experiência na função que exerce e o tempo de atuação em conjunto.

A Obtenção, que é subdividida em exploração, classificação e formatação e estruturação das informações, é a etapa que possui o maior gargalo do fluxo, pois é onde está a maior dificuldade por parte das GT. A exploração é entravada quando há necessidades de buscar informações junto a centenas de unidades escolares em um período de tempo por vezes curto, com o agravante da dificuldade na formatação e estruturação das informações, que são as fases aonde os dados chegam e precisam ser tratados. Porém, por diversos fatores, esses dados chegam com o mínimo de padrão possível, dificultando ainda mais o andamento do processo de forma eficiente.

O passo da Distribuição é simples, visto que a informação estruturada (produtos de informação) não precisa percorrer muito os níveis hierárquicos da instituição. Dessa forma, o que é garimpado pela gerência tática é levado diretamente ao Gerente Estratégico.

É após a apresentação das informações ao GE que o feedback acontece, e de forma imediata. No caso de um comando de alteração a ser feita por parte de uma GT, essa ação é dada no instante que o GE recebe as informações. No entanto, de acordo com os entrevistados, apesar de terem que ser feitos regularmente, os ajustes são normalmente simples de realizar. Essa fase não está explícita no modelo de Davenport (2002), mas foi inserida para melhor visualização. Mostrando que o feedback ocorre antes da etapa de utilização e o andamento do fluxo somente ocorre após as informações terem sido validadas completamente pelo GE.

O quarto e último passo é o da Utilização, que é onde os produtos de informação recebidos, tratados e contextualizados antes de serem efetivamente aplicado para um processo decisório praticado pelo GE. De acordo com Davenport (2002), o andamento dessa fase depende muito do intrapessoal do gerente e Choo (2003) considera que fatores políticos, de barganha, de interesses e emocionais são alguns dos aspectos que são levados em conta para uma tomada de decisão.

Dessa forma, o fluxo de informação que acontece entre as gerências se baseia pelo modelo de Davenport (2002), adicionando a ele a fase do feedback: 
Figura 1: Etapas do fluxo de informação

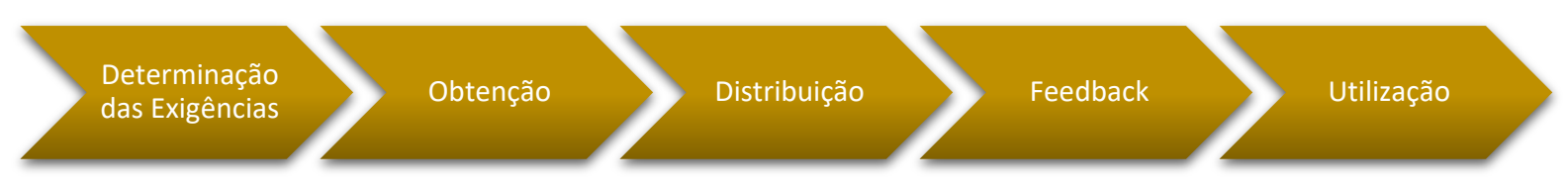

Fonte: adaptado de Davenport (2002)

\subsection{AS INFORMAÇÕES GERADAS E SEUS ATRIBUTOS DE QUALIDADE}

Para apontar se as informações geradas do nível tático para o estratégico possuem atributos de qualidade pertinentes aos dois grupos, utilizou-se das entrevistas aplicadas para o GE, GT 1 e GT 2.

Conforme já exposto no capítulo referente à qualidade da informação, é difícil garantir discernimento entre os atributos que garantam a qualidade de uma informação, pois todos eles estão interligados entre si.
Para a GT 1 a fidedignidade, precisão e confiabilidade são considerados os principais atributos de uma informação qualificada para qualquer tipo de levantamento feito por ela. Já GT 2 considera que precisão, confiabilidade e integridade fazem parte de sua rotina de trabalho por estar em um cargo chefia, o que demanda confiança por parte de seus gerenciados e de seu superior. Além dessas características, ela também acredita que a atualidade é importante, pois as mudanças na área de atuação do órgão são constantes.

Quadro 5: Principais atributos de qualidade da informação sob os olhares dos entrevistados.

\begin{tabular}{l|l|}
\multicolumn{1}{c|}{} & \multicolumn{1}{c}{ Atributos De Qualidade Da Informação } \\
GT 1 & Precisão / Confiabilidade / Fidedignidade \\
\hline GT 2 & Precisão / Confiabilidade / Integridade / Atualidade \\
\hline GE & Fidedignidade / Integridade \\
\hline
\end{tabular}

Fonte: elaborado pelo autor.

Para o GE, a informação íntegra é primordial, pois as informações são passíveis de erros em relação à quantidade de estudantes, por exemplo, até porque o fluxo é contínuo e diariamente há mudanças nos números. Porém, a fidedignidade da informação apresentada é essencial. Numa consideração final, ele garante que o curto período de tempo, apesar de ser um fator que sempre está presente nas suas decisões, não é tão importante, pois acredita que sempre é possível esperar um pouco mais para garantir um produto de informação mais qualificado.

Portanto, pode-se extrair que as gerentes táticas estão em consonância com o gerente estratégico, pois a partir do quadro é possível verificar que os atributos considerados essenciais por elas estão de acordo tanto entre si quanto com o do GE em pelo menos uma das características desejáveis.

\section{CONSIDERAÇÕES FINAIS}

Este estudo teve como proposta analisar como as gerências táticas numa instituição pública estadual organizam as informações disponibilizadas ao gerente do nível estratégico, que, por sua vez, objetiva principalmente utilizar estes insumos para tomadas de decisões.

Através dos procedimentos metodológicos descritos no capítulo terceiro deste trabalho, foi possível verificar os tipos de informações que as GT disponibilizam ao GE, fazendo, em paralelo, um cruzamento entre as necessidades do superior em relação ao que ele recebe de suas gerentes. E como resultado de pesquisa, infere-se que as necessidades informacionais do GE são compatíveis com os produtos informacionais que são levados até ele por suas gerentes 
táticas, facilitando por consequência suas escolhas em um processo decisório.

No que se refere aos produtos informacionais, é consenso entre os agentes entrevistados que a comunicação verbal por meio de reuniões e diálogos informais são os principais meios para a diminuição de incertezas. No entanto, é imprescindível o uso de suportes desenvolvidos, como planilhas, notas técnicas, relatórios escritos, apresentação em slides, etc., que devem ser disponibilizados ao GE de acordo com a necessidade de cada demanda, prioritariamente quando se trata de informações que devem ultrapassar o cerco da organização estudada e alcançar horizontes. Quer seja para a sociedade, quer seja para um órgão regulador.

Em relação ao fluxo informacional, este, na organização pública de estudo, foi criado a partir de experiências dos envolvidos, e para o atual estudo foi utilizado o modelo de fluxo de Davenport (2002) como base para observações pertinentes, onde se pode fazer uma pequena adaptação para a realidade da instituição. Foi adicionada a fase do feedback em relação ao modelo original.

A partir de uma análise feita através do fluxo, foi possível identificar problemas em determinadas etapas, causados pela dificuldade de obtenção de dados de lugares fisicamente distantes, mas que estão sob a jurisdição do órgão. Mesmo com um leque de opções tecnológicas que possuímos atualmente, foram encontradas barreiras tanto num grande intervalo entre a solicitação e a entrega da informação, quanto na fase de formatação das informações colhidas pelas GT, que acabam por não atender de forma eficiente as necessidades sumárias.

Voltando-se para a qualidade da informação, um dos objetivos do estudo foi de apontar se os atributos de qualidade, segundo Sordi (2008), são encontrados nos produtos de informações disponibilizados pelas gerências táticas, na visão delas próprias e do seu gerente estratégico. Com o resultado alcançado depreendeu-se que as características de uma informação qualificada no olhar dos agentes seguem basicamente os mesmos atributos, em suma: Precisa, Confiável e Íntegra. O que, por conseguinte, garante melhor entendimento entre eles e melhorias nos processos decisórios do gerente estratégico, tanto para medidas imediatas quanto para escolhas que impactem em longo prazo o andamento da organização pública.

Este trabalho ficou limitado no tocante ao aprofundamento da verificação do gargalo encontrado no fluxo informacional da organização estudada, sem que fosse feita uma análise mais aguda para verificação dos problemas causadores do fenômeno. Portanto, fica sugestão para trabalhos posteriores, que visem alcançar resultados relativos à melhoria do fluxo em ambiente remotos a uma organização, estudando como a etapa de formatação pode ser mais eficiente nesses casos.

\section{REFERÊNCIAS}

[1] AMARAL, Sueli Angélica do.; SOUSA, Antônio José Figueiredo Peva de. Qualidade da informação e intuição na tomada de decisão organizacional. Perspectiva em Ciência da informação, Belo Horizonte, v.16, n.1, p.133-146, jan./mar. 2011. Disponível em: < http://www.scielo.br/pdf/pci/v16n1/a08v16n1.pdf>.

\section{Acesso em: 30 maio 2015.}

[2] BARBOSA, Ricardo Rodrigues. Gestão da informação e do conhecimento: origens, polêmicas e perspectivas. Informação \& Informação, Londrina, v. 13, n. esp., p. 1-25, dez. 2008. Disponível em: http://www.uel.br/revistas/uel/index.php/informacao larticle/view/1843/1556>. Acesso em: 23 maio 2015.

[3] BARDIN, Laurence. Análise de conteúdo. Lisboa: Edições 70, 1977.

[4] BEAL, A. Gestão estratégica da informação. São Paulo: Atlas, 2004.

[5] BONI, Valdete; QUARESMA, Sílvia Jurema. Aprendendo a entrevistar: como fazer entrevistas em Ciências Sociais, Em Tese [Revista Eletrônica dos Pós-Graduandos em Sociologia Política da UFSC], Santa Catarina, v.2, n.1, p.68-80, jan./jul. 2005. Disponível em: < https://periodicos.ufsc.br/index.php/emtese/article/ viewFile/18027/16976 > . Acesso em: 26 set. 2015.

[6] BRASIL. Constituição (1988). Constituição da República Federativa do Brasil. Disponível em: 
<http://www.planalto.gov.br/ccivil_03/constituicao/c onstituicao.htm>. Acesso em: 28 jul. 2015.

[7] BRASIL. Constituição (1988). Emenda constitucional n.. 19, de 4 de junho de 1998. Modifica o regime e dispõe sobre princípios e normas da Administração Pública, servidores e agentes políticos, controle de despesas e finanças públicas e custeio de atividades a cargo do Distrito Federal, e dá outras providências. Diário Oficial [da] República Federativa do Brasil, Poder Executivo, Brasília, DF, 06 jun. 1998. Seção 1, p.1. Disponível em:

http://www.planalto.gov.br/ccivil_03/Constituicao/E mendas/Emc/emc19.htm>. Acesso em: 28 jul. 2015.

[8] CÂNDIDO, C. A.; VALENTIM, M. L. P.; CONTANI, M. L. Gestão estratégica da informação: semiótica aplicada ao processo de tomada de decisão. DataGramaZero, Rio de Janeiro, v.6, n. 3, jun./2005. Disponível em: < http://www.dgz.org.br/jun05/Art_03.htm>. Acesso em: 29 set. 2015.

[9] CASANOVA, M. B. Information: the major element for change. In: WORMELL, I. Information quality: definitions and dimensions. London: Taylor Graham, 1990. p. 42-53.

CASTELLS, M. A Sociedade em Rede. São Paulo: Paz e Terra, 1999.

[11] CASTELLS, M. O espaço de fluxos. In: A Sociedade em Rede. 6.ed. Rio de Janeiro: Paz e Terra, 2001. v. 1. Cap. 6. p. 467-521.

[12] CHIAVENATO, Idalberto. Administração geral e pública. 2.ed. Rio de Janeiro: Elsevier, 2008.

[13] $\mathrm{CHOO}$, Chun Wei.; ROCHA, Eliana. A Organização do Conhecimento: como as Organizações usam a informação para criar significado, construir conhecimento e tomar decisões. São Paulo: Senac, 2003.

[14] DAVENPORT, Thomas $\mathrm{H}$. Ecologia da Informação: por que só a tecnologia não basta para o sucesso na era da informação. Tradução Bernadette Siqueira Abrão. São Paulo: Editora Futura, 2002.

[15] DI PIETRO, Maria Sylvia Zanella. Direito Administrativo. 18.ed. São Paulo. Ed. Atlas, 2005.

[16] DIAS, Maria Matilde Kronka.; BELLUZZO, Regina Célia Baptista. Gestão da informação em ciência e tecnologia sob a ótica do cliente. Bauru, SP: EDUSC, 2003.

[17] GOLDENBERG, M. A arte de pesquisar. Rio de Janeiro: Record, 1997.

[18] GONÇALVES, Marcos Rogério; GOUVEIA, Sônia Mara; PETINARI, Valdinéa Sônia. A Informação como produto de alto valor no mundo dos negócios, CRB-8 Digital, São Paulo, v. 1, n. 1, p. 43-54, jul. 2008. Disponível em: < http://revista.crb8.org.br/index.php/crb8digital/articl e/viewFile/42/43 >. Acesso em: 26 set. 2015.

[19] JUSTEN FILHO, M. Curso de Direito administrativo. 7.ed. Belo Horizonte: Fórum,

[20] 2011.

[21] LAKATOS, E. M.; MARCONI, M. A. Fundamentos de Metodologia Científica. 5.ed. São Paulo: Atlas, 2003.

[22] LAUDON, J.; LAUDON, K. Sistemas de Informação Gerenciais. 9. ed. São Paulo: Pearson do Brasil, 2011.

[23] LE COADIC, Yves François. A Ciência da Informação. Tradução de Maria Yêda F. S. de Filgueiras Gomes. Brasília: Briquet de Lemos, 1996.

[24] LEITÃO, D. M. A informação como insumo estratégico. Ci. Inf., Brasília, v.22, n.2, p.118-123, maio/ago. 1993. Disponível em: $<$ http://www.brapci.inf.br/_repositorio/2010/03/pdf_ 3d440d3530_0008997.pdf>. Acesso em: 26 set. 2015.

[25] LESCA, H.; ALMEIDA, F. C. Administração estratégica da informação. Revista de Administração, São Paulo, v. 29, n. 3, p. 66-75, jul./set. 1994. Disponível em: < www.rausp.usp.br/download. asp?file=2903066. pdf >. Acesso em 26 set. 2015.

[26] MCGEE, J.; PRUSAK, L. Gerenciamento estratégico da informação. Rio de Janeiro: Campus, 1994.

[27] MEIRELLES, Hely Lopes. Direito Administrativo Brasileiro. 29.ed. São Paulo: Malheiros. 2004.

[28] OLETO, Ronaldo Ronan. Percepção da qualidade da informação. Ciência da Informação, Brasília, v.35, n.1, p. 57-62, jan./abr., 2006. Disponível: http://www.brapci.inf.br/_repositorio/2010/02/pdf_c da54faea9_0008087.pdf >. Acesso em: 26 set. 2015.

[29] PAIM, I.; NEHMY, R. M. Q.; GUIMARÃES, C. G. Problematização do conceito qualidade da informação. Perspectivas em Ciência da Informação, Belo Horizonte, v. 1, n. 1, p. 111-119, jan./jun., 1996. Disponível em: < http://www.brapci.ufpr.br/documento.php?dd0=000 0006717\&dd1=e6315 > . Acesso em: 26 set. 2015.

[30] PEREIRA, A. L. C.; SILVA, A. B. da. As competências gerenciais nas instituições federais de educação superior. Cadernos EBAPE, Rio de Janeiro, v. 9, ed. esp., artigo 9, p. 627-647, jul. 2011. Disponível em: < http://bibliotecadigital.fgv.br/ojs/index.php/caderno 
sebape/article/view/5445/4179 >. Acesso em: 26 set. 2015.

[31] SCHWUCHOW, W. Problems in evaluating the quality of information services. In: WORMELL, I. Information quality: definitions and dimensions. London: Taylor Graham, 1990. p. 69-72.

[32] SENDOV, Blagovest. Entrando na era da informação. Estudos avançados, São Paulo, v.8, n.20, p.28-32, abr. 1994. Disponível em: < http://www.scielo.br/scielo.php?pid=S010340141994000100008\&script=sci_arttext>. Acesso em: 25 jul. 2015.

[33] SILVA, Andressa Hennig; FOSSÁ, Maria Ivete Trevisa. Análise de conteúdo: exemplo de aplicação da técnica para análise de dados qualitativos, Qualitas [Revista Eletrônica especializada em Administração, Ciências Contábeis, Economia, Comunicação Social, Serviço Social e áreas afins], Paraíba, v.16, n.1, p.1-14, jan./mar. 2015. Disponível em: < http://revista.uepb.edu.br/index.php/qualitas/article/ view/2113/1403>. Acesso em: 26 mar. 2015.

[34] SMIT, J. W.; BARRETO, A. A. Ciência da Informação: base conceitual para a formação do profissional. In: VALENTIM, M.L. (Org.). Formação do profissional da informação. São Paulo: Polis, 2002. cap.1. p. 9-23.

[35] SOBRAL, Filipe; PECl, Alketa. Administração: teoria e prática no contexto brasileiro. 2.ed. São Paulo: Person, 2013.

[36] SORDI, J. O. de. Administração da informação: fundamentos e práticas para uma nova gestão do conhecimento. São Paulo: Saraiva, 2008.

[37] SORDI, J. O. de.; COSTA, M. A. M. da.; GRIJÓ, R. N. Gestão de qualidade da informação no contexto das organizações: percepções a partir do experimento de análise da confiabilidade dos jornais eletrônicos, Perspectivas em Ciência da Informação, Brasília, v.13, n.2, p.168-195, maio/ago. 2008. Disponível em: < http://www.researchgate.net/publication/250991517 _Gesto_da_qualidade_da_informao_no_contexto_d as_organizaes_percepes_a_partir_do_experimento _de_anlise_da_confiabilidade_dos_jornais_eletrnic os>. Acesso em: 26 set. 2015.

[38] SORDI, José Osvaldo de.; MEIRELES, Manuel. Dimensões de Qualidade da Informação como Elemento Classificatório para Localidades com Concentração de Atividades da Cadeia Produtiva. In: ENCONTRO DO ANPAD, 35., 2008, Rio de Janeiro. Anais... RJ: ANPAD, 2011.

[39] VIEIRA, Mauro César; CARVALHO, Rodrigo Baroni de; CARVALHO, Juliana Amaral Baroni de. Contribuição dos Sistemas de Gestão Empresarial para o Processo de Tomada de Decisão Estratégica: Estudos de Casos Múltiplos. In: ENCONTRO DO ANPAD, 37., 2013, Rio de Janeiro. Anais... RJ: ANPAD, 2013.

[40] VITAL, Luciana Paula; FLORIANI, Vivian Mengarda; VARVAKIS, Gregório. Gerenciamento do fluxo de informação como suporte ao processo de tomada de decisão: revisão, Informação \& Informação, Londrina, v.15, n.1, p.85-103, jul./jun. 2010. Disponível em: < http://www.uel.br/revistas/uel/index.php/informacao larticle/view/5335/5880 > . Acesso em 26 set. 2015. 


\section{Bapítulo 7}

PERCEPÇÕES DOS GERENTES DE PROJETO EM RELAÇÃO ÀS FALHAS E BARREIRAS DE COMUNICAÇÃO

Marilyn de Souza Cyganczuk

Ricardo Mendes Junior

Jose Eduardo Pecora jr

Resumo: O gerenciamento da comunicação dentro de um projeto pode ser considerado tão importante quanto qualquer outro dentro de uma organização, pois a comunicação transmite e conecta ideias, conceitos, experiências e informações em um projeto. Este artigo descreve uma investigação sobre os problemas de comunicação encontrados pelos gerentes de projeto em empresas de diferentes portes e setores na área de gerenciamento de projetos e compara estes problemas com o que consta na literatura. Com base no estudo realizado, foi possível identificar quais são as principais barreiras e falhas de comunicação nestas organizações e verificá-las com o que existe na literatura. Os resultados permitiram concluir que as principais barreiras e falhas encontradas são a falta de feedback aos integrantes da equipe de projetos, a falta de confiança entre os membros da equipe, a transmissão de informações equivocadas e distorcidas, a falta de envio da informação ou envio em momento inoportuno e as competências e conhecimentos limitados dos gerentes de projetos, representando uma liderança fraca e consequentemente repercutindo na comunicação.

Palavras-chave: Comunicação; Gerenciamento de Projetos; Barreiras; Falhas. 


\section{INTRODUÇÃO}

A comunicação consiste em qualquer tipo de transmissão de informações. Neste sentido, torna-se fundamental compreender como funcionam as comunicações nos projetos.

Um efetivo processo de comunicação é necessário para garantir que todas as informações desejadas cheguem às pessoas corretas no tempo certo e de uma maneira economicamente viável. O gerente de projeto utiliza-se da comunicação para assegurar que o time do projeto trabalhe de maneira integrada para resolver os problemas do projeto e aproveitar suas oportunidades (VARGAS, 2009).

A eficácia da comunicação em projetos pode ser avaliada através da existência de uma perfeita troca de informações e depende de atividades como definição, organização e transmissão da informação, que geralmente ocorrem de maneira fragmentada e informal ao longo das diversas fases do projeto. Os gerentes de projeto muitas vezes não constatam que uma comunicação acurada implica positivamente no projeto, negligenciando o seu uso eficaz.

Um estudo organizado pelo Project Management Institute Brasil (PMI) em 2014 onde participaram 400 organizações, provenientes da Argentina, Brasil, Canadá, Chile, Colômbia, França, México, EUA e Uruguai; apontou os problemas mais frequentes em projetos, $64,2 \%$ das organizações citaram 0 item problemas de comunicação. Foi identificado no mesmo estudo as habilidades necessárias e valorizadas ao gerenciar projetos nas organizações, sendo que $61,6 \%$ das organizações revelaram a comunicação como sendo a principal habilidade, seguido da liderança com 57,8\% e negociação com 43,6\%. Entretanto, $44 \%$ das organizações pesquisadas citaram a comunicação como principal deficiência dos gerentes de projetos. O estudo mostra também os canais de comunicação mais utilizados pelas equipes de projetos, por ordem: email, conversas presenciais, telefone, mensagens instantâneas, videoconferência e redes sociais (PMI, 2014).

Com esse cenário, o estudo busca uma compreensão ampla dos problemas de comunicação em projetos, sendo norteada a pesquisa pela seguinte questão: Qual a percepção dos gerentes de projeto em relação às falhas e barreiras de comunicação?

O estudo constitui-se nesta introdução, seguido da revisão teórica que abrange conceitos de gerenciamento de projeto, gerenciamento da comunicação e as falhas na comunicação em projetos. Após será apresentada a metodologia, seguindo a apresentação dos resultados, e finalmente são apresentadas as considerações finais.

\section{REFERENCIAL TEÓRICO}

Nesta seção é apresentado o referencial teórico a fim de possibilitar uma melhor compreensão e assegurar a fundamentação do tema abordado este artigo, no qual se apresenta conceitos sobre gerenciamento de projetos, gerenciamento da comunicação e os problemas encontrados na literatura referentes à comunicação em um projeto.

\subsection{GERENCIAMENTO DE PROJETOS}

Projeto é um esforço temporário empreendido para criar um produto, serviço ou resultado exclusivo. A natureza temporária dos projetos indica que eles têm um início e um término definidos. O término é alcançado quando os objetivos do projeto são atingidos ou quando o projeto é encerrado porque os seus objetivos não serão ou não podem ser alcançados, ou quando a necessidade do projeto deixar de existir (PMI, 2013).

Segundo descreve o guia PMBOK (PMI, 2013) o Gerenciamento de Projetos é a aplicação do conhecimento, habilidades, ferramentas e técnicas às atividades do projeto para atender aos seus requisitos. O gerenciamento de projetos é realizado através da aplicação e integração apropriadas dos 47 processos de gerenciamento de projetos, logicamente agrupados em cinco grupos de processos (Iniciação, Planejamento, Execução, Monitoramento e Controle, e Encerramento).

Estes cinco grupos de processos auxiliam o gerente de projetos para que se possa alcançar o sucesso nos projetos. Para realizar o gerenciamento dos projetos, o guia ainda define o gerente de projetos como sendo a pessoa alocada pela organização executora para liderar a equipe responsável por alcançar os objetivos do projeto. Os gerentes de projetos eficazes devem possuir uma 
combinação equilibrada de habilidades éticas, interpessoais e conceituais para ajudálos a analisar situações e interagir de maneira apropriada, tais como: liderança, construção de equipes, motivação, influência, tomada de decisões, consciência política e cultural, negociação, ganho de confiança, gerenciamento de conflitos, Coaching e finalmente a comunicação (PMI, 2013).

\subsection{GERENCIAMENTO DA COMUNICAÇÃO}

O sucesso do gerenciamento de projetos em uma organização é altamente dependente de um estilo de comunicação organizacional eficaz, especialmente em decorrência da globalização da profissão de gerenciamento de projetos. As capacidades de comunicação organizacional exercem grande influência em como os projetos são conduzidos. Consequentemente, os gerentes de projetos em locais distantes estão mais capacitados a se comunicar eficazmente com todas as partes interessadas pertinentes no âmbito da estrutura organizacional a fim de facilitar 0 processo de tomada de decisões (PMI, 2013).

Segundo Daim et al. (2012) os gerentes de projetos terão de assegurar nos projetos uma informação eficiente e um conhecimento eficaz, através dos recursos disponíveis distribuídos. A comunicação eficaz será a marca do sucesso para estes gerentes de projeto.

O guia PMBOK desenvolvido pelo PMI (Project Management Institute) organiza $\mathrm{O}$ gerenciamento de projetos em dez áreas, sendo uma destas o Gerenciamento das Comunicações.

O gerenciamento das comunicações do projeto inclui três processos: Planejar o gerenciamento das comunicações, gerenciar as comunicações e controlar as comunicações. Estes processos são necessários para assegurar que as informações do projeto sejam planejadas, coletadas, criadas, distribuídas, armazenadas, recuperadas, gerenciadas, controladas, monitoradas e finalmente dispostas de maneira oportuna e apropriada. Os gerentes de projetos passam a maior parte do tempo se comunicando com os membros da equipe e outras partes interessadas do projeto, quer sejam internas (em todos os níveis da organização) ou externas à organização. A comunicação eficaz cria uma ponte entre as diversas partes interessadas do projeto, que podem ter diferenças culturais e organizacionais, diferentes níveis de conhecimento, e diversas perspectivas e interesses que podem impactar ou influenciar a execução ou resultado do projeto (PMI, 2013).

Segundo Hsu et al. (2012) a comunicação é o componente fundamental no trabalho em equipe, principalmente em se tratando do gerenciamento de projetos. Para Jacobson (2011) a comunicação é um dos meios mais importantes para realizar a coordenação de projetos.

A comunicação desempenha um papel importante na redução dos altos níveis de risco, incerteza e complexidade associada aos projetos (RYYNANEN et al. 2013).

Ziek \& Anderson (2015) afirmam que a comunicação constitui a trajetória de um projeto e compreender isto fornece aos gerentes de projeto meios adicionais para o completo controle do projeto.

\subsection{FALHAS NA COMUNICAÇÃO EM UM PROJETO}

Para compor o referencial a respeito das falhas de comunicação em projetos, foi feita uma busca na base de dados Periódicos Capes e Web of Science. As palavras-chave utilizadas na pesquisa foram Gerenciamento de Projeto, Gerenciamento de comunicação, Comunicação, Barreiras, Falhas; e seus termos em inglês: "Project management", "Communication Management", "Communication", "Barriers" e "Failures". Foi utilizado como filtro os artigos publicados nos últimos 5 anos. Assim, foi obtido um resultado de 117 artigos. A partir destes 117 artigos, foi lido o título, resumo e palavras-chave. Considerando a relevância do estudo e sua correlação com o objetivo e proposta deste trabalho, foram selecionados 10 artigos para realizar o estudo, conforme a Tabela 1. 
Tabela 1 - Referências sobre gerenciamento e falhas ou barreiras de comunicação em projetos.

\begin{tabular}{|c|c|c|}
\hline \multicolumn{2}{|c|}{ Gerenciamento da comunicação } & Falhas ou barreiras de comunicação \\
\hline $\begin{array}{l}\text { Palavras-chave: } \quad \text { Project } \\
\text { Communication, } \\
\text { management. }\end{array}$ & $\begin{array}{l}\text { management, } \\
\text { Communication }\end{array}$ & $\begin{array}{l}\text { Palavras-chave: Communication, Barriers, } \\
\text { Failures, Project management. }\end{array}$ \\
\hline Awati (2011) & & Andersson (2016) \\
\hline Badir et al. (2012) & & Daim et al. (2012) \\
\hline Hsu et al. (2012) & & Fukuyama et al. (2016) \\
\hline Jacobsson (2011) & & Silva et al. (2015) \\
\hline \multicolumn{3}{|l|}{ Ryynanen et al. (2013) } \\
\hline Ziek \& Anderson (2015) & & \\
\hline
\end{tabular}

Fonte: Os autores (2016).

De acordo com Badir et al. (2012), a comunicação é um elemento fundamental para a entrega satisfatória do produto do projeto, sendo considerado como um fator de sucesso.

Considerando os canais de comunicação, há barreiras com relação à tecnologia, pois ocorre uma limitação de conhecimentos referentes à tecnologia de informação (DAIM et al. 2012). A falta de confiança entre os integrantes que compõe a equipe de projetos também é considerada uma barreira na comunicação, conforme Awati (2011) e Daim et al. (2012).

Segundo Silva et al. (2015) a principal barreira na comunicação diz respeito aos canais pelas quais a comunicação flui. E-mails e outras comunicações impessoais podem oferecer riscos às comunicações nos projetos, principalmente quando há conjunção de pessoas em países diferentes. Segundo os autores a comunicação presencial aumenta a motivação da equipe. Isso pode servir como limitador ao excesso do uso de ferramenta de comunicação online no gerenciamento de projetos, principalmente a distância. $\mathrm{O}$ excesso de formalização através de relatórios de acompanhamento indica também uma possível barreira nas comunicações como indica o estudo. A insegurança do gerente de projetos ao finalizar o projeto aumenta a busca por formalizações e isto pode servir como potencial ameaça ao projeto, uma vez que a simples entrega do relatório final não contempla toda a complexidade e riqueza do produto final do projeto. Como Silva et al.
(2015), a dependência da comunicação eletrônica também foi apontada como barreira por Daim et al. (2012).

Os autores Andersson (2016), Fukuyama et al. (2016) e Daim et al. (2012), também destacam, as competências e conhecimentos limitados dos gerentes de projetos, representando assim uma liderança fraca e consequentemente repercutindo na comunicação.

De acordo com Fukuyama et al. (2016) a informação incompleta ou o contrário, excesso de informações, informações equivocadas ou distorcidas também são apresentados como falhas na comunicação, apesar do estudo apontar a resistência dos funcionários em comunicar as situações dos projetos. Ainda segundo os autores, uma das barreiras de comunicação mais importantes é a falta de feedback, seguindo do não conhecimento ou não utilização das ferramentas de comunicação.

Já as diferenças culturais são responsáveis pela falha na comunicação devido às barreiras linguísticas, segundo estudos de Daim et al. (2012), Silva et al. (2015) e Fukuyama et al. (2016).

Com base nas barreiras e falhas de comunicação apresentadas, foi aplicado um questionário com gerentes de projetos de diversos setores e posteriormente foi verificada a concordância ou discordância em relação ao que consta na literatura. 


\section{PROCEDIMENTOS METODOLÓGICOS}

O presente trabalho consiste em uma pesquisa quantitativa, para verificar os problemas de comunicação encontrados pelos gerentes de projeto em empresas de diferentes portes e setores na área de gerenciamento de projetos, utilizando um levantamento de dados por amostragem. Como instrumento de coleta de dados foi aplicado um questionário composto de 37 questões fechadas, sendo 31 assertivas estruturadas em escala tipo Likert de 5 pontos.

A coleta de dados ocorreu de forma eletrônica, sendo utilizada a ferramenta Google Formulários e o link do questionário foi enviado por e-mail para gerentes de projetos de diversos setores com o objetivo de coletar todos os dados necessários para compor o estudo. Os gerentes de projetos interpretaram as afirmações de acordo com os seguintes níveis de concordância/discordância: 1) se discorda; 2) se discorda parcialmente; 3) se indiferente (neste item, foi levado em consideração que o gestor não quis responder a tal pergunta); 4) se concorda parcialmente e 5) se concorda totalmente.
A análise do questionário foi resultado da média geral das respostas dos gestores com relação ao grau de concordância/discordância da escala tipo Likert. Através da utilização do software Microsoft Office Excel foram criadas tabelas reunindo os dados extraídos do questionário.

\section{RESULTADOS}

Com relação à amostra, o questionário foi encaminhado a 82 gerentes de projetos, obtendo 52 questionários respondidos, sendo a sua maioria do gênero masculino $(86,5 \%)$, na faixa etária de 26 a 35 anos (55,8\%). Em relação ao nível de instrução, $78,8 \%$ possuem Especialização, 15,4\% Mestrado e 5,8\% Ensino Superior. O relato sobre o tempo que exerce a função de gerente de projetos mostra que 51,9 \% desempenha a função de 6 a 10 anos. Conforme Figura 1 se destacaram alguns setores de atuação dos gerentes de projetos com 34,6\% na tecnologia da informação, 23,1 \% no setor automotivo e $17,3 \%$ na indústria.

Figura 1 - Setor de atuação dos gerentes de projeto.

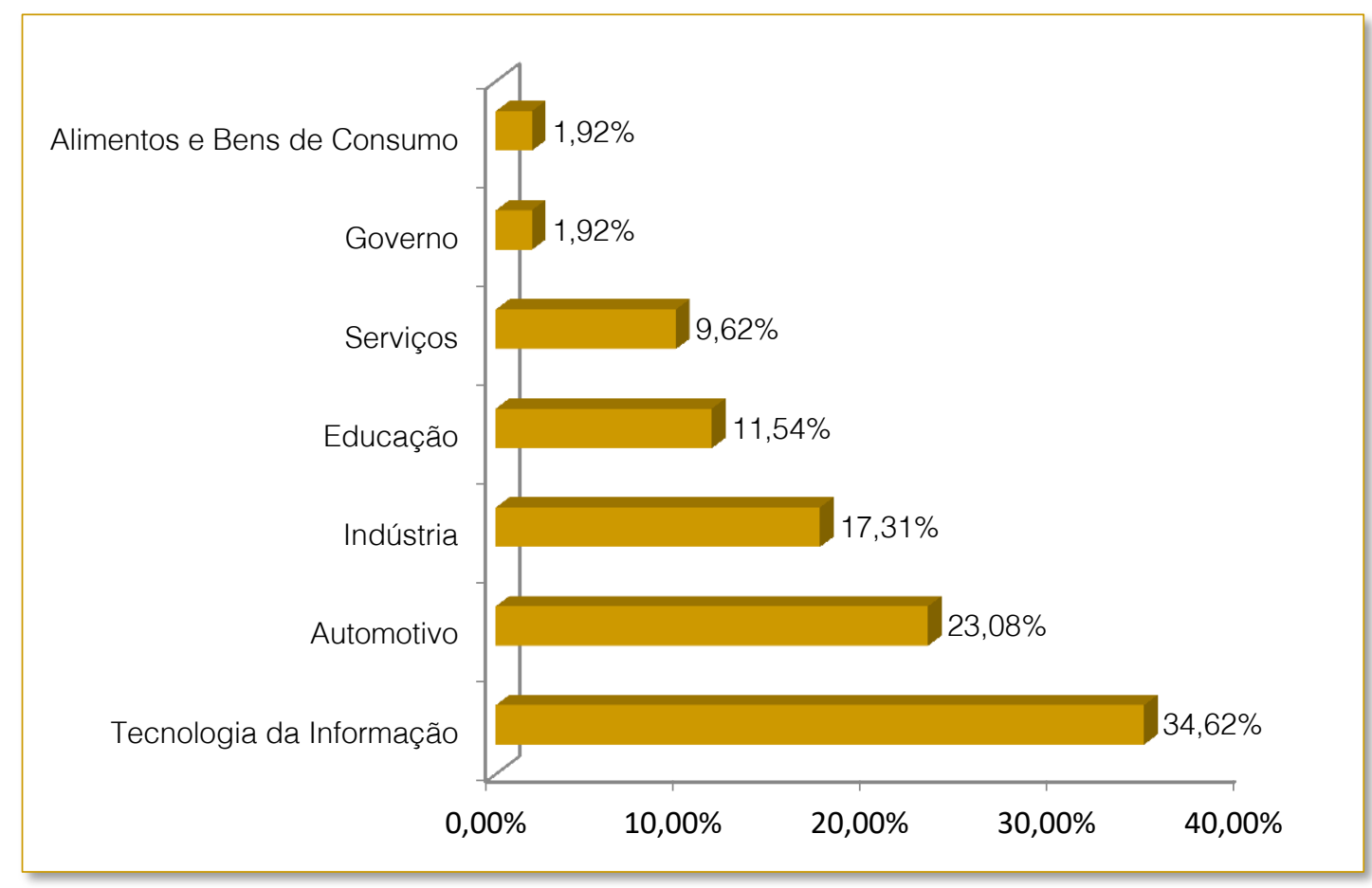

Fonte: Os autores 
O questionário foi dividido em duas partes, a primeira analisa as percepções referentes à comunicação na organização, a segunda analisa as barreiras e falhas na comunicação dentro da organização. Na análise da primeira parte do questionário, 94,3\%, soma das porcentagens das respostas concorda parcialmente e concorda totalmente, concordam que a comunicação é um elemento fundamental para a entrega satisfatória do produto do projeto, sendo um fator de sucesso do projeto, condizente com o estudo de Badir et al. (2012). Já 90,4\% concordam que a comunicação eficaz faz com que a informação flua com facilidade entre os componentes da equipe e se ocorrem falhas, estas prejudicam os trabalhos na organização conforme apontado no estudo de Daim et al. (2012).

$\mathrm{Na}$ tabela 2 são apresentados os resultados relacionados às percepções referentes à comunicação das pessoas nas organizações em que os gerentes de projeto pesquisados atuam. A porcentagem se refere a soma das porcentagens das respostas concorda parcialmente e concorda totalmente.

Tabela 2 - Afirmativas em relação às percepções referentes à comunicação das pessoas nas organizações.

\begin{tabular}{|c|c|c|}
\hline Afirmativa & Porcentagem & Média Geral \\
\hline $\begin{array}{l}\text { 1. Utilizam um meio inadequado ao conteúdo/tema da } \\
\text { mensagem. }\end{array}$ & $51,92 \%$ & 3,38 \\
\hline $\begin{array}{l}\text { 2. Manipulam mensagens, de forma que elas favoreçam } \\
\text { os seus interesses. }\end{array}$ & $51,92 \%$ & 3,11 \\
\hline $\begin{array}{l}\text { 3. Tem muita resistência em comunicar situações dos } \\
\text { projetos. }\end{array}$ & $67,31 \%$ & 3,67 \\
\hline
\end{tabular}

Fonte: Os autores

Com relação à afirmativa 1, a maioria dos gerentes de projeto concorda que os meios utilizados para transmitir as mensagens são inadequados, o resultado das respostas correspondeu à média geral de 3,38. Na segunda afirmativa $51,92 \%$ dos pesquisados concordaram que os colaboradores manipulam mensagens favorecendo seus próprios interesses, representado como média geral 3,11. Na afirmativa 3, o resultado da média geral foi 3,67. Portanto os gerentes concordam que os funcionários têm muita resistência em comunicar as situações dos projetos, conforme mostrado no estudo de Fukuyama et al. (2016).

Analisando a segunda parte do questionário, a Tabela 3 apresenta os resultados relacionados às barreiras e falhas na comunicação dentro da organização.

Discutindo-se a afirmativa 4, o resultado da média geral foi 4,65. Então, com relação a esta afirmativa, a maioria dos gerentes de projeto concorda que a falta de feedback sobre 0 serviço realizado gera a desmotivação dos funcionários, conforme afirma Fukuyama et al. (2016).

$\mathrm{Na}$ quinta afirmação a maioria dos pesquisados acreditam que as falhas na comunicação interferem no prazo de entrega e qualidade dos produtos finais, o resultado da média geral foi 4,75 , este resultado confirma os estudos de Silva et al. (2015) e Fukuyama et al. (2016). Apontado como uma barreira de comunicação, a falta de confiança entre os integrantes que compõe a equipe de projetos foi considerada pela maioria dos respondentes, obtendo média geral igual a 4,63. Esta afirmação reforça a menção de autores como Awati (2011) e Daim et al. (2012).

De acordo com a percepção da maioria dos gestores, a comunicação entre os níveis mais altos da organização e o gerente de projeto é falha, a média geral desta afirmativa resultou o valor 3,40. No estudo de Fukuyama et al. (2016) são apontadas barreiras ligadas à relação entre emissor e receptor como diferenças de posição ou status. 
Tabela 3 - Afirmativas em relação às barreiras e falhas na comunicação dentro da organização.

\begin{tabular}{|c|c|c|}
\hline Afirmativa & Porcentagem & Média Geral \\
\hline $\begin{array}{l}\text { 4. A Falta de feedback sobre o serviço realizado, tem como } \\
\text { consequência a desmotivação. }\end{array}$ & $92,31 \%$ & 4,65 \\
\hline $\begin{array}{l}\text { 5. As falhas na comunicação interferem no prazo de entrega e } \\
\text { qualidade dos produtos finais. }\end{array}$ & $94,23 \%$ & 4,75 \\
\hline $\begin{array}{l}\text { 6. A falta de confiança entre os integrantes que compõe a } \\
\text { equipe de projetos é uma barreira de comunicação. }\end{array}$ & $94,23 \%$ & 4,63 \\
\hline $\begin{array}{l}\text { 7. A comunicação entre os níveis mais altos da organização e o } \\
\text { gerente de projeto é falha. }\end{array}$ & $61,54 \%$ & 3,40 \\
\hline $\begin{array}{l}\text { 8. As diferenças culturais são responsáveis pela falha na } \\
\text { comunicação devido às barreiras linguísticas. }\end{array}$ & $67,31 \%$ & 4,00 \\
\hline $\begin{array}{l}\text { 9. A falta de comunicação face a face e dependência da } \\
\text { comunicação eletrônica são responsáveis pela falha na } \\
\text { comunicação. }\end{array}$ & $71,15 \%$ & 4,03 \\
\hline $\begin{array}{l}\text { 10. Falta de percepção das lideranças e uma liderança fraca } \\
\text { são responsáveis pela falha na comunicação. }\end{array}$ & $90,38 \%$ & 4,63 \\
\hline $\begin{array}{l}\text { 11. Não saber ou não utilizar as ferramentas ou meios de } \\
\text { comunicação são responsáveis pela falha na comunicação. }\end{array}$ & $78,85 \%$ & 4,19 \\
\hline $\begin{array}{l}\text { 12. Informações equivocadas e distorcidas causam falhas na } \\
\text { comunicação. }\end{array}$ & $94,23 \%$ & 4,76 \\
\hline $\begin{array}{l}\text { 13. Falta de envio da informação ou envio no momento errado } \\
\text { causam falhas na comunicação. }\end{array}$ & $94,23 \%$ & 4,61 \\
\hline
\end{tabular}

Fonte: Os autores

Na afirmativa 8, a média geral das respostas foi 4,00 . Portanto, os gerentes de projeto concordam que as diferenças culturais são responsáveis pela falha na comunicação devido às barreiras linguísticas, esta afirmação foi apontada nos estudos de Daim et al. (2012), Silva et al. (2015) e Fukuyama et al. (2016). Nota-se que a falta de comunicação face a face e dependência da comunicação eletrônica também são responsáveis pela falha na comunicação, pois a maioria dos pesquisados concordou com esta afirmação, obtendo-se média geral 4,03. Silva et al. (2015) e Daim et al. (2012) também destacaram esta afirmação em seus estudos.

Analisando as afirmativas relacionadas aos itens responsáveis pelas falhas de comunicação relatados nos estudos de Daim et al. (2012) e Fukuyama et al. (2016), a afirmação 10, obteve média geral alta de resposta, 4,63, mostrando a falta de percepção das lideranças e uma liderança fraca, também apontada por Andersson (2016). O estudo mostra outro problema de comunicação em relação as competências e conhecimentos limitados dos gerentes de projetos, representado assim uma liderança fraca. Já a afirmativa 11, alcançou média geral de 4,19, apontando que o não conhecimento ou não utilização das ferramentas ou meios de comunicação também são considerados como barreiras ou falhas na comunicação. Além disso, a afirmativa 12 apontou que os gestores concordam que informações equivocadas e distorcidas causam falhas na comunicação, atingindo média geral 4,76. Tratando da afirmação com relação a falta de envio da informação ou envio no momento errado, mostrou-se que a média geral desta afirmativa resultou o valor 4,61 .

\section{CONCLUSÕES}

Podemos concluir, à vista dos resultados da pesquisa empreendida, obtidos junto aos questionários aplicados aos gerentes de projetos, que existem algumas barreiras ou falhas na comunicação mais evidentes como: 
a falta de feedback aos integrantes da equipe de projetos, ocasionando desmotivação dos funcionários; a falta de confiança entre os membros da equipe; a transmissão de informações equivocadas e distorcidas; a falta de envio da informação ou envio em momentos inoportunos e as competências e conhecimentos limitados dos gerentes de projetos, representando uma liderança fraca. Esses resultados puderam confirmar as barreiras e falhas de comunicação apontadas na literatura.
Por fim, 94,3\% dos pesquisados acreditam que a comunicação é um fator de sucesso do projeto, e 90,4\% afirmam que as falhas de comunicação prejudicam os trabalhos na organização. Sugere-se para um próximo estudo a análise destas barreiras e falhas com possíveis sugestões para a melhoria do processo de comunicação dos projetos das empresas, de forma a facilitar a transmissão de informações reduzindo, consequentemente, os problemas de comunicação que surgem num projeto.

\section{REFERÊNCIAS}

[1] ANDERSSON A. Communication barriers in an interorganizational ERP - project. International Journal of Managing Projects in Business, v. 9, n. 1, p. 214-233, 2016.

AWATI, K. Mapping project dialogues using IBIS: a case study and some reflections. International Journal of Managing Projects in Business, v. 4, n. 3, p. 498-511, 2011.

[3] BADIR, Y. F.; BUCHEL, B.; TUCCI, C. L. A conceptual framework of the impact of NPD Project team and leader empowerment on communication and performance: An Alliance case context. International Journal of Project Management, v. 30, n. 2, p. 914-926, 2012.

[4] DAIM, T.U.; HA, A.; REUTIMAN, S.; HUGHES, B.; PATHAK, U.; BYNUM, W.; BJATLA, A. Exploring the communication breakdown in global virtual teams. International Journal of Project Management, v. 30, n. 2, p. 199-212, 2012.

[5] FUKUYAMA, D.; LOPES, A. P. V. B.; NADAE, J.; CARVALHO, M. M. Barreiras à comunicação e suas influências no desempenho de projeto. Revista Mundo PM, ano 12, n. 67, p. 1019, 2016.

[6] HSU, J. S.; SHIL, S. CHIANG, J. C.; LIU, J. $Y$. The impact of transactive memory systems on IS development teams coordination, communication, and performance. International Journal of Project Management, v. 30, n. 2, p. 329-340, 2012.
JACOBSSON, M. On the importance of liaisons for coordination of projects. International Journal of Managing Projects in Business, v. 4, n. 1 , p. 64-81, 2011.

[8] PMI (PROJECT MANAGEMENT INSTITUTE). Um Guia do Conhecimento em Gerenciamento de Projetos - Guia PMBOK. 5. ed. EUA: PMI, 2013.

[9] PMI. PMSURVEY.ORG 2014. Edition: relatório personalizado. 2014. Disponível em:<http://www.pmsurvey.org/>. Acesso em: 03 de maio 2016.

[10] RYYNANEN, H.; JALKALA, A.; SALMINEN, R. T. Supplier's Internal communication network during the Project sales process. Project Management Journal, v. 44, n. 3, p. 5-20, 2013.

SILVA, M. A. C.; REGO, M. L.; FAILLACE JR., J. E. M. É mais importante comunicar do que fazer: como é feita e percebida a comunicação nos projetos segundo o gerente de projetos brasileiro. Revista de Gestão e Projetos, v. 6, n. 2, p. 16-26, 2015.

[12] VARGAS, R. Gerenciamento de projetos: estabelecendo diferenciais competitivos. $7^{\mathfrak{a}}$ edição, Rio de Janeiro, Ed. Brasport, 2009.

[13] ZIEK, P.; ANDERSON, J. D. Communication, dialogue and project management. International Journal of Managing Projects in Business, v. 8, n. 4, p. 788-803, 2015. 


\section{Bapítulo 8}

\section{EVIDENCIAÇÃO DAS INOVAÇÕEES REALIZADAS PELAS AGROINDUSTRIAS LISTADAS NA ABIOVE}

\section{Pablo de Lima}

Fernanda Mosseline Josende Coan

Marcelo Elias dos Santos

Resumo: O objetivo desta pesquisa foi identificar as características das inovações presentes nos relatórios da administração - RAs elaborados por agroindústrias do setor de processamento de soja, listadas na ABIOVE. Os dados foram coletados nos RAs de 8 empresas, no período de 2011 a 2014, e foram verificados pela análise de conteúdo com base em tais documentos. As inovações organizacionais foram as que tiveram maior expressão nos relatórios analisados, sendo o elemento "mudanças implementadas para atender novas estratégias" o mais encontrado. Os resultados obtidos por meio da pesquisa apontam que as empresas de fato se preocupam em evidenciar, nos seus RAs, investimentos direcionados a mudanças ou implementação desses ativos intangíveis tão singulares denominados inovações.

Palavras-chave: Inovação. Relatórios de Administração. ABIOVE. 


\section{INTRODUÇÃO}

Grandes são os grupos de cientistas, acadêmicos, e empresários que têm se dirigido no sentido de elucidar e descrever a terminologia inovação, bem como, suas características que a tornam singular. Esse assunto se tornou tão relevante nas últimas décadas, que discussões e reflexões acerca dele podem ser observadas em diversos lugares. Artigos científicos, sites empresariais, blogs universitários, e relatórios de cunho contábil/administrativo são apenas alguns exemplos de onde se pode encontrá-las.

Mas um questionamento relevante se faz necessário: o porquê da importância que tem sido dada a tal conceito. A resposta pode estar no fato de que a inovação contribui do ponto de vista econômico para a empresa, bem como, possibilita a manutenção e continuidade das suas atividades, frente ao cenário mercadológico de acirrada competição.

Diante disso, o economista e cientista político Joseph Alois Schumpeter, que foi um dos primeiros a escrever sobre $\mathrm{O}$ assunto, argumenta que "a concorrência do produto novo, a nova tecnologia, a nova fonte de abastecimento, o novo tipo de organização não afeta apenas as margens de lucros e os resultados das empresas existentes, mas a sua própria vida (Tidd \& Bessant, 2008, p. 45). No mesmo sentido, Schumpeter relata que os empresários buscam utilizar inovação, seja ela qual for, para obter vantagem estratégica. Descreve também o processo de destruição criativa, onde há uma procura incessante para criar algo novo, que possa consequentemente gerar novas fontes de lucros para as organizações.

$\mathrm{Na}$ busca pela sobrevivência e continuidade de suas operações, as empresas desenvolvem inovações substancialmente importantes, sejam elas de processos, produtos, marketing ou organizacionais. Estas, conforme será explicado no referencial teórico constituem um tipo particular de ativo, que compõe o patrimônio das organizações. Os usuários externos têm acesso a esse gênero de informações principalmente por meio dos relatórios contábeis/administrativos que estão disponíveis ao público. Tendo por base tais argumentos, construiu-se a seguinte questão de pesquisa: quais as características das inovações evidenciadas nos Relatórios da Administração (RAs) elaborados pelas agroindústrias listadas na Associação Brasileira das Indústrias de Óleos Vegetais ABIOVE? Assim, este artigo tem como objetivo identificar as características das inovações presentes nos relatórios da administração elaborados por agroindústrias do setor de processamento de soja.

Esse artigo se faz relevante em função da evidenciação ser um tema de interesse daqueles que fazem uso das informações contábeis, que buscam além de outras coisas, acompanhar as inovações realizadas pelas empresas, pois essas se constituem um "instrumento essencial para aumentar a produtividade e a competitividade das organizações e, dessa forma, melhorar a sua performance, tanto financeira quanto administrativa." (Becker \& Dal Bosco, 2005, p. 09).

O ponto central desse artigo foi o setor de processamento da soja, sendo essa uma das unidades que formam o grande complexo da agricultura brasileira. A escolha desse setor se justifica, por ser ele um dos pilares da economia do país, visto que, "o Brasil é o segundo maior produtor, processador mundial da soja em grão do mundo e o segundo exportador mundial de soja, farelo e óleo, garantindo a ele um papel de grande potencial para o produto. (Batista, Lima \& Silva, 2010).

A escolha da amostra de dados também se faz importante, pois a ABIOVE se constitui numa autoridade no que diz respeito ao processamento de soja no país, e de acordo com as informações expostas em sua página na web, ela

além de representar as indústrias de óleos vegetais e dar suporte aos seus associados, a ABIOVE tem como objetivos cooperar como o governo brasileiro na execução das políticas que regem o setor, promover programas de sustentabilidade da cadeia produtiva, gerar estatísticas e preparar estudos setoriais. ABIOVE (2015).

É possível por meio disso, entender o verdadeiro mérito de tal instituição no cenário agroindustrial brasileiro, sendo que sua atuação no país é de longa data, foi fundada em 11 de junho de 1981, e seus associados são responsáveis por $60 \%$ do volume de processamento de soja do Brasil. (ABIOVE, 2015).

O conteúdo desse artigo está particionado da seguinte maneira: após esta introdução, é 
demonstrado um apanhado teórico acerca do assunto inovação e suas características, ativo intangível e agroindústria. Logo em seguida, é apresentada a metodologia de pesquisa utilizada no estudo em questão, posteriormente, a análise dos resultados obtidos com a coleta dos dados. E por fim, nas considerações finais é exposta a conclusão e contribuição do estudo.

\section{INOVAÇÃO}

A palavra inovação deriva dos termos latinos in e novare e significa fazer algo novo ou renovar. (Bispo et. al., 2010, p. 08). É possível perceber por meio disso que o termo inovação não diz respeito apenas ao desenvolvimento de algo novo, mas abrange também a renovação ou melhoria de algo já existente, nesse sentido Drucker argumenta que "inovação é a habilidade de transformar algo já existente em um recurso que gere riqueza, e qualquer mudança no potencial produtor de riqueza de recursos já existentes constitui inovação." (Drucker, 1987, p. 40).

Uma das obras de maior relevância no que tange o assunto é o Manual de Oslo da Organização para a Cooperação e Desenvolvimento Econômico - OCDE, que descreve inovação como sendo a "implementação de um produto (bem ou serviço) novo ou significativamente melhorado, ou um processo, ou um novo método de marketing, ou um novo método organizacional nas práticas de negócios, na organização do local de trabalho ou nas relações externas." (Manual de Oslo, 2010, p. 55). No mesmo sentido Sáenz \& Garcia Capote (2002) argumentam que a inovação é um processo baseado na integração de conhecimento novos e de outros existentes, que resultam em produtos, processos, sistemas ou serviços, novos ou melhorados.

A inovação para Schumpter é o mecanismo que faz com que as empresas continuem a avançar e progredir no contexto econômico e social em que atuam. (Tidd \& Bessant, 2008). Sendo que, o implemento de novas máquinas agrícolas que ampliam o plantio, o melhoramento genético de oleaginosas que tem por fim aumentar sua resistência frente a pragas, os investimentos em pesquisa e desenvolvimento de novos métodos de produção e distribuição, são exemplos de elementos que atuam no sentido de impulsionar o agronegócio, que é a área de estudo definida.

Fazendo a devida interpretação dos conceitos exibidos, é possível chegar ao entendimento de que inovação trata-se do desenvolvimento e implementação de um novo item ou melhoria de um já existente, de forma que esse se constitua em um elemento único com características próprias e colabore para impulsionar os negócios da empresa.

\subsection{CARACTERÍSTICAS DA INOVAÇÃO}

Toda a inovação possui suas particularidades, por isso se constituem em uma fonte de riqueza tão singular para as organizações, abaixo buscou-se descrever tais caraterísticas das inovações, de forma a facilitar a sua compreensão.

\subsubsection{CLASSIFICAÇÃO DA INOVAÇÃO}

O Manual de Oslo como já mencionado, diferencia ou classifica a inovação em quatro tipos principais, sendo eles a inovação de produto, processo, marketing e organizacional.

Uma inovação de produto é a inserção de um bem ou serviço novo ou significativamente melhorado no que diz respeito a suas características ou usos previstos. Incluem-se melhoramentos significativos em especificações técnicas, componentes e materiais, softwares incorporados, facilidades de uso ou outras características funcionais. Manual de Oslo (2010, p. 23). Exemplos dessa classe seria a introdução de uma nova semente no mercado do agronegócio, a produção de um novo tipo de biodiesel proveniente do processamento da soja, ou criação de uma nova máquina colheitadeira.

A implementação de um método de produção ou distribuição novo ou significativamente melhorado, constitui-se uma inovação de processo. Incluindo-se nessa classe de inovação, mudanças significativas em técnicas, equipamentos e/ou softwares. Manual de Oslo (2010, p. 23). Mudanças nos parâmetros utilizados no processo de fabricação, uso de novos equipamentos para a produzir um produto, ou mesmo mudanças nos procedimentos administrativos, constituem inovação de processo. 
Inserção de um novo método de marketing com mudanças significativas na concepção do produto ou em sua embalagem, no posicionamento do produto, em sua promoção ou na fixação de preços caracteriza uma inovação de marketing. Essa classe está voltada para melhor atender as necessidades dos consumidores, abrindo novos mercados, ou reposicionando o produto de uma empresa no mercado, com o objetivo de aumentar as vendas. Manual de Oslo (2010, p. 23).

Um novo método organizacional nas práticas de negócios da empresa, na organização do seu local de trabalho ou em suas relações externas constituem uma inovação organizacional. Manual de Oslo (2010, p. 24). Novos mecanismos ou técnicas de gestão, bem como, mudanças nas relações interpessoais entre os colaboradores, novas formas de interagir com os consumidores e/ou fornecedores, caracterizam-se como inovação organizacional.

\subsubsection{INTENSIDADE E ABRANGÊNCIA}

O Manual de Inovação, desenvolvido pelo Movimento Brasil Competitivo (MBC), do Ministério da Ciência e Tecnologia, classifica a inovação quanto à intensidade e abrangência.

Quanto à intensidade ela pode ser (Mattos et. al., 2008):

Inovação incremental - Quando existe melhoria no que se faz e/ou aperfeiçoamento do modo como se faz, por acrescentar novos materiais, ou desenhos ou embalagens que tornam mais práticos produtos ou processos já anteriormente existentes, ou ainda acrescentando utilidades diferenciadas ou melhoras evidentes que os tornam mais desejados pelos seus clientes/consumidores e portanto mais competitivos;

Inovação radical - Quando as novas ideias resultam em produtos ou processos totalmente novos, que antes não existiam no mercado; as inovações radicais são capazes de gerar mudanças revolucionárias também, quando alcançam um nível relativamente elevado de intensidade; como exemplos: abertura de um novo mercado, novo método de tratar comercialmente uma commodity ou novo método de transporte, desenvolvimento de novas fontes de provisão para matériasprimas;

Inovação revolucionária - Quando os novos produtos têm um impacto tão grande sobre o sistema produtivo que podem tornar obsoletas as bases tecnológicas existentes, criar novos mercados e até alterar o comportamento da sociedade. Exemplos de inovação tecnológica revolucionária a telefonia celular, os computadores pessoais e a internet.

No que se refere à abrangência ou alcance da inovação, ela pode ocorrer das seguintes formas (Mattos et. al., 2008):

a) inovação para a empresa - Quando a novidade implementada está limitada ao âmbito da empresa, mesmo que as mudanças já existam em outras empresas ou instituições, ou ainda que utilize conhecimentos técnicos já dominados e difundidos em outros lugares ou empresas;

b) inovação para o mercado - Quando a empresa é a primeira a introduzir a inovação no seu mercado, seja esse regional ou setorial;

c) inovação para o mundo - quando os resultados das mudanças são introduzidos pela primeira vez em todos os mercados, nacionais e internacionais, no mundo todo, ou seja, não eram praticadas por outras empresas no país ou no exterior.

A seguir tem-se uma figura que resume bem as características da inovação. 
Figura 1 - Características da inovação

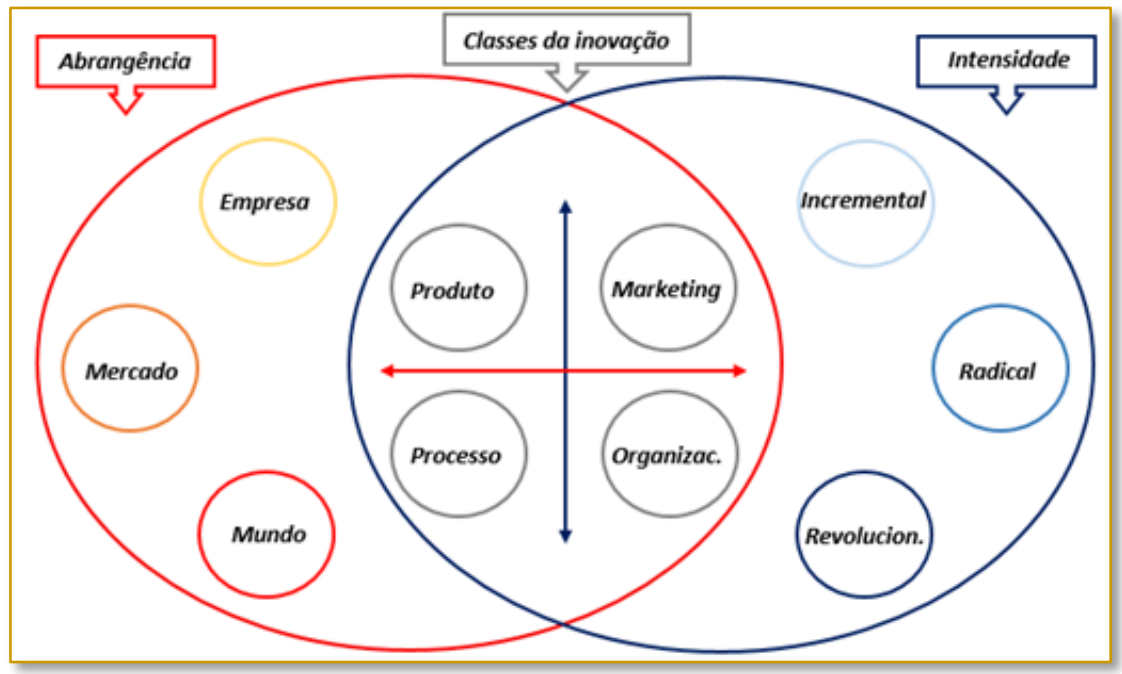

Fonte: Elaborada pelo autor

Por meio deste diagrama é possível entender como se caracteriza uma inovação, de forma que, dentro de cada quadrante do círculo central está posicionada uma espécie de inovação, que terá um respectivo grau de abrangência e intensidade, sendo representados nos círculos convergentes.

Uma inovação pode possuir tanto uma característica quanto outra, ou seja, ela pode ser uma inovação organizacional no que tange sua classificação, inovação para a empresa em face da sua abrangência, e incremental no que se refere a sua intensidade. Para exemplificar, é possível imaginar uma indústria, que atue em um determinado ramo da economia, e que ela desenvolva e disponibilize ao mercado um produto que não fabricava antes, portanto, novo. E que esse produto seja tão bem aceito pelos consumidores, que ao decorrer do tempo, outras indústrias que operam no mesmo seguimento passem a produzi-lo também, de forma a garantir sua fatia nesse mercado.

Analisando tal contexto essa inovação se caracterizaria da seguinte forma: inovação de produto quanto a sua classificação, inovação para o mercado no que tange a sua abrangência, pois as outras empresas concorrentes, percebendo o sucesso de sua medida inovadora, também incorporaram o produto a sua matriz produtiva, e radical no que diz respeito a sua intensidade, pois a organização criou um novo produto, tendo particularidades que não havia em nenhum outro.
Através da explanação acerca dos elementos que constituem a característica de uma inovação, bem como por meio do exemplo apresentado, pode-se compreender como se específica esse ativo tão singular. Sendo que, conhecer a natureza de uma inovação se faz importante para entender como essa atua no ambiente em que foi desenvolvida, e também contribui no processo de identificação do seu valor.

\subsection{INOVAÇÃO COMO ATIVO INTANGÍVEL}

Conforme Drucker (1995), está surgindo uma nova sociedade, onde, apesar dos fatores tradicionais - terra, capital e trabalho - não terem desaparecido, eles se tornaram secundários e o conhecimento parece ter adquirido o status de principal recurso econômico, tornando-se o grande diferencial competitivo entre pessoas, empresas e até nações. Oliveira e Souza (apud Antunes, 2009, p. 49) acrescenta, afirmando que a criação de riqueza não está mais na alocação de capital, nem de mão de obra, mas sim na capacidade de aplicação do conhecimento agregado ao trabalho, ainda que nenhum dos demais fatores seja dispensável.

Importante destacar que, essa sociedade do conhecimento não diz respeito apenas às grandes corporações de softwares e tecnologias da informação, mas as novas fontes de vantagens competitivas, como capacidade de inovar, criar novos produtos, expandir para novos mercados, e isto pode se estender a todo tipo de empresas, sejam 
elas empresas rurais, prestadoras de serviços, comerciais, indústrias ou mesmo agroindústrias.

É possível se observar em diversas publicações científicas que o conceito de inovação converge com o de ativo intangível, muitas vezes, tanto de forma implícita, quanto explícita. Gomes, Machado \& Vicenti (2012, p. 09) argumentam que "por dedução, infere-se que as inovações realizadas pelas empresas enquadram-se na evidenciação dos ativos intangíveis e se calcam em resultados de estudos de organizações industrias que relacionam estes ativos com inovação."

Considerando a inovação como um ativo intangivel, faz-se relevante conceituar esse. Para Hendriksen e Van Breda (1999, p. 388) "a palavra intangíve/vem do latim tangere, ou tocar. Os bens intangíveis, portanto, são bens que não podem ser tocados, porque não têm corpo. Mas formalmente, diz-se que os ativos intangíveis são incorpóreos."

Outro autor, Kayo (2002, p. 14) argumenta que os ativos intangíveis "podem ser definidos como um conjunto estruturado de conhecimentos, práticas e atitudes da empresa que, interagindo com seus ativos tangíveis, contribui para a formação do valor das empresas."

Os ativos intangíveis não possuem, portanto, existência física, mas esses têm grande importância na composição dos ativos totais da organização, pois muitos intangíveis estão incrustados em ativos tangíveis, como as marcas dos carros, melhoramento genético de uma planta, sistemas e os computadores, designer inovador de um produto, por exemplo. Sendo que, atualmente o que produz mais valor às empresas é a interação entre tangíveis e intangíveis. Nesse sentido, Famá \& Perez (apud Boulton, Libert \& Samek, 2011 , p. 06) argumentam que "as organizações estão criando valor de um modo totalmente novo e diferente, utilizando ativos tangíveis e intangíveis e combinações destes ativos até agora não reconhecidos pelos sistemas contábeis tradicionais." Ainda segundo Teh, Kayo \& Kimura (2008, p. 88), "a inovação é um importante ativo intangível. Ela gera vantagens competitivas sustentáveis que permitem erguer barreiras contra algumas ameaças competitivas."

Esse tipo de ativo está supervalorizado e presente nas empresas, pois conforme Lev (2001) os ativos intangíveis têm ganhado força pela combinação única de dois fenômenos:

a) a intensificação da competição nos negócios gerada pela globalização do comércio, pela desregulamentação de setores-chave da economia, como telecomunicações, eletricidade, transportes e infraestrutura etc.; e

b) o avanço da tecnologia da informação e a consolidação da internet.

Ainda segundo Lev (2001), "estes dois fenômenos, um político e econômico e o outro tecnológico, têm afetado dramaticamente a estrutura e estratégia das empresas e elevado os intangíveis à categoria de maior direcionador de valor das empresas nos países desenvolvidos."

Isso pode ser observado também nos países emergentes como o Brasil que em função do próprio processo de globalização tem sofrido essas alterações no seu cenário econômico. Portanto os ativos intangíveis têm tido uma expressiva valorização também nas empresas brasileiras, sendo elas dos mais variados ramos e modelos.

Nesse tocante Famá \& Perez (2011, p. 04), argumentam que:

A crescente competição entre as empresas tem elevado a importância estratégica dos ativos intangíveis como fator de diferenciação entre empresas, proporcionando vantagens competitivas aos seus detentores para enfrentar a concorrência e se sobressair em seus mercados de atuação, pois os ativos tangíveis como fábricas ou equipamentos, por exemplo, não seriam mais os responsáveis pela maior parte da geração de valor em uma empresa, já que em um ambiente competitivo, eles poderiam ser rapidamente reproduzidos ou com facilidade se tornariam obsoletos. Ativos intangíveis como tecnologia, processos de fabricação, patentes, redes de distribuição ou marcas seriam os grandes responsáveis pela geração de valor.

Todo o atual cenário econômico nacional e internacional tem forçado as organizações a buscar alternativas a fim de conseguir sobreviver e continuar competitivas. Frente a isto, destaca Oliveira e Souza (2009, p. 51) que a "inovação contínua, principalmente decorrente de investimentos em capital 
humano e em pesquisa e desenvolvimento (ativos intangíveis), será uma das únicas alternativas para assegurar sucesso e liderança, mesmo nas indústrias tradicionais."

Em função disso é possível compreender que os ativos intangíveis têm ganhado cada vez mais importância estratégica dentro do ambiente empresarial, pois "a criação de marcas mundiais, o registro de patentes, sólidas redes de relacionamento, investimentos em equipes bem treinadas e canais de distribuição, por exemplo, são ativos intangíveis com características únicas, que diferenciam empresas, produtos e serviços, trazendo vantagens competitivas muito difíceis de serem eliminadas." Famá \& Perez (2011, p. 06).

No setor econômico, foco deste estudo, esses ativos são também importantes pois permitem que as indústrias processadoras de soja que se mantenham alinhadas as tendências e exigências de mercado. O próximo item do texto mostrará o conceito de agroindústrias, bem como o atual cenário econômico da soja no Brasil.

\subsection{AGROINDÚSTRIAS E SOJA DENTRO DO COMPLEXO AGROPECUÁRIO BRASILEIRO}

O conceito de agroindústria surgiu no Brasil com o início do processo de modernização e industrialização da produção agropecuária ocorrida no país em meados de 1950. Em relação a isso, Pereira (2010, p. 05) argumenta que a "agroindústria faz parte do agronegócio, sendo basicamente o setor que transforma ou processa matérias-primas agropecuárias em produtos elaborados, adicionando valor ao produto."

A mesma terminologia é descrita de outra maneira pelo IBGE (2006, p. 31), que define agroindústria como sendo

o conjunto das atividades de transformação e beneficiamento de produtos agropecuários de origem animal ou vegetal, que foram realizadas em instalações próprias, comunitárias ou de terceiros, a partir de matéria-prima produzida no próprio estabelecimento agropecuário ou adquirida de outros produtores, desde que a destinação final do produto tivesse sido dada pelo produtor.

Considerando que a agroindústria é uma das unidades que constituem o grande complexo agropecuário brasileiro, se faz importante destacar uma de suas principais matérias primas, o grão, denominado soja.

No que diz respeito a tal oleaginosa, Brum et. al. (2005, p. 07) defendem que "a soja foi uma das principais responsáveis pela introdução do conceito de agronegócio no país, não só pelo volume físico e financeiro envolvido, mas também pela necessidade da visão empresarial de administração da atividade por parte dos produtores, fornecedores de insumos, processadores de matéria-prima e negociantes".

A participação econômica da soja assumiu funções importantes no panorama agrícola brasileiro ao influenciar questionamentos e decisões sobre cadeias produtivas, infraestrutura, agroindústria, pesquisas e desenvolvimento de tecnologias. Em conformidade a isso, "ela pode ser confundida com o próprio processo de modernização da agricultura brasileira, justamente por sua expansão ser responsável por numerosos novos processos que se desenvolveram." Brum et. al. (2005).

Por meio de dados estatísticos, é possível perceber que o agronegócio brasileiro nos últimos 35 anos, tem-se comportado como um sistema produtivo altamente eficiente e competitivo. Tem tido uma expressiva participação no PIB - Produto Interno Bruto, representando $21,78 \%$ desse índice, em 2010, e 22,74\% em 2011 (CEPEA, 2012), e no ajuste da balança comercial do Brasil, conforme (CRIBB, 2014).

A soja, como já falado anteriormente, tem um papel importante nesse desenvolvimento da economia brasileira. Em 2011, foram movimentados cerca de 24 bilhões de dólares apenas nas exportações de soja, farelo e óleo. A sojicultora brasileira gera 1,5 milhões de empregos em 17 estados do país (ABIOVE, 2014). Frente a isso, vários pesquisadores de campos científicos específicos argumentam que esses resultados estão relacionados entre outros motivos, ao fato do setor estar passando por um processo de modernização, que visa o aumento da competitividade e o fomento da economia, aumentando a produção e a exportação. Nesse sentido, Tavares et. al. (2012, p. 02) apud Silva (1990) afirma que "o progresso tecnológico vem sofrendo modificações substanciais. Decorrem do emprego de novas formas de produção e, principalmente, da crescente adoção de 
técnicas oriundas do processo de inovação tecnológica."

Não apenas as inovações de cunho tecnológico, mas também muitas outras de diversas naturezas, estão presentes na agricultura, de modo que, são determinantes para a continuidade do desempenho econômico hoje, existente nesse filo do mercado brasileiro. De acordo com dados da ABIOVE (2014) "O crescimento dos setores envolvidos com a soja por meio de investimentos em tecnologias, novas áreas agrícolas e indústrias de processamento de grãos e refino de óleos tem promovido resultados positivos".

E os bons resultados tendem a continuar se expressando nos próximos anos conforme os dados do Ministério da Agricultura e Pecuária - MAPA; as exportações de soja em grão projetadas para 2023/2024 são de 65,2 milhões de toneladas, representam um aumento de 19,9 milhões de toneladas em relação a quantidade exportada pelo Brasil em 2013/2014. A variação prevista em 2024 relativamente a 2013/2014 é de um aumento na quantidade exportada de soja grão da ordem de $44 \%$.

Em relação ao farelo e o óleo de soja, a produção de farelo deve aumentar $25,1 \%$ e a de óleo $25,9 \%$, enquanto que, as exportações de farelo devem aumentar 15,6\% entre 2014 e 2024 e as de óleo 18,4\%, MAPA (2014). Por meio das informações apresentadas e da argumentação desenvolvida, é possível ter a percepção do impacto econômico que as atividades relacionadas ao agronegócio têm no país. Assim como refletir acerca dos elementos que estimulam o crescimento desse segmento econômico, nesse caso foi dada ênfase a inovação, mas não se pode desconsiderar a existência e relevância de outros fatores.

\subsection{EVIDENCIAÇÃO VOLUNTÁRIA VERSUS OBRIGATORIEDADE LEGAL}

Entende-se evidenciação por "demonstração da situação econômico-financeira e patrimonial de uma empresa, realizada com base nas informações advindas dos registros contábeis, seja através das demonstrações obrigatórias de publicação, seja através dos mais variados tipos de relatórios emitidos pelos contabilistas. Nunes (2010, p. 03). Nesse tocante a referida terminologia diz respeito ao processo em que as organizações fazem prestação de contas das suas atividades para todos os interessados.

Portanto, periodicamente, as organizações se reportam aos seus usuários internos ou externos, com o objetivo de sanar suas necessidades de informações de caráter administrativo e contábil. Tais informações "são fornecidas através de um conjunto de peças divulgadas, abrangendo: o relatório da administração, as demonstrações financeiras e suas notas explicativas, e o parecer dos auditores independentes quando necessário. Nunes (2010, p. 09).

A divulgação dos ativos intangíveis nas demonstrações contábeis se legalizou por meio da Lei no $11.638 / 2007$ de forma compulsória. Em 2008, o Pronunciamento Técnico CPC 04, torna obrigatória a inclusão de informações contábeis dos ativos intangíveis. Nesse sentido, uma vez que as inovações são consideradas ativos intangíveis, a evidenciação dessas está amparada por lei.

Porém a legislação vigente obriga apenas a divulgação da inovação implementada e o valor monetário desse investimento, não sendo necessária a descrição pormenorizada nos demonstrativos contábeis ou em notas explicativas. O relatório da administração nesse contexto se constitui num "importante complemento das demonstrações contábeis divulgadas pela empresa, uma vez que fornece informações adicionais aos usuários externos, analisando atividades passadas, que podem ser indicadores de tendências futuras." Nunes (2010, p. 11).

Os dados que não são englobados pelos demonstrativos contábeis ou por suas notas explicativas, geralmente estão dispostos nos relatórios da administração, que funcionam basicamente como documentos auxiliares ao processo de divulgação de informações.

De forma sintética, a obediência a legislação vigente está relacionada com o fato de que as organizações temem as medidas punitivas pelo não cumprimento de tais normas, e portanto evidenciam as inovações simplesmente pela necessidade de atender a lei. Quando as empresas contextualizam em seus relatórios contábeis/administrativos as inovações, de forma a descrevê-las minuciosamente desde seu projeto até sua implementação, não apenas com objetivo de acatar a lei, mas sim com o intuito de se 
destacar em relação a outras empresas, ou mesmo conseguir a atenção de usuários externos, nesse caso a empresa se propôs a evidenciar voluntariamente as inovações. A legislação pertinente, ou seja, a obrigatoriedade legal, exige que as empresas divulguem de forma genérica os ativos intangíveis, mas o fato delas se preocuparem em contextualizar esses ativos constitui evidenciação voluntária.

\section{METODOLOGIA}

Esta pesquisa teve como objetivo identificar as características das inovações evidenciadas nos Relatórios da Administração (RAs) elaborados pelas agroindústrias listadas na ABIOVE. Em função disso o estudo se configura como qualitativo em relação a abordagem, e descritivo no que diz respeito aos procedimentos.

A pesquisa qualitativa apresenta significados distintos no campo das ciências sociais, e conforme argumenta Neves apud (Maanen 1996, p. 01) tal modelo de pesquisa "compreende um conjunto de diferentes técnicas interpretativas que visam a descrever e a decodificar os componentes de um sistema complexo de significados". Esse conceito se encaixa corretamente na pesquisa desenvolvida, pois ela buscou traçar as características inerentes as inovações presentes nos RAs elaborados pelas agroindústrias listadas na ABIOVE. Bem como, o seu referencial teórico se dirigiu no sentido de tornar mais clara a compreensão desse importante ativo intangível, a inovação.

No tocante aos procedimentos, Gil (2008, p. 22) alega que "as pesquisas descritivas possuem como objetivo a descrição das características de uma população, fenômeno ou uma experiência, bem como, o estabelecimento de relações entre variáveis". Isso está de acordo com o objetivo traçado, uma vez que, o estudo limitou-se a caracterizar as inovações divulgadas pelas empresas escolhidas nos seus RAs, ou seja, inovações que a organizações reconhecem existir em seu ambiente (interno e externo), ficando a cabo dessa pesquisa apenas descrevê-las e criar relações entre suas características.

Por fundamentar-se nos RAs das empresas para a coleta dos dados, tem ela característica de pesquisa documental. Tal formato de pesquisa leva em consideração a natureza das fontes, "pois esta forma vale-se de materiais que não receberam ainda um tratamento analítico. Além de analisar os documentos de primeira mão, existem também aqueles que já foram processados, mas podem receber outras interpretações, como relatórios de empresas, tabelas, etc." Gil (2008, p. 28), neste estudo, conforme já comentado, usou-se os RAs.

\subsection{COLETA E ANÁLISE DOS DADOS}

O estudo é constituído por 8 empresas do setor econômico de processamento de soja, especificamente para a produção de óleo vegetal e alimentos diversos listadas na Associação Brasileira das Indústrias de Óleos Vegetais - ABIOVE. No quadro 1 estão apresentadas as agroindústrias objeto desse estudo.

Quadro 1 - Agroindústrias processadoras de soja

\begin{tabular}{|c|c|c|c|c|c|}
\hline LOGOTIPO & $\mathbf{N}^{\circ}$ & EMPRESA & LOGOTIPO & $\mathbf{N}^{\circ}$ & EMPRESA \\
\hline & 01 & $\begin{array}{l}\text { Archer Daniels-Midland } \\
\text { Company S/A }\end{array}$ & Cargll & 05 & Cargill Agrícola S/A \\
\hline Algar & 02 & Abc Indústria e Comércio S/A & GFIAGRII & 06 & Fiagril Ltda \\
\hline 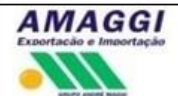 & 03 & $\begin{array}{l}\text { Amaggi Exportação } \quad \text { e } \\
\text { Importação Ltda }\end{array}$ & $\begin{array}{l}\text { Louis Dreyfus } \\
\text { Commodities }\end{array}$ & 07 & $\begin{array}{l}\text { Louis Dreyfus Commodities } \\
\text { Brasil S/A }\end{array}$ \\
\hline BÜ & 04 & Bunge Alimentos S/A & $\begin{array}{l}\text { ble } \\
\text { sup }\end{array}$ & 08 & Noble Brasil S/A \\
\hline
\end{tabular}

Fonte: Associação Brasileira das Indústrias de Óleos Vegetais - ABIOVE. Empresas Listadas. 
Como parâmetro de classificação das inovações definiu-se o Manual de Oslo da Organização para a Cooperação e Desenvolvimento Econômico (OCDE), que propõe quatro tipos fundamentais: produtos, processos, marketing e organizacionais. No que tange a intensidade, e abrangência, utilizou-se o critério proposto pelo Manual de
Inovação, desenvolvido pelo Movimento Brasil Competitivo (MBC), que as descreve da seguinte forma: quanto a intensidade, uma inovação, pode ser incremental, radical ou revolucionária, enquanto que, sua abrangência pode envolver a empresa, o mercado, ou mesmo o mundo.

Quadro 2 - Campos e elementos possibilitam identificar e classificar as inovações

\begin{tabular}{|c|c|}
\hline Tipos de Ir & ntos \\
\hline $\begin{array}{l}\text { Produto/ } \\
\text { Serviço }\end{array}$ & $\begin{array}{l}\checkmark \text { Adição de novos usos, funções ou características em produtos/ serviços } \\
\text { decorrentes de pequenas modificações; } \\
\checkmark \text { Incorporação de softwares em produtos/serviços existentes; } \\
\checkmark \text { Introdução de novos produtos/ serviços; } \\
\checkmark \text { Melhorias em componentes de produtos/ serviços existentes; } \\
\checkmark \text { Melhorias em especificações técnicas de produtos/ serviços; } \\
\checkmark \text { Melhorias em materiais de produtos existentes; } \\
\checkmark \text { Melhorias na oferta de serviços. }\end{array}$ \\
\hline Processo & $\begin{array}{l}\checkmark \text { Adição de novas técnicas, equipamentos, softwares às atividades de } \\
\text { apoio como compras, contabilidade, computação e manutenção; } \\
\checkmark \text { Implementação de um novo método de distribuição de produtos/ } \\
\text { serviços (logística); } \\
\checkmark \text { Implementação de uma nova técnica, equipamentos, softwares de } \\
\text { produção de produtos/ serviços; } \\
\checkmark \text { Melhorias em métodos de produção e distribuição existentes; } \\
\checkmark \text { Melhorias em técnicas, equipamentos, softwares das atividades de apoio } \\
\text { existentes como compras, contabilidade, computação e manutenção; } \\
\checkmark \text { Métodos novos ou melhorados para a criação e provisão de serviços. }\end{array}$ \\
\hline Marketing & $\begin{array}{l}\checkmark \text { Introdução de novos canais de vendas (posicionamento); } \\
\checkmark \text { Introdução de novos símbolos à marca do produto/ serviço que não } \\
\text { sejam atualizações regulares; } \\
\checkmark \text { Introdução de um novo método de fixação de preço a partir das } \\
\text { especificações de produtos e serviços solicitadas pelos clientes; } \\
\checkmark \text { Introdução de um novo sistema de informação personalizado (cliente } \\
\text { VIP); } \\
\checkmark \text { Mudanças na embalagem do produto; } \\
\checkmark \text { Mudanças na fixação de preços para comercialização de produto/ } \\
\text { serviço pela adoção de novas estratégias; } \\
\checkmark \text { Mudanças no design do produto (alterações na forma, aparência, } \\
\text { embalagem ou sabor); } \\
\checkmark \text { Uso de novos conceitos para a apresentação de produtos/ serviços; }\end{array}$ \\
\hline Organiza & $\begin{array}{l}\checkmark \text { Implementação de novas práticas para compartilhar conhecimento e } \\
\text { aprendizado; } \\
\checkmark \text { Nova organização nas relações externas como colaboração, parcerias, } \\
\text { subcontratações de produção, distribuição, recrutamento; } \\
\checkmark \text { Novos métodos de organizar rotinas e procedimentos de trabalho; } \\
\checkmark \text { Novos modelos de gestão - participativa/descentralizada; } \\
\checkmark \text { Primeira implementação de práticas para desenvolvimento dos } \\
\text { empregados; } \\
\checkmark \text { Primeira introdução de gerenciamento para produção geral ou cadeia de } \\
\text { fornecedores, produção enxuta, sistema de gerenciamento de qualidade; } \\
\checkmark \text { Mudanças implementadas para atender novas estratégias; } \\
\checkmark \text { Primeira Integração de diferentes atividades. }\end{array}$ \\
\hline
\end{tabular}

Fonte: Gomes, Vicenti \& Machado, adaptado do Manual de Oslo (2013, p. 33). 
Os dados foram estruturados em categorias conforme o esquema apresentado no quadro 2, e analisados pelo método de análise de conteúdo em documentos que de acordo com Bardin (1979, p. 42) "trata-se de um conjunto de técnicas de análise das comunicações visando obter, por procedimentos, sistemáticos e objetivos de descrição do conteúdo das mensagens, indicadores que permitam a inferência de conhecimentos relativos às condições de produção/recepção destas mensagens."

Após a coleta, os dados, foram organizados em quadros, em conformidade com os campos e elementos de inovações propostos pelo Manual de Oslo (OCDE, 2010).

$\mathrm{Na}$ análise dos dados são apresentadas as inovações em produtos/serviços, processos, marketing, e organizacionais, todas elas evidenciadas nos Relatórios da Administração elaborados pelas agroindústrias listadas na ABIOVE. Para efetuar análise de conteúdo nos RAs, foi necessário fazer o download deles, junto aos sites das respectivas empresas escolhidas.

\section{ESTUDO}

\subsection{CARACTERIZAÇÃO DAS INOVAÇÕES EM PRODUTOS/SERVIÇOS}

Esse tópico aborda as inovações desenvolvidas em produtos ou serviços pelas empresas listadas no quadro $1 \mathrm{em}$ conformidade com a ABIOVE, sendo essas inovações evidenciadas nos seus respectivos RAs, no intervalo de tempo entre 2011 a 2014.

Quadro 3 - Elementos que caracterizam inovações de produtos/serviços.

\begin{tabular}{|c|c|c|c|c|c|c|c|c|c|}
\hline \multicolumn{10}{|c|}{ EMPRESAS PESQUISADAS } \\
\hline $\begin{array}{l}\text { ELEMENTOS } \\
\text { PESQUISADOS }\end{array}$ & 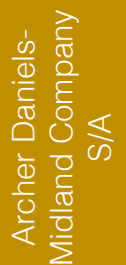 & 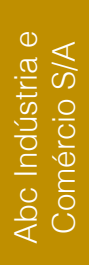 & 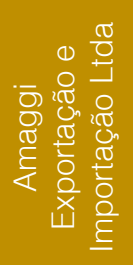 & 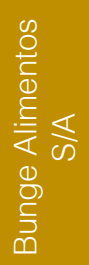 & $\begin{array}{l}\frac{\sigma}{0} \\
\frac{0}{0} \\
\frac{0}{0} \frac{1}{6} \\
\overline{\overline{0}} \\
\frac{\sigma}{\sigma} \\
0\end{array}$ & 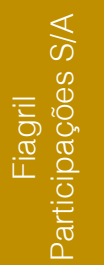 & 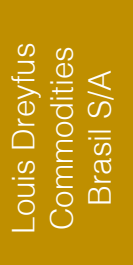 & $\begin{array}{l}\frac{\pi}{\omega} \\
\frac{1}{\overline{0}} \\
\frac{0}{0} \\
\frac{0}{0} \\
\frac{0}{0} \\
\frac{0}{0} \\
z\end{array}$ & Total \\
\hline $\begin{array}{l}\text { Introdução de novos } \\
\text { prod./serviços }\end{array}$ & 2 & 0 & 0 & 9 & 7 & 0 & 2 & 0 & 20 \\
\hline $\begin{array}{l}\text { Melhorias em } \\
\text { componentes }\end{array}$ & 0 & 0 & 0 & 2 & 1 & 0 & 0 & 0 & 3 \\
\hline $\begin{array}{l}\text { Melhorias em } \\
\text { especificações } \\
\text { técnicas }\end{array}$ & 0 & 0 & 1 & 7 & 1 & 0 & 0 & 0 & 9 \\
\hline $\begin{array}{l}\text { Melhorias em } \\
\text { Materiais }\end{array}$ & 0 & 0 & 0 & 0 & 0 & 0 & 0 & 0 & 0 \\
\hline $\begin{array}{l}\text { Melhorias na oferta } \\
\text { de serviços }\end{array}$ & 0 & 0 & 0 & 0 & 0 & 0 & 4 & 0 & 4 \\
\hline $\begin{array}{l}\text { Adição de novos } \\
\text { usos }\end{array}$ & 1 & 0 & 0 & 0 & 0 & 0 & 0 & 0 & 1 \\
\hline $\begin{array}{l}\text { Incorporação de } \\
\text { softwares }\end{array}$ & 0 & 0 & 0 & 0 & 0 & 0 & 0 & 0 & 0 \\
\hline TOTAL & 3 & 0 & 1 & 18 & 9 & 0 & 6 & 0 & 37 \\
\hline
\end{tabular}

Fonte: Adaptado de Gomes, Vicenti \& Machado (2013).

Das empresas pesquisadas, três não evidenciaram nenhum elemento nos seus RAs que possibilitasse a caracterização desse tipo específico de inovação, de forma que, cinco evidenciaram alguns itens. Percebeu-se ainda que o elemento com maior destaque foi a introdução de novos produtos ou serviços no mercado em que essas organizações atuam.

Nota-se que, das empresas que evidenciaram inovações, quatro deixaram claro introdução 
de novos produtos, e outras informaram os elementos: melhorias em especificações técnicas, melhoria na oferta de serviços, melhorias em componentes, e adição de novos usos, visto que, os itens, incorporação de softwares e melhorias em materiais, não foram evidenciados em nenhum dos RAs.

A organização que mais se destacou pelo lançamento de novos produtos, totalizando 9 no espaço de tempo analisado foi a Bunge Alimentos S/A, seguida pela Cargill Agrícola $\mathrm{S} / \mathrm{A}$. Nesse tocante, a segunda empresa afirma que "inovação foi a palavra chave de 2013, com o lançamento de sete novos produtos, a exemplo do Gallo Calçada e Gallo 400ml, lançados no Rio de Janeiro [...]." (CARGILL, 2014, p. 87).

O item melhoria em especificações técnicas, que foi o segundo a ter maior concentração de evidenciações no período, apresentou, no que diz respeito a abrangência, uma inovação para o mundo, sendo essa identificada no RA da Amaggi Exportação e Importação Ltda, que argumenta: "a Amaggi foi a primeira empresa com atuação no agronegócio, em todo o mundo, a receber certificação por produzir soja de acordo com os princípios e critérios da RTRS ${ }^{3}$, no ano de 2011." (AMAGGI, 2013, p. 40).

Em termos gerais pode-se chegar ao entendimento de que algumas empresas, como a Amaggi e a ADM, divulgaram poucas inovações em produtos ou serviços no período pesquisado, em função da própria forma de atuação, que não é direcionada totalmente ao processamento da soja, mas sim a produção e transporte dessa, diferentemente das organizações que se destacaram neste item como a Bunge e Cargill, que têm na produção de alimentos e óleos vegetais a partir da soja seu principal escopo.

O Manual de Oslo, além das inovações em produtos, também aborda inovações em processos, sendo que, no próximo tópico serão expostas as análises acerca dessas inovações, em conformidade com os seus elementos dispostos no referido livro.

\footnotetext{
${ }^{3}$ RTRS (Round Table on Responsible Soy) - é uma iniciativa internacional na qual produtores, comerciantes e processadores de soja trabalham em conjunto com bancos e organizações sociais para assegurar o cultivo de soja sustentável em todo o mundo e a responsabilidade social do setor.
}

Constata-se que de todos os elementos destacados, apenas a Bunge Alimentos S/A e Cargill Agrícola S/A mencionaram inovações em mais de dois itens. Ambas as empresas expuseram introdução de novos produtos, melhorias em componentes, e melhorias em especificações técnicas.

\subsection{CARACTERIZAÇÃO DAS INOVAÇÕES EM PROCESSOS}

Tendo como base os elementos que caracterizam as inovações em processos, buscou-se identificar essas nos relatórios de administração das empresas pesquisadas no intervalo de tempo definido. O quadro 4 apresenta os resultados obtidos.

Nota-se que 88 inovações em processos foram evidenciadas nas empresas analisadas. O elemento implementação de uma nova técnica, equipamentos, softwares de produção foi o que concentrou maior inovações radicais. Ao passo que, os itens adição de novas técnicas, equipamentos, softwares às atividades de apoio, e melhorias em métodos de produção e distribuição existentes foram os que apresentaram maior número de inovações incrementais, conforme demonstrado no trecho a seguir, "[...] a Amaggi Agro também manteve os investimentos no aperfeiçoamento do manejo de culturas e na utilização de insumos agrícolas, permitindo o uso racional de corretivos, fertilizantes e defensivos." (AMAGGI, 2013, p. 26).

A Louis Dreyfus Commodities Brasil S/A foi a que mais evidenciou inovações em processos no período analisado totalizando 27 , com o maior número de vezes o elemento melhorias em métodos de produção e distribuição. Porém a Amaggi foi a que promoveu inovações em todos os seis elementos de inovações em processos.

Os dados indicam também que o elemento menos evidenciado foi a implementação de um novo método de distribuição, isso pode ser explicado pelo fato de que as empresas pesquisadas já exploram uma grande variedade de meios de transporte, e a logística é um componente crucial em sua atuação, portanto desenvolver ou implementar algo nesse sentido é mais raro de ser encontrado em seus relatórios administrativos.

Fazendo uma comparação entre as inovações de produtos e de processos, conclui-se no que tange a primeira classe, que nem todas 
as empresas evidenciaram todos os elementos, enquanto que, na segunda, todas divulgaram ao menos um elemento. Relacionando as duas, é possível ainda perceber que as empresas inovaram mais em processos do que em produtos.

A razão das organizações apresentarem mais inovações em processos do que em produtos no período de análise, pode ser explicada pelo nível de recursos desembolsados e tempo necessários ao desenvolvimento de cada uma. Ou seja, as inovações em produtos por serem geralmente radicais, demandam para sua efetivação altos gastos com pesquisa e desenvolvimento, além de um certo tempo que possibilite o produto estar em condições de ser fabricado e comercializado. Diferente do que ocorre com as inovações em processos, que por terem natureza mais incremental, e estarem relacionadas a melhoria das atividades de produção, distribuição e apoio, são mais comuns e não requerem elevados dispêndios e muito tempo para sua execução.

O próximo tópico abordará os elementos relacionados as inovações em marketing, esses por sua vez, estão dispostos no quadro 5.

Quadro 4 - Elementos que caracterizam inovações em processos.

\begin{tabular}{|c|c|c|c|c|c|c|c|c|c|}
\hline \multicolumn{10}{|c|}{ Empresas Pesquisadas } \\
\hline Elementos Pesquisados & 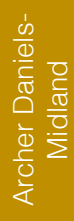 & 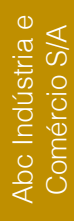 & 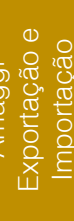 & 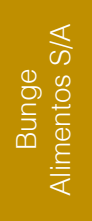 & 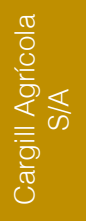 & 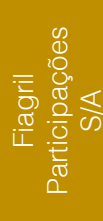 & 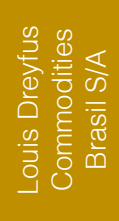 & $\begin{array}{l}\frac{\pi}{\omega} \\
\frac{\pi}{\bar{D}} \\
\frac{\pi}{0} \\
0 \\
\frac{0}{0} \\
\frac{0}{0} \\
\frac{0}{2}\end{array}$ & TOTAL \\
\hline $\begin{array}{l}\text { Melhorias em métodos de } \\
\text { produção e distribuição }\end{array}$ & 2 & 4 & 5 & 4 & 6 & 0 & 17 & 0 & 38 \\
\hline $\begin{array}{l}\text { Melhorias em técnicas, equiptos. } \\
\text { softwares das atividades de apoio }\end{array}$ & 0 & 0 & 1 & 1 & 0 & 0 & 0 & 0 & 2 \\
\hline $\begin{array}{l}\text { Métodos novos ou melhorados } \\
\text { para a criação e provisão de } \\
\text { prod./serviços }\end{array}$ & 0 & 1 & 1 & 0 & 0 & 0 & 0 & 0 & 2 \\
\hline $\begin{array}{l}\text { Adição de novas técnicas, } \\
\text { equiptos, softwares às atividades } \\
\text { de apoio }\end{array}$ & 0 & 3 & 3 & 0 & 0 & 6 & 1 & 0 & 13 \\
\hline $\begin{array}{l}\text { Implementação de uma nova } \\
\text { técnica, equiptos, softwares de } \\
\text { produção }\end{array}$ & 0 & 6 & 3 & 1 & 5 & 0 & 9 & 8 & 32 \\
\hline $\begin{array}{l}\text { Implementação de um novo } \\
\text { método de distrib. }\end{array}$ & 0 & 0 & 1 & 0 & 0 & 0 & 0 & 0 & 1 \\
\hline TOTAL & 2 & 14 & 14 & 6 & 11 & 6 & 27 & 8 & 88 \\
\hline
\end{tabular}

Fonte: Adaptado de Gomes, Vicenti \& Machado (2013).

\subsection{CARACTERIZAÇÃO DAS INOVAÇÕES EM MARKETING}

Buscou-se, nesta seção, identificar as inovações em marketing evidenciadas nos relatórios de administração das organizações analisadas no intervalo de tempo definido. Isso foi feito com base nos elementos que possibilitam a caracterizaram de tais inovações. Os resultados são apresentados no quadro 5. 
Quadro 5 - Elementos que caracterizam inovações em marketing.

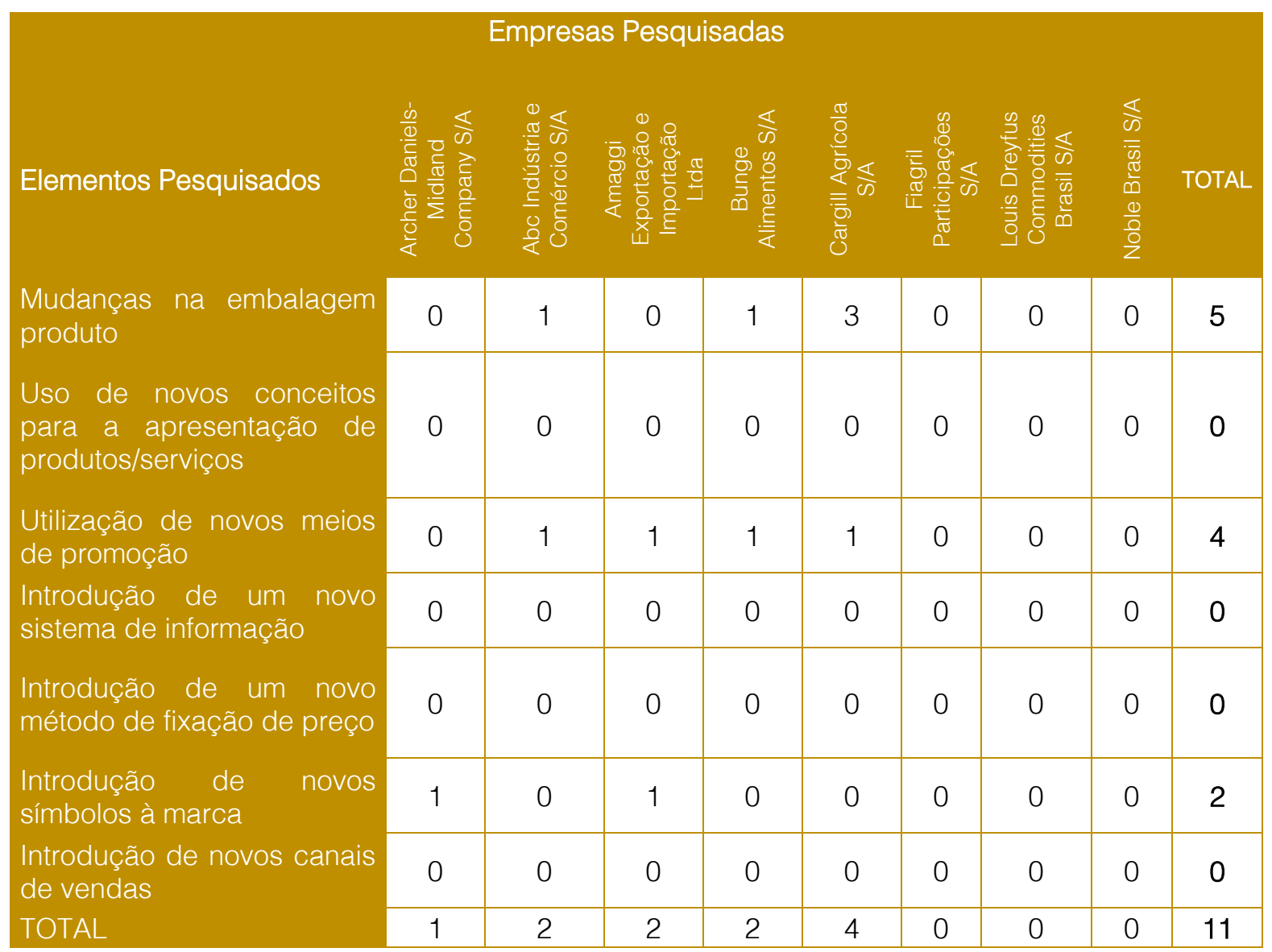

Fonte: Adaptado de Gomes, Vicenti \& Machado (2013).

Por meio dos dados obtidos, é possível compreender que das empresas pesquisadas, cinco evidenciaram inovações em marketing, de forma que, o item com maior quantidade de inovações desse tipo, foi o de mudanças na embalagem do produto.

A empresa que se destacou pela implementação de inovações em marketing foi a Cargill, totalizando 4, tendo se concentrado no mesmo elemento acima mencionado. O trecho a seguir confirma a introdução de uma dessas inovações: "em 2013, quando o produto Elefante completou 70 anos, a Cargill para comemorar, lançou uma edição especial de aniversário, com embalagens estilizadas." (CARGILL, 2013, p. 29).

As organizações Bunge, Amaggi, e Abc desenvolveram o mesmo número de inovações no período de análise, somando 2 inovações cada uma delas. A ADM foi a empresa que deu origem a menor quantidade de inovações em marketing, sendo apenas uma inovação.
O elemento introdução de novos símbolos à marca foi o que teve menor concentração de inovações entre as empresas pesquisadas, de forma que apenas a ADM e a Amaggi pontuaram no referido item. Nesse tocante, é possível por meio do RA da Amaggi identificar o referido elemento, no momento em que a empresa argumenta que, "no início de 2014, o Grupo André Maggi, por questões estratégicas, alterou o nome da companhia para AMAGGI. Também houve alteração no nome de suas áreas de negócios [...]." (AMAGGI, 2013, p. 08).

Em suma, é concebível entender que tal classe de inovação não teve tantas ocorrências no período analisado, levando em conta que inovações em marketing para algumas empresas são mais raras de acontecer, em função do segmento em que atuam, e das políticas internas relacionadas ao atendimento das necessidades dos clientes e das imposições do mercado. Por exemplo, os clientes da empresa Abc não são tão sensíveis às mudanças nas embalagens dos produtos por ela ofertados, quanto o são 
em relação as melhorias em componentes ou em especificações técnicas que possibilitam ganhos de produtividade, isso em consequência de suas necessidades singulares.
As inovações em produtos/serviços, processos e marketing expostas até o momento são importantes, mas outra classe também se faz relevante, a das inovações organizacionais, essas estão expostas no quadro 6.

Quadro 6 - Elementos que caracterizam inovações organizacionais.

\begin{tabular}{|c|c|c|c|c|c|c|c|c|c|}
\hline \multicolumn{10}{|c|}{ Empresas Pesquisadas } \\
\hline Elementos Pesquisados & 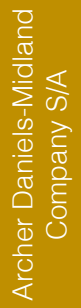 & 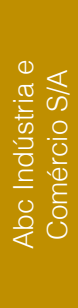 & 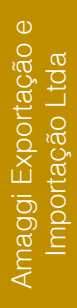 & 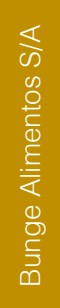 & $\begin{array}{l}\frac{\varangle}{\omega} \\
\frac{\pi}{0} \\
\frac{0}{\overline{0}} \\
\frac{0}{\mathbb{D}} \\
\overline{\overline{0}} \\
\frac{D}{0}\end{array}$ & 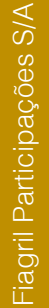 & 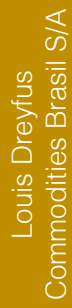 & $\begin{array}{l}\frac{a}{c} \\
\overline{\bar{c}} \\
\frac{0}{0} \\
\frac{0}{0} \\
\frac{0}{0} \\
\frac{0}{0}\end{array}$ & Total \\
\hline $\begin{array}{l}\text { Novos modelos de } \\
\text { gestão }\end{array}$ & 0 & 1 & 7 & 1 & 4 & 0 & 4 & 0 & 17 \\
\hline $\begin{array}{l}\text { Primeira implementação } \\
\text { de treinamentos }\end{array}$ & 0 & 0 & 0 & 0 & 0 & 0 & 0 & 0 & 0 \\
\hline $\begin{array}{l}\text { Primeira introdução de } \\
\text { gerenciamento p/ } \\
\text { produção geral }\end{array}$ & 0 & 0 & 0 & 0 & 0 & 0 & 0 & 0 & 0 \\
\hline $\begin{array}{l}\text { Mudanças } \\
\text { implementadas novas } \\
\text { estratégias }\end{array}$ & 17 & 5 & 6 & 2 & 2 & 1 & 5 & 9 & 47 \\
\hline $\begin{array}{l}\text { Primeira integração de } \\
\text { atividades }\end{array}$ & 0 & 0 & 0 & 0 & 0 & 0 & 0 & 0 & 0 \\
\hline $\begin{array}{l}\text { Novos métodos de } \\
\text { organizar rotinas de } \\
\text { trabalho }\end{array}$ & 0 & 2 & 0 & 2 & 1 & 0 & 1 & 0 & 6 \\
\hline $\begin{array}{l}\text { Nova organização nas } \\
\text { relações externas }\end{array}$ & 0 & 0 & 3 & 2 & 4 & 0 & 2 & 0 & 11 \\
\hline $\begin{array}{l}\text { Implementação de novas } \\
\text { práticas para } \\
\text { compartilhar } \\
\text { conhecimento }\end{array}$ & 0 & 8 & 2 & 19 & 13 & 1 & 2 & 0 & 45 \\
\hline TOTAL & 17 & 16 & 18 & 26 & 24 & 2 & 14 & 9 & 126 \\
\hline
\end{tabular}

Fonte: Adaptado de Gomes, Vicenti \& Machado (2013).

\subsection{CARACTERIZAÇÃO DAS INOVAÇÕES ORGANIZACIONAIS}

Os resultados apresentados no quadro 6 demonstram as inovações organizacionais identificadas nos RAs das empresas pesquisadas com base nos elementos que possibilitam tal ação.

No referido quadro, verifica-se que 126 evidenciações foram expostas pelas empresas pesquisadas. Os elementos mudanças implementadas para atender a novas estratégias, e implementação de novas práticas para compartilhar conhecimento foram os que se destacaram em número de relatos, com 47 e 45 respectivamente.

Dentre as empresas analisadas, as que mais implementaram inovações organizacionais no período considerado, foram a Bunge, Cargill e Amaggi. Visto que, as duas primeiras concentraram-se no item implementação de novas práticas para compartilhar conhecimento, e a terceira no elemento novos modelos de gestão.

Como já mencionado acima, é possível visualizar entre as empresas estudadas, declarações de investimentos direcionados à implementação de novos modelos de gestão, 
o que geralmente diz respeito a aquisição de novos equipamentos, criação de softwares, ou desenvolvimento de programas organizacionais que melhorem ou alterem drasticamente a forma de gerir a empresa como um todo ou apenas parte dela. O seguinte cenário expressa investimentos dessa natureza:

"A partir do investimento de mais de $\mathrm{R} \$ 300$ mil no desenvolvimento de softwares e na aquisição de 150 tabletes equipados com GPS, a Agro promove a gestão automatizada, o que facilita as tomadas de decisão no campo. A tecnologia trouxe ganhos na produtividade e socioambientais e, em razão de iniciativas como essa, a AMAGGI Agro fechou o ano de 2013 com um incremento de $25 \%$ na receita e como destaque no segmento de Produção Agropecuária no Anuário do Agronegócio, da revista Globo Rural." (AMAGGI, 2013, p. 22).

Os dados obtidos indicam ainda, que os itens novos métodos de organizar rotinas de trabalho, e nova organização nas relações externas foram os que tiveram menor ocorrência. E no que diz respeito ao primeiro elemento, é possível identificá-lo na empresa Louis Dreyfus Commodities Brasil S/A no seguinte trecho de seu relatório administrativo: "[...] O avanço foi obtido por meio do melhor uso de nossos ativos, maior produtividade de nossos colaboradores e foco permanente no menor uso de materiais de consumo." (LDC, 2011, p. 67). Esse relato deixa claro o esforço da empresa no sentido de reordenar os fatores que compõem o seu ambiente de trabalho, o que configura-se como uma inovação organizacional.

De maneira abrangente, percebe-se que as inovações organizacionais tiveram um número expressivo de evidenciações durante o período analisado, e em comparação as outras classes pesquisadas foi a que teve maior quantidade de relatos. Isso pode ser explicado pelo fato de que as empresas estudadas estão passando por mudanças em suas estruturas corporativas, seja na forma de administrar unidades específicas de seus negócios, no relacionamento com seus clientes e fornecedores, ou mesmo na maneira de capacitar seu quadro funcional.

No próximo e último quadro, exibe-se um apanhado geral acerca das inovações desenvolvidas pelas empresas estudadas.

\subsection{SÍNTESE DAS INOVAÇÕES CARACTERIZADAS}

O quadro 7 apresenta um resumo dos resultados obtidos por meio da análise dos relatórios administrativos das empresas pesquisadas.

Quadro 7 - Totais das inovações evidenciadas no período analisado

\begin{tabular}{|c|c|c|c|c|c|}
\hline \multirow{2}{*}{ Empresas Pesquisadas } & \multicolumn{5}{|c|}{ Tipos de Inovações Pesquisadas } \\
\hline & Produto & Processo & Marketing & Organizacionais & Total \\
\hline $\begin{array}{ll}\text { Archer } & \text { Daniels-Midland } \\
\text { Company S/A } & \end{array}$ & 3 & 2 & 1 & 17 & 23 \\
\hline Abc Indústria e Comércio S/A & 0 & 14 & 2 & 16 & 32 \\
\hline $\begin{array}{l}\text { Amaggi Exportação } \\
\text { Importação Ltda }\end{array}$ & 1 & 14 & 2 & 18 & 35 \\
\hline Bunge Alimentos S/A & 18 & 6 & 2 & 26 & 52 \\
\hline Cargill Agrícola S/A & 9 & 11 & 4 & 24 & 48 \\
\hline Fiagril Participações S/A & 0 & 6 & 0 & 2 & 8 \\
\hline $\begin{array}{l}\text { Louis Dreyfus Commodities } \\
\text { Brasil S/A }\end{array}$ & 6 & 27 & 0 & 14 & 47 \\
\hline Noble Brasil S/A & 0 & 8 & 0 & 9 & 17 \\
\hline TOTAL & 37 & 88 & 11 & 126 & 262 \\
\hline
\end{tabular}

Fonte: Adaptado de Gomes, Vicenti \& Machado (2013). 
Fazendo uma leitura global dos resultados obtidos, é possível compreender que as empresas que mais evidenciaram inovações no período considerado foram: a Bunge com 52 ponderações, a Cargill com 48, e a Louis Dreyfus Commodities com 47.

Das 262 inovações caracterizadas, 126 se concentraram na classe de inovações organizacionais, sendo essa a que teve maior expressão, 11 na classe de inovações em marketing, 88 na classe inovações em processos, e 37 na classe inovações em produtos.

Quanto a abrangência das inovações, todas as organizações se mantiveram alinhadas apresentando em sua maioria inovações para a própria empresa ou para o mercado em que atuam, visto que, apenas a empresa Amaggi divulgou uma inovação para o mundo no ano de 2011. No que diz respeito a intensidade, as inovações em produtos se mostraram radicais, enquanto que as inovações em processos apresentaram-se incrementais na sua maioria, as inovações em marketing expressaram-se de forma radical, e as inovações organizacionais também tiveram natureza preponderantemente radical.

\section{CONSIDERAÇÕES FINAIS}

Pela análise de conteúdo realizada nos RAs das empresas selecionadas, somado aos demais procedimentos metodológicos, foi possível atingir o objetivo definido neste artigo, que era identificar as características das inovações presentes nos relatórios da administração elaborados por agroindústrias do setor de processamento de soja. Os resultados obtidos por meio da pesquisa apontam que as empresas de fato se preocupam em evidenciar nos seus RAs investimentos direcionados a mudanças ou implementação desses ativos intangíveis tão singulares denominados inovações.

Verificou-se que as inovações que foram relatadas com maior riqueza de detalhes foram as pertencentes a classe de inovações organizacionais, de forma que, em alguns trechos dos RAs eram especificadas até mesmo a importância investida e a finalidade de desenvolver e implementar a inovação. Os elementos mais evidenciados foram de mudanças implementadas para atender novas estratégias e o de implementação de novas práticas para compartilhar conhecimento, este último, sua grande ocorrência está relacionada aos constantes dispêndios de recursos direcionados a programas de treinamentos dos colaborados.

Os relatórios administrativos que superaram os outros em número de pormenores expostos acerca das inovações foram os pertencentes as organizações Cargill, Bunge, Amaggi, e Louis Dreyfus Commodities. Essas empresas possibilitaram a identificação de uma quantidade maior de inovações em função da forma de como expuseram seus elementos inovativos.

Por meio dos RAs analisados pode-se constatar que as organizações pesquisadas evidenciam voluntariamente os detalhes relacionados a esse ativo intangível. Sendo que, tais demonstrativos não se limitam apenas ao que a lei determina, mas fornecem uma gama maior de informações acerca da terminologia. Isso acontece principalmente em função da nova configuração existente no segmento em que essas empresas operam, uma vez que, investimentos dessa natureza têm gerado cada vez mais valor para as entidades, e portanto interessam os usuários das informações provenientes dos documentos pesquisados.

As informações advindas dos relatórios administrativos possibilitaram também, o entendimento de que as empresas, do segmento de processamento de soja, atuam em um mercado extremamente competitivo. $\mathrm{E}$ em termos gerais para garantir sua participação nesse mercado, direcionam seus esforços no sentido de melhorar métodos de produção e distribuição, implementação de novas técnicas, equipamentos, e softwares de produção, isso somado a devida qualificação do seu quadro funcional.

Dentre as dificuldades encontradas ao desenvolver a pesquisa, pode-se citar o fato de que as informações relacionadas aos elementos de inovação estão fragmentadas em diversos locais dos relatórios administrativos, tornando complexa sua exata identificação e caracterização. Em diversas situações as empresas reconhecem terem inovado, e muitas vezes utilizam a terminologia inovação, mas a ausência de contextualização e esclarecimentos relevantes restringem 0 processo de caracterização. Outro obstáculo é a repetição 
das informações ao longo do relatório administrativo, algo que mereceu devida atenção durante a análise efetuada.

Para pesquisas futuras ressalta-se a relevância em se desenvolver estudos nesta área. Assim sendo, sugere-se que esses novos estudos tenham por escopo entender como as inovações surgem, qual a preocupação das organizações em gerir esses ativos intangíveis. Além disso, seriam de muita valia pesquisas que investiguem, se as inovações exercem influência no preço das ações de determinadas empresas, e se essas organizações reconhecem o impacto desse tipo de investimento ao receberem o feedback dos acionistas.

\section{REFERÊNCIAS}

[1] ABIOVE, Associação Brasileira das Indústrias de Óleos Vegetais - Empresas associadas. Disponível em: $<$ http://www.abiove.org.br/site/index.php?page=as sociados\&area $=M y 0 \times L T Q=>$. Acesso em: 07/02/2015

[2] AMAGGI. Relatório de sustentabilidade 2013. Disponível em: < http://amaggi.com.br/> Acesso em: 10/03/2015.

[3] BISPO, Cláudio dos Santos; SOUZA, Diego de Jesus; ARAÚJO, Felipe Pascoal de; CARDOSO, Nayara Holanda; SILVA, Paula Sousa da; JUNIOR, Valmir Rosa dos Santos. Empreendedorismo e Inovação. Disponível em: <http://www.ibes.edu.br/aluno/arquivos/artigo_emp reendorismo_inovacao.pdf $>$. Acesso em: 06/01/2015

[4] CARGILL. Relatório anual 2014. Disponível em: < http://www.cargill.com.br/pt/index.jsp>. Acesso em: 10/03/2015.

[5] DRUCKER, P. Administrando em tempos de grandes mudanças. 2. ed. São Paulo: Pioneira, 1995, p. 230.

[6] DRUCKER, Peter Ferdinand, 1909 Inovação e espírito empreendedor (entrepreneurship): prática e princípios. Tradução de Carlos Malferrari. São Paulo: Cengage Learning, 2008

FAMÁ, Rubens; PEREZ, Monteiro Marcelo. Características Estratégicas dos Ativos Intangíveis e o Desempenho Econômico das Empresas no Brasil. Disponível em: $<$ http://www.ead.fea.usp.br/semead/7semead/pagi nas/artigos\%2Orecebidos/Finan\%E7as/FIN14-

_Caracter\%EDsticas_Estrat\%E9gicas_dos_Ativos.P DF>. Acesso em: 10/12/2014.

[8] GIL, Antônio Carlos. Como elaborar projetos de pesquisa. 5. Ed. São Paulo: Atlas, 2008.
Del Prá Netto; VICENTI, Terezinha. Evidenciação das inovações em Relatórios de Administração de Empresas da Indústria Alimentícia Listadas na BM\&F BOVESPA. Disponivel em: <http://revistagt.fpl.edu.br/get/article/view/446>. Acesso em: 14/02/15.

[10] LDC. Relatório anual 2011. Disponível em: $<$ http://www.ldcom.com.br/default.aspx>. Acesso em: 10/03/2015.

[11] MANUAL DE OSLO: Diretrizes para coleta e interpretação de dados sobre inovação; OECD; 3 ed.; $2010 . \quad$ Disponível em: $<$ http://www.uesc.br/nucleos/nit/manualoslo.pdf>. Acesso em: 08/06/2014.

[12] MAPA - Ministério da agricultura: Projeções 2013/2024. Disponível em: <http://www.agricultura.gov.br/vegetal/culturas/soja >. Acesso em: 21/03/15

[13] NUNES, Marcelo Santos. A evidenciação das informações contábeis: sua importância para o usuário externo. Disponível em: <http://www.unifin.com.br/Content/arquivos/200804 16134816. pdf>. Acesso em: 20/06/2015.

[14] OLIVEIRA E SOUZA, Rodrigo de. Valoração de Ativos Intangíveis: seu papel na transferência de tecnologias e na promoção da inovação tecnológica. Universidade Federal do Rio de Janeiro Escola de Química. 2009. Disponível em: <http://tpqbb.eq.ufrj.br/download/valoracaode-ativos-intangiveis.pdf>. Acesso em: 05/12/2014.

[15] TEH, C.C.; KAYO, E. K.; KIMURA, H.; Marcas, patentes e criação de valor. Revista de Administração Mackenzie, v. 9, n. 1, p. 86-106, 2008. Disponível em: < http://www.spell.org.br/documentos/ver/4082/marc as--patentes-e-criacao-de-valor>. Acesso em: 20/10/14.

[16] TIDD, Joe; BESSANT, John; PAVITT, Keith. Gestão da inovação. Tradução Elizamari Rodrigues Becker...[et.al.] - 3.ed. - Porto Alegre: Bookman, 2008.

[9] GOMES, Giancarlo; MACHADO, Denise 


\section{Bapítulog}

\section{ANÁLISE DA BASE DE ATENDIMENTO DE EMERGÊNCIA E URGÊNCIA NAS UNIDADES PÚBLICAS DE SAÚDE DE CAMPOS DOS GOYTACAZES}

\section{Vaneska Tavares Rangel Prestes}

Maria Eugenia S. S. Vasconcelos

Geórgia Regina Rodrigues Gomes

Resumo: Caracterizada como um direito de todos e um dever do Estado, é notória a crise em que a saúde pública se encontra, com deficiências na estrutura física, nos recursos humanos, na falta de materiais, medicamentos ou ainda de equipamentos. Diante do grande desafio de auxiliar o gestor público municipal na tomada de decisões no âmbito da saúde, o presente artigo apresenta como objetivo principal a obtenção de conhecimento, a partir de um banco de dados dos atendimentos de emergência e urgência em unidades de saúde pública municipal por meio da aplicação de mineração de dados. A partir de um banco de dados fornecido pela Prefeitura Municipal de Campos, contendo 45.911 registros de atendimentos de emergência e urgência na rede municipal no mês de agosto de 2015, foram analisados os dados extraídos através da aplicação do algoritmo SimpleK-means, rendendo bons resultados em cluster, bem como o algoritmo Apriori, cujas associações identificadas pelo sistema servem de auxílio ao gestor municipal nas tomadas de decisão principalmente no que tange a gestão hospitalar e gestão dos recursos públicos. Em conclusão, este trabalho mostra que a mineração de dados pode ser uma ferramenta útil para aplicações nos dados de hospitais e unidades pré-hospitalares, sobretudo auxiliando o gestor municipal nas tomadas de decisão, seja no que se refere à gestão hospitalar ou mesmo na gestão dos recursos públicos destinados à saúde, com o estabelecimento de políticas de melhoria, a fim de minimizar os efeitos negativos na saúde da população.

Palavras-chaves: Saúde Pública; Apriori; SimpleK-Means; Mineração de Dados. 


\section{INTRODUÇÃO}

Segundo Poll, Lunardi e Lunardi Filho (2008), as unidades de saúde podem ser classificadas da seguinte forma: unidades de saúde e atendimento hospitalar podendo ser do tipo privada, pública, filantrópica, previdenciária e estatal.

O que pode ser verificado nos dias atuais é que o sistema de saúde pública apresenta falhas em seus principais programas de saúde assim como no atendimento da população que se depara com hospitais cada vez mais lotados. Rossi (2015), aponta em seu trabalho dados levantados pelo Tribunal de Contas da União (TCU), que 64\% dos hospitais estão sempre lotados e que $6 \%$ dos mesmos nunca ficam cheios e um outro problema: a mão de obra.

Ainda que apresentem problemas, Garlet et al. (2009) relata que os serviços prestados pelas unidades de pronto atendimento e emergência hospitalares são consideradas resolutivas pela ótica do paciente, uma vez que fornecem vários recursos como: exames, consultas, procedimentos, internações e etc.

O serviço de urgência e emergência é considerado por Souza, Paulo e Barros (2009), uma forma de acesso rápido pelos pacientes aos serviços de atendimento de saúde em decorrência da precaridade do atendimento fornecido pelas unidades básicas de saúde.

Devido à importância apresentada sobre a saúde pública, se torna necessário, explorar, analisar e minerar dados provenientes dos atendimentos realizados em unidades de saúde. A mineração de dados conhecida como Data Mining (DM), de acordo com Galvão e Marin (2009), acaba sendo uma alternativa viável para obter conhecimentos a partir de um banco de dados onde é possível buscar relações, associações e regras para relacionar dados que poderão ajudar nas tomadas de decisões assim como aumentar o grau de confiança.

Desta forma, o artigo proposto, tem como base o uso da técnica da mineração em uma base de dados referente ao número de atendimentos de emergências e urgências realizados em todas as unidades públicas de saúde no município de Campos dos Goytacazes no mês de agosto de 2015.

\section{SAÚDE PÚBLICA}

Considerada como um grande desafio a ser vencido e como uma grande preocupação pelos brasileiros, a saúde, é um dever do Estado assim como, um direito de todos, segundo a Constituição Federal de 1988. O Sistema Único de Saúde (SUS) teve sua qualidade atestada através de um levantamento realizado pelo Ministério da Saúde onde em uma escala que varia entre 0 a 10 , a média obtida foi de 5,5 .

A saúde pública do Brasil vive atualmente uma crise onde é notável a deficiência na estrutura física, deficiência de mão de obra e ainda pouco ou falta de materiais, medicamentos e equipamentos.

Antes da década de 1980, os serviços de emergência funcionavam com profissionais não capacitados com treinamentos específicos para atendimento às vítimas de trauma. No Brasil, a década de 80 foi marcada pelo início da especialização dos profissionais que atuam no atendimento de emergência (SOUZA, PAULO e BARROS, 2009).

A unidade de emergência é uma área que precisa de atenção pela sua diversidade de condições e situações além de ser um ambiente de velocidade e desafios que necessita de profissionais capacitados para atuarem de forma habilidosa, ágil e humanizada (DAL PAI \& LAUTERT, 2005).

Poll, Lunardi e Lunardi Filho (2008), definem emergência como condições de agravo à saúde que acarreta um risco de vida iminente precisando dessa forma de um rápido atendimento médico. Já urgência é considerada como uma piora da saúde de forma não prevista que pode ter ou não riscos potenciais de vida.

Para Garlet et al. (2009) a atenção às urgências ainda é preocupante uma vez que esse tipo de atendimento provoca uma superlotação das salas de atendimento comprometendo a qualidade do serviço prestado

Diante dos fatos expostos, faz-se necessário discussões mais aprofundadas acerca dos serviços de urgência e emergência de unidades de saúde. 


\section{KDD E MINERAÇÃO DE DADOS}

Muitos pesquisadores tratam 0 termo "mineração de dados" como um sinônimo de $K D D$, porém, trata-se de uma etapa desse processo (STEINER, 2006). O KDD é composto de cinco etapas: seleção dos dados; pré-processamento e limpeza dos dados; transformação dos dados; Mineração de Dados (Data Mining); e interpretação e avaliação dos resultados (FAYYAD, 1996).

O primeiro passo de extração de dados é geralmente a seleção de dados - extrair os dados relevantes para um banco de dados. Já no pré-processamento, os dados, conforme disponibilizados, são preparados para as etapas seguintes. Ocorre a conversão dos dados, em uma forma bruta, para um formato mais apropriado, por meio da limpeza, transformação e remoção de dados ruidosos, por exemplo. A finalidade da limpeza de dados é para remover o ruído e informações irrelevantes para fora do conjunto de dados. A finalidade da transformação de dados é modificar os dados de origem em diferentes formatos em termos de tipos e valores de dados. Em seguida, ocorre a aplicação de técnicas de mineração de dados, com a possibilidade da execução de diversos tipos de algoritmos sobre um conjunto de dados, com o objetivo de produzir um modelo preditivo ou descritivo. No pós-processamento, o modelo obtido é analisado, avaliado e apresentado de maneira compreensível (WITEN, 2011).

Destarte, o software de Mineração de dados é uma ferramenta analítica para análise de dados. Permite usuários analisar dados de muitas dimensões diferentes ou ângulos, categorizá-lo, e resumir as relações identificadas. A mineração de dados é o processo de encontrar correlações ou padrões, entre dezenas de campos em grandes bases de dados relacionais.

Parâmetros de mineração de dados incluem: associação, à procura de padrões em que um evento é conectado a um outro evento; sequência ou análise de trilha, procura de padrões em que um evento leva a outra mais tarde evento; classificação, à procura de novos padrões; clustering, encontrar e documentar visualmente grupos de fatos não anteriormente conhecidos; forecasting, descobrindo padrões nos dados que pode levar a previsões razoáveis sobre o futuro.

Assim, enquanto o KDD refere-se a todo processo de descoberta de conhecimento útil em bases de dados, a Data Mining, principal etapa do KDD, refere-se à aplicação de técnicas de forma a extrair modelos dos dados (STEINER, 2006).

A Figura 1 demonstra as etapas do processo de $K D D$, dentro do contexto do processo de descoberta de conhecimento, segundo Fayyad et. al (1996).

Figura 1: Etapas do processo KDD

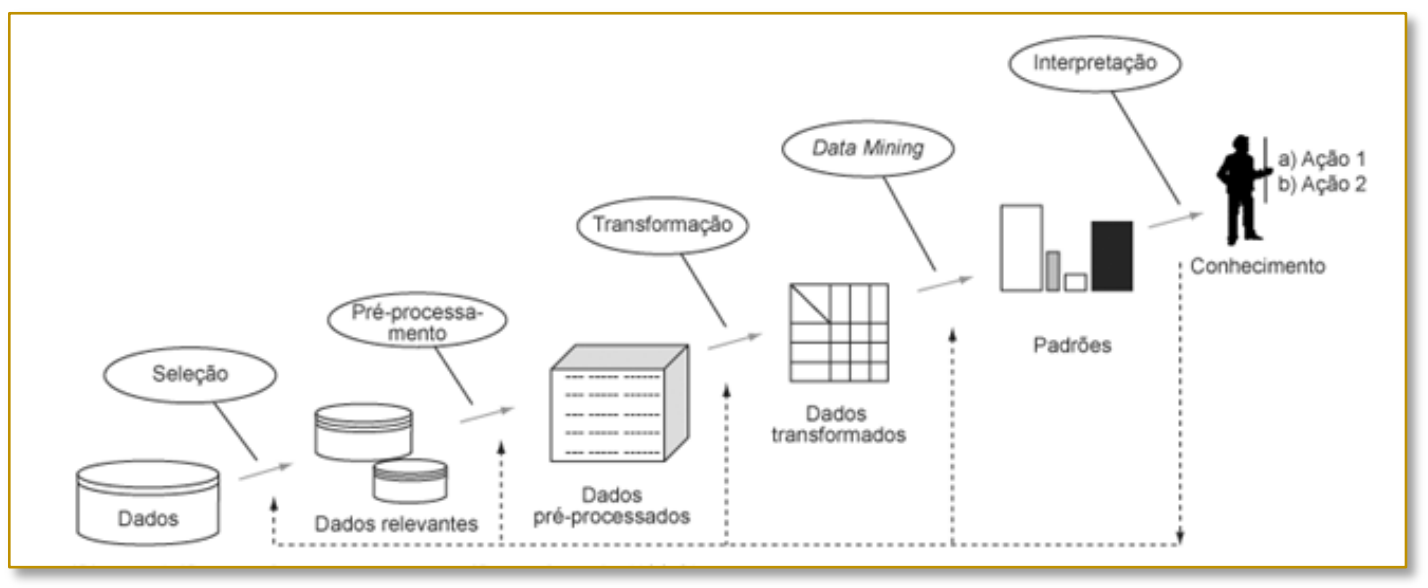

Fonte: Fayyad et. Al (1996)

O trabalho aqui apresentado analisa os dados extraídos através da aplicação de regras de associação e clusterização - algoritmos de mineração usando WEKA como ferramenta de mineração de dados. O algoritmo SimpleKMeans rendeu bons resultados em cluster. As associações identificadas pelo sistema, que são interpretados a partir do ponto de vista do 
desenvolvimento também são significativas do ponto de vista de gestão pública.

\subsection{REGRA DE ASSOCIAÇÃO}

A associação gera regras que descrevem os padrões mais relevantes presentes nos dados. As regras são compostas por precedentes e consequentes, ou seja, a regra contém no precedente um subconjunto de atributos e seus valores e no consequente um subconjunto de atributos que decorrem do precedente (KHATTAK, 2010).

As regras servem para diversas utilidades, dentre elas a descoberta de padrões de comportamento, aplicações em marketing e desenvolvimento de novos produtos. O exemplo clássico é a associação entre a compra de cerveja e fraldas (KHATTAK, 2010).

O algoritmo Apriori é um exemplo de ferramenta que implementa a tarefa de descoberta de associações. O conjunto de dados que iremos utilizar será o saude.arff. Este conjunto de dados descreve um conjunto de atendimentos ocorridos no mês de agosto de 2015 em todas as unidades públicas de saúde no município de Campos dos Goytacazes.

\subsection{REGRA DE CLUSTERIZAÇÃO}

O algoritmo de agrupamento utiliza técnicas iterativas para casos de grupos em um conjunto de dados em clusters com semelhantes características. Estes grupos são úteis para explorar dados, identificando anomalias nos dados, e criar previsões.

Por meio do agrupamento de dados os clusters são definidos baseados em medidas de similaridade ou modelos probabilísticos. Promove a associação de um item a uma ou várias classes categóricas em que as classes são determinadas pelos dados, diversamente da classificação em que as classes são prédefinidas. A análise de cluster tem como objetivo verificar a existência de diferentes grupos dentro de um determinado conjunto de dados, e em caso de sua existência, determinar quais são eles (SFERRA \& CORRÊA, 2003).

K-Means é o algoritmo utilizado para o agrupamento de dados com base no(s) parâmetro(s) especificado(s).Modelos de clusterização identificam relacionamentos em um conjunto de dados que pode não derivar logicamente através ocasional observação (KHATTAK, 2010).

\section{METODOLOGIA}

A metodologia proposta neste trabalho, utilizando os dados das unidades públicas de saúde do município de Campos dos Goytacazes, no mês agosto de 2015, visa criar uma associação entre as taxas de urgência e emergência e demais atributos conforme especificados no Quadro 1:

Quadro 1: Atributos da base de dados das unidades públicas de saúde

\begin{tabular}{cl|}
\hline Ref & \multicolumn{1}{c|}{ Atributos } \\
1 & Unidade de Saúde \\
2 & Sexo \\
3 & Faixa Etária do Paciente \\
4 & Bairro \\
\hline 5 & Diagnóstico \\
6 & Especialidade Clínica \\
\hline 7 & Tipo de Atendimento \\
\hline 8 & Tipo de Saída \\
\hline
\end{tabular}


Os dados foram disponibilizados pela Prefeitura Municipal de Campos dos Goytacazes através de uma planilha eletrônica com 45911 registros de atendimentos em nove unidades hospitalares municipais: Hospital Ferreira Machado, Hospital Geral de Guarus, Unidade Pré Hospitalar de Guarus, Unidade Pré Hospitalar São José, Unidade Pré Hospitalar de Travessão, Unidade Pré Hospitalar de Farol, Unidade Pré Hospitalar de Ururaí e Unidade Pré Hospitalar Santo Eduardo e Unidade Pré Hospitalar Saldanha Marinho.

As datas de atendimento e de conclusão assim como o nome do paciente não foram levadas em consideração tendo em vista a singularidade desses dados para o trabalho. Da mesma forma o município de residência foi descartado muito embora alguns hospitais como Hospital Ferreira Machado seja referência regional em atendimento à emergência vermelha, não houve registros relevantes quanto atendimentos a pacientes oriundos de outros municípios.

Com relação à Faixa Etária do Paciente foi realizada uma transformação do banco de dados original tendo em vista a impossibilidade do apriori trabalhar com números. Então a idade foi transformada em faixa etária como especificado no Quadro 2.

Quadro 2: Faixa Etária

\begin{tabular}{|l|l|}
\multicolumn{1}{c|}{ Idade } & \multicolumn{1}{c|}{ Faixa Etária } \\
0 a 11 anos & Criança \\
\hline 12 a 18 anos & Adolescente \\
\hline 19 a 59 anos & Adulto \\
\hline 60 anos ou mais & Idosos \\
\hline
\end{tabular}

A etapa de mineração de dados foi realizada com a utilização do software WEKA, que compreende uma coleção de algoritmos de aprendizado de máquina para a realização de tarefas de mineração de dados. Esses algoritmos podem ser executados diretamente sobre um conjunto de dados, ou utilizados dentro do contexto de aplicações escritas em linguagem Java (BOUCKAERT, 2010).

O WEKA contém ferramentas para préprocessamento, tarefas de mineração em classificação, regressão, análise de agrupamentos (clustering), associação e, ainda, mecanismos para visualização de resultados na forma de dados estatísticos e artefatos gráficos, além da possibilidade de ser utilizado no desenvolvimento de novas abordagens ao aprendizado de máquina, considerando que todo pacote de software é open source (código fonte aberto) (HALL et. al., 2009).

\section{RESULTADOS}

Diante dos critérios adotados, foram geradas vinte regras de associação, a partir do algoritmo Apriori, onde destacamos no Quadro 3, as oito mais relevantes. 
Quadro 3: Regras de Associação

\begin{tabular}{|c|c|}
\hline Regras geradas pelo algoritmo apriori & $\begin{array}{l}\text { Coeficiente de } \\
\text { confiança }\end{array}$ \\
\hline $\begin{array}{l}\text { SE Faixa Etária do Paciente=Adulto, Especialidade Clinica=Clinica Medica } \\
\text { ENTÃO Tipo de Atendimento = Urgência }\end{array}$ & $98 \%$ \\
\hline $\begin{array}{l}\text { SE Sexo do Paciente=Feminino, Especialidade Clinica=Clinica Medica } \\
\text { ENTÃO Tipo de Atendimento = Urgência }\end{array}$ & $98 \%$ \\
\hline $\begin{array}{l}\text { SE Especialidade Clinica= Clinica Medica ENTÃO Tipo de Atendimento = } \\
\text { Urgência }\end{array}$ & $98 \%$ \\
\hline SE Sexo do Paciente = Feminino, ENTÂO Tipo de Atendimento = Urgencia & $96 \%$ \\
\hline $\begin{array}{l}\text { SE Sexo do Paciente=Feminino, Faixa Etária do Paciente=Adulto ENTÃO } \\
\text { Tipo de Atendimento=Urgencia }\end{array}$ & $96 \%$ \\
\hline SE Faixa Etária do Paciente=Adulto ENTÂO Tipo de Atendimento=Urgencia & $94 \%$ \\
\hline SE Sexo do Paciente=Masculino ENTÃO Tipo de Atendimento=Urgencia & $93 \%$ \\
\hline $\begin{array}{l}\text { SE Tipo de Saida=A-Alta por Decisao Medica ENTÃO Tipo de } \\
\text { Atendimento=Urgencia }\end{array}$ & $85 \%$ \\
\hline
\end{tabular}

A primeira regra demonstra que se a faixa etária do paciente for adulto e a especialidade for clínica médica então o tipo de atendimento é urgência, ressaltando que esta é considerada uma piora da saúde não prevista que pode ou não ter riscos potenciais à vida.

Já a segunda regra denota que se o sexo for feminino e a especialidade for clínica médica então $O$ atendimento também será de urgência.

Quanto a regra número três destaca-se que se a especialidade for clínica médica consequentemente o tipo de atendimento será de urgência.

Com relação a quarta e a sétima regra verifica-se que o atributo sexo do paciente não foi determinante para especificação da regra uma vez que se o sexo for masculino ou feminino $O$ atendimento também será de urgência.
Considerando as várias modalidades de alta médica, dentre elas, por óbito, por decisão médica, por desistência ou à revelia, a oitava regra demonstra que se o tipo de saída for alta por decisão médica logo o tipo de atendimento é de urgência.

Contudo, verifica-se que não foram geradas regras considerando os atributos unidades de saúde e diagnóstico, o que seria bem mais relevante. Isso se deve ao fato de que em um total de 45911 registros, somente 7511 atendimentos ocorreram no Hospital Ferreira Machado, representando $16,35 \%$ do total aliado a diversidade dos diagnósticos registrados nesta unidade, que é referência regional em emergência vermelha.

Por sua vez, a utilização do algoritmo SimpleK-Means rendeu bons resultados em cluster, onde foi determinado o número máximo de seis agrupamentos para 0 tratamento dos dados em questão conforme é apresentado no Quadro 4. 
Quadro 4: Resultado da aplicação do algoritmo de Clusterização

\begin{tabular}{|c|c|c|c|c|c|}
\hline Attribute & $\begin{array}{c}0 \\
(11797)\end{array}$ & $\begin{array}{c}1 \\
(11670)\end{array}$ & $\begin{array}{c}2 \\
(9086)\end{array}$ & $\begin{array}{c}3 \\
(8475)\end{array}$ & $\begin{array}{c}4 \\
(3541)\end{array}$ \\
\hline Unidade de Saude & $\begin{array}{l}\text { Hospital Geral de } \\
\text { Guarus }\end{array}$ & PU Guarus & $\begin{array}{l}\text { Hospital Sao } \\
\text { Jose }\end{array}$ & $\begin{array}{l}\text { PU } \\
\text { Travessao }\end{array}$ & PU Ururai \\
\hline Sexo do Paciente & Feminino & Masculino & Masculino & Feminino & Feminino \\
\hline $\begin{array}{l}\text { Faixa Etária do } \\
\text { Paciente }\end{array}$ & Adulto & Idoso & Adulto & Adulto & Adolescente \\
\hline $\begin{array}{ll}\text { Bairro } & \text { de } \\
\text { Residencia } & \end{array}$ & Centro & Travessao & Goytacazes & Travessao & Ururai \\
\hline $\begin{array}{l}\text { Especialidade } \\
\text { Clinica }\end{array}$ & clinica medica & $\begin{array}{l}\text { clinica } \\
\text { medica }\end{array}$ & $\begin{array}{l}\text { clinica } \\
\text { medica }\end{array}$ & $\begin{array}{l}\text { Clinica } \\
\text { medica }\end{array}$ & $\begin{array}{l}\text { Clinica } \\
\text { medica }\end{array}$ \\
\hline
\end{tabular}

Utilizando cinco atributos: unidade de saúde, sexo do paciente, faixa etária do paciente, bairro de residência e especialidade clínica foram gerados seis agrupamentos de dados nos quais, para o trabalho, foram considerados os cinco mais relevantes.

O primeiro cluster obteve um total de 11797 registros de atendimentos no Hospital Geral de Guarus na especialidade clínica médica, cuja a população feminina adulta residia no Centro.

Em seguida, com 11670 registros destaca-se o agrupamento dos atendimentos na Unidade Pré Hospitalar de Guarus em que a maioria da população atendida é do sexo masculino, público idoso, residentes de Travessão, $7^{\circ}$ Distrito de Campos.

O terceiro cluster refere-se ao Hospital São José que concentrou 9086 registros em que o público mais atendido foi do sexo masculino e adultos, moradores de Goytacazes também considerado distrito de Campos dos Goytacazes. A especialidade mais atendida neste caso foi a de clínica médica.

O cluster da Unidade Pré Hospitalar de Travessão registrou 8475 atendimentos no qual o público de maior expressão foi do sexo feminino, adulto, residentes neste distrito e que tiveram atendimento do tipo clínica médica. Este agrupamento demonstra uma possível deficiência quanto ao direito constitucionalmente previsto de proteção à maternidade, já que foi constatada a preferência pela clínica médica em detrimento de ginecologia e obstetrícia considerando a taxa de fecundidade deste público, que é adulto e mulher.
No último cluster destacam-se os atendimentos da Unidade Pré Hospitalar de Ururaí onde 3541 adolescentes do sexo feminino moradores deste distrito buscaram a especialidade clínica médica.

\section{CONCLUSÃO}

Em conclusão, este trabalho demonstra que a abordagem de mineração de dados pode ser uma ferramenta útil para aplicação na gestão hospitalar, principalmente no que se refere à gestão dos recursos públicos destinados à saúde.

Podemos citar, a título de exemplo, alguns trabalhos práticos utilizando técnicas de mineração de dados como:

ZHANG et. al (2012) através da combinação de mineração de dados, análise de dados e análise de histórico de acidentes, utilizou software para executar a mineração de dados e implementar os casos de acidentes de fogo e análise de dados com quatro algoritmos comumente usados - análise de cluster, regras de associação, de séries temporais e árvore de decisão. A mineração de dados tem o objetivo de fornecer uma referência no método de aplicação na análise de incidentes, sendo útil como forma de identificar o potencial de acidente de incêndio, prevenir e controlar a fonte.

SANMIQUEL et. al. (2015) realizou um estudo sobre as principais causas dos acidentes ocorridos nas minas da Espanha, aplicando técnicas de mineração em uma base de dados composta por cerca de 70.000 acidentes ocupacionais e relatório de fatalidades correspondentes à década 2003- 
2012. As análises estatísticas foram realizadas utilizando o software Weka e padrões de comportamento foram obtidos com base em certas regras. A partir dessas regras, algumas conclusões são extraídas que pode ajudar a desenvolver políticas de prevenção adequadas para reduzir acidentes e mortes.

No estudo em questão, os dois algoritmos utilizados na mineração dos dados dos atendimentos ocorridos na rede municipal de saúde em Campos dos Goytacazes alcançaram os resultados desejados. Regras de associação produzidas podem ajudar o gestor a entender as relações estabelecidas com o atributo tipo de atendimento, assim como o conhecimento obtido através da clusterização refletiu a característica de diferentes grupos, permitindo desta forma ao gestor direcionar os recursos públicos em função do público alvo atendido nas diversas unidades públicas de saúde no Município.
Este estudo, como uma referência ou um método, é valioso em atendimentos na rede pública de saúde. O processo de mineração de dados pode usar abordagem diferente para analisar os atendimentos e explorar um grande número de casos. Contudo, a descoberta do conhecimento potencial é valiosa ainda, considerando que é difícil de ser obtido através de métodos tradicionais de análise; este conhecimento pode ajudar os gestores públicos a compreender a natureza e essência dos atendimentos de saúde no município.

Com efeito, uma das áreas de maior importância para a aplicação de mineração de dados é a de saúde, podendo ser útil no auxílio ao diagnóstico das doenças, no controle de infecções, no tratamento de várias doenças, além da gestão de hospitalar, gestão de recursos, entre outros (SHARMA et. al., 2014).

\section{REFERÊNCIAS}

[1] BOUCKAERT, RemcoR. et al. WEKA--Experienceswith a Java Open-Source Project. The JournalofMachine Learning Research, v. 11, p. 2533-2541, 2010.

[2] DE SOUZA, I. C. S.N.; PAULO, S.C.L.; Barros, M.M.A. - Urgência e Emergência: Refletindo sobre as dificuldades do Enfermeiro na realização do exercício profissional. Disponível em: http://www.revistaintertexto.com.br/adm/arquivos/Ar tigoURG\%C3\%8ANCIA\%20E\%20EMERG\%C3\%8A NCIA-Edicao-24-3132014-H143024URG\%C3\%8ANCIAEEMERG\%C3\%8ANCIA.pdf Acesso em 06/10/2015.

[3] DIAS, M. M.; PACHECO, R. C. S. Uma Metodologia para o Desenvolvimento de Sistemas de Descoberta de Conhecimento. Acta Scientiarum (UEM), Maringá - PR - Brasil, v. 27, n. 1, p. 61-72, 2005.

[4] DUBEUX, L.S.; FREESE, E.; DOS REIS, Y.A.C. - Avaliação dos Serviços de Urgência e Emergências da rede hospitalar de referência no Nordeste Brasileiro. Caderno de Saúde Pública, RJ, p.1508 - 1518, agosto de 2010.

[5] FAYYAD, U.M.: PIATETSKY-SHAPIRO, G.; SMYTH, P.; UTHURUSAMY, R. Advances in Knowledge Discovery \& Data Mining. 1 ed. American Association for Artificial Intelligence, Menlo Park, Califórnia, 1996. 611 folhas.

[6] GARLET, E.R. et. al; Finalidade do Trabalho em urgências e emergências: concepções de profissionais. Revista Latino
Americana de Enfermagem, on-line version ISSN 1518-8345. Vol. 17, n 4, Ribeirão Preto, Jul/Aug. 2009. Disponível em: http://dx.doi.org/10.1590/S010411692009000400016. Acesso em 06/10/2015.

[7] GALVÃO, N.D.; MARIN, H. De F. - Técnica de Mineração de Dados: Uma revisão da literatura. ACTA Paul Enferm, p. 686 - 690. 2009

[8] GARDINER, Eleanor J.; GILLET, Valerie J. Perspectives on Knowledge Discovery Algorithms Recently Introduced in Chemoinformatics: Rough Set Theory, Association Rule Mining, Emerging Patterns, and Formal Concept Analysis. Journalofchemicalinformation and modeling, 2015.

[9] HALL, Mark et al. The WEKA data mining software: an update. ACM SIGKDD explorations newsletter, v. 11, n. 1, p. 10-18, 2009.

[10] KHATTAK, Asad Masood et al. Analyzing association rule mining and clustering on sales day data with xIminer and weka. International Journal of Database Theory and Application, v. 3, n. 1, p. 1322, 2010.

[11] POLL, M.A.; LUNARDI, V.L.; LUNARDI FILHO, W.D. - Atendimento em unidade de emergência: Organização e Implicações Éticas. Disponível

em:

http://www.scielo.br/pdf/ape/v21n3/pt_21.pdf

Acesso em 05/10/2015.

[12] SANMIQUEL, Lluis; ROSSELL, Josep M.; VINTRÓ, Carla. Study of Spanish mining accidents using data mining techniques. Safety science, v. 75, p. 49-55, 2015. 
[13] SFERRA, Heloisa Helena; CORREA, Ângela M. C. Jorge. Conceitos e Aplicações de Data Mining. Jul/Dez de 2003, Revista Ciência \& Tecnologia, PP. 19-34.

[14] SHARMA, Ashok; MANSOTRA, Vibhakar.Emerging applications of data mining for healthcare management-A critical review. In: Computing for Sustainable Global Development (INDIACom), 2014 International Conference on. IEEE, 2014. p. 377-382.

[15] STEINER, Maria Teresinha Arns et al. Abordagem de um problema médico por meio do processo de KDD com ênfase à análise exploratória dos dados.GestProd, v. 13, n. 2, p. 325-37, 2006
[16] TAN, Pang-Ning; STEINBACH, Michael; KUMAR, Vipin.Introductionto data mining AddisonWesley. 2005.

[17] WITTEN, Ian H.; FRANK, Eibe. Data Mining: Practical machine learning tools and techniques. Morgan Kaufmann, 2005.

[18] ZHANG, Dake; JIANG, Kang. Application of Data Mining Techniques in the Analysis of Fire Incidents. Procedia Engineering, v. 43, p. 250-256, 2012. 


\section{Bapítulo 10}

\section{MODELAGEM DE PROCESSO E PRIORIZAÇÃO DE PROJETOS DE TI UTILIZANDO MÚLTIPLOS CRITÉRIOS}

\section{Renata Gomes Cordeiro}

Munir de Sá Mussa

Rafael Leite de Freitas

Henrique Rego Monteiro da Hora

Simone Vasconcelos Silva

Resumo: Este trabalho apresenta a modelagem do processo de negócio relacionado à priorização de projetos de tecnologia da informação e propõe um processo de priorização utilizando o método de análise multicritério Promethee. Foi utilizada como estudo de caso a área de desenvolvimento de software no departamento de tecnologia da informação de uma instituição federal de ensino. Após levantamento de critérios, atribuição de pesos e valores pelas equipes de gestão e técnica e execução do método Promethee, é apresentado um ranking com seis projetos de TI que foram selecionados para análise. Por considerar que ambas as visões, gestão e técnica, devem estar alinhadas na definição dos projetos que devem ser priorizados, a combinação de todos os critérios fornece um resultado que deverá agradar tanto a gestão quanto a equipe responsável. Considerando que cada área possui competências específicas que permitem-na avaliar da melhor forma os critérios a ela atribuídos. A partir da análise dos resultados é possível concluir que é viável e importante a utilização de uma metodologia baseada em um processo bem definido na gestão de portfólio

Palavras-chave: Priorização de projetos; Múltiplos critérios 


\section{INTRODUÇÃO}

Cada vez mais, as organizações tem buscado utilizar de modelos que possibilitem guiar as ações em busca do aperfeiçoamento e melhoria dos seus resultados. Neste sentido a definição dos processos tem um papel destacado como meio de propiciar um melhor entendimento e organização dos objetivos em busca da obtenção da missão e da visão das corporações de maneira mais satisfatória.

A área de Tecnologia da Informação (TI), especificamente, é pautada na inovação, dinâmica e constante preocupação com sua atualização. Essa característica é um desafio ainda maior para o gerenciamento de portfólio nessa área. A demora na tomada de uma decisão pode acarretar em perdas significativas nos resultados. Nesse sentido um planejamento correto, uma definição detalhada e a escolha das melhores decisões são imprescindíveis ao definir a adoção do modelo baseado em processos na área de $\mathrm{TI}$.

Uma vez definidos os processos detalhados da forma de trabalho do negócio na área de $\mathrm{TI}$, as demandas geradas, muitas vezes, são ricas de detalhes, envolvem tarefas, profissionais e setores internos diferentes o que transforma essa demanda em algo mais complexo e que necessita de um planejamento diferenciado para atendimento. Nesse contexto está inserida a criação dos projetos de $\mathrm{TI}$.

Existe o cenário em que a quantidade de projetos que um setor de $\mathrm{Tl}$ tem em seu portfólio é, muitas vezes, elevada para quantidade de recursos disponibilizados. Portanto, compondo a etapa de iniciação e planejamento do processo de gerenciamento de portfólio de projetos é fundamental geri-lo de maneira inteligente e para isso faz-se necessária a aplicação de um processo de priorização dos projetos que permita identificar quais são mais importantes, que despendem de maior quantidade de recursos a serem investidos, que trazem maior retorno e que riscos estão envolvidos.

Para a priorização de projetos podem ser utilizados métodos multicritérios, que são definidos como aqueles que se baseiam em vários critérios para determinar a solução para um determinado problema (COSTA, 2002).

Para atingir bons resultados no gerenciamento de portfólio, além de um método de priorização pode-se atrelar a definição de processos, de forma a organizar e prover uma visão do que ocorre desde a inicialização de um projeto até a definição de sua prioridade. A Gestão de Processos de Negócio surge, portanto, como uma necessidade das empresas para conhecerem e aprimorarem seus respectivos negócios. Os conceitos e atividades propostas por esta área visam o desenvolvimento de metodologias e ferramental para a gestão de processos em organizações. De modo geral, as empresas buscam um modelo para a definição de seus processos, seja para buscar certificações do mercado ou estabelecer novas práticas, organização e melhoria de seus processos internos (MELO; ALBUQUERQUE; SILVEIRA, 2013).

Dessa forma, utilizando como estudo de caso a área de desenvolvimento de software no departamento de tecnologia da informação de uma instituição de ensino, este trabalho tem o objetivo de propor um processo de priorização utilizando o método de análise multicritério PROMETHEE. Visando facilitar a atuação dos gestores, baseando as prioridades conforme critérios amplamente estabelecidos e adequados a realidade da organização a fim de alcançar melhores resultados.

Através da modelagem dos processos de negócio é possível visualizar o processo como um todo, podendo tornar explícitos gargalos e facilitar o entendimento do mesmo pela equipe envolvida (ABMP BRASIL, 2013). $\mathrm{E}$ utilizando um método de análise multicritério, baseado em critérios que estejam relacionados aos objetivos estratégicos da organização e não apenas através da subjetividade para priorização de demandas, acredita-se que os recursos possam ser melhor aproveitados. Consequentemente, os resultados percebidos tanto pela equipe quanto pelos servidores que demandam os serviços podem ser otimizados.

\section{FUNDAMENTAÇÃO TEÓRICA}

\subsection{ABORDAGEM MULTICRITÉRIO}

Os processos decisórios fazem parte do ciclo de vida de todas as organizações e pessoas. Segundo Costa (2002), uma das metodologias mais recentes de apoio a tomada de decisão é o Auxílio Multicritério à 
Decisão (AMD), caracterizada pela solução de problemas de acordo com muitos critérios. Ainda segundo Costa (2002), metodologias AMD reconhecem a subjetividade como parte do processos decisórios.

As principais metodologias de Auxílio Multicritério à Decisão disponíveis atualmente são o Método de Análise Hierárquica (AHP), os métodos da família ELECTRE e o PROMETHEE (COSTA, 2002).

\subsection{BREVE DESCRIÇÃO DO MÉTODO PROMETHEE}

O PROMETHEE é um método proposto na Bélgica por J. P. Brans e Ph. Vincke em 1985. Os métodos previamente existentes como os da família ELECTRE conseguiam resolver os problemas, mas eram um tanto complexos. Como solução para este problema foi proposto um conceito de tipos estendidos de critérios e duas possibilidades de solução para problemas de ranqueamento: uma ordem parcial (PROMETHEE I) ou uma ordem completa (PROMETHEE II) (BRANS; VINCKE, 1985).

Neste trabalho, utilizaremos o método PROMETHEE II pelo fato de fornecer uma ordem completa das alternativas.

\subsection{EXTENSÃO DO CONCEITO DE CRITÉRIOS}

O método PROMETHEE propõe a extensão do conceito de critério, distinguindo-o em seis tipos, de forma a serem facilmente compreendidos pelos envolvidos na análise decisória. Neste trabalho, foram utilizados dois tipos descritos a seguir.

$$
\begin{aligned}
& \text { Tipo I - Critério Usual } \\
& p(x)=\left\{\begin{array}{l}
0, \forall x \leq 0 \\
1, \forall x>0
\end{array}\right.
\end{aligned}
$$

É um tipo de critério sem nenhuma extensão, não é necessário informar nenhum parâmetro. Deve ser utilizado quando qualquer diferença for suficiente para considerar que uma opção sobreclassifica a outra.

Figura 5 - Tipo I: Critério usual (BRANS; VINCKE, 1985).

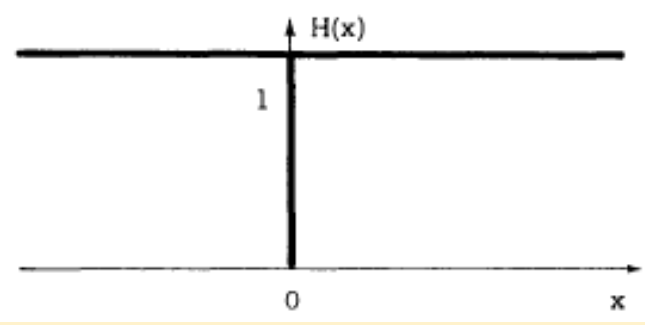




\section{IIII}

Tipo IV - Critério em níveis

$$
p(x)=\left\{\begin{array}{c}
0, x<p \\
\frac{1}{2}, p \leq x \leq p+q ; \\
1, x>p+q
\end{array}\right.
$$

Este tipo de critério inclui o conceito de preferência fraca $(1 / 2)$ quando a diferença entre as opções está no intervalo entre $\mathrm{p}$ e q.
Neste caso, a e b são indiferentes desde que a diferença entre os dois seja menor ou igual ao parâmetro q.

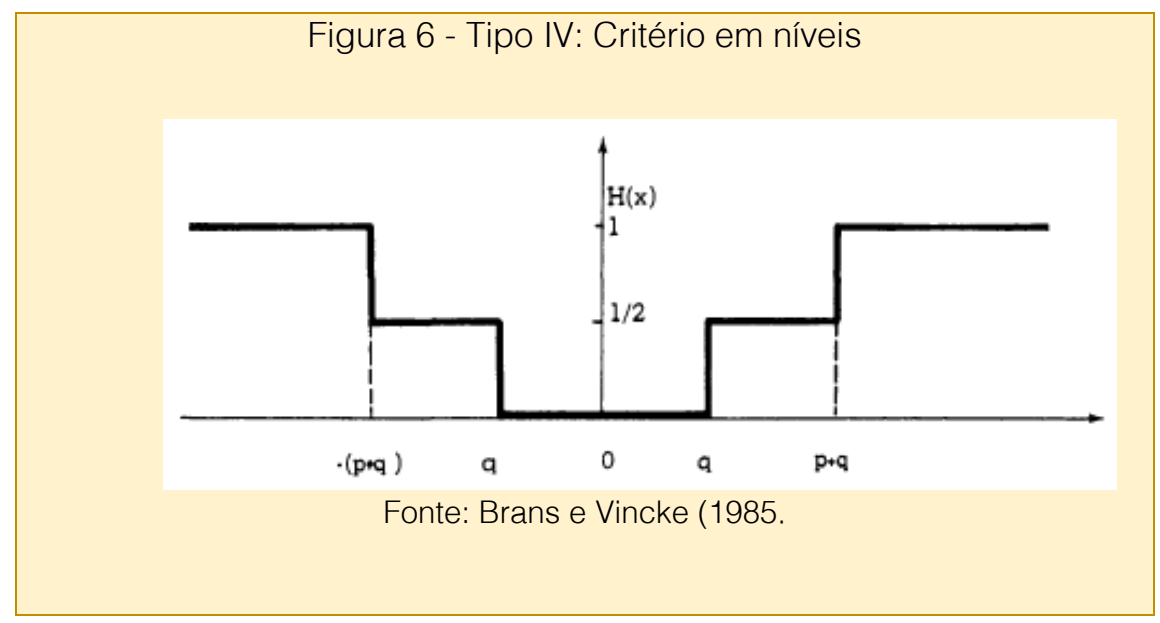

Para ordenar as alternativas, é necessário primeiramente realizar a montagem da matriz de preferência, calculando a soma de preferências de cada par de alternativas à luz de cada um dos critérios, conforme exemplificado na Tabela 1 (BRANS; VINCKE, 1985).

Tabela 1 - Matriz de Pagamentos

\begin{tabular}{|c|c|c|c|c|c|c|} 
& A1 & A2 & A3 & A4 & A5 & A6 \\
A1 & - & 0,296 & 0,250 & 0,268 & 0,100 & 0,185 \\
\hline A2 & 0,462 & - & 0,389 & 0,333 & 0,296, & 0,500 \\
\hline A3 & 0,236 & 0,180 & - & 0,333 & 0,056 & 0,429 \\
\hline A4 & 0,399 & 0,505 & 0,305 & - & 0,223 & 0,212 \\
\hline A5 & 0,444 & 0,515 & 0,487 & 0,380 & - & 0,448 \\
\hline A6 & 0,286 & 0,399 & 0,250 & 0,432 & 0,133 & - \\
\hline
\end{tabular}

Fonte: Brans e Vincke (1985).

Com esses valores, se faz a soma de todos os valores de preferência de cada alternativa em relação às outras para obter o quanto esta alternativa sobreclassifica as outras $\left(\varphi^{+}(a)\right)$.
Também deve-se obter o valor de $\varphi^{-}(a)$ somando as preferências das outras alternativas em relação a uma determinada alternativa. 
Para obter o valor final de sobreclassificação de cada alternativa $(\varphi(a))$, deve-se calcular a diferença entre $\varphi^{+}(a)$ e $\varphi^{-}(a)$. Com esses valores, basta ordenar de forma decrescente os valores de $\varphi(a)$ para obter o ranking de alternativas.

\subsection{GERÊNCIA DE PORTFÓLIO}

A demanda por serviços de Tecnologia da Informação é crescente e consequentemente a quantidade de projetos também, já que as organizações têm, cada vez mais, utilizado projetos para o cumprimento de suas tarefas e objetivos. Porém, quando a demanda é superior a quantidade de recursos humanos, financeiros e físicos para atendê-los, é necessário definir e escolher os projetos prioritários (DUTRA, 2012; FERRAZ, 2013).

Projeto é um esforço temporário, com um início e um término definidos, empreendido para criar um produto, serviço ou resultado único. Um portfólio é uma coleção de projetos, programas, subportfólios e operações gerenciados como um grupo para o alcance de objetivos estratégicos (PMI, 2013a).

O gerenciamento de portfólio auxilia na decisão dos projetos que devem ser desenvolvidos. É uma abordagem para alcançar os objetivos estratégicos da organização, selecionando, priorizando, avaliando e gerindo projetos, programas e outros trabalhos relacionados, considerando a contribuição desses projetos para as estratégias e os objetivos da organização (PMI, 2013b). Através da priorização de projetos, temática que está englobada pela gestão de portfólio, é possível determinar quais projetos terão prioridade na utilização dos recursos existentes sempre focando nos objetivos estratégicos da organização. Cooper, Edgett e Kleinschmidt (2001) acrescentam que a Gestão de Portfólio de Projetos possui quatro objetivos: Maximização do valor do portfólio, buscando o equilíbrio correto de projetos, assegurando que esteja estrategicamente alinhado, e ter o número de projetos de acordo com os recursos disponíveis. Em suma, estabelece critérios de priorização e seleção de projetos, de forma a otimizar a alocação de recursos e atingir os resultados esperados.

\section{ESTRATÉGIA METODOLÓGICA}

\subsection{ETAPAS DA PESQUISA}

A pesquisa produzida neste trabalho pode ser dividida em algumas fases que compuseram a sua realização, como está apresentada na Figura 7. A primeira fase consiste na modelagem do processo de novos projetos de desenvolvimento de software demandados ao departamento de TI da instituição de ensino estudada e alguns processos de suporte. Na segunda fase foi realizada a pesquisa bibliográfica a fim de embasar os conhecimentos acerca de métodos adotados e conteúdo de apoio para a construção da pesquisa. Na terceira fase foi definido o método de análise multicritério adotado assim como os detalhes necessários para a realização do estudo de caso proposto. Este, então, compõe a quarta fase do trabalho, onde foram realizadas entrevistas com profissionais do setor, gestores do Instituto a fim de encontrar as informações necessárias para produzir o estudo de caso. Por fim a quinta fase aborda e analisa os resultados encontrados a partir do estudo de caso realizado.

\section{Figura 7 - Etapas da pesquisa}

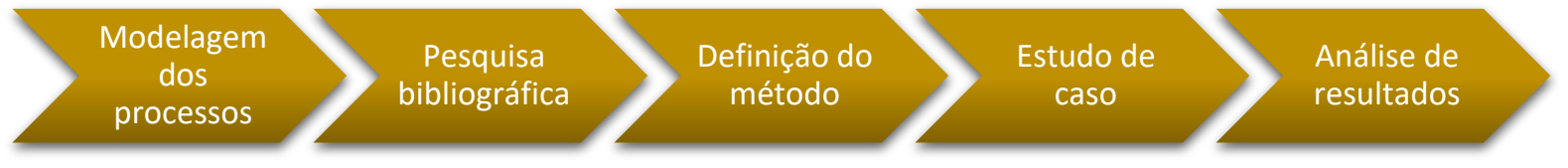

Fonte: Elaboração própria 


\subsection{PRIORIZAÇÃO DE PROJETOS UTILIZANDO O MÉTODO PROMETHEE}

A proposta deste trabalho é realizar a priorização de projetos através de um ranking. Para isso, foi utilizado o método PROMETHEE II que fornece uma ordem completa dentre as alternativas analisadas.

A primeira etapa é a definição dos critérios que serão utilizados na análise. Tal definição representa grande importância, Bouyssou (1990) ressalta que o sucesso de uma metodologia de suporte à decisão está fortemente ligada aos critérios definidos, devendo levar em conta diversos pontos de vista que "representam os diferentes eixos ao longo dos quais os diversos atores do processo decisório justificam, transformam e questionam suas preferências".

Os critérios utilizados na metodologia foram divididos em duas categorias: relacionados à gestão e à equipe técnica. Foram levantados a partir de documentos, como o Plano estratégico da instituição. Considerando que o setor, objeto de estudo do presente trabalho, considera de extrema relevância a participação dos gestores no processo de priorização dos projetos desenvolvidos.

Após a definição dos critérios, é necessário atribuir pesos para os diferentes critérios de acordo com a relevância de cada um. Para essa etapa, o método de cem pontos. Foi utilizado o conhecimento e a experiência dos profissionais da gestão e da área técnica para realizar esta avaliação, que consistiu em solicitar que cada um distribuísse cem pontos entre os critérios competentes à sua área. Para um resultado final os pesos foram normalizados de forma que as duas áreas tivessem a mesma importância, ou seja cinquenta pontos para cada uma.

Foram selecionados, então, seis projetos para aplicar a metodologia proposta. Os profissionais também atribuíram valores para cada critério relacionado a cada projeto. Os critérios definidos e a forma de pontuação dos mesmos são apresentados nos Quadros 1 (relacionados à operação) e 2 (relacionados à gestão).

\section{Quadro 1 - Critérios Relacionados à Operação}

\begin{tabular}{|c|c|c|c|}
\hline Critério & Descrição & Pontuação & Preferível \\
\hline Capacitação & $\begin{array}{l}\text { Avalia a necessidade de treinamentos } \\
\text { específicos para a equipe adquirir } \\
\text { conhecimentos necessários para atuação no } \\
\text { projeto. }\end{array}$ & $\begin{array}{l}\text { Baixo, Médio } \\
\text { ou Alto. }\end{array}$ & Valor mínimo \\
\hline Prazo & $\begin{array}{l}\text { Avalia a duração, o cronograma de } \\
\text { implementação, bem como o prazo final de } \\
\text { conclusão do projeto. }\end{array}$ & $\begin{array}{l}\text { Curto, Médio } \\
\text { ou Longo. }\end{array}$ & Valor mínimo \\
\hline $\begin{array}{l}\text { Alocação de } \\
\text { profissionais }\end{array}$ & $\begin{array}{l}\text { Analisa a quantidade de profissionais de } \\
\text { diferentes áreas da operação precisam estar } \\
\text { envolvidos. }\end{array}$ & $\begin{array}{l}\text { Baixa, Média } \\
\text { ou Alta. }\end{array}$ & Valor mínimo \\
\hline Complexidade & $\begin{array}{l}\text { Analisa o esforço em conjunto de toda } \\
\text { equipe que é necessário no projeto e os } \\
\text { riscos envolvidos para o alcance dos } \\
\text { resultados esperados. }\end{array}$ & $\begin{array}{l}\text { Baixa, Média } \\
\text { ou Alta. }\end{array}$ & Valor mínimo \\
\hline $\begin{array}{l}\text { Alocação de } \\
\text { recursos }\end{array}$ & $\begin{array}{l}\text { Analisa os recursos, a infraestrutura } \\
\text { necessária para a realização do projeto. }\end{array}$ & $\begin{array}{l}\text { Baixa, Média } \\
\text { ou Alta. }\end{array}$ & Valc \\
\hline
\end{tabular}

Fonte: Elaboração própria.

A coluna preferível representa o valor que um projeto deve receber para sobreclassificar outro em relação a cada critério. Ou seja, um projeto com o critério capacitação classificado como baixo sobreclassifica um projeto classificado como alto para este critério, onde é preferível o valor mínimo. 
Quadro 2 - Critérios Relacionados à Gestão

\begin{tabular}{|c|c|c|c|}
\hline Critério & Descrição & Pontuação & Preferível \\
\hline $\begin{array}{l}\text { Alinhamento com } \\
\text { o negócio }\end{array}$ & $\begin{array}{l}\text { Mede a abrangência do projeto em relação } \\
\text { aos temas e objetivos estratégicos, ou seja, a } \\
\text { maior ou menor contribuição do projeto para } \\
\text { a estratégia da instituição, de forma } \\
\text { sistêmica. }\end{array}$ & $\begin{array}{l}\text { Baixa, Média } \\
\text { ou Alta. }\end{array}$ & Valor máximo \\
\hline $\begin{array}{l}\text { Determinação } \\
\text { legal ou da } \\
\text { Administração }\end{array}$ & $\begin{array}{l}\text { Pontua as iniciativas em função de } \\
\text { cumprimento de lei ou de determinação da } \\
\text { Administração da Organização. }\end{array}$ & $\begin{array}{l}\text { Atende ou } \\
\text { Não atende. }\end{array}$ & Valor máximo \\
\hline Tempo & $\begin{array}{l}\text { Examina o tempo necessário para que o } \\
\text { projeto comece a gerar os resultados } \\
\text { esperados. }\end{array}$ & $\begin{array}{l}\text { Curto, Médio } \\
\text { ou Longo. }\end{array}$ & Valor mínimo \\
\hline Prazo final & $\begin{array}{l}\text { Pontua se o projeto tem uma data limite para } \\
\text { a entrega final. }\end{array}$ & $\begin{array}{l}\text { Definido ou } \\
\text { Indefinido. }\end{array}$ & Valor máximo \\
\hline
\end{tabular}

Fonte: Elaboração própria.

Para a conversão dos critérios do tipo em nível, foi necessário realizar a conversão dos valores qualitativos para valores quantitativos, de forma a possibilitar a realização dos cálculos, conforme Tabela 2.

Tabela 2 - Conversão de valores qualitativos para quantitativos

\begin{tabular}{|c|c|}
\hline Valor Qualitativo & Valor Quantitativo \\
\hline Baixa / Curto & 1 \\
\hline Média / Médio & 3 \\
\hline Alta / Longo & 5 \\
\hline
\end{tabular}

Fonte: Elaboração própria.

Para a agregação dos valores e dos pesos atribuídos por cada profissional, foi calculada a mediana nos critérios do tipo em nível e a moda nos critérios do tipo usual. Como limites de preferência ( $p$ ) e indiferença ( $q$ ) foram atribuídos os valores 1,5 para a preferência e 2,0 para a indiferença. Após a obtenção de todos os dados, foi utilizado o software Visual PROMETHEE para a execução dos cálculos e obtenção do ranking.

\subsection{ESTUDO DE CASO}

\subsubsection{CARACTERIZAÇÃO DO OBJETO DE PESQUISA}

A pesquisa realizada neste trabalho foi desenvolvida no Departamento de Tecnologia da Informação de uma instituição de ensino. A instituição possui 12 campi e a Reitoria distribuídos por 11 municípios.

O Departamento de TI está vinculado a Reitoria do Instituto e conta atualmente com 18 servidores sendo 8 na equipe de desenvolvimento de software, 3 no escritório de projetos, 2 na equipe de redes, 4 na equipe de serviços e um diretor. Cada campi possui um setor de Tecnologia da Informação e o departamento de TI atua como um concentrador, gerenciando os serviços em comum à todos os campi. Com relação a área de desenvolvimento de software, somente o departamento de TI possui uma equipe para este fim, recebendo demandas com esta finalidade de todos os campi.

O período de desenvolvimento deste trabalho coincide com uma fase de reorganização estrutural e de elaboração e formalização de processos relacionados às atividades 
desenvolvidas pelo departamento. Por questões de delimitação do objeto de pesquisa, este trabalho foca no processo de novos projetos de desenvolvimento de software.

\subsubsection{MODELAGEM DO PROCESSO DE PRIORIZAÇÃO DE DEMANDA}

Como ponto de partida para a realização do estudo de caso, foi necessária realização da modelagem dos processos relacionados a execução de novos projetos de desenvolvimento de software no departamento de TI. Tal modelagem tem o objetivo de obter uma melhor compreensão da definição dos processos de negócio existentes no departamento.

Foi identificado que apesar de haver a etapa de priorização da demanda, não existia um método para realização desta tarefa. Sendo esta executada baseada apenas em critérios subjetivos e não formalizada. Nesse aspecto, visando propor uma forma consistente de priorização dos projetos do setor, é apresentada na seção seguinte uma proposta do Subprocesso de priorização de demanda modelado utilizando uma metodologia de decisão multicritério.

A partir da modelagem do processo de desenvolvimento de novos projetos demandados por servidores da instituição ao departamento de TI, foi identificada que existe a necessidade da priorização de demandas, mas a não existência de um processo definido e tampouco uma metodologia com essa finalidade. Tal identificação pode ser considerada um gargalo no processo e uma falha no gerenciamento do portfólio de projetos do departamento. De forma que, se os projetos estivessem sendo priorizados através de uma metodologia consistente e não apenas por meio de critérios subjetivos, os recursos poderiam estar sendo melhor aproveitados. Consequentemente, os resultados percebidos tanto pela equipe quanto pelos servidores que demandam os serviços poderiam ser otimizados.

A proposta de priorização utiliza o método de análise multicritério PROMETHEE para a elaboração de um ranking de todas as demandas que o setor possui. A Figura 8 apresenta a proposta do Subprocesso de priorização de demanda.

Figura 8 - Modelagem do Subprocesso de Priorização de demanda

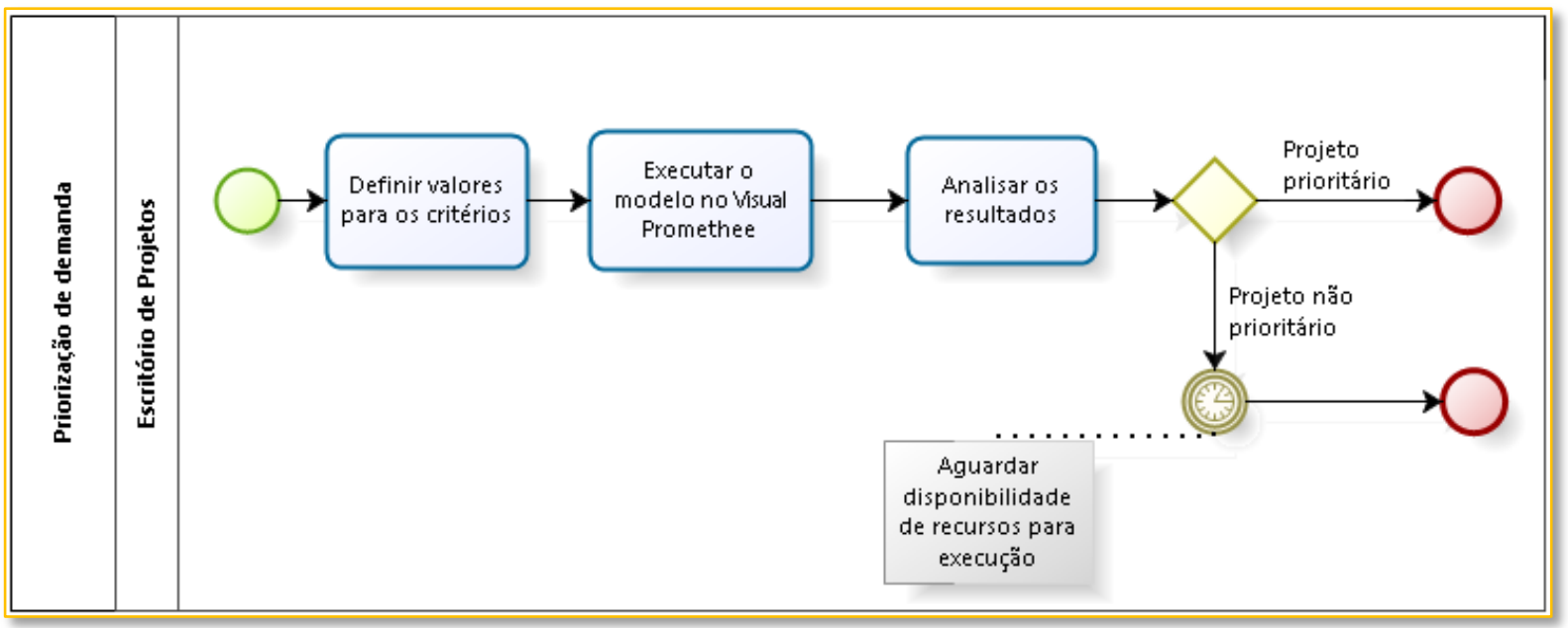

Fonte: Elaboração própria

Na primeira etapa do processo o Escritório de projetos deve definir os valores para cada critério do novo projeto. Considerando que os demais projetos já possuam seus valores definidos, uma vez que também passaram por esse processo, a próxima tarefa é a execução do modelo no software Visual PROMETHEE para obtenção do ranking. $\mathrm{Na}$ tarefa de análise dos resultados, deve ser verificado qual a posição do novo projeto em relação aos demais. Caso o mesmo esteja em uma posição elevada, caracterizando-o como projeto prioritário, o mesmo deverá prosseguir no subprocesso de análise da solicitação. Em caso negativo, o novo projeto deve aguardar 
a disponibilidade de recursos para sua execução.

4 RESULTADOS
$\mathrm{Na}$ etapa de atribuição de pesos, realizada pelas equipes de gestão e técnica e após o tratamento dos dados foram obtidos os pesos demonstrados nas Tabelas 3 e 4.

Tabela 3 - Critérios e pesos relacionados à Operação

\begin{tabular}{ll|c|}
\multicolumn{1}{c|}{ Cód. } & \multicolumn{1}{c|}{ Critério } & Peso \\
CO-1 & Capacitação & 5 \\
\hline CO-2 & Prazo & 15 \\
CO-3 & Alocação de profissionais & 5 \\
CO-4 & Complexidade & 15 \\
CO-5 & Alocação de recursos & 10 \\
\hline
\end{tabular}

Fonte: Elaboração própria.

Tabela 4 - Critérios e pesos relacionados à Gestão

\begin{tabular}{|c|c|c|}
\hline Cód. & Critério & Peso \\
\hline CG-1 & Alinhamento com o negócio & 15,8 \\
\hline CG-2 & Determinação legal ou da Administração & 15,8 \\
\hline CG-3 & Tempo & 7,9 \\
\hline CG-4 & Prazo final & 10,5 \\
\hline
\end{tabular}

Fonte: Elaboração própria.

Através dos pesos obtidos é possível perceber que do ponto de vista da equipe de operação, projetos que, mesmo com baixa necessidade de capacitação e alocação de profissionais para desenvolvê-los, não tendem a configurar projetos prioritários por estes fatores possuírem pesos inferiores aos demais. Enquanto que projetos com prazo de entrega definido e baixa complexidade tendem a figurar entre os projetos de maior prioridade de execução.

Quadro 3 - Matriz de Pagamentos

\begin{tabular}{|c|c|c|c|c|c|c|c|c|c|}
\hline Projeto & $\mathrm{CO}-1$ & CO-2 & $\mathrm{CO}-3$ & $\mathrm{CO}-4$ & $\mathrm{CO}-5$ & CG-1 & CG-2 & CG-3 & CG-4 \\
\hline Projeto 1 & Médio & Médio & Baixa & Baixa & Baixa & Média & $\begin{array}{l}\text { Não } \\
\text { atende }\end{array}$ & Médio & Indefinido \\
\hline Projeto 2 & Alto & Curto & Alta & Alta & Média & Média & Atende & Médio & Definido \\
\hline Projeto 3 & Médio & Longo & Média & Média & Baixa & Alta & $\begin{array}{l}\text { Não } \\
\text { atende }\end{array}$ & Curto & Indefinido \\
\hline Projeto 4 & Alto & Curto & Média & Média & Média & Alta & Atende & Curto & Definido \\
\hline Projeto 5 & Médio & Médio & Baixa & Baixa & Baixa & Alta & Atende & Curto & Indefinido \\
\hline Projeto 6 & Médio & Longo & Baixa & Baixa & Baixa & Média & $\begin{array}{l}\text { Não } \\
\text { atende }\end{array}$ & Curto & Indefinido \\
\hline
\end{tabular}

Fonte: Elaboração própria.
No que diz respeito a avaliação dos gestores, projetos que estejam alinhados com o negócio e que configurem sua aplicação devido a determinações legais estão mais propensos a serem considerados prioritários.

Depois de consultar os especialistas, chegouse à seguinte matriz de pagamentos apresentada no Quadro 3. 
Após a execução do modelo no software Visual PROMETHEE, chegou-se ao resultado apresentado na Tabela 5.

Tabela 5 - Ranking final dos Projetos de acordo com o método PROMETHEE.

\begin{tabular}{cl|c|c|c|}
\hline $\begin{array}{c}\text { Colocação } \\
1^{\circ}\end{array}$ & Projeto 4 & 0,2788 & 0,2788 & 0,0000 \\
\cline { 5 - 5 } $2^{\circ}$ & Projeto 5 & 0,0928 & 0,1348 & 0,0420 \\
$3^{\circ}$ & Projeto 2 & 0,0788 & 0,2388 & 0,1600 \\
$4^{\circ}$ & Projeto 1 & $-0,0968$ & 0,0400 & 0,1368 \\
$5^{\circ}$ & Projeto 6 & $-0,1568$ & 0,0400 & 0,1968 \\
$6^{\circ}$ & Projeto 3 & $-0,1968$ & 0,0000 & 0,1968 \\
\hline
\end{tabular}

Fonte: Elaboração própria.

Conforme pode ser visto na Tabela 5, o Projeto 4 foi classificado em $1^{\circ}$ no ranking resultante do modelo proposto. Cabe destacar que, apesar de ter tido a segunda melhor sobreclassificação sobre os outros projetos, o Projeto 2 ficou em terceiro lugar por ter sido muito sobreclassificado por outros projetos em outros critérios.

Os projetos 1 e 6 possuírem a mesma intensidade de preferência (fluxo positivo) sobre os demais projetos. Em compensação a preferência (fluxo negativo) dos outros projetos sobre o Projeto 6 foi maior do que sobre o Projeto 1, resultando em um fluxo líquido e posicionamento no ranking inferior ao Projeto 1.

\section{CONCLUSÕES}

No presente trabalho, foi abordada a importância da modelagem de processos, dada a percepção visual que a mesma proporciona aos envolvidos nos processos. Tornando-se ponto de partida para processos de melhoria e detecção de gargalos. Também foi abordada a utilização de métodos decisórios como ferramenta de auxílio à gestão de portfólio, apresentando uma proposta para a priorização de projetos no setor de TI, tendo como base a utilização de um método de análise multicritério da família PROMETHEE.

Foi apresentado um estudo de caso no departamento de tecnologia da informação de uma instituição de ensino. No estudo foram desenvolvidas as modelagens do macroprocesso de desenvolvimento de novas demandas e alguns de seus subprocessos. Tais modelagens tornaram visuais e formalizaram processos que já eram executados pela equipe, porém de maneira intuitiva. No estudo de caso foi identificado o gargalo existente no subprocesso de priorização de demanda, sendo proposta a utilização do método de análise multicritério PROMETHEE II como forma de introduzir no processo anteriormente executado de forma intuitiva, um método consolidado para ordenação completa.

No presente trabalho, foram consideradas duas visões: gestão e técnica, por considerar que ambos devem estar alinhados na definição dos projetos que devem ser priorizados. Uma vez que cada área possui competências específicas que permitem-na avaliar da melhor forma os critérios a ela atribuídos. E a combinação de todos os critérios fornece um resultado que deverá agradar tanto a gestão quanto a equipe responsável pelo desenvolvimento do projeto.

A partir da análise dos resultados é possível concluir que a utilização de um método multicritério na gerência de portfólio mostra-se viável devido a sua fácil execução através de um software gratuito. E também importante devido ao embasamento fornecido para auxiliar na tomada de decisões dos envolvidos no processo.

Como trabalho futuro propõe-se a implantação do método PROMETHEE para priorização de demanda no dia a dia da equipe que foi objeto de estudo. Outra proposta é a comparação do ranking de projetos obtida de forma intuitiva, como atualmente acontece e com a utilização do método. 


\section{REFERÊNCIAS}

[1] ABMP BRASIL. BPM CBOK V3.0 - Guia para o Gerenciamento de Processos de Negócio Corpo Comum de Conhecimento. $1^{\text {a }}$ ed. Brasil: ABMP Brasil, 2013. v. 3

[2] BOUYSSOU, D. Building Criteria: A Prerequisite for MCDA. In: COSTA, C. A. B. E (Ed.). . Readings in Multiple Criteria Decision Aid. Berlin: Springer Berlin Heidelberg, 1990. p. 58-80.

[3] BRANS, J. P.; VINCKE, P. A Preference Ranking Organisation Method. Management Science, v. 31, n. 6, p. 647-656, 1 jun. 1985.

[4] COOPER, R. G.; EDGETT, S. J.; KLEINSCHMIDT, E. J. Portfolio Management for New Products. Cambridge: Basic Books, 2001.

[5] COSTA, H. G. Introdução ao método de análise hierárquica (análise multicritério no auxílio à decisão). Niterói: UFF, 2002.

[6] DUTRA, C. C. Modelo econômicoprobabilístico para seleção e priorização de projetos. Disponível em: <https://www.lume.ufrgs.br/bitstream/handle/10183 /61379/000864264.pdf?sequence=1>. Acesso em: 20 jun. 2016.

FERRAZ, A. B. DE S. D. Definição de um método que estabelece critérios para priorização de novos projetos e aplicação em um processo de desenvolvimento de software. 10 dez. 2013.

[8] MELO, F. V. S.; AlBUQUERQUE, C. R. E S. DE; SILVEIRA, D. S. DA. Da necessidade de gerenciar à complexidade de modelar: descrevendo o processo de aprendizagem de administradores na utilização de um software de modelagem de processos. Revista Brasileira de Administração Científica, v. 4, n. 1, p. 201-214, 14 ago. 2013.

[9] PMI. Um Guia Do Conhecimento Em Gerenciamento De Projetos (Guia PMBOK). São Paulo: Project Management Inst, 2013a.

[10] PMI. The standard for portfolio management. 3rd. ed. Newtown Square: Project Management Institute, 2013b. 


\section{Bapítulo 11}

TRANSFERENNCIA DE TECNOLOGIA: A CULTURA COMO UM CONTRIBUTIVO APORTE TEÓRICO À INVESTIGAÇÃO DA RELAÇÃO ENTRE OS LABORATÓRIOS PÚBLICOS DE PESQUISA E AS EBT S

\section{Daisy Campos Alvim}

Valderez Ferreira Fraga

Resumo: Buscar compreender, em parte, o motivo pelo qual a produção acadêmica brasileira, embora considerada entre as maiores, se comparada com a países em desenvolvimento, não se traduzir, de forma compatível, em transferência de tecnologia para o setor produtivo, foi a motivação deste estudo. A abordagem da cultura como aporte teórico para a análise das relações entre os sujeitos situados no ambiente de transferência de tecnologia partiu da suposição que apontava para a existência de códigos éticos diferentes entre os sujeitos envolvidos no referido processo de ttransferência de tecnologia. Nesse sentido, buscou-se identificar elementos que confirmassem ou rejeitassem estas suposições, no processo de relacionamento de grupos de pesquisa e empresas de pequeno/médio porte, classificados como de base tecnológica (EBT's). Como referencial teórico utilizou-se o modelo de análise de cultura de Johann, visando a identificar possível impacto da cultura como fator de sucesso ou fracasso no relacionamento em pauta, aplicado com base em método de pesquisa qualitativo. As principais conclusões rejeitam a suposição de códigos éticos diferentes, mas apontam para um conjunto de valores e visões estereotipadas que os grupos estabelecem entre si.

Palavras chave: Transferência tecnologia, Cultura, Inovação tecnológica. 


\section{INTRODUÇÃO}

A busca de competitividade e desenvolvimento sustentável, lastreados em investimentos em Pesquisa e Desenvolvimento (P\&D), mostra-se cada vez mais relevante quando analisado o destaque de países em desenvolvimento, no ambiente de economias cada vez mais globalizado. A vocação tecnológica, entendida como pesquisa e desenvolvimento vinculados à competência em tornar útil a inovação gerada, tem sido fator determinante para o destaque dos países em desenvolvimento.

Nesse contexto, a dinâmica de um sistema de inovação tecnológica pode ser avaliada pela efetiva capacidade de transferir o conhecimento produzido nos ambientes de pesquisa para o setor produtivo. Espera-se que o intercâmbio da informação científica e a busca por soluções complementares e cooperativas sejam fatores capazes de acelerar o processo de crescimento econômico e de bem estar social nos países envolvidos.

A produção acadêmica brasileira apesar de considerada entre as maiores, se comparada com os países em desenvolvimento, não se coloca em posição tão favorável ao se analisar a efetiva transferência desse conhecimento para o setor produtivo.

É neste contexto que este artigo apresenta resultados parciais de uma investigação que busca compreender, por meio da análise de elementos culturais inconscientes incorporados ao cotidiano da organização, práticas que interferem positiva ou negativamente no processo de transferência de tecnologia.

\section{CONTEXTUALIZAÇÃO}

A oportunidade de desenvolvimento de economias emergentes passa pela capacidade de produzir tecnologias de alto valor agregado para a renda nacional. A busca por identificação de nichos nos quais se apresentam condições de competitividade vantajosas e de alto potencial de desenvolvimento tecnológico, é tarefa primordial para o enfrentamento das dificuldades econômicas porque passam os países em desenvolvimento como o Brasil. Entretanto, à pesquisa tecnológica é necessário agregar resultados efetivos em aplicações comerciais.

Obter resultados que façam diferença na melhoria da qualidade de vida do povo brasileiro pressupõe, em boa parte, capacidade de gerar solução que agregue as inovações provenientes de instituições de pesquisa à capacidade empreendedora de Empresas Baseadas em Tecnologia (EBT's).

Estudos realizados pelo Banco Mundial (2005), sobre a "A inovação nos países. Brasil' afirma que metade das diferenças de renda per capta entre os países em desenvolvimento tem como origem diferenças de produtividade, geralmente associadas ao progresso tecnológico, indicando como medida do sucesso da inovação, o crescimento da renda per capta.

Ainda neste mesmo estudo, foi medido e avaliado o Sistema Nacional de Inovação (NIS) do Brasil. Apesar de não abrangente quanto aos elementos diferenciados que o compõe, o NIS teve como propósito indicar o nível de eficiência do esforço de inovação no país em relação a um contexto internacional. Conclui que o desempenho negativo do Brasil explica-se, em parte, pela "fraca colaboração entre empresas privadas e pesquisadores de universidades e a qualidade das instituições de pesquisa" que contribui para a pouca eficiência em transformar P\&D em aplicações comerciais.

Em 2008, novo estudo também realizado pelo Banco Mundial, "Conhecimento e Inovação para a Competitividade" analisa os problemas e deficiências derivadas do processo de preparação do Brasil para enfrentar os desafios da economia do conhecimento, os quais repercutem no processo de inovação nas empresas e afetam negativamente a competitividade do País. Constata que o

"Brasil já produziu avanços em nível mundial na agricultura e aeronáutica e na exploração de petróleo em águas profundas nos últimos anos. Mas, como outras nações com grande desigualdade de renda, o País reconhece a necessidade de reavaliar seu sistema educacional, sua infra-estrutura tecnológica e sua política de inovação para assegurar mais avanços contra a pobreza"

Apesar de a nova lei da inovação (10973 de 02/12/2004) ter preenchido algumas lacunas, ainda não é suficiente para garantir a inovação. Dentre outros fatores a considerar, destaca-se a necessidade de relações sociais 
e ações institucionais que estimulem a interação entre universidade-empresa e promovam a mudança de culturas desfavoráveis à criação de mecanismo de interação de forma salutar, ética e com respeito às singularidades de cada instituição.

Diante desse cenário, percebe-se que o estabelecimento de uma nova política industrial que tenha como foco a incorporação de novas tecnologias aos produtos brasileiros, de forma a aumentar seu valor agregado, tem exigido novas estratégias que facilitem a transferência de tecnologia e a incorporação de inovações pelo setor produtivo.

Percebe-se que a possibilidade de colocação de produtos inovadores no mercado perde-se em decorrência de dificuldades de aproximação e de negociação entre os atores envolvidos no processo: grupos de pesquisa ligados às universidades, institutos, centros de pesquisa e setores produtivos interessados no novo conhecimento.

No processo que vai desde um estudo científico que pode levar até a inovação e à promoção de ofertas de produtos e serviços aceitos e usados pelo mercado, vários atores são envolvidos. Apesar da mutualidade, é muito difícil o diálogo. A competitividade das empresas passa cada vez mais a depender de fatores como a inovação tecnológica, que pode ser obtida através de investimento em P\&D ou através de formação de redes de conhecimento que envolve atores como institutos de pesquisa, universidade $e$ consórcio de empresas. Pequenas empresas, apesar de já apresentarem alguma mudança no interesse quanto a inovação, não desenvolveram cultura de pesquisa nem capacidade de investimento em P\&D. Pequenas e médias empresas, intensivas em tecnologia, dependem, cada vez mais, dos resultados obtidos nos centros de pesquisa dos institutos e universidades.

\section{APORTE TEÓRICO}

O suporte teórico do estudo foi, fundamentalmente, direcionado à cultura organizacional, porém, sem descolá-la de sua raiz as subculturas nacionais, somadas à cultura da área de formação - porque os grupos tipificados cujos sujeitos são entrevistados, apresentam um estilo próprio de agir e reagir que, embora com boa carga de características das organizações nas quais atuam, apresentam peculiaridades culturais próprias de suas origens, manifestando tendências, escolhas, valores, talentos e estilos diferentes de vida.

Além disso, os fundamentos buscam os construtos relativos à inovação tecnológica, como modelo de desenvolvimento do país. Sendo as instituições públicas de pesquisa parte do modelo de desenvolvimento econômico brasileiro, precisam estar articuladas com outras instituições privadas, de forma a estarem orientadas a um visão de longo prazo que contribua para que os avanços do conhecimento se traduzam em agregação de valor em produtos, processos e serviços e viabilizem uma melhor distribuição da qualidade de vida e riqueza nacional

Para cumprir este papel, a capacidade de interação e troca entre os diferentes tipos de pessoas/profissionais e organizações deve estar respaldada por respeito mútuo aos saberes de cada uma, para que o bem comum prevaleça, sem que suas singularidades sejam perdidas, comprometendo, desta forma, a possibilidade de potencializar ao máximo a sinergia na administração de problemas que, neste caso, se referem à transferência de tecnologia.

\subsection{CULTURA}

Trata-se se um tema relativamente recente, em termos do interesse organizacional. A cultura organizacional, na verdade, passoua a despertar maior atenção dos teóricos da administração vindo a ser vinculada à gestão, a partir do momento em que o Japão, década de 1980, configurou-se como uma das grandes lideranças industriais, colocando em cheque "certezas" até então consideradas como progresso permanente, mercados fechados, dentre outras . Barboza (2002: 11) cita, inclusive que em 1983, duas importantes revistas especializadas na área, a "Administrative Science Quartely" e "Organization Dynamics", dedicaram, simultaneamente, dois números exclusivos ao assunto "cultura organizacional".

No Brasil os estudos organizacionais sobre cultura ganharam expressão ao final dos anos 80 e inícios dos anos 90. No entanto na opinião de Fischer\&Mac-Allister (2001:253) poucos ousaram associar a cultura brasileira 
a cultura organizacional brasileira.

Divididos entre uma visão objetivista/funcionalista e uma visão subjetivista/interpretativa da realidade social, os estudiosos do campo criam uma grande variedade de abordagens. Na opinião de Laino, para os objetivistas, o significado da cultura é resultado de um "conjunto de dados que podem ser levantados e mensurados. Já, os "subjetivistas", consideram a cultura única, sendo seu significado o resultado da interpretação das relações simbólicas e dos significados da interação entre os membros da organização em estudo (2003:p.2) . Existem, ainda, aqueles que não se enquadram em uma visão específica, posicionando-se em categorias intermediárias, se consideradas as abordagens citadas.

Já, para Fleury, os sociólogos, mais afinados com a visão objetivista tem uma visão de cultura como o conjunto de opiniões e comportamentos sociais. Os antropólogos, porém, preferem a postura de observadores ou observadores participantes, fazendo interpretações dos significados que permeiam as relações entre os membros do grupo. Ainda dentro do campo da antropologia, existem abordagens diferenciadas - aqueles que adotam a "perspectiva fenomenal", enfatizando os artefatos e comportamentos observáveis - ritos, estórias e credos e os que preferem dar mais ênfase aos pressupostos básicos (inconscientes) que são "compartilhados pelos membros da organização' (Fleury, 1996 :16), .

Para Mota (1997:16) a cultura é um conceito antropológico e sociológico. Pode ser vista como a forma pela qual "a comunidade satisfaz suas necessidades materiais e psico sociais... ou como a adaptação em si' resultante da forma como a sociedade se adapta ao ambiente. Estas duas visões consideram que a evolução ou correção dessa adaptação seriam provenientes da experiência vivida. Ainda, Motta identifica duas outras formas de ver a cultura - como proveniente do inconsciente humano ou como formas diversas de cognição. No primeiro caso, as condições ambientais internas e externas da sociedade combinadas com "traços" presentes no inconsciente se transformam em símbolos, cujos significados se materializam como cultura de uma determinada comunidade humana. Já, no segundo caso, representam escolhas dos indivíduos quanto a formas de "pesquisar, perceber e compreender a realidade". Se modificam, quando situações específicas se apresentam.

Há três aspectos importantes a considerar, quando se analisa cultura organizacional:

- O primeiro estimula a busca por grupos que possam ser tipificados, por suas peculiaridades, para se poder observar até que ponto uma cultura pode ser única no interior da organização;

- O segundo, aspecto refere-se à questão da dinâmica da cultura, o que possibilita observá-la viva, em mudança contínua;

- O terceiro aspecto é decorrente dessa dinâmica da cultura com sua propensão para mudança, o que pode trazer expectativas às dificuldades que poderão estar na base dos relacionamento nos processos de transferência de tecnologia.

À mesma variedade de definições da cultura corresponde uma variedade de formas de análise. Diversos autores consideram ser possível analisar a cultura em níveis ou camadas que representam degraus, a partir dos quais os fenômenos culturais são observados.

O Modelo de Schein (Figura 1:Representação gráfica - tradução do modelo de análise de cultura -SCHEIN) aponta para três níveis que são classificados de acordo com o grau de acessibilidade. No primeiro nível, estariam os artefatos (estruturas, cerimônias, etc ) que podem ser observados com pouco esforço. Ao segundo nível, pertence os valores que vão dar suporte às estratégicas, metas e filosofias organizacionais. Ao terceiro, pressupostos básicos - cabem as crenças inconscientes, o que não é negociável, em princípio. 
Figura 1:Representação gráfica - tradução do modelo de análise de cultura -SCHEIN

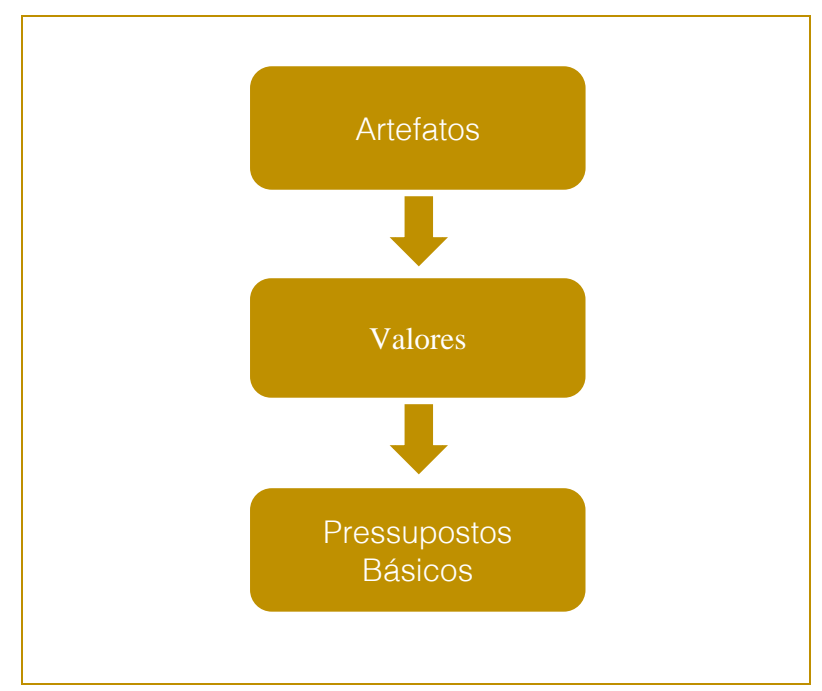

Fonte: Organizacional Culture and Ledership , pág. 14

Geert Hofstede (1991), que realizou uma pesquisa comparativa de cultura em sessenta e um países, defende que a análise da cultura pode ser aplicada a organizações, nações, grupos religiosos ou étnicos. Também analisa os elementos em camadas e os compara, quanto à visibilidade, às características estruturais de uma cebola. Classifica, a partir da camada mais externa para as internas (), os níveis em: Símbolo, Heróis, Rituais e Valores.

Figura 1: Representação gráfica - tradução do modelo de análise de cultura de HOFSTEADE

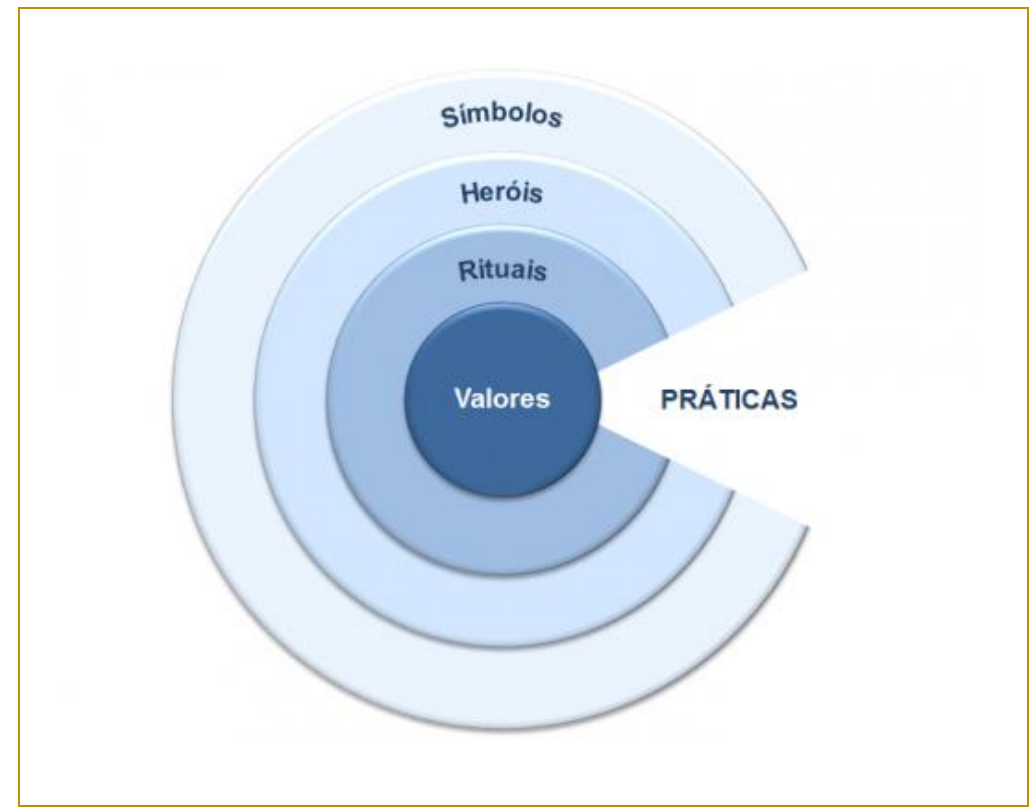

Fonte: Culture and Organizations software of the mind -pag. 9 
Para Johann (2004:27) as camadas que compõem a cultura organizacional

"parecem atuar de forma desordenada, quase caótica., ou seja, ao mesmo tempo que toda a empresa é impelida numa mesma direção (força motriz) são constantemente feitas referências a um conjunto de regras (ideologia central) em paralelo a elementos inconscientes (self) e, até mesmo indesejáveis (zona de sombras). Isso sem falar na resistência a mudanças (novos valores adjacentes) que é a maior dificuldade na valoração da cultura organizacional".

Figura 2- Representação gráfica do modelo de análise de cultura -

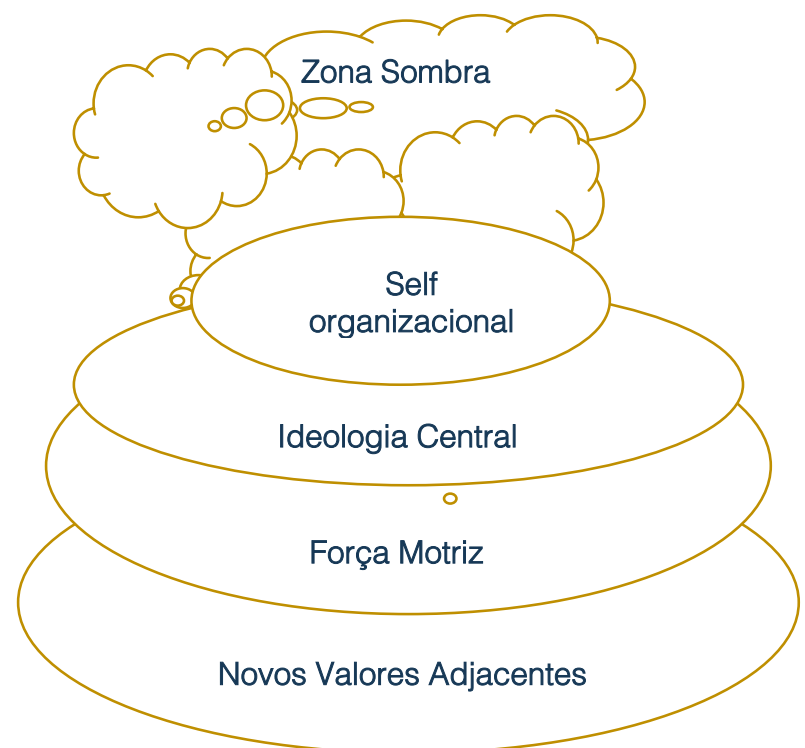

Fonte: Adaptado E Johann Estrutura da cultura Corporativa - (2004:28)

Esta perspectiva considera ser o "self" organizacional, a exemplo do "self individual" de Jung (Apud Johann, 2004:28) o ponto onde a comunicação entre os sistemas consciente e inconsciente se dá, de forma a funcionar como elemento regulador da cultura organizacional. Assim, conhecer o "self" organizacional pode ser o caminho que dá acesso ao inconsciente coletivo organizacional. Segundo essa posição, é no inconsciente coletivo que também reside a "zona de sombras" - preconceitos, tabus, medos inconfessos,... - onde pode estar a explicação do motivo pelo qual decisões racionais de uma organização podem não dar certo. Vale investigar, nestes casos, o quanto estas decisões não representam rota de colisão com as "zonas de sombras".

Em decorrência de experiência teórica e prática em fusão organizacional, Fraga sugere que, diante de situações sombrias, pesquisadores e gestores se proponham a, eles próprios, as seguintes questões:

"Há possibilidade de reorientar atitude intervencionista no sentido da agregação cultural? Há implicações relativas a valores?" e, ao fazer essa sugestão, complementa: "através da busca por intangíveis culturais [...] trazer à tona valores como uma esperança para uma nova cultura organizacional com raízes comuns."( 2005:.p. 12).

\subsection{INOVAÇÃO TECNOLÓGICA}

O conceito de inovação é freqüentemente utilizado referindo-se a duas dimensões. De um modo específico, mais aplicado a novos produtos ou técnicas particulares, inovação é definida como conhecimentos técnicos sobre como fazer coisas de um modo diferente e considerado melhor que o estado da arte existente. De uma forma ampla, ela é vista como um processo que promove mudanças técnicas. Na literatura o termo inovação é utilizado, muitas vezes, com o significado de progresso técnico, referindo-se ao conjunto amplo de mudanças no conhecimento tecnológico e aos efeitos deste conhecimento nos produtos, nos processos de produção e na produtividade e organização das 
atividades. Processo de inovação neste contexto refere-se às atividades que contribuem para produzir novos bens e serviços e as novas formas de produzi-los (Winter, 1984; Freeman e Soete:1997:6)

Schumpeter (1951:88-89) utiliza na sua distinção entre invenção e inovação, a expressão inovação no sentido da primeira introdução de um novo produto, processo, método ou sistema. A palavra inovação é utilizada tanto para indicar a primeira introdução de um novo produto ou processo como para descrever o processo de conduzir uma invenção até seu lançamento comercial, processo que pode levar muitos anos de trabalho de desenvolvimento, teste de produção e de marketing e comercialização.

Schumpeter distingue: Inovações radicais aparecimento de novas formas de produção e produtos, de mecanismos de gerenciamento e de venda de produtos e serviços, assim como a descoberta de fontes alternativas de matérias primas e de mercados. Inovações radicais representam descontinuidades no processo de desenvolvimento tecnológico, podendo ter impacto destruidor sobre o sistema produtivo e estando relacionadas com a abertura de novos caminhos. Além dessa, as chamadas Inovações incrementais melhorias sucessivas nos produtos e processos a que estão submetidas as tecnologias com o uso através da mudança de qualidade, na produtividade, na eficiência técnica ou nos custos.

No processo que vai desde um estudo científico que pode levar a uma invenção até à inovação e a promoção de ofertas de produtos e serviços aceitos e usados pelo mercado vários atores e atividades são envolvidos e com dissonâncias que merecem tratamento específico.

\subsection{TRANSFERÊNCIA TECNOLOGIA}

Como forma de reduzir os custos de pesquisa e para potencializar o uso de desenvolvimentos tecnológicos disponíveis, em muitos países industrializados, desde o início da década de 70, ocorreram experiências de pesquisa compartilhada como, por exemplo, as citadas por Pirró e Longo (2001-Anexo:p.38) por meio de "redes cooperativas", "coalizões", "centros de pesquisa cooperativa", "Centros, redes ou coalizões virtuais", dentre outros. Apesar de estruturados de forma diferenciada e de atender a demandas ou momentos específicos, todas tiveram como propósito acelerar o "ciclo de pesquisa, desenvolvimento, produção e lançamento no mercado". Percebe-se, pois, que o desafio vem sendo enfrentado há muito.

Ainda na leitura de Pirró e Longo"(1989:9), no que diz respeito à velocidade de aplicação dos novos conhecimentos, afirma ser cada vez menor o tempo decorrido entre a invenção e a respectiva inovação, entendendo-se por invenção "a primeira concepção do produto em forma substancialmente comercial" e por inovação "a primeira aplicação comercial ou a venda".

Além de representar um caminho para a auto - sustentabilidade institucional da pesquisa, a transferência de tecnologia entre institutos de pesquisa público e iniciativa privada deve ter motivação na melhoria de qualidade de vida da população, novos postos de trabalho, novos produtos e maior competitividade das empresas . Essa é uma percepção que remete ao "em comun" da abordagem fenomenológica à gesão que Fraga discutiu em ambiente de tecnologia avançada, em "Gestão pela Formação Humana" ( 2009), em busca do desenvolvimento de uma postura da "eficiência metodológica", de "eficácia de resultados confiáveis", da possibilidade de "efetividades social" desses resultados, à partir da consideração da "relevãncia do humano", para poder oferecer ao "homem concreto", no mundo da vida, como desejava Husserl, a "legitimação" da transferência de tecnologia para o "fim último do bem comum" da sociedade (pp66-69).

Outra questão em discussão, diz respeito à delimitação do papel dos institutos públicos de pesquisa e da empresa quando da transferência de tecnologia. Por exemplo, na opinião de Melo (2005:7), nos casos de pesquisa tecnológica "o máximo que cabe à universidade é chegar ao protótipo. Desse ponto em diante, é de responsabilidade de outros agentes implementá-lo e fazê-lo chegar ao cliente final'. Outra visão, entende que os institutos de pesquisa devem se estruturar para um papel pró-ativo no processo de transferência tecnológica, incluindo o acompanhamento da implementação do produto na cadeia de produção e mesmo o suporte à criação de empresas "spin off". Esta última posição está hoje fortalecida pela da nova lei de incentivo a inovação e pesquisa 
científica e tecnológica no ambiente produtivo, regulamentada pelo congresso em outubro de 2005. Nela é sugerida a criação de "Núcleos de Inovação Tecnológica - NIT" para cada instituto ou grupo de institutos de pesquisa tendo como papel fomentar a transferência de tecnologia para os setores produtivos utilizando inclusive os recursos de infra-estrutura própria como, por exemplo, laboratórios para viabilizar a absorção tecnológica para as micro e pequenas empresas.

Ainda para a gestão dos Institutos de pesquisa, na opinião de Zouain, colocou-se um novo "processo de interação e negociação com interlocutores com quem os institutos não tinham relacionamento anterior". Anteriormente, estas negociações cabiam às agencias de fomento federais.(2001:11)

Em pesquisa elaborada por Santos (2002), para identificar a existência de "Escritórios de Assessoria Tecnológica" em 143 universidades, apesar do pouco retorno (18\%), constatou que das 26 que responderam 25 utilizavam escritórios ou estruturas equivalentes para assessoria tecnológica. Outra pesquisa financiada pela FINEP e executado pela UFRGS, para identificar as empresas que tinham interagido com as universidades nos últimos dois anos, também identificou que, em 93\% dos casos, a interação ocorre por iniciativa das empresas.

Considerando os dois resultados, podemos inferir que as assessorias tecnológicas não estão obtendo sucesso na intermediação e/ou que falta atitude mais pró - atividade no sentido das estruturas de assessoria tecnológica para a empresa.

Em entrevista exclusiva à Agência Gestão CT\&l de Notícias, o presidente do Fórum Nacional de Gestores de Inovação e Transferência de Tecnologia (Fortec) em 2013 faz um diagnóstico sobre o setor e afirma: "Os processos de transferência de tecnologia ainda não acontecem com a densidade $e$ intensidade que o País precisa." Além disso, tecnologias que apresentam alto grau de inovação também apresentam maior custo e incertezas para a empresa licenciada. Assim, ao invés de desenvolvimento de novos produtos, empresas já instaladas optam, frequentemente, pela compra de empresas menores de alta tecnologia que já tenham iniciado a inserção do produto no mercado. $\mathrm{Na}$ ausência de investidores privados ou por acreditarem em suas tecnologias, os inventores se lançam na constituição de empresas para explorar seus inventos. Assim, se formam as chamadas empresas "Spin off" constituída por empreendedores oriundos da universidade ou instituição de pesquisa. Neste caso outros desafios se colocam quando analisadas experiência, conhecimento do mercado e capacitação para gestão destes empreendedores.

\section{PERSPECTIVA E APLICAÇÃO METODOLÓGICA}

Entender a complexidade cultural do universo organizacional significa, além de compreender os elementos que constituem sua estrutura, compreender, também, as características do contexto cultural na qual está inserida.

O estudo origem deste artigo, optou pelo uso de metodologias qualitativas que dependem de inúmeros aspectos, incluindo-se a afinidade teórica do pesquisador. Usualmente escolhas qualitativas se dão baseadas no pressuposto teórico que considera a cultura como única e, portanto o elemento só possui significado se analisado no contexto cultural observado.

Dentro das organizações de pesquisa que correspondem ao escopo deste estudo, a escolha de participantes foi feita tendo como critério sujeitos que, em seu conceito próprio de produção científica, tiveram experiência em transferir para o mercado produtos resultantes de suas pesquisas, sejam elas básicas ou aplicadas.

Ao optar por entrevistas se está abrindo espaço para pesquisa de campo, uma modalidade frequentemente considerada "penosa" demandando "habilidades interacionais" exigindo, por

vezes, "audácia, integridade e habilidade para aceitar sofrimento", o que Guba e Lincoln em sua consistente experiência consideram compensador (1981,pp. 170171).Das entrevistas individuais participaram, como representantes das instituições públicas de pesquisa cinco pesquisadores, sendo três do CBPF, um da UFRJ e um da UFF. Na categoria de intermediários na transferência de tecnologia, foram entrevistados um responsável por incubadora do LNCC, um responsável pelo parque tecnológico da UFRJ e uma funcionária da FINEP e, 
posteriormente, convidado à participação no grupo focal um representando do NIT Rio . Completa o grupo de entrevistados quatro empresários proprietários de empresas de alta tecnologia nas áreas de (tubos, filtros, TI e software de prospecção de petróleo). Destes, três são de experiência de sucesso e um de experiência que não obteve o resultado esperado

No caso das empresas do tipo EBT's, os entrevistados foram os sócios fundadores e participantes do processo de transferência de tecnologia. Foram contatados cinco empresários e uma empreendedora para as entrevistas. Estes foram localizados por várias fontes - indicação do grupo de pesquisa onde correu ou está ocorrendo o processo de transferência, indicação proveniente da própria rede social da pesquisadora, do livro da FINEP contendo os empresários contemplados com premiação. Do total contatado, um foi descartado por ter sido apenas incubado, mas não ter passado pelo processo de transferência de tecnologia. Neste contato inicial, todos foram convidados à participação no grupo focal, exceto um por ter concluído o relacionamento com o grupo de pesquisa. de forma pouco amigável, o que traria constrangimento à reunião.

Como intermediários foram incluídos atores que vêm participando e sendo observadores privilegiados da transferência de tecnologia com tempo de experiência diversificado. No entanto, tem como característica comum, serem profissionais atuantes neste segmento - incubadora tecnológica, parque tecnológico, Núcleo de Inovação e agencia de fomento aos contratos de transferência de tecnologia - Incubadora LNCC, Parque Tecnológico da UFRJ, NIT Rio e FINEP .

A coleta de informações foi efetuada utilizando duas técnicas distintas. entrevistas individuais e grupo focal .

Para a entrevista individual foi construído um conjunto de assertivas, pinçadas deste próprio estudo e consideradas relevantes para identificar a lógica de reflexão dos três tipos de sujeitos - pesquisadores, intermediários e empresários. As entrevistas individuais foram gravadas e, posteriormente, transformadas em texto Ocorreram no período de janeiro a abril de 2007.

O grupo focal, seguindo a metodologia proposta por Ruediger,m. a. e Riccio, v.grupo (2004) e Gaatti, Bernardete, ( 2005) um evento diretamente orientado para o foco desta pesquisa, reuniu sujeitos tipificados segundo os tres grupos - pesquisadores, intrmediários e empresários - todos em situação, atual ou potencial, em torno da transferência de tecnologia, além de um espe.ialista em cultura que contribuiu para a dinâmica metodológica.

\section{CONCLUSÃO}

O referencial teórico discutido no referido capítulo possibilitou a leitura e a interpretação, pelo menos aproximada, dos discursos, relatos, valores manifestos e /ou subjacentes nas percepções e argumentos explicitados pelos sujeitos dos dois grupos, bem como favoreceu a visibilidade de algumas singularidades que se destacaram das tipificações culturais de pesquisadores e empresários em situação de transferência de tecnologia.

Como síntese de nossa interação com os grupos tipificados colocamos, na Tabela 1, as principais questões que, segundo apreendido, mais impactam o processo de transferência. Na camada do SELF, as questões estão apresentadas já segundo ordem de importância percebida pela pesquisadora. Nas outras camadas, foi estabelecido o contraponto referente ao mesmo quesito na visão de cada grupo tipificado. Para essa comparação basta verificar a numeração de cada item na coluna. Da mesma forma que na camada anterior, o itens aparecem expostos segundo a importância percebida pela pesquisadora. 
Tabela 1-Síntese dos elementos identificados nas entrevistas e Grupo Focal, segundo camadas do modelo

\begin{tabular}{|c|c|c|}
\hline Camadas do Modelo & \multicolumn{2}{|l|}{ Pesquisadores } \\
\hline $\begin{array}{l}\text { Contexto do ambiente } \\
\text { pesquisa }\end{array}$ & $\begin{array}{l}\text { 1. Direcionamento da pesquisa } \\
\text { 2. Valorização do processo } \\
\text { metas e políticas públicas }\end{array}$ & $\begin{array}{l}\text { pelos fundos setoriais } \\
\text { transferência em função das }\end{array}$ \\
\hline Self & $\begin{array}{l}\text { 1. Valor simbólico do dinheiro } \\
\text { para cada grupo tipificado } \\
\begin{array}{l}\text { 2. Pouca valorização do } \\
\text { conhecimento prático do } \\
\text { empresário } \\
\text { 3. Competição/disputa entre } \\
\text { pesquisadores }\end{array}\end{array}$ & $\begin{array}{l}2 \text {. Percepção de prepotência } \\
\text { do pesquisador }\end{array}$ \\
\hline Ideologia Central & $\begin{array}{l}\text { 1. Produção do conhecimento } \\
\text { 2. Reconhecimento pelos } \\
\text { pares } \\
\text { 3. Qualidade }\end{array}$ & $\begin{array}{l}\text { 1. Resultado financeiro } \\
\text { 2. Produtos inovadores } \\
\text { 3. Custo } x \text { tempo } \times \text { qualidade }\end{array}$ \\
\hline Força Motriz & $\begin{array}{l}\text { 1. Avaliado por publicação } \\
\text { 2. Foco no processo como } \\
\text { meio de acúmulo de } \\
\text { conhecimento. } \\
\text { 3. Perfil analítico e metódico }\end{array}$ & $\begin{array}{l}\text { 1. Avaliado pelo mercado } \\
\text { 2. Foco no processo como } \\
\text { meio de otimização da } \\
\text { produção } \\
\text { 3. Pressa por resultado/ } \\
\text { queima de etapa }\end{array}$ \\
\hline Valores Adjacentes & $\begin{array}{l}\text { 1. Importância da mudança já } \\
\text { percebida, mas não } \\
\text { internalizada. } \\
\text { 2. Pouca maturidade no } \\
\text { processo de transferência } \\
\text { 3. Importância para a } \\
\text { formação } \\
\text { 4. Importância da Propriedade } \\
\text { intelectual }\end{array}$ & $\begin{array}{l}\text { 1. Parceria com ICT's vista } \\
\text { como estratégica } \\
\text { 2. Interesse na parceria surge } \\
\text { quando ocorrem problemas na } \\
\text { produção } \\
\text { 3. Importância da formação já } \\
\text { percebida, mas não } \\
\text { internalizada. } \\
\text { 4. Interesse e valorização da } \\
\text { pesquisa }\end{array}$ \\
\hline
\end{tabular}

Ao apresentar as situações resumidas na tabela 6, o exercício de priorização dos resultados não foi submetido a uma medida quantitativa. Utilizou-se de percepção da pesquisadora quanto ao impacto no relacionamento que representam. É resultado da ênfase ou carga emocional com que os temas foram tratados no decorrer das entrevistas ou grupo focal. Tem como objetivo alertar para as situações que requerem maior cuidado ao se estabelecer a parceria

A questão do valor simbólico do dinheiro emerge como elemento de grande importância. Nele reside a principal fonte de desconforto do relacionamento. Acreditamos que, ao poder contar com a nova lei de inovação como referencial para tratar a parte mais prática deste ponto, muitos zonas sombras tendem a se diluir.

Em segundo lugar aparece o tripé tempo $x$ custo $x$ qualidade. Acreditamos que o que aparentemente passa como divergência de valores entre os dois mundos pode ser objeto de negociação de forma a acertar o tom das expectativas das partes. . Do lado do pesquisador, é necessário flexibilizar quanto ao nível de qualidade para viabilizar um produto, desde que não comprometa a 
segurança do usuário. No "mundo da vida" estamos habituados, no momento da decisão de compra, a escolher, dentre diversos produtos/serviços aquele que em termos de preço e qualidades apresenta a configuração mais adequada ao que estamos dispostos a pagar sem que isto represente algum risco a nossa vida, quando a postura em comum reaparece. Estamos, nesse ato, praticando a equalização de custo $x$ benefício $x$ capacidade de pagamento, tendemos inclusive a valorizar mais os produtos que nos oferecem possibilidades de escolha. Levar este tipo de avaliação para o processo de interação é outro procedimento que pode agregar possibilidades de sucesso às parcerias

O terceiro ponto, mais difícil de equalização, é quanto aos critérios sob os quais os acadêmicos são medidos pelo CNPq. O peso do critério publicação científica em periódicos indexados, ocupa tempo considerável do pesquisador competindo, em situação vantajosa, com a própria política de inovação que valoriza as patentes e a

\section{REFERÊNCIAS}

[1] BANCO MUNDIAL , (2008)"Conhecimento e Inovação para a Competitividade"; dispónível em http://siteresources.worldbank.org/BRAZILINPORE XTN/Resources/3817166-

1220382779545/Conhecimentoelnovacaolivrocomp letoPortugues.pdf; acessado em 30/05/2015

[2] ---------: Sinopse da pesquisa: http://www.esalq.usp.br/esalqtec/artigos/art_001.pd f - acessado em 30/05/2015

[3] BARBOSA, Lívia. Cultura e Empresas. Rio de Janeiro: Jorge Zahar ed, 2002.

[4] CALDAS, M.; FACHIN, R.; FISCHER, T. (Orgs.). Handbook de estudos organizacionais: modelos de análise e novas questões em estudos organizacionais. São Paulo: Atlas, v. 2. No prelo. (1993)

[5] FLEURY, M.T.Fischer. Cultura e poder nas organizações. São Paulo: Atlas, 1996.

[6] FORTEC (2013) Entrevista exclusiva do presidente a ABIPT: disponível em http://www.agenciacti.com.br/index.php?option=co m_content\&view=article\&id=3779:os-nits-estaomorrendo-diz-presidente-do-fortec; acesada em 30/05/2013 transferência de tecnologia para o setor produtivo. Reconhecemos que momentos de transição se configuram como possibilidade de apresentar incoerências entre política e prática. Nesse sentido, identificamos que as regras de avaliação dos pesquisadores pelos institutos de pesquisa, as regras de avaliação dos pesquisadores pelo CNPq sinalizam para valores passados enquanto as políticas públicas e as regras de liberação de recursos financeiros pelos órgãos públicos de fomento já apontam para um novo cenário incentivo a transferência de tecnologia. Esta sinalização dúbia, também é outro fator que contribui para o impacto negativo das parecerias.

As outras situações explicitadas tendem a se resolver pelo exercício e amadurecimento do relacionamento ou são mudanças de resultado a longo prazo, como por exemplo a formação dos jovens para as questões envolvidas na inovação quando a postura citada gestão pela formação poderá ser implmentada en futuros estudos.

FRAGA, V.F. Challenges of Organizational Spin-Offs/Mergers: An Example in Brazilian Culture. International Journal of Knowledge, Culture and Change Management. Volume 5, Issue 9, pp.7180.

[8] Gestão pela formação humana: uma abordagem fenomenológica. Rio de Janeiro:2003.

[9] --------Gestão pela formação humana: um abordagem fenomenológica. -Barueri, SP: Manole; 2a ed.;(2009).

[10] Choque cultural como aprendizado profissional e humano. Revista de Administração Pública -RAP, V. 33, no 5, set/out, Rio de Janeiro, 1999.

[11] FREITAS, Maria Ester de. Cultura Organizacional: Identidade, Sedução e Carisma? 4a.edição - Rio de Janeiro:Editora FGV, 2005

[12] -------- Cultura Organizacional: Formação, tipologia e impacto. São Paulo:Makron Books. 1991

[13] -------- -cultural chock. International Education Journal, Canberra - Australia, v., n. 3, p. 1-20, 1999.

[14] FINEP, 2007, Financiadora de estudos e Projetos. Disponível na internet (http://www.finep.gov.br/) ${ }^{\circ}$

[15] GAATTI, Bernardete, A. Grupo focal na pesquisa em ciências sociais e humanas. Brasília, DF: líber livro, 2005 
[16] GUBA, Egon G.; LINCOLN, Yvonna S. Effective evaluation: improving usefulness of evaluation results

[17] trough responsive and naturalistic approaches. San Francisco; Jossey-Bass, 1981.

[18] HOFSTEDE, G. Culture and Organization: Software of the mind. New York:McGraw-Hill, 1991

[19] JOHANN, Silvio Luiz; Gestão da Cultura Corporativa: Como as Organizações de alto desempenho gerenciam sua cultura organizacional. São Paulo, Editora Saráiva, 2004

[20] JUNG, C. G. Estudos sobre psicologia analítica, v. VII. Petrópolis:Vozes, 1981

[21] LAINO, Aparecida de Souza; Artigo Comprando Metodologias para o Estudo da Cultura Organizacional - apresentado no X SIMPEP - Simpósio de Engenharia de Produção UNESP-Bauru-SP; 2003 -

[22] MELO, Pedro Antônio de. A transferência de conhecimentos científicos e tecnológicos da UFSC. Revista Produção vol. 5 /num 3/set 2005

[23] MCT - Ministério de Ciência e Tecnologia, 2007. Disponível na internet (http://www.capitalderisco.gov.br/vcn/e_CR.asp. ).

[24] MOTTA, Fernando C. Prestes, Cultura organizacional e cultura brasileira / Fernando C. Prestes Motta, Miguel P.Caldas organizadores São Paulo: Atlas, 1997

[25] MORGAN, G. Imagens da Organização. São Paulo: Atlas, 1996

[26] PIRRÓ e Longo, W. Ciência e Tecnologia: evolução, inter-relação e perspectivas.Rio de Janeiro: Anais do 9o Encontro Nacional de Engenharia de Produção (ENEGEP), vol. I, 42, 1989.

[27] Inovações Tecnológicas: Parcerias e Incentivos; ESG; 2001.

[28] _ Parcerias Estratégicas - Edição Especial - Memória da Conferência Nacional de CT\&।

[29] _ Ciência e Tecnologia: Evolução, Inter-relação e perspectivas; publicado nos Anais do 9o encontro Nacional de Engenharia de Produção (ENEGEP) - vol.1,42 (1989)

[30] REICHERS, Amon E; Schneider, Benjamin.Climate and culture: An evolution of contructs. In: Shneider. B (org) Organizacional Climate and culture. San Franciscoc.Jossey-Bass, 1990
RUEDIGER, M. A. E Riccio, V.Grupo focal : método e análise simbólica da organização e da sociedade. In Vieira, M. F. V. E Zouain, D. M.. (Org.)Pesquisas Qualitativa Em Administração.Rio De Janeiro : FGV, 2004.( 153-172).

SANTOS, M.E.R. Escritórios de Assessoria Tecnológica - EAT's e a interação Universidade Empresa - Projeto FINEP no 2468/00 - Convenio FINEP no 22.01.0198.00 - Universidade Federal do Rio Grande do Sul. Rio Grande do Sul.2002

[33] SCHEIN, Edgar H. Organizational culture and leadership. 2a edição San Francisco: JosseyBass, 1985

[34] SCHUTZ, A. Fenomenologia e relações sociais: textos escolhidos. Org e Introd. Helmut $r$. Wagner. Tradução Algela Melin. São paulo: Zahar, 1979 .

[35] On Phenomenology and social relations:selected wrhitings. Edit by.Helmut $R$. Wagner.Chicago: The university of chicago press, 1970

[36] SCHWARTZMAN, SIMON Formação da Comunidade Científica no Brasil, Rio de Janeiro FINEP -1979

[37] --------- (Coord.), KRIEGER, EDUARDO; et al. Ciência e Tecnologia no Brasil: política industrial, mercado de trabalho e instituições de apoio. Rio de Janeiro: Ed. da Fundação Getúlio Vargas, 384 p., 1995.

[38] TROMPENNARS, Fons. Nas Ondas da Cultura: como entender a diversidade cultural nos negócios.Tradução de claudiney Fullmann. São Paulo: educator, 1994

[39] WINTER, S.G. Schumpeterian Competition in Alternative Technological Regimes. Journal of Economic Behavior and Organization, v. 5, p. 287320. (1984).

[40] VELHO, Sílvia. Relações universidadeempresa: desvelando mitos. Campinas, SP: Autores Associados, 1996. 154 p. (Coleção Educação Contemporânea).

ZOUAIN, Deborah Moraes; Gestão das Instituições de Pesquisa. ,Rio de Janeiro: Editora FGV, 2001 


\section{Bapítulo 12}

\section{O PROCESSO DE IMPLEMENTAÇÃO DO BPM NO CLOUD COMPUTING}

Rodolfo de Amorim Paulo

Luiz Gabriel Pereira Herzog

Stephany Pereira dos Santos

Roquemar de Lima Baldam

Resumo: A necessidade de se obter processos de negócios executados com maior rapidez e sistemas de armazenamento e compartilhamento de informações que sejam eficazes e seguras são os grandes destaques na atualidade. Portanto, o presente artigo tem por objetivo apresentar o processo de implementação do BPM no Cloud Computing e esclarecer detalhadamente os elementos que um sistema desse porte deve levar em consideração para o seu desenvolvimento. Além disso, a pesquisa baseou-se na análise de estudos referentes a processos elásticos pois foi observado que processos de negócios que são implementados em outro tipo de modelo são chamados de elásticos. Apesar da pequena quantidade de informação sobre processos elásticos, a Plataforma Vienna para Processos Elásticos foi apresentada de forma a exemplificar o estudo. E, a partir dela, conclui-se que a implementação de um modelo BPM na nuvem é aconselhado em virtude de apresentar estruturas definidas para todos os membros do processo e garantir a segurança e eficácia das informações do sistema.

Palavras-chave: Processos, Nuvem, Implementação, Elástico. 


\section{INTRODUÇÃO}

A modelagem de processos está inserida em diversas fases de um processo de negócios, dentre eles, definir as interações entre homem e máquina, promover a melhoria contínua do trabalho e qualificar os processos que foram definidos (PERNICl, 2005). A partir de um processo modelado e definido, tem-se a necessidade de expandir a capacidade de armazenamento de informações em um sistema. Nesse sentido, a computação nas nuvens é, então, inserida no mercado como vantagem competitiva para empresas em virtude de proporcionar oportunidades de modo que as mesmas possam gerenciar e armazenar os seus processos e dados de forma eficaz.

A computação nas nuvens tem 0 foco principal em infraestrutura e software. A infraestrutura está relacionada com recursos computacionais enquanto os softwares com os aplicativos criados para auxiliar o gerenciamento do processo de negócios. Portanto, a computação nas nuvens traz ferramentas que auxiliam na estruturação do BPM (Business Process Management) em uma organização (CORIA et al., 2014).

A metodologia da pesquisa consiste na análise de estudos de caso que envolvem o processo de implantação do Business Process Management para o Computação nas Nuvens. Para isso, os conceitos e as características do Gerenciamento de Processos de Negócios e da Computação nas Nuvens foram abordados nas próximas seções deste artigo de forma a elucidá-los de maneira simplificada. Ainda, o modelo de processo de negócios na nuvem foi analisado e cada passo para sua implementação foram exemplificados e, por fim, um modelo que representa a implementação do Business Process Management na nuvem foi apresentado como um dos exemplos comumente utilizados na literatura para esclarecer esse processo.

Portanto, o objetivo geral da pesquisa delimita-se em esclarecer como os modelos de processos de negócios são implementados em sistema de computação nas nuvens. A partir disso, os objetivos específicos do artigo possuem a finalidade de destacar as principais características e vantagens do Cloud Computing, identificar os processos para a implementação do BPM na nuvem e apresentar um modelo que representa essa interação (posteriormente chamada de BPM elástico).

\section{REFERENCIAL TEÓRICO}

\subsection{BUSINESS PROCESS MANAGEMENT}

Business Process Management está relacionado com o alinhamento dos processos com objetivos estratégicos da organização. Vulksic (2013) afirma que pode englobar desde a concepção e implementação do processo até o estabelecimento de sistemas de medição de processo que se alinharão com os objetivos organizacionais. Ainda pode ser definido como uma realização de negócios de forma eficiente (SCHMIEDEL et al., 2013).

O BPM se disseminou nas últimas duas décadas, concedendo às organizações administrar seus processos de negócios (DUIPMANS, 2014). Agrupa todas as atividades realizadas em uma organização, incluindo a melhoria contínua dos processos de negócios além de ser considerado um método que pode proporcionar vantagem competitiva para empresas. Independente do período de tempo o BPM tem grandes chances de atingir um nível elevado de sucesso a partir do momento em que objetivos prédeterminados conseguem ser alcançados (TURKMAN, 2010).

Deste modo, Business Process Management inclui não só a análise e modelagem de processos, mas também a execução dos processos, a liderança e o controle do desempenho. Segundo Schulte et al. (2015), o BPM faz uma integração com o planejamento, controle, acompanhamento, obtendo assim, a melhoria contínua do processo de forma consistente e frequente. Porém, o BPM enfrenta grandes discussões a respeito de sua forma ótima de implementação apesar de ser considerado uma ferramenta de extrema importância para as empresas (ROHLOFF, 2010). Em suma, o BPM é uma aplicação de Six Sigma, produção enxuta e gestão total da qualidade de forma a se tornar mais produtivo e flexível.

A fim de se manterem competitivas, as empresas medem, monitoram e analisam o seu desempenho com o auxílio do BPM. As atividades que dividem o BPM possuem 
enfoque específico em cada etapa. Como podemos visualizar na Figura 1, consideramos como primeira etapa o Design e Análise e as outras três são essenciais para o processo: Configuração, Consolidação e
Avaliação. Após a última etapa retorna-se à primeira, o que proporciona dinamismo, flexibilidade e garantia de melhoria contínuo ao processo.

Figura 1: Ciclo de Vida do BPM

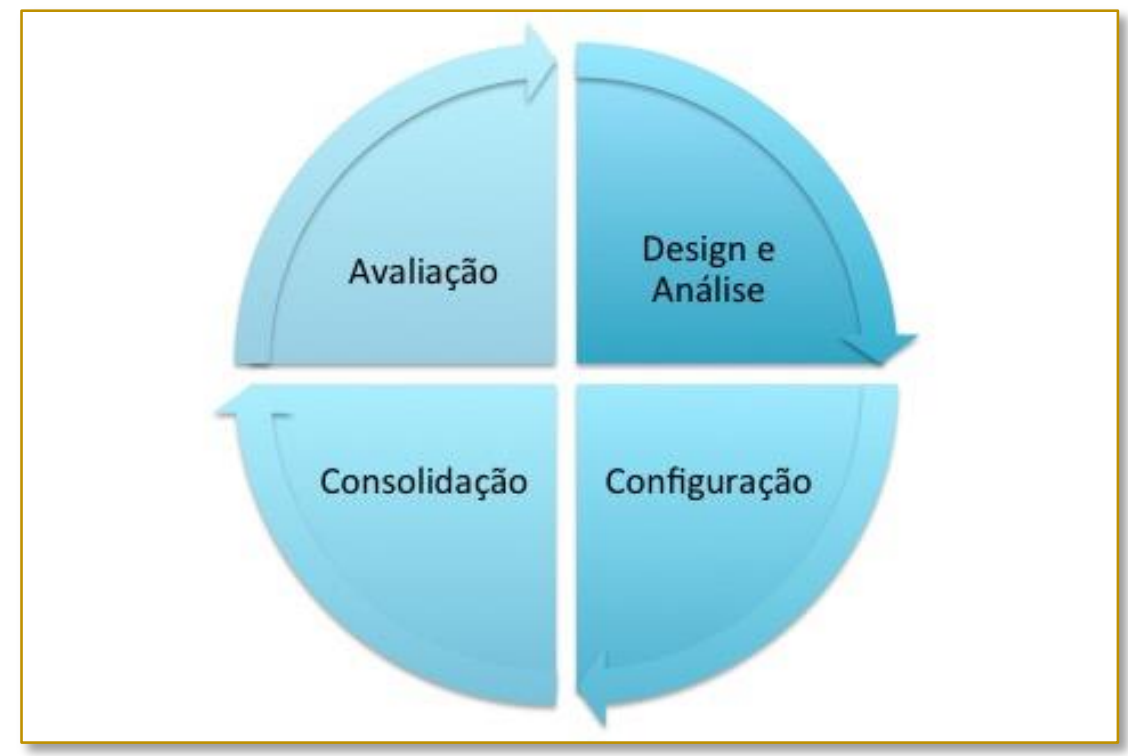

Fonte: Adaptado de Weske (2012)

O foco da pesquisa será na etapa de Consolidação e, como veremos posteriormente, o termo usado será BPM Elástico pois todos os processos envolvidos na correlação entre BPM e Cloud Computing são considerados elásticos (SCHULTE et al. 2015).

\subsection{CLOUD COMPUTING}

Com o crescente aumento do uso e gerenciamento de dados é percebido uma procura intensa para que as informações possuam sistemas com alta capacidade de armazenamento, segurança e acessibilidade. Esse método pode oferecer o aumento do valor agregado do processo e gera novos serviços (CHANG et al. 2013). A computação nas nuvens é uma modalidade de serviço da tecnologia da informação que pode contribuir para melhor interação do usuário com o sistema (WU et al. 2013). Ainda, oferece mecanismos que tornam as aplicações no sistemas automáticas de forma a atender a necessidade do usuário (KRANAS, 2012).

É um modelo de serviços que fornece gerenciamento de dados sob demanda através de uma rede dados. Desta forma, um cliente pode fazer o uso da mesma sem impedimentos quanto a equipamentos e localização. Além disso, os recursos fornecidos pela computação nas nuvens permite a diminuição de desperdício da organização (GREENWELL, 2014). Deste modo, percebe-se que utilizar os recursos que as nuvens fornecem não interferem nos processos já existentes (ACCORSI, 2011).

A Figura 2 apresenta a estrutura básica para um sistema na nuvem. Nele, aparelhos eletrônicos, como por exemplo computadores desktop, laptops e celulares que possuem os requisitos mínimos de nível de qualidade de serviço, são utilizados pelos usuários para a prática de um serviço selecionado. Através da internet, esse serviço é realizado e instantaneamente é compartilhado com o sistema provedor de informação na nuvem (MARSTON et al., 2011). Dessa forma, qualquer usuário que possua o acesso de compartilhamento é capaz de interagir com o sistema e consequentemente realizar as operações em que se deseja, independente de sua localização. 
Figura 2 - Estrutura do Cloud Computing

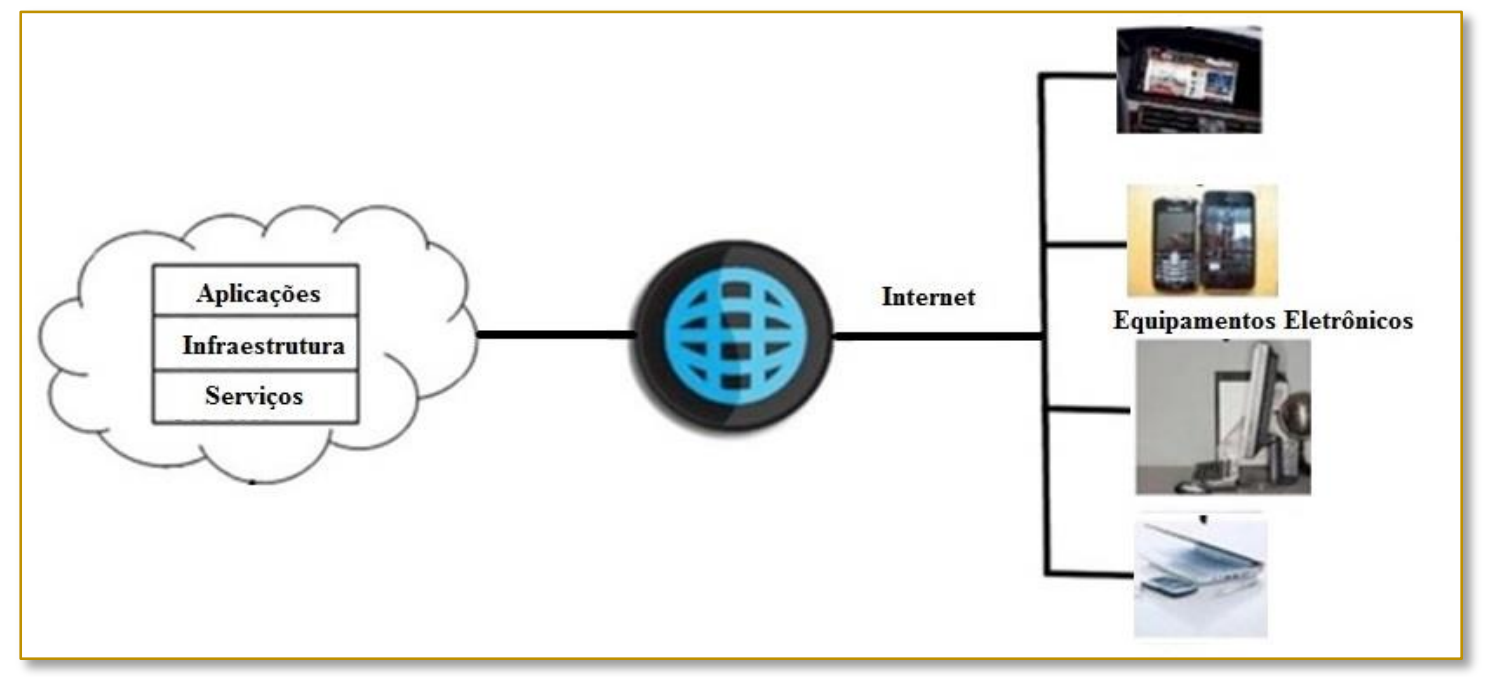

Fonte: Adaptado de Marston et al., 2011

Para que essa interação seja capaz de realizar e suportar atividades e ainda sim 0 sistema suportar tamanha demanda pelos usuário, deve-se garantir que esse sistema possua a característica de ser escalável. Hayes (2008) explica que essa característica significa que o sistema pode continuar em processo sem interrupções independente da quantidade de usuários atuantes no mesmo. Assim, a rede de sistemas pode suportar demasiadas interações entre os usuários e permite ainda que esse sistema não sofra falhas ou que necessite ser totalmente desligado ao receber atualizações (SUN, 2013). O sistema de rede em questão, então, necessita enfrentar alguns desafios, tais como: melhoria do processamento do disco rígido, aquisição de equipamentos adequados, criação condições de armazenamento em cachê que sejam suficientes e, por fim, criação de um sistema que seja integrado (HULL, 2013).

A partir da utilização dos recursos computacionais, a computação nas nuvens permite rápida reação e adaptação às mudanças de demandas sofridas pelas empresas (FANG, 2010). É necessário ainda considerar que isso não é só aplicado apenas para infraestruturas virtuais armazenadas na nuvem, já que processos de negócios completos também podem ser armazenados. Essa prática permite a consolidação de processos chamados elásticos que são executados utilizando recursos (SCHULTE et al., 2015). Portanto, a próxima seção será dedicada exclusivamente para detalhar o a realização de um modelo de processo de negócios na nuvem.

\section{MODELO DE PROCESSO DE NEGÓCIOS NA NUVEM}

Dentre as empresas que podem se beneficiar com o uso de um sistema BPM na nuvem estão aquelas que necessitam de um grande investimento em armazenagem de dados computacionais. Por exemplo, uma empresa que gerencia dados de logística precisa seguir certa ordem para cálculos e transformação dos dados recebidos e armazenados. Schulte et al. (2015) afirma que organizações como essa devem ter acesso à recursos elásticos na nuvem visto que fornecer apenas uma interface Web não seria suficiente para suprir a demanda.

Processos elásticos são definidos quando recursos limitados são oferecidos de forma ilimitada para uso e os provedores os gerenciam, de forma escalável, o quanto for necessário (DUSTDAR et al., 2011). A ideia de utilizar o Elastic Business Process Management (eBPM) é estruturar uma nova forma de modelagem, cultura e performance, e assim monitorar de melhor forma os processos afim de ser proativo e adquirir uma melhor gestão de recursos. Dessa forma, conseguir integrar os processos de negócios com a nuvem.

De acordo com Dustdar et al. (2011), algumas propriedades do eBPM são:

a) Custo: de acordo com os serviços oferecidos são estabelecidos preços. Para 
estabelece-los são usados itens, tais como: o custo de investimento, de fornecedores, de manutenção das máquinas (peças de computador), memória, uso de dados e transmissão que podem ser dinâmicos visto que são utilizados para desenvolver modelos elásticos de computação nas nuvens.

b) Qualidade: é uma forma de mensurar, de fato, a qualidade do uso do recurso. Em outras palavras é quantificar a qualidade em função dos custos. Assim, nota-se a necessidade da melhor utilização do serviço com o uso dos recursos necessários.

Mesmo com tais ofertas de melhoria de processos existe pouca informação disponível a respeito de softwares de BPM que permitem executar um sistema na nuvem. O BPM na nuvem oferece um foco exclusivo em fornecer plataformas de pedidos e softwares para Internet além de vender as tradicionais licenças de softwares para instalação em servidores.

Durante o desenvolvimento de protótipos de pesquisa na área de BPM Elástico, Schulte et al. (2015) citou os desafios enfrentados no armazenamento de processos de negócio na nuvem tais como programação para processos elásticos, alocação de recursos, coleta de dados, coordenação descentralizada e gerenciamento dos estados do ciclo de vida do BPM.

\subsection{PROGRAMAÇÃO PARA PROCESSOS ELÁSTICOS}

O objetivo principal é montar o cronograma que descreve quais tarefas serão executadas em determinado espaço de tempo e utilizando um recurso computacional, dessa forma, maximizando a qualidade de serviço advindo da otimização de um processo.

Para um processo de programação em um cenário de BPM Elástico, é extremamente importante conhecer o tempo de execução de certas tarefas em determinados recursos, o que leva à definição de um intervalo de tempo. Porém, com os processos de negócios na nuvem, esse intervalo precisa ser definido com base em um banco de dados, histórico e ainda com um grau de incerteza (SCHULTE et al., 2015). Porém, no BPMS tradicional, as tarefas são atribuídas seguindo um fluxo de programação orientada com base na origem - humana ou máquina - e a partir daí o processo segue sem foco no prazo. Para esse processo de programação são utilizados conhecimentos dos campos de Pesquisa Operacional e Gestão de Operações. A programação é feita considerando os tempos e controle de fluxo, pois quando não é baseado em prazos, ela segue uma abordagem FIFO (First-In-FirstOut).

Schulte et al. (2015) propôs um modelo de programação baseado em Fluxos de Trabalho Científico que poderia ser usado em recursos armazenados na nuvem e, consequentemente, objetivava redução de custos. Porém, na fase de teste, foram observadas algumas diferenças entre Fluxo de Trabalho Científico e os Processos de Negócios em si, o que está destacado na Tabela 1.

Tabela 1 - Diferenças entre Processos de Negócio e Fluxo de Trabalho Científico

\begin{tabular}{|c|c|}
\hline Processos de Negócios & Fluxo de Trabalho Científico \\
\hline $\begin{array}{l}\text { Possui objetivo orientado para os negócios e } \\
\text { os requisitos para um serviço de qualidade } \\
\text { são mais importantes. }\end{array}$ & $\begin{array}{l}\text { Possui como objetivo criar e organizar tarefas } \\
\text { relativas aos experimentos dos pesquisadores, } \\
\text { facilitando a análise dos dados. }\end{array}$ \\
\hline $\begin{array}{l}\text { O fluxo de controle é explicitamente } \\
\text { modelada enquanto interdependências } \\
\text { relacionadas a dados entre instâncias do } \\
\text { processo são de importância secundária }\end{array}$ & $\begin{array}{l}\text { Possui fluxo de dados orientado onde o fluxo } \\
\text { de execução segue o fluxo de dados. }\end{array}$ \\
\hline $\begin{array}{l}\text { Quanto às características das instâncias do } \\
\text { processo é comum que um grande número } \\
\text { de processos idênticos seja realizada } \\
\text { simultaneamente. }\end{array}$ & $\begin{array}{l}\text { As características das instâncias do processos } \\
\text { são interdependentes, o que resulta em } \\
\text { diferentes instâncias do mesmo fluxo de } \\
\text { trabalho sendo transportadas em lotes. }\end{array}$ \\
\hline
\end{tabular}

Fonte: Adaptado de Schulte et al. (2015) 
Baseado nessas diferenças encontradas, conclui-se que as abordagens atuais referentes ao Fluxo de Trabalho Científico não são aplicáveis aos Processos de Negócios. Todas as abordagens de programação para processos elásticos devem levar em consideração a alocação de recursos, assunto da próxima seção.

\subsection{ALOCAÇÃO DE RECURSOS}

O avanço do Cloud Computing beneficia o sistema BPM a partir do momento em que é explorado todo o potencial de recursos da nuvem e ainda utilizando esses recursos na quantidade que for preciso (SCHULTE et al., 2015). A alocação de recursos está relacionada com a previsão de pedidos e cargas de trabalho. Dentre seus objetivos, está a decisão de quantos recursos de certo tipo serão utilizados para que certo processo seja executado da maneira esperada.

Para que essa previsão de carga de trabalho seja realizada, é necessário prever o número de pedidos feitos em um modelo de processo considerando quanto de carga de trabalho esse pedido pode precisar, como exemplo: a solicitação dentro de um processo elástico pode ser caracterizada através de uma troca de mensagens entre servidores que podem influenciar o fluxo de produção. Schulte et al. (2015) destaca que, quanto aos processos de negócios na nuvem, existem abordagens diretas para alocação de recursos, porém essas ainda não garantem adaptação para cenários de BPM na nuvem pois possuem muitas limitações.

\subsection{MONITORAMENTO DO PROCESSO E COLETA DE DADOS}

O monitoramento do processo e a coleta de dados são baseados nos conceitos de EDA e SOAs. O EDA, ou elaboração de um evento orientado, se caracteriza pelo desenvolvimento de um software que fornece ferramentas de acompanhamento de fácil utilização. Os SOAs, conhecidos como a elaboração de um serviço orientado, oferecem serviços de comunicação entre cliente e sistema através da web ou para comunicação (SCHULTE et al., 2015).

Desde modo, com o crescente aumento no número de dados, adotam-se uma nova definição para evento que passa a ser definido como um registro de atividades que já ocorreu ou ainda irá ocorrer (FITÓ, 2012). Para que tal processamento de eventos seja realizado utiliza-se a tecnologia CEP (Complex Event Processing). O CEP se insere no BPM como parte elástica e é utilizado para analisar e verificar o andamento do processo. Isso aumenta a eficiência do CEP que acaba por ajudar na tomada de decisões e gerenciamento de negócios (SCHULTE et al., 2015).

\subsection{DESCENTRALIZAÇÃO COORDENADA PARA A CONSOLIDAÇẨO DO PROCESSO}

O BPMS (Business Process Management Systems) possui fraca escalabilidade quando está centralizado, trazendo alguns problemas a rede (SCHULTE et al., 2015). Existem diversos modelos de descentralização, em um deles há um motor "mestre" que encarrega tarefas a motores menores que administram as funções, uma delas é o gerenciamento de dados. Um outro exemplo é o peer-to-peer (P2P) que tem por principal característica a descentralização da rede. Onde cada computador pode funcionar como servidor e cliente ao mesmo tempo. Baseados no P2P surgiram diversos programas, estes são: SwinDew- $C$, com a função de comunicação; OSIRIS-SR; BPELcube.

Fazendo uma comparação entre a descentralização e centralização, nota-se que a descentralização coordenada apresenta vantagens como o aumento da confiabilidade, escalabilidade e a estabilidade dos recursos econômicos enquanto o centralizado tem o benefício de ter as provisões de recursos.

\subsection{O GERENCIAMENTO DE ESTADO}

O processo de consolidação pode necessitar um ambiente específico de comunicação, disponibilidade, desempenho, segurança e condições isoladas. Ele envolve o estado atual das tarefas que estão em execução, a lista de tarefas que estão esperando para serem executadas e o fluxo de dados que estão em progresso. Portanto, pode-se concluir que o processo de consolidação deve ser consistente através de toda e qualquer operação para que falhas sejam evitadas, para isso os dados devem exibir caráter consistente, verdadeiro, confiável e durável no momento em que são adicionados 
ou removidos de um sistema de gerenciamento de dados (SCHUSTER et al., 1999).

\section{ESTUDO DE CASO}

A partir do processo de um modelo de negócios na nuvem mostrado nas seções anteriores, apresentamos nesta seção um exemplo de implementação do BPM na nuvem chamada Plataforma Vienna para processos elásticos

\subsection{A PLATAFORMA VIENNA PARA PROCESSOS ELÁSTICOS}

A plataforma Vienna para processos elásticos é considerado um BPM elástico e considera o cuidado com o recebimento e gerenciamento de serviços de software em um ambiente na nuvem e mapeamento de pedidos de processos, estes requeridos pelos clientes (SCHULTE et al., 2015).

Figura 4 - Estrutura da Plataforma Vienna

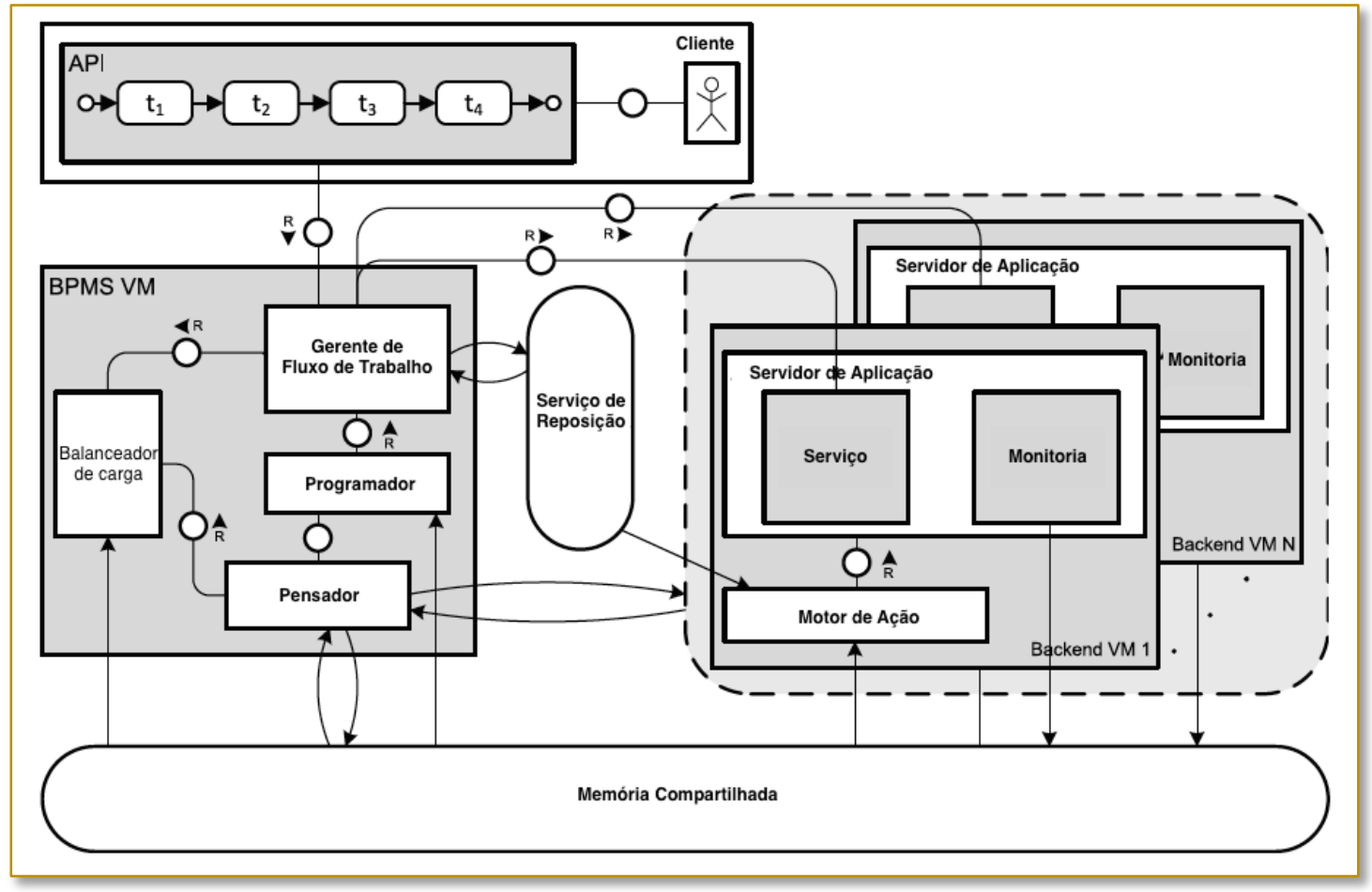

Fonte: Adaptado de Schulte et al. (2015)

O cliente pode requisitar um processo e pode definir acordos de níveis de serviço para um processo; o Gerente de Fluxo de Trabalho é responsável pela aceitação da solicitação dos processos e ainda pela execução do processo (em que cada tarefa é direcionada a um software específico); o programador é capaz de computar em quais períodos de tempo a execução deve ser iniciada para que garanta que o acordo de nível de serviço seja aderida; o pensador é responsável pela planejamento de programação o qual computa recursos requeridos; o balanceador de carga é capaz de equilibrar os pedidos de serviços em recursos disponíveis para que possa ter uma relativa carga igual em caga memória virtual (VM).

A informação é lida através da memória compartilhada. Além disso, uma fonte crucial de troca de informação é o chamado Sistema de Memória Virtual Backend. Na Plataforma Vienna apresentada pela Figura 4, vários sistemas de memória virtual Backend são implementados. O servidor de aplicações recebe uma única modalidade de serviço. 0 monitor é iniciado e mede a capacidade de memória usadas no sistema e o tempo de resposta do serviço implementado. Os dados 
e informações são então armazenados e compartilhados entre BPMS com memórias virtuais na seção de compartilhamento de memórias e um mecanismo de ação, que é capaz de executar diferentes ações comandadas pelo pensador, é implementado (SCHULTE et al., 2015).

\section{CONCLUSÃO}

A presente pesquisa apresentou como seu objetivo principal como o processo de implementação de um modelo baseado a partir do Business Process Management na Computação nas Nuvens ocorre. Para isso, foram ilustrados os elementos fundamentais do BPM e do Cloud Computing e um processo de modelo de negócio implementado na nuvem foi detalhado em cinco subseções. Sendo o exemplo mais referido na literatura, a Plataforma Vienna para processos elásticos foi, então, escolhida como modelo de um BPM na nuvem com o intuito de apresentar o funcionamento desse processo.

O estudo de caso deste artigo mostrou o funcionamento básico de um modelo BPM aplicado e implementado em um processo de Computação nas Nuvens. A Plataforma Vienna para processos elásticos permite a integração dos usuários do sistema e

\section{REFERENCIAS}

ACCORSI, R. Automated Certification for Compliant Cloud-based Business Processes. Business \& Information Systems Engineering, V. 3, p. 145-154, 2011. (clique aqui)

[2] CHANG, V. et al. Case Studies and Organizational Sustainability Modelling presented by Cloud Computing Business Framework. International Journal of Web Services Research, V. 8, No. 3, 2011. (clique aqui)

[3] CHANG, Victor. The Business Intelligence as a Service in the Cloud. Future Generation Computer Systems, V. 37, p. 512-534, 2013. (clique aqui)

[4] CHANG, Victor; WALTERS, Robert J.; WILLS, Gary. The development that leads to the Cloud Computing Business Framework. International Journal of Information Management, V. 33, p. 524-538, 2013. (clique aqui)

[5] CHOUDHARY, R. A Survey on Cloud Computing Architecture. International Journal of Computing Technology and Application, V. 3, p. 1400-1405, 2012. (clique aqui) claramente define as suas respectivas funções dentro do processo. Além disso, a plataforma ainda esclarece o processo de armazenamento de informação do sistema, sendo esse altamente escalável. Ainda, mostra a importância dos sistemas de memórias virtuais, servidores de aplicações e monitores, pois influenciam diretamente nos elementos de memória compartilhada do sistema como um todo.

Portanto, da leitura apresentada, a implementação do BPM no Cloud Computing é aconselhado pois há a presença de estruturas definidas para cada usuário e os elementos de base das informações do sistema são concisos de forma a garantir a eficácia e segurança do sistema. Porém, a partir do estudo das realizações de um modelo BPM elástico, é imprescindível salientar que é necessário o estudo e desenvolvimento de mais aplicações sobre o processo de implementação de um modelo de gerenciamento de processos de negócios na nuvem pois foi observado que as informações obtidas para esse tipo de processo se encontram escassas e limitadas a poucos estudos. Um dos motivos que gerou a limitação do desenvolvimento do estudo de caso desta pesquisa pode ser advinda da baixa maturidade do assunto no âmbito literário.

[6] CORIA, J. A.; CASTELLANOS-GARZÓN, J. A.; CORCHADO, J. M. Intelligent business processes composition based on multi-agent systems. Expert Systems with Applications, V. 41, p. 1189-1205, 2014. (clique aqui)

[7] DEVGAN, Mandeep; DHINDSA, Kanwalvir S. A Study of Different QoS Management Techniques in Cloud Computing. International Journal of Soft Computing and Engineering, V. 3, p. 37-41, 2013. (clique aqui)

[8] DUIPMANS, Evert F.; PIRES, Luís F.; SANTOS, Luiz O. B. S. A Transformation-Based Approach to Business Process Management in the Cloud. Journal of Grid Computing, V. 12, p. 191219, 2014. (clique aqui)

[9] DUSTDAR, S.; GUO, Y.; SATZGER, B. Principles of Elastic Processes. IEEE Internet Computing, p. 66-71, 2011. (clique aqui)

[10] FANG, Z.; TIN, C. BPM Architecture Designed based on Cloud Computing. Intelligent Information Management, V. 2, p. 329-333, 2010. (clique aqui)

[11] FITÓ, J. Business-driven management of Infrastructure-level risks in Cloud providers. Future 
Generation Computer Systems, V. 32, p. 41-53, 2014. (clique aqui)

[12] GREENWELL, R.; LIU, X.; CHALMERS, K. Benefits Management of Cloud Computing Investments. International Journal of Advanced Computer Science and Applications, V. 5, 2014. (clique aqui)

[13] HAYES, B. Cloud Computing. Communications of the ACM, V. 51, No. 7, p. 9-11, 2008. (clique aqui)

[14] HULL, S. 20 Obstacles to scalability. Communications of the ACM, V. 56, p. 54-59, 2013. (clique aqui)

[15] JARARWEH, Y. et al. CloudExp: A comprehensive Cloud Computing experimental framework. Simulation Modelling Practice and Theory, V. 49, p. 180-192, 2014. (clique aqui)

[16] KRANAS, P. et al. ElaaS: An innovative Elasticity as a Service framework for dynamic management across the cloud stack layers. Sixth International Conference on Complex, Intelligent, and Software Intensive Systems, 2012. (clique aqui)

[17] MARSTON, S. et al. Cloud Computing The business perspective. Decision Support Systems, V. 51, p. 176-189, 2011. (clique aqui) [18] MOHAMED, M. et al. An autonomic approach to manage elasticity of business processes in the Cloud. Future Generation Computer Systems, 2014. (clique aqui)

PRASAD, A.; GREEN, P.; HEALES, J. On governance structures for the cloud computing services and assessing their effectiveness, V. 15, p. 335-356, 2014. (clique aqui)

[20] PERNICI, B.; WESKE, M. Business Process Management. Data \& Knowledge Engineering, V. 56, p. 1-3, 2006. (clique aqui)

[21] ROHLOFF, M. Advances in business process management implementation based on a maturity assessment and best practice exchange. Information Systems and e-Business Management, V. 9, p. 383-403, 2010. (clique aqui)

[22] SCHMIEDEL, T.; BROCKE, J. V.; RECKER, J. Development and Validation of an Instrument to
Measure Organizational Culture's Support of Business Process Management. Information and Management, V. 51, p. 43-56, 2014. (clique aqui)

[23] SCHULTE, Stefan. et al. Elastic Business Process Management: State of the art and open challenges for BPM in the cloud. Future Generation Computer Systems, V. 46, p. 36-50, 2015. (clique aqui)

[24] SCHUSTER, H.; NEEB, J.; SCHAMBURGER R. A configuration management approach for large workflow management systems. International Joint Conference on Work Activities Coordination and Colaboration, p. 177-186, 1999. (clique aqui)

[25] SUN, A. Enabling collaborative decisionmaking in watershed management using cloud computing services. Environmental Modelling and Software, V. 41, p. 93-97, 2013. (clique aqui)

[26] TRKMAN, P. The critical success factors of business process management. International Journal of Information Management, V. 30, p. 125134, 2010. (clique aqui)

[27]VULKSIC, V. B.; BACH M. P.; POPOVIC, A. Supporting performance management with business process management and business intelligence: A case analysis of integration and orchestration. International Journal of Information Management, V. 33, p 613-619, 2013. (clique aqui) [28] WELHARDT, C. et al. Cloud Computing - A classification, business models, and research directions. Business \& Information Systems Management, V. 5, p. 391-399, 2009. (clique aqui) [29] WESKE, M. Business Process Management: Concepts, Languages, Architectures, second ed., Springer, 2012. (clique aqui)

[30] WONG, W. P. et al. The impact of external environmental on business process management and organizational performance. Service Business, V. 8, p. 559-586, 2014. (clique aqui)

[31] WU, Y. et al. Cloud Computing in Support of Supply Chain Information System Infrastructure: Understanding when to go to the Cloud. Journal of Supply Chain Management, V. 49, No. 3, p. 25-41, 2013. (clique aqui) 


\title{
Bapítulo 13
}

\section{INOVAÇÃO NO PLANEJAMENTO MESTRE DE PRODUÇÃO E OPERAÇÕES NO RAMO ALIMENTÍCIO}

\author{
Murilo Gonçalves Almeida \\ Thiago José Barbosa Dantas \\ Flávio de São Pedro Filho \\ Carolina Yukari Veludo Watanabe \\ Tomás Daniel Menendez Rodrigues
}

Resumo: As organizações portovelhenses necessitam de planejamento de suas atividades. Esta trabalho sobre o Planejamento Mestre de Produção de uma empresa do ramo alimentício localizada no município de Porto Velho, Capital do Estado de Rondônia. Tem por base a Teoria Contingencial, reunindo os conceitos da Análise SWOT e de inovação como vem sendo tratado em Silva et al (2011) e Queiroz et al (2012). Tem por objetivo geral estudar o Planejamento Mestre de Produção e Operação em uma empresa do ramo alimentício; e como objetivos específicos levantar o processo de produção e operações da empresa (1), demonstrar as práticas adotadas para o planejamento mestre de produção e operações na plataforma produtiva em estudo (2) e efetuar uma análise crítica sobre os possíveis elementos de inovação nos processos a serem praticados na empresa (3). O preparo seguiu pelo Método do Estudo de Caso, com suporte em levantamento bibliográfico orientado em Pizzani et al (2012); como procedimentos realizou-se visita in situ, entrevistas, observação para coleta e seleção de dados, e outros requeridos pelo método. Como resultados tem-se que a empresa utiliza o Planejamento Mestre de Produção, a mesma não possui estoque de materiais e realiza as vendas de acordo com a demanda. Foi possível perceber a importância da análise SWOT para melhorar a performance organizacional em face do conhecimento da realidade a qual a empresa está inserida, bem como suas potencialidades e fraquezas. Este estudo interessa a todos os envolvidos na excelência do desempenho organizacional da produção.

Palavras-chave: Administração. Amazônia. Gestão. Inovação. Planejamento. Produção. 


\section{INTRODUÇÃO}

Este trabalho trata sobre o planejamento mestre de produção e operações em uma empresa do ramo alimentício do município de Porto Velho, Capital do Estado de Rondônia. O que se observa neste cenário é a predominância da necessidade de estudos voltados para a estratégia competitiva das empresas em geral, e em especial naquelas relacionadas ao ramo de alimentos como as panificadoras, objeto desta pesquisa.

O Planejamento envolve o estabelecimento de planos e alguns são estratégicos para o desempenho eficiente de uma panificadora; envolve o levantamento de máquinas, equipamentos, pessoas, materiais diversos, energia e demais recursos a serem mobilizados para a entrega do produto final ao consumidor. Esta tarefa seguirá este raciocínio, primeiro indicando os objetivos e depois tratando sobre uma revisão teórica e conceitual que permita a interpretação do estado da arte; uma metodologia será considerada e os resultados serão tratados aqui, seguidos dos resultados, conclusão e referências.

Diante dessa realidade, o presente trabalho visa responder ao seguinte problema de pesquisa: De que forma a empresa em estudo realiza seu planejamento das atividades produtivas? Para responder à pergunta foi admitido como objetivo geral estudar o Planejamento Mestre de Produção e Operação em uma empresa do ramo alimentício. Para que tal objetivo seja atendido foram designados três objetivos específicos; para isso admite-se como objetivos específicos levantar o processo de produção e operações da empresa em estudo (1), demonstrar as práticas adotadas para 0 planejamento mestre de produção e operações na plataforma produtiva focalizada (2), e efetuar uma análise crítica sobre os possíveis elementos de inovação nos processos a serem praticados na empresa pesquisada (3).

\section{REVISÃO TEÓRICO-CONCEITUAL}

O Planejamento Mestre de Produção está baseado na teoria das contingências e sua aplicação nas empresas e organizações de modo a atender as necessidades emergentes e situacionais bem como nos aspectos de inovação necessários para suscitar seu sucesso e aplicação social e mercadológica. Nesse sentido, a revisão em questão abordará em primeiro a Teoria das Contingências, em um segundo momento no Planejamento Mestre de Produção, em seguida a respeito da Inovação nesse segmento e por último abordará a análise de SWOT.

\subsection{TEORIA DA CONTINGÊNCIA}

O levantamento bibliográfico efetuado em Souza et al (2013) teoriza que o ambiente influencia diretamente na organização e, sendo um sistema aberto, essas influências serão essenciais para a sobrevivência dessa organização. A Teoria da Contingência é levada em consideração pois focaliza a influência do comportamento organizacional para a adequação ao ambiente como estratégia para o alcance dos objetivos.

A Teoria da Contingência é a mais recente das teorias da administração, sendo uma junção das teorias clássicas e das teorias científicas, possibilitando uma aplicação variada e diversificada. Esta teoria também mostra que as organizações sofrem influência tanto do ambiente interno como do ambiente externo. Delimita que não há nada absoluto nas organizações e, conforme trata Bächtold (2012), essa abordagem afirma que a relação entre as condições e as técnicas administrativas traz a eficácia e atendimento dos objetivos propostos pela organização. Esta realidade é tratada em Santos (2014) ao afirmar que na Teoria da Contingência não há apenas uma forma das empresas em se estruturarem; o autor se refere à perspectiva em ambientes estáveis, com baixa possibilidade e incerteza, quando as atividades serão executadas com eficácia por meio de uma hierarquia centralizada, com trabalho diário e distinção entre as responsabilidades. Por outro lado, em ambientes instáveis e com possibilidades de inovações constantes, o autor focaliza a possibilidade de maior desenvolvimento em estruturas orgânicas, mediante diversificação de tarefas, menor formalização de cargos e planificação na hierarquia. Em outras palavras, nas organizações estáveis vigoraria a Teoria Clássica, ao passo que em organizações mais instáveis vigoraria a Teoria das Relações Humanas.

Por outro lado, e ainda de acordo com o mesmo autor Santos (2014), diferentes formas 
de organização gerem diferentes formas de expansão, ou pela expansão através de uma estratégia, ou no sentido contrário. De modo que para realizar o aumento das empresas são necessárias a criação de novas atividades, recursos e uma nova estrutura para a mesma. É importante considerar que a adaptação da empresa às novas situações não se processa de modo automático, mas alguns fatores atuam diretamente nessas questões, podendo citar como: a existência de uma estrutura organizacional adequada, o que dificulta a adequação, a natureza multifacetada do envolvimento dos membros da organização, entre outros.

A Teoria Contingencial é abordada em Rocha (2011) ao se referir à influência nos processos produtivos. O seu estudo está direcionado a uma manufatura de processos contínuos, na qual acontece a aquisição de matéria prima, a sua melhoria através dos processos de transformação para obtenção de produto final. É neste processo que as influências ambientais ocorrerem, cabendo conhecer a forma. O autor explicita que, ao passo em que se armazenam as matérias primas para a produção, uma inadequação pode acarretar em alteração do resultado do produto final, que poderá gerar insatisfação na demanda.

\subsection{PLANEJAMENTO MESTRE DE PRODUÇÃO (PMP)}

O Planejamento Mestre de Produção (PMP), para Rocha (2011), advém das terminologias inglesas Master Production Shedule (MPS); é uma normativa interna da empresa que especifica quais os itens serão produzidos, bem como suas quantidades, em um determinado período, funciona com um planejamento estratégico reduzido. No Planejamento Mestre de Produção, serão elaborados cálculos detalhados das necessidades dos produtos finais, que servirão para a elaboração das quantidades de tempo e material necessários para os produtos estarem prontos. Estes dados serão baseados ainda em alguns fatores como demanda pelos produtos do portfólio, nível de estoque e controle de prazos de validade, nos casos de material perecível, por exemplo.

Por outro lado, o PMP, de acordo com o pensamento de Ferreira (2012), tem como função coordenar ou até mesmo balancear os suprimentos e demandas dos produtos acabados, em períodos de médio prazo, além de atuar também em baixo nível pelo curto prazo. O PMP é ajustado diariamente de acordo com as necessidades do cliente e das empresas. Essas mudanças se fazem importantes de acordo com a relação da capacidade de produção e sua consequente variabilidade de processos, já que esses devem estar atentos às mudanças de prazos das organizações. Portanto, o PMP deve saber o que fazer, onde fazer, em quanto tempo irá realizar a operação e quando irá fazer determinado produto.

O PMP conforme o pensamento de Pretto, Ramos e Pretto (2011) é a base para o estabelecimento de compromissos entre os interesses de diversas ações dentro da organização e influencia a totalidade dos setores, como por exemplo, o marketing realiza a divulgação do produto, mas a produção de um dado produto poderá ser possível somente em detrimento nos prazos de produção do mesmo, caso contrário a propaganda e a venda deixam de ter validade e acabam frustrando o cliente. Por outro lado, um aumento nas vendas e na produção repercute na movimentação do setor de Recursos Humanos na contratação de novos profissionais, além de treinamento, por exemplo. Ainda se terá um aumento na área de finanças com acréscimo de gastos com estoques, horas extras, contratação de profissionais, entre outros.

Como forma complementar, Evangelista et al (2011) consideram que o PMP é mais detalhado de médio período, realizado de tempos em tempos, por meio de produtos já vendidos ou confirmados na carteira de vendas. Entretanto, desenvolver o PMP de forma adequada não é uma tarefa simples, pois são vários os elementos avaliados. O desenvolvimento do PMP é uma tarefa árdua e complexa, pois é conduzido por diversas tentativas até que se chegue ao modelo ideal de desenvolvimento. O PMP atua ainda nas ações de mudança e modernização das empresas podendo ser inserido como uma estratégia de competição, já que, de acordo com Antunes, Sehnem e Lima (2014), ele promove a conquista e sustentação das vantagens competitivas, mas para que tal fenômeno aconteça é necessário que a organização tenha bem claro e definido seus objetivos e as estratégias para alcançar os mesmos. 


\subsection{O PLANEJAMENTO MESTRE DE} PRODUÇÃO E A INOVAÇÃO

A inovação para o pensamento de Severo et al (2012) está relacionada com a adoção de um novo método de produção, de um novo produto, de uma nova forma de organização ou de uma conquista recente de mercado. Ou ainda, a inovação acontece no momento em que as empresas introduzem mudanças capazes de criar melhorias para 0 desempenho organizacional. Para que uma organização possa estar constantemente alimentada pela inovação é fundamental a presença de um ambiente composto de profissionais qualificados e constantemente treinados, com espaço aberto para a criatividade e aceitação das propostas, um nível reduzido de ruídos na comunicação, propício a troca de informações, entre outras qualificadoras.

Sobre inovação, Souza et al (2013) citam a importância desta nos processos de competitividade, abordando uma visão sistêmica da empresa com o ambiente, assim influenciando o crescimento tecnológico. Seguindo esse caminho, levantamentos bibliográficos efetuados em Evangelista et al (2011) e em Peixoto (2013) indicam que nos sistemas de produção, sendo eles de pequeno ou grande porte se faz necessário o Planejamento de Controle e Produção.

No pensamento de Hékiset al (2013) o desempenho inovador de uma organização está diretamente relacionado com sua capacidade de obter informação, processá-la e disponibilizá-la de forma segura. E diante dessa realidade a gestão informacional é chave no processo de construção e de realização de projetos e programas, além de ser geradora da sustentabilidade $e$ de sustentação no mercado dos negócios. A capacidade de inovação pode ser melhorada por um conjunto de dimensões como estratégia, liderança, relacionamento, cultura, pessoas, estrutura, processo, entre outros.

O Planejamento de Controle e Produção pode ser desenvolvido de três formas, sendo de longo, médio e curto prazo. Portanto, pode-se considerar o Plano Mestre como a formalização da produção, sendo demonstradas as necessidades específicas de material e capacidade. Sendo assim, se faz necessária também a avaliação das necessidades de mão-de-obra, equipamentos e materiais a serem utilizados no processo de produção.

\subsection{ANÁLISE SWOT}

Silva et al (2011) citam que esta ferramenta foi criada por professores da Harvard Business School, e utilizada por acadêmicos posteriormente. A ferramenta em questão aborda a competitividade de uma organização e segue quatro variáveis: Strengths (Forças), Weaknesses (Fraquezas), Oportunities (Oportunidades) e Threats (Ameaças). Dentre as variáveis, as forças e fraquezas estão ligadas à empresa e oportunidades e ameaças ao ambiente externo à organização.

Ainda segundo o estudo feito em Silva et al (2011), Chiavenato e Sapiro (2003) citam que cruzar as oportunidades e ameaças do ambiente com as fortalezas e fraquezas da organização é a função principal da análise de SWOT. Estas quatro zonas variáveis servem de direção para a situação da organização.

Em Queiroz et al (2012), Do Valle et al (2008) dizem que a análise SWOT é muito utilizada no planejamento estratégico, onde se relaciona o ambiente externo e interno da organização. Esta análise direciona a identificação das oportunidades, que usadas podem melhorar o desempenho e as ameaças que podem afetar este desempenho. Além das variáveis do ambiente externo, identifica também as do interno, que são as forças e fraquezas.

\section{PROCEDIMENTOS METODOLÓGICOS}

A presente pesquisa inicialmente foi do tipo bibliográfica que, para Pizzaniet al (2012), trata-se da revisão de literatura sobre as principais teorias norteadoras do trabalho científico, podendo ainda ser chamada de levantamento bibliográfico e pode ser realizada em livros, periódicos, artigos de jornais, sites da internet, entre outros. Dentre os objetivos da revisão de literatura tem-se a possibilidade de proporcionar um aprendizado sobre uma determinada área do conhecimento, como é o caso do PMP, além de facilitar a identificação dos métodos a serem utilizados pelos pesquisadores e oferecer subsídios para a introdução e redação da discussão do trabalho. 
A pesquisa foi também do tipo estudo de caso, já que se caracteriza por um estudo aprofundado da plataforma de estudo. Ainda foi do tipo de estudo de campo a qual procura o aprofundamento de uma realidade específica, realizado em sua maioria por meio de observação da realidade, entrevistas e aplicação de questionário a fim de captar as explicações e interpretações da situação in 10co. O instrumento da coleta de dados será a entrevista semiestruturada, na qual os pesquisadores realizam um roteiro prévio das perguntas, de modo a atender os objetivos da pesquisa. Os dados coletados serão comparados mediante a teoria e a prática realizada no levantamento dos dados.

Com relação à apresentação e discussão dos resultados da pesquisa, serão demonstrados mediante a base teórica as tendências e os contrapontos da temática relacionada ao planejamento estratégico bem como os objetivos estabelecidos de modo inicial pela presente pesquisa. Por fim, e não menos importante, será apresentada uma proposta de inovação relacionada ao planejamento da produção na empresa em estudo. Com vistas a compreender melhor a realização dos procedimentos metodológicos, segue a Figura 1 e o respectivo Quadro 1, que trazem detalhes desses aspectos.

Figura 1: Diagrama dos procedimentos metodológicos
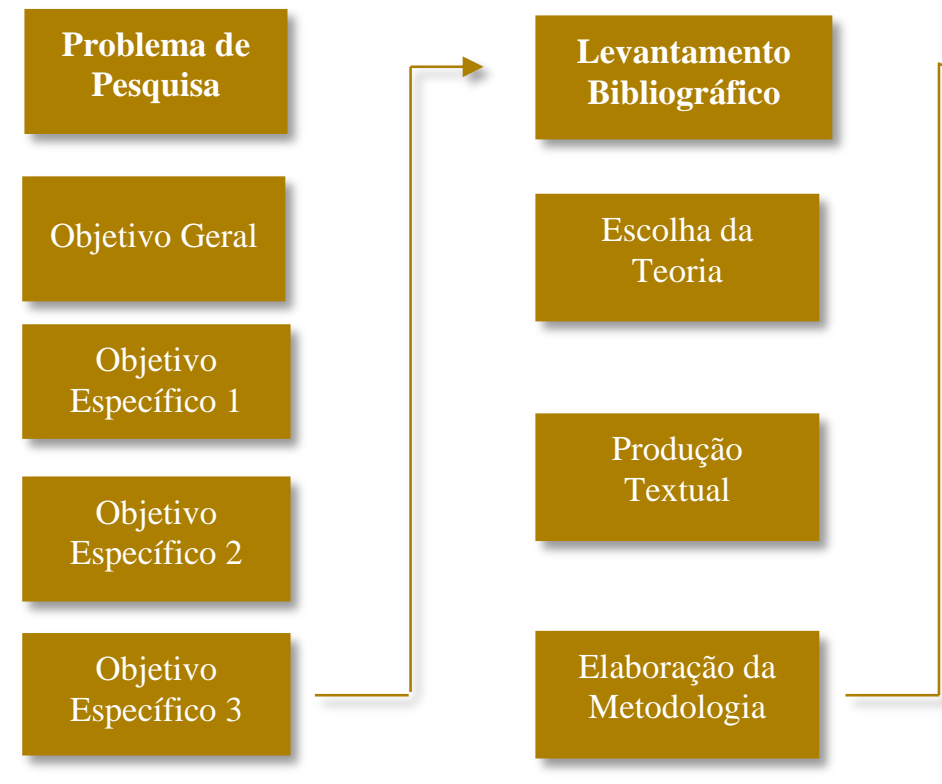

\section{Estudo de caso e de campo}

Visita e

entrevista in loco

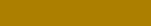

Análise dos

dados

\section{Resposta aos}

objetivos

Fonte: Elaborado pelos autores 
Quadro 1: Detalhamento dos procedimentos adotados

\begin{tabular}{|c|c|}
\hline Procedimentos Adotados & Descritiva dos procedimentos \\
\hline 1. Problema de pesquisa & $\begin{array}{l}\text { O problema de pesquisa trata-se de um questionamento que } \\
\text { irá perpassar por toda a pesquisa, seja a parte do } \\
\text { levantamento bibliográfico, a metodologia, a aplicação do } \\
\text { instrumental de coleta de dados, a análise dos dados e } \\
\text { principalmente, a resposta aos objetivos e o alcance dos } \\
\text { mesmos na realização dos processos científicos. }\end{array}$ \\
\hline 2. Objetivos & $\begin{array}{l}\text { Os objetivos são considerados a base para a realização da } \\
\text { pesquisa. Tratam-se do caminho a ser seguido para } \\
\text { responder a indagação do problema de pesquisa. Para } \\
\text { melhor ser compreendidos foram desmembrados em objetivo } \\
\text { geral e objetivos específicos. Esses por fim, direcionam o } \\
\text { andamento técnico da pesquisa. }\end{array}$ \\
\hline $\begin{array}{l}\text { 3.Levantamento } \\
\text { bibliográfico }\end{array}$ & $\begin{array}{l}\text { O levantamento bibliográfico é a realização de um apanhado } \\
\text { nas publicações científicas dos pesquisadores da temática } \\
\text { em discussão, de modo a compreender como esses } \\
\text { pensadores compreendem o fenômeno do Planejamento } \\
\text { Mestre de Produção (PMP). Nesse item foram apresentados } \\
\text { os principais artigos publicados no Brasil desde o ano de } \\
2010 \text {. }\end{array}$ \\
\hline $\begin{array}{l}\text { 4. Elaboração da } \\
\text { Metodologia }\end{array}$ & $\begin{array}{l}\text { A metodologia é como a pesquisa foi realizada, desenvolvida } \\
\text { e implementada no seu local de realização. É nesse item que } \\
\text { foram abordadas a questão da pesquisa bibliográfica, do } \\
\text { estudo de caso por ser uma realidade específica e do estudo } \\
\text { de campo já que os acadêmicos foram em busca de seus } \\
\text { resultados. }\end{array}$ \\
\hline $\begin{array}{l}\text { 5. Respostas aos } \\
\text { objetivos }\end{array}$ & $\begin{array}{l}\text { Por fim, após o levantamento bibliográfico, a construção da } \\
\text { metodologia e a análise dos dados. A resposta aos objetivos } \\
\text { e a problemática da pesquisa é ponto fundamental para } \\
\text { verificar se os dados recolhidos e analisados são suficientes } \\
\text { para atender a esses questionamentos. Esse ponto é crucial } \\
\text { para a conclusão da pesquisa. }\end{array}$ \\
\hline
\end{tabular}

Fonte: Elaborado pelos autores

\section{ESTUDO DE CASO SOBRE OPLANEJAMENTO MESTRE DE PRODUÇÃO E OPERAÇÕES}

O estudo foi desenvolvido em uma empresa do ramo alimentício (panificação) do município de Porto Velho, capital do Estado de Rondônia, onde em levantamento realizado in loco pôde-se acompanhar os processos produtivos da empresa, onde se percebeu que os procedimentos adotados são desenvolvidos de forma organizada, com o auxílio de maquinário próprio para panificação, adquirido recentemente para o atendimento da demanda, além de promover uma melhor qualidade ao produto, atraindo assim uma quantidade maior de clientes. Os processos produtivos da panificadora são desenvolvidos em três etapas: aquisição de matéria prima (1); processos de transformação da matéria prima em produtos (2); disponibilização dos produtos para venda (3). Na Figura 2 e no Quadro 2 estão respectivamente o fluxograma e a descrição dos processos produtivos da empresa em estudo. 
Figura 2: Fluxograma dos processos produtivos da empresa em estudo

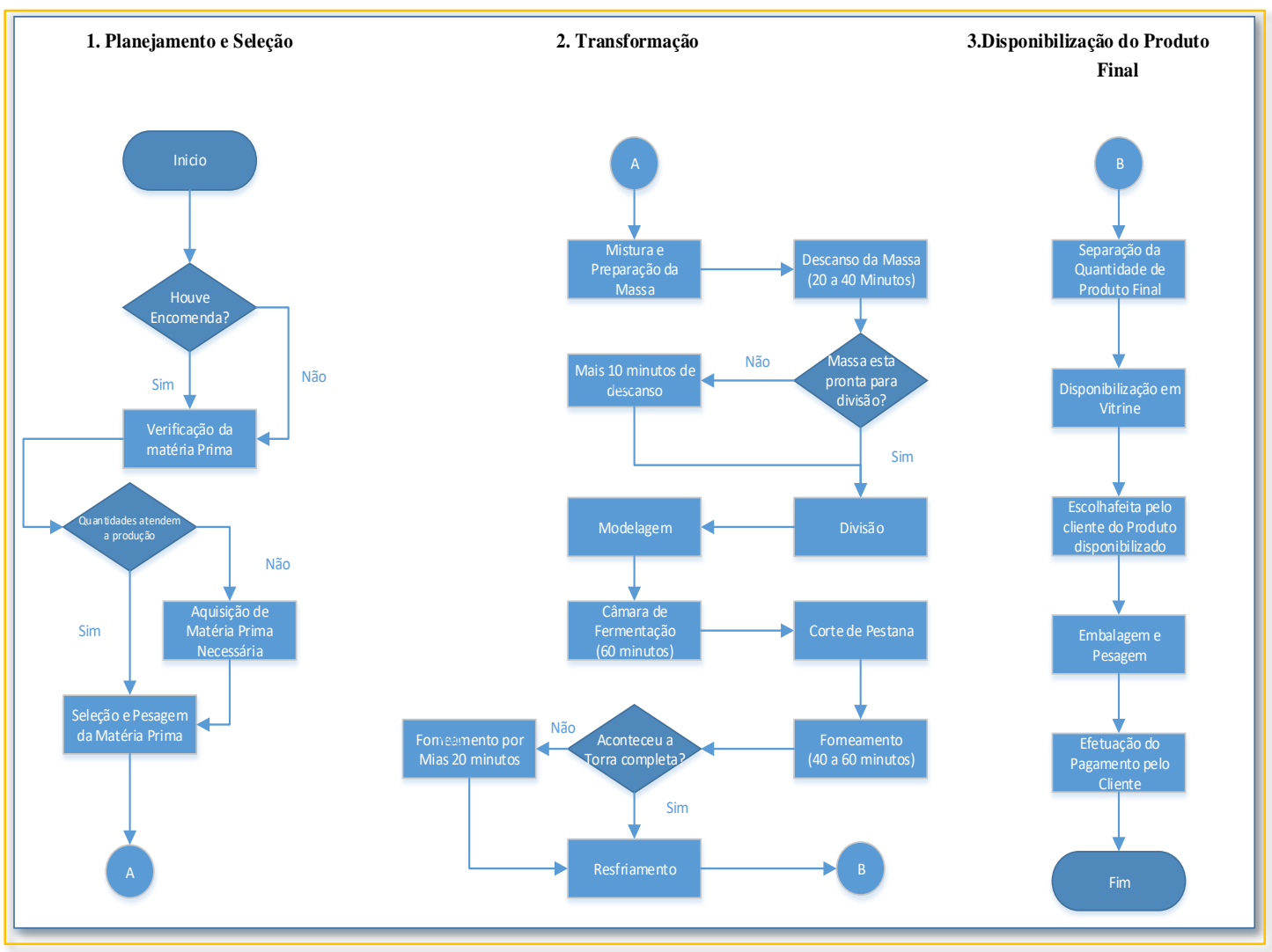

Fonte: Elaborado pelos autores

Quadro 2: Teoria da Contingência em confronto com a prática na empresa

\begin{tabular}{ll}
\multicolumn{1}{c}{ Processos Produtivos } & \multicolumn{1}{c}{ Descrição dos Processos Produtivos } \\
1. Planejamento e Seleção & $\begin{array}{l}\text { O processo de planejamento e seleção da matéria prima na } \\
\text { plataforma de estudo é realizado diariamente, em } \\
\text { adequação com a oferta e procura da produção realizada } \\
\text { anteriormente, assim, aumentando ou diminuindo as } \\
\text { quantidades ofertadas. }\end{array}$ \\
\hline $\begin{array}{l}\text { Nesta etapa acontecem os processos de transformação da } \\
\text { matéria prima bruta em matéria prima transformada, por } \\
\text { meio dos processos de mistura, descanso, divisão, } \\
\text { modelagem, fermentação, pestanação, forneamento e } \\
\text { resfriamento. }\end{array}$ \\
$\begin{array}{l}\text { Na etapa de disponibilização do produto, estes são } \\
\text { divididos em quantidades adequadas para o preenchimento } \\
\text { da vitrine, de forma que a vitrine esteja sempre abastecida. }\end{array}$ \\
Estes serão escolhidos pela clientela, embalados e pesados \\
Final \\
e, por fim, entregues após efetivação do pagamento.
\end{tabular}

Fonte: Elaborado pelos autores 


\subsection{LEVANTAMENTO DO PROCESSO DE PRODUÇÃO E OPERAÇÕES DA EMPRESA EM ESTUDO}

Ao passo em que se analisa os processos produtivos da empresa alvo de estudo foi observado que em suas atividades há uma tipologia extremamente variada, que demanda uma adaptabilidade aos processos muito alta, pois, além dos produtos produzidos em escala diária, há ainda as demandas de atendimento individual. Por outro lado, pode-se perceber que o ambiente interfere de modo significativo na organização, e no caso da empresa em pesquisa, faz com que haja a produção e comercialização de inúmeros produtos da espécie alimentícia como pães, bolos, tortas, salgados, bebidas, entre outros. Nesse sentido, a Teoria das Contingências atua de modo que a empresa com essa variedade de produtos e inserida em uma sociedade altamente variada diminua a possibilidade de baixo consumo da produção, o que tende a manter em evidência a organização.

É importante salientar que apesar da grande variedade de produtos, o PMP foi baseado na produção ou fabricação apenas do pão tipo francês. Tal escolha se deve pela quantidade desse produto que é produzida diariamente na empresa pesquisada, de modo que esse é o principal ingrediente de sucesso da mesma. Diante dessa situação, pode-se perceber que a produção desses pães é determinada de acordo com a demanda diária, especialmente, baseada na experiência pessoal dos empresários, bem como dos profissionais que produzem esses produtos. A empresa ainda trabalha por meio da produção de demanda, ou seja, de acordo com as encomendas por parte dos clientes e ainda personalizando seus serviços e produtos de modo a atender as necessidades, bem como com as contingências demandadas pelo mercado. Em confronto com a teoria explanada em revisão teórica, demonstraremos no Quadro 3 os aspectos da produção que se enquadram nesta teoria.

Em análise do Quadro 3 que segue, se observa que a empresa aplica os preceitos da Teoria da Contingência. Constitui-se em um sistema aberto, ou seja, sofre interferências do meio interno e externo, como indica Chiavenato (2014). Este autor teoriza que uma característica relevante da Teoria da Contingência é a de que não se consegue um alto nível de sofisticação organizacional com a aplicação de um só modelo; assim, não há uma só forma de tornar uma organização eficaz e eficiente.

Quadro 3: Teoria da Contingência em confronto com a prática na empresa.

\begin{tabular}{|c|c|c|}
\hline Processos Produtivos & Teoria & $\begin{array}{c}\text { Aplicação Prática na } \\
\text { Empresa }\end{array}$ \\
\hline $\begin{array}{l}\text { Processos de Produção } \\
\text { Diária }\end{array}$ & $\begin{array}{l}\text { As características } \\
\text { organizacionais apresentam } \\
\text { uma interação entre si e com o } \\
\text { ambiente. }\end{array}$ & $\begin{array}{l}\text { A empresa trabalha com } \\
\text { processos pré-determinados, } \\
\text { que podem sofrer alteração } \\
\text { de acordo com a } \\
\text { necessidade diária. }\end{array}$ \\
\hline $\begin{array}{l}\text { Processos de Produção } \\
\text { por Demanda }\end{array}$ & $\begin{array}{l}\text { A organização é de natureza } \\
\text { sistêmica, isto é, ela é um } \\
\text { sistema aberto. }\end{array}$ & $\begin{array}{l}\text { Em casos específicos } \\
\text { trabalha por demanda, } \\
\text { atendendo a pedidos } \\
\text { específicos, com produtos e } \\
\text { quantidades variadas. }\end{array}$ \\
\hline $\begin{array}{l}\text { Processos de Produção } \\
\text { por Sazonalidade }\end{array}$ & $\begin{array}{l}\text { As características ambientais } \\
\text { são as variáveis } \\
\text { independentes, enquanto as } \\
\text { características organizacionais } \\
\text { são variáveis dependentes } \\
\text { daquelas. }\end{array}$ & $\begin{array}{l}\text { Atende ainda pedidos } \\
\text { específicos em determinados } \\
\text { períodos do ano, como } \\
\text { festividades juninas e } \\
\text { natalinas. }\end{array}$ \\
\hline
\end{tabular}

Fonte: Elaborado pelos autores. 


\subsection{DEMONSTRAÇÃO DAS PRÁTICAS ADOTADAS PARA O PLANEJAMENTO MESTRE DE PRODUÇÃO E OPERAÇÕES NA PLATAFORMA PRODUTIVA EM ESTUDO}

A aplicabilidade do PMP (planejamento mestre de produção) na plataforma de pesquisa em questão acontece de forma adequada, pois são seguidas determinações criteriosas para o desenvolvimento das atividades. Estas se fazem de extrema necessidade, visando o seguimento das estratégias, pois se trata de uma produção de curto prazo. Além disso, há ainda a perecibilidade dos produtos, tanto da matéria prima, quanto do produto final. Visando o melhor aproveitamento das matérias primas, são utilizados cálculos e equipamentos que auxiliam na obtenção de quantidades exatas destes, para que não haja desperdícios durante o processo de elaboração dos produtos.

O PMP tem uma aplicabilidade mais adequada em processos produtivos mais longos, porém aplica-se perfeitamente na produção de produtos alimentícios, pois demanda de uma análise minuciosa a cada etapa, visando a produção com o menor descarte possível, bem como a utilização dos materiais em sua totalidade, pois estes, no caso de estudo são adquiridos conforme a utilização, evitando-se que estes permaneçam em estoque. Segue a Figura 3 e Quadro 4 com estes elementos.

Figura 3: Demonstração do Planejamento Mestre de Produção

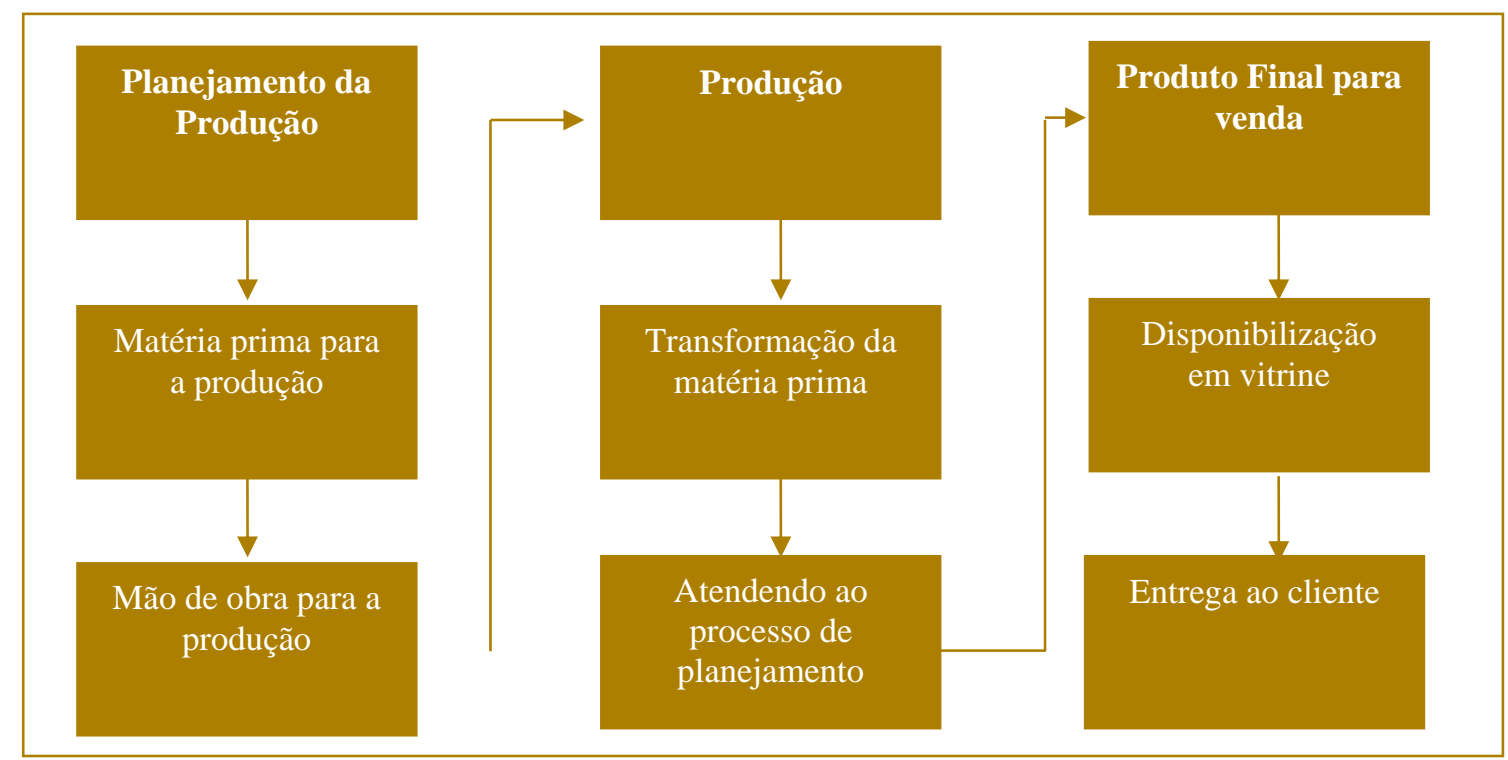

Fonte: Elaborado pelos autores 
Quadro 4: Planejamento Mestre de Produção em confronto com a prática na empresa

\begin{tabular}{l}
\multicolumn{1}{c}{$\begin{array}{c}\text { Etapas do Processo } \\
\text { Produtivo }\end{array}$} \\
$\begin{array}{l}\text { Nesta etapa são avaliadas as necessidades da matéria prima } \\
\text { para a produção, aquisição desta, contabilização da quantidade } \\
\text { necessária para a elaboração do produto, quantidade do tempo } \\
\text { necessário para todo o processo produtivo, quantidade de } \\
\text { funcionários necessários para o desenvolvimento da tarefa, bem } \\
\text { como quantidade de tempo que cada um necessita para realizar } \\
\text { sua tarefa, quantidade de energia e gás que os equipamentos } \\
\text { utilizarão. }\end{array}$ \\
$\begin{array}{l}\text { 1. Planejamento da } \\
\text { Produção }\end{array}$ \\
$\begin{array}{l}\text { Esta é a etapa em que as matérias primas passarão pelo } \\
\text { processo de transformação, por meio dos processos } \\
\text { transformadores, seguindo todo o planejamento traçado } \\
\text { anteriormente. }\end{array}$ \\
\hline $\begin{array}{l}\text { 2. Produção } \\
\text { são disponibilizados para venda, com o intuito de atender toda a } \\
\text { demanda da clientela. }\end{array}$ \\
\hline Produto Final para venda
\end{tabular}

Fonte: Elaborado pelos autores

\subsection{ANÁLISE CRÍTICA SOBRE OS POSSÍVEIS ELEMENTOS DE INOVAÇÃO NOS PROCESSOS PRATICADOS PELA EMPRESA}

Analisar os ambientes internos e externos da organização é um ponto de suma importância no planejamento. Vieira et al (2013) cita que para tal análise utiliza-se a matriz SWOT Strengths (Forças), Weaknesses (Fraquezas), Opportunities (Oportunidades) e Threats (Ameaças), chamada de F.O.F.A. por alguns autores, capaz de monitorar o ambiente interno e externo da organização, auxiliando no planejamento estratégico. Os mesmos autores citam que surge a oportunidade de se fazer o marketing se a empresa pode obter lucro ao atender seus consumidores em determinado seguimento. A ausência de um marketing defensivo pode levar à queda das vendas e dos lucros.

Para Samonetto e Campos (2013) a matriz SWOT é utilizada para analisar o ambiente e serve de base à gestão e planejamento estratégico numa empresa ou instituição. Verifica, também, a posição estratégica da empresa no ambiente ao qual se encontra. Citam ainda que para Martins (2006), matriz SWOT é comum nas empresas voltadas para o pensamento estratégico e praticar a análise com tal ferramenta traz uma melhoria de negócios, devido à grande e constante mudança de cenários onde a empresa se encontra. A Figura 4 contém estes elementos. De acordo com essas circunstâncias e visando compreender a realidade estudada segue o Quadro $4 \mathrm{com}$ indicações de uma análise SWOT da empresa em questão. 
Figura 4: Modelo de Análise SWOT

\begin{tabular}{|c|c|c|c|}
\hline \multirow{4}{*}{ 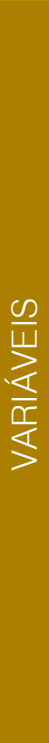 } & & FORÇAS & FRAQUEZAS \\
\hline & 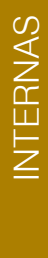 & $\begin{array}{c}\text { São recursos que a empresa tem à } \\
\text { sua disposição, podendo ser } \\
\text { controlados por esta (Preço, } \\
\text { Imagem). }\end{array}$ & $\begin{array}{c}\text { São os fatores que enfraquecem a } \\
\text { organização, podendo ser notados } \\
\text { não apenas por quem analisa, mas } \\
\text { também por quem está de fora. } \\
\text { Falta de treinamento seria uma } \\
\text { grande fraqueza. }\end{array}$ \\
\hline & & OPORTUNIDADES & AMEAÇAS \\
\hline & 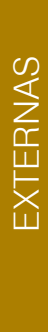 & $\begin{array}{c}\text { São as variáveis que podem } \\
\text { determinar o crescimento da } \\
\text { organização, porém são fatores } \\
\text { que esta não tem como dominar, } \\
\text { entretanto, uma pesquisa prévia } \\
\text { pode prever fatos que podem } \\
\text { auxiliar a organização no melhor } \\
\text { uso destas oportunidades. }\end{array}$ & $\begin{array}{c}\text { As ameaças são os fatores externos } \\
\text { que não podem ser controlados. É } \\
\text { importante estar preparado para } \\
\text { enfrentar as ameaças, pois podem } \\
\text { prejudicar o planejamento } \\
\text { estratégico, bem como os } \\
\text { resultados. }\end{array}$ \\
\hline
\end{tabular}

Fonte: Elaborado pelos autores baseado em LIMA et al(2013).

Quadro 4: Análise SWOT da empresa estudada

\begin{tabular}{ll|}
\hline $\begin{array}{l}\text { Etapas do Processo } \\
\text { Produtivo }\end{array}$ & $\begin{array}{l}\text { O tempo de atuação da empresa no mercado há } \\
\text { aproximadamente } 20 \text { anos; } \\
\text { 1.Fortalezas }\end{array}$ \\
Inúmeras opções de consumo; \\
Atendimento rápido por parte dos atendentes e caixas; \\
Produtos apresentados de fácil acesso para os consumidores. \\
\hline 2.Oportunidades & $\begin{array}{l}\text { A localização da empresa em discussão, estando disposta no } \\
\text { centro da cidade, de fácil acesso; }\end{array}$ \\
\hline $\begin{array}{l}\text { Pouca concorrência próxima a sua localização. } \\
\text { 3.Fraquezas }\end{array}$ & $\begin{array}{l}\text { Ausência de realização de propaganda ou de ações de } \\
\text { marketing, em quaisquer das mídias (televisiva, internet, rádio, } \\
\text { entre outras), fato que se torna uma fraqueza em comparação } \\
\text { com as outras empresas do mesmo ramo; } \\
\text { Dificuldade em modernização do modo de atendimento aos } \\
\text { clientes, como por exemplo, oferecimento de café da manhã com } \\
\text { serviço de Buffet; } \\
\text { Falta de espaço para estacionamento adequado dos automóveis } \\
\text { de seus clientes, o que em alguns momentos dificulta o } \\
\text { estacionamento e impede a compra dos produtos. }\end{array}$ \\
\hline $\begin{array}{l}\text { Aumento da concorrência com o passar dos anos nas } \\
\text { proximidades, que apesar de serem poucos já se demonstram } \\
\text { ativos e preocupados em atender a demanda dos clientes; } \\
\text { População tem se demonstrado com dificuldades em manter o } \\
\text { poder aquisitivo adequado para realizar compras de produtos } \\
\text { mais específicos e até mesmo personalizados. }\end{array}$ \\
4.Ameaças
\end{tabular}

Fonte: Elaborado pelos autores 


\section{CONCLUSÕES E SUGESTÕES}

O presente trabalho discutiu a questão do Planejamento Mestre de Produção em uma empresa do ramo alimentício instalada no município de Porto Velho. O PMP trabalha com vistas a atuar na estratégia competitiva das organizações, aumentando os lucros e reduzindo os custos. Inicialmente foi realizado um levantamento bibliográfico da Teoria das Contingências, a qual está diretamente relacionada com as condições ambientais que as empresas estão inseridas. Essa teoria ainda traz que as empresas possuem mecanismos para se adaptarem de acordo com as circunstâncias e conseguirem sobreviver em um mercado altamente competitivo, tal como o atual.

No que tange ao cumprimento dos objetivos, no que se refere a questão do levantamento do processo de produção teve-se a percepção da variabilidade dos produtos, tanto os vendidos diariamente bem como os que são encomendados e desenvolvidos de forma personalizada, ou seja, atendendo a um grupo específico que demandam tais serviços. Nesse aspecto, por demandar produtos específicos e ao mesmo tempo gerais, a teoria das contingências é a que se adéqua melhor a essa realidade, já que não utiliza apenas um olhar para a produção em questão, mas o olhar mais adequado para cada produto produzido.
Por outro lado, o outro objetivo específico visava responder ao questionamento de quais práticas são adotadas para o planejamento mestre de produção e operações na plataforma produtiva. E como respostas a esse questionamento teve-se que o PMP é realizado de forma prévia e seguido a risca por parte da organização pesquisada, pois o mesmo é essencial para o bom funcionamento dos processos e do pleno atendimento aos clientes. E no que tange aos elementos de inovação tem-se a necessidade de uma atuação de propaganda da empresa em detrimento da concorrência clara e aparente das demais empresas do mesmo ramo de atuação.

No que tange a questão da resposta ao questionamento realizado, de que forma a empresa realiza o planejamento das atividades produtivas, pode-se afirmar desse instrumento ser desenvolvido com base na experiência pessoal dos gerentes da empresa, especialmente, com estratégias de ensaio e erro da produção. O planejamento é realizado diariamente e assim se realizam as compras dos produtos a serem manufaturados. Por outro lado, a presente tarefa foi essencial para a organização pesquisada visando apontar possíveis ações as quais auxiliaram a produção adequada dos produtos e no aumento considerável dos lucros.

\section{REFERÊNCIAS}

ANTUNES, Luciana Soares; SEHNEM, Simone; LIMA, Maurício Andrade. Análise do planejamento e controle de produção no setor de usinagem, corte e conformação em industrial metal-mecânica. Navus- Revista de Gestão e Tecnologia, Florianópolis, v. 4, n.1, 2014. Disponível em:<www.navus.sc.senac.br>. Acesso em 22 de abril de 2015.

BÄCHTOLD, Ciro. Noções de Administração Pública. Instituto Federal do Paraná, 2012. Disponível em:<www.netapi.ifpi.edu.br>. Acesso em 22 de abril de 2015.

[3] CHIAVENATO, Idalberto. Introdução à Teoria Geral da Administração. Editora Manole: Barueri, 2014.

[4] EVANGELISTA, Armindo Aparecido et al. O impacto da eficiência do planejamento e controle de produção (PCP) como um fator de competitividade: um estudo de caso em uma empresa de médio porte. Inovação, Gestão e Produção, v.03, n.07, 2011.Disponível em:<www.ingepro.com.br>. Acesso em 1 de junho de 2015

[5] FERREIRA, Fernando Henrique de Oliveira. Implementação da eficiência global de equipamento (OEE) no padrão da produção e análise dos impactos. Universidade Estadual Paulista, 2012. Disponível em: <base.repositorio.unesp.br>. Acesso em 22 de abril de 2015

[6] HÉKIS, Helio Roberto et al. Planejamento e controle de produção através de uma análise do fluxo informacional em empresa do ramo alimentício do município de Mossoró/RN. Rev. Cienc. Admin., v.19, n.1, 2013. Disponível em:<ojs.unifor.br>. Acesso em 22 de abril de 2015.

PIZZANI, Luciana et al. A arte da pesquisa bibliográfica na busca do conhecimento. Rev. Dig. 
Dibli. Ci. Inf., v.10, n.1, 2012. Disponível em:<www.sbu.unicamp.br>. Acesso em 22 de abril de 2015

[8] PRETTO, Fernando Natal de; RAMOS, Andre Luiz; PRETTO, Cristine. Jogos de empresas no ensino do planejamento e controle da produção. Simpósio de Administração da Produção, Logística e Operações Internacionais, 2011. Disponível em:<www.simpoi.fgvsp.br>. Acesso em 01 de junho de 2015.

[9] ROCHA, Henrique Martins. Planejamento e controle da produção. Universidade do Estado do Rio de Janeiro, 2011. Disponível em:<www.fat.uerj.br>. Acesso em 22 de abril de 2015.

[10] SANTOS, José Vitor Palhares dos. Caso de ensino sobre o hotelzinho doce encanto: o lado não tão doce da relação entre estrutura, estratégia e sobrevivência organizacional. Revista de Empreendedorismo e gestão de pequenas empresas, v.3, n.3, 2014. Disponível em:<www.regepe.org.br>. Acesso em 22 de abril de 2015 .

[11] SEVERO, Eliana Andrea et al. Inovação de processo e produção mais limpa em uma indústria de plásticos da serra gaúcha. Gestão Contemporânea, 2012 Disponível em:<seer4.fapa.com.br>. Acesso em 22 de abril de 2015

[12] VIEIRA, Romero Rondinele dos Santos et al. Análise da Matriz SWOT e Matriz BCG como ferramenta estratégica no setor farmacêutico de Mossoró/RN. XXXIII Encontro Nacional de Engenharia da Produção, 2013. Disponível em: $<$ www.abepro.org.br>. Acesso em 1 de junho de 2015.

[13] SAMONETTO, Valdemir; CAMPOS, Fernando Celso de. Análise de Aspectos Estratégicos para gestão de IES privada. . XXXIII Encontro Nacional de Engenharia da Produção, 2013. Disponível em: <www.abepro.org.br>. Acesso em 1 de junho de 2015.

[14] LIMA, HellanyCybelle Araújo de et al. Análise das Estratégias Administrativas sob a ótica da competitividade: Estudo de caso realizado em uma empresa comercial de material de construção. XXXIII Encontro Nacional de Engenharia da Produção, 2013. Disponível em: $<w w w$.abepro.org.br>. Acesso em 2 de junho de 2015 .

[15] QUEIROZ, Jamerson Viegaset al. Franchising e Especialização de serviços como estratégia de crescimento e manutenção: Uma análise através da Matriz SWOT e GUT na DDExDirecttoDoor Express. Gepros. Gestão da Produção, Operações e Sistemas, Ano 7, n.1, 2012. Disponível em: <www.gepros.feb.unesp.br> Acesso em 3 de Junho de 2015. 


\section{Bapítulo 14}

\section{AS INFORMAÇÕES CONTÁBEIS E O PROCESSO DE TOMADA DE DECISÃO NAS ORGANIZAÇÕES}

\section{Elias Garcia}

Jorge Bidarra

Resumo: Reduzir as incertezas e aumentar o nível de entendimento dos relatórios contábeis sempre foi considerado um dos objetivos da informação contábil no processo de comunicação entre esta e seus usuários. Os ruídos presentes na comunicação, tais como o uso de uma terminologia contábil inadequada, a quantidade excessiva ou insuficiente da informação divulgada, a dificuldade de entendimento dos relatórios por parte dos usuários e o uso de expressões e/ou termos em outros idiomas ou ambíguos são uns dos principais responsáveis pelos problemas técnicos e também jurídicos na área da contabilidade. Na tentativa de minimizar os prejuízos provocados por esses ruídos na comunicação contábil, um conjunto de diretrizes foi publicado e recomendado pela ONU. Inúmeros trabalhos têm sido publicados no sentido de mostrar a Contabilidade como um sistema de informação confiável. Poucos, no entanto, são aqueles que colocam o foco do debate no problema de compreensão dos termos e expressões, seja por parte do profissional ou do cliente. Diante desse contexto, o principal objetivo deste artigo é refletir sobre a qualidade das informações, mas também chamar a atenção para alguns aspectos semânticos que podem distorcer o significado da informação no momento que o usuário necessita tomar uma decisão gerencial. Para o debate, apresenta-se aqui um estudo teórico a respeito do assunto, baseado na literatura revisada até o momento, algumas considerações a respeito dos prejuízos trazidos pela má aplicação de termos/conceitos fundamentais para as Ciências Contábeis e os esforços que vêm sendo empreendidos no sentido de proporcionar uma maior segurança e confiabilidade a ambos, profissionais da área e seus usuários-clientes.

Palavras-chave: Informações, Ambiguidade Lexical, Polissemia, Ciências Contábeis. 


\section{INTRODUÇÃO}

O mundo moderno vive um dos períodos mais críticos de sua história, no qual a manipulação da informação passou a ser um requisito indispensável para todas as áreas do conhecimento. No que diz respeito às Ciências Contábeis, o mau uso de termos e/ou conceitos de grande importância contábil, de uma maneira geral, vêm provocando uma série de transtornos nas relações comerciais, nacionais e internacionais, e, a reboque, prejuízos vultosos para aqueles que dos serviços especializados na área dependem.

Com o advento do computador e o desenvolvimetno da tecnologia de informação (STI) muito se tem avançado, quer em termos de confiabilidade e clareza, quer no que se refere à segurança da informaçãoo e de todos os seus usuários, profissionais de área ou apenas clientes.

Os recursos computacionais proporcionados pelos STI, tanto com relação ao tratamento dos dados, bem como no que diz respeito ao seu gerenciamento, vêm ocupando um lugar de destaque não só para a sociedade como um todo, mas em particular no mundo dos negócios.

Não se admite hoje uma empresa que queira competir com vantagem, sem a utilização dessas ferramentas. Estes fatos abrem lacunas para que os novos gestores, com novas visões busquem o aperfeiçoamento contínuo para suas empresas. $\mathrm{O}$ desenvolvimento e o aumento da competitividade entre as empresas, em boa parte, têm sido favorecidos pela evolução do conhecimento e da informação, bem como na sua forma de geração e/ou aquisição.

As transformações decorrentes do desenvolvimento tecnológico nas áreas de informação e comunicação, sem dúvida, afetaram o modus operandi até então conhecido pela sociedade moderna. Para acompanhar essas transformações, tanto as pessoas quanto as empresas/organizações têm procurado formas mais rápidas e eficientes para se inserirem nesse novo modelo. Nesse sentido, o presente artigo tem por objetivo discutir o processo de geração da informação contábil e a contribuição que as tecnologias da informação têm proporcionado ao processo decisorial nas organizações do qual presidentes e/ou diretores, empregados e clientes são os maiores beneficiados.

Para este debate, o artigo assim se estrutura. $\mathrm{Na}$ seçãoo 2, são apresentados os principais conceitos aplicados na área da contabilidade, cujo debate se inicia com a devida distinção entre "dados, informação e conhecimento". Estabelecidas as diferenças e os conceitos caros às Ciências Contábeis. Na seção 3 o texto chama a atenção para o fluxo das informações e das decisões no ambiente gerencial, onde procura demonstrar a importância de uma boa organização das informações, a parametrização dos sistemas e os principais aspectos que fortalecem os sistemas de informaão gerencial. Para encerrar essa fase, discute um pouco sobre os relatórios emitidos pelos sistemas, bem como as condições necessárias para a tomada de decisões, discorrendo sobre três possibilidades ambientais que existem para o processo decisorial em uma organização. $\mathrm{Na}$ seção 4, o texto chama a atenção do leitor para a discussão central que deve ser buscada no artigo, que é a ambiguidade lexical na geração da informação. Aqui o texto busca adentrar um pouco nos conceitos linguísticos pouco observados pelos profissionais das áreas empresariais mas que fazem toda a diferença no momento em que o usuário da infornação vai tomar decisão. Encerrando o artigo, apresenta-se a conclusão chamando a atenção para os aspectos de quantidade e qualidade da informação, além de propor novas pesquisas sobre o assunto.

\section{CONCEITOS E AS PRINCIPAIS CARACTERÍSTICAS DA INFORMAÇÃO CONTÁBIL}

\subsection{DADOS, CONHECIMENTO. \\ INFORMAÇÃO E}

Inicialmente, torna-se necessário conceituar os elementos que conduzem as empresas nos seus negócios. Segundo BATISTA (2004, p. 20), "do ponto de vista da administração de empresas em concordância com a definição de sistemas, existem dois elementos fundamentais para a tomada de decisões: os canais de informação e as redes de comunicação". Pelos canais de informação, as organizações definem de onde serão adquiridos os dados, e as redes de 
comunicação definem para onde os dados serão direcionados.

Para a formação dos sistemas e a consequente obtenção dos elementos fundamentais para a tomada de decisão é necessário o conhecimento dos conceitos de Dados, Informação e Conhecimento: Para DAVENPORT e PRUSAK (1999), é essencial para a realização bem-sucedida dos trabalhos ligados ao conhecimento, que as organizações saibam definir o que são dados, informações e conhecimento, pois o sucesso ou o fracasso organizacional muitas vezes pode depender da aplicação desses elementos para solução de problemas e tomada de decisões. Os dados apresentamse como elementos em sua forma bruta, os quais não podem por si só sustentar a estruturação necessária para tomada de ação. Os dados precisam passar por análise e transformações para se tornarem úteis. OLIVEIRA (2002, p.51), escreve que "dado é qualquer elemento identificado em sua forma bruta que, por si só, não conduz a uma compreensão de determinado fato ou situação". Assim, para a compreensão de determinado fato ou situação em uma organização é necessário que os dados se transformem em informação.

PADOVEZE (2011, p. 43) apud NAKAGAWA, demonstra que "informação é o dado que foi processado e armazenado de forma compreensível para seu receptor e que apresenta valor real percebido para suas decisões correntes ou prospectivas". Para OLIVEIRA (1997), a informação auxilia no processo decisório, pois quando devidamente estruturada é de crucial importância para a empresa, associa os diversos subsistemas e capacita a empresa a impetrar seus objetivos. O valor atribuído pelos gestores às informações depende dos resultados alcançados pela empresa. Os benefícios oferecidos pelas decisões acertadas, baseadas em informações valiosas representam o sucesso da empresa.

O conceito de valor da informação, segundo PADOVEZE (2011, p. 44), está relacionado com:

a) A redução da incerteza no processo de tomada de decisão;

b) A relação do benefício gerado pela informação versus custo de produzi-la;

c) Aumento da qualidade da decisão.
Para medir o valor da informação o gestor deve dispor de forma que ela reduza as incertezas encontradas no decorrer do processo decisorial, e consequentemente, aumente a qualidade da decisão. Segundo STAIR (1998, p. 5), "conjunto de dados, regras, procedimentos e relações que devem ser seguidos para se atingir o valor informacional ou resultado adequado do processo está contido na base do conhecimento". A base do conhecimento facilita reconhecer quais dados e informações são úteis para se atingir os objetivos traçados pela organização.

Para LAUDON e LAUDON (1999, p. 10), "conhecimento é o conjunto de ferramentas conceituais e categorias usadas pelos seres humanos para criar, colecionar, armazenar e compartilhar a informação". As informações são criadas a partir da transformação dos dados, através da aplicação do conhecimento humano.

\subsection{INFORMAÇÕES CONTÁBEIS}

As informações contábeis são aquelas obtidas como produto final dos sistemas contábeis, aquelas resultantes do processamento de dados da contabilidade ou da administração.

As informações contábeis são normalmente passadas para os gestores a partir de relatórios, conclusões de análises e pesquisas sobre determinado assunto, servindo para estes como bases para a tomada das decisões dentro das empresas.

As informações contábeis devem servir como auxílio para que o processo decisório das organizações possa agregar alguma vantagem competitiva para a empresa.

\subsection{USUÁRIOS DAS INFORMAÇÕES CONTÁBEIS}

Os usuários das informações contábeis podem ser gestores, investidores, pessoas físicas, pessoas jurídicas, enfim, todos que possuem ou terão vínculo com a empresa em questão.

O Conselho Federal de Contabilidade (2011) classifica como usuários externos, o governo 
e órgãos reguladores ou autoridades tributárias.

Já Stroeher (2005, p. 31), além dos já citados pelo CFC, cita ainda, acionistas, clientes, fornecedores, governo, credores e investidores. Enquanto que os usuários internos são o proprietário, administradores e funcionários.

Ainda Stroeher (2005, p. 157) continua e escreve de forma mais explícita que os usuários são pessoas físicas ou jurídicas com interesses na entidade. Além desses, descreve que os usuários da contabilidade são os integrantes do mercado de capitais, fornecedores, autoridades governamentais, meios de comunicação, entidades que agem em nome de outros, empregados, controladores, acionistas, administradores e o público em geral.

Percebe-se que todo e qualquer indivíduo pode ter interesse nas informações contábeis de uma entidade, não deixando de destacar o governo e os gestores que a utilizam como meio de tomada de decisão.

\subsection{UTILIDADE DAS INFORMAÇÕES CONTÁBEIS}

A utilidade da informação contábil, infelizmente, é vista apenas como mero instrumento fiscal, porém sua real utilização é na tomada de decisões.

Favero et al. (2011, p. 1) afirmam que "a contabilidade desenvolveu-se buscando responder aos anseios da sociedade, tendo como objetivo gerar informações para o controle e tomada de decisões".

A ciência contábil deve ser encarada como uma ciência da informação que os usuários necessitam. Na essência, a contabilidade nasceu da necessidade da humanidade conhecer e controlar a sua riqueza, serve como auxiliar da gestão, e se tornou a linguagem universal dos negócios.

A importância global da contabilidade ficou mais evidenciada nos últimos anos a partir do processo de convergência das normas locais para as normas internacionais, que visa transformar a contabilidade local, independentemente da língua ou cultura do usuário em uma linguagem universal. A partir do momento que investidores e acionistas utilizam demonstrações contábeis para avaliar a viabilidade de um investimento a importância destes demonstrativos ultrapassou fronteiras, servindo de instrumento comum no processo decisório em nível internacional, principalmente no atual cenário de globalização de mercados.

Uma boa informação contábil só será útil para seus usuários se, de alguma forma, minimizar as incertezas do gestor na tomada de decisão, aumentando a segurança e o nível de acertos no atingimento aos objetivos empresariais. Essa posição é reforçada por Stroeher (2005, p. 28), quando escreve que o objetivo a ser atingido pela informação contábil é ter utilidade na tomada de decisões.

A informação contábil de qualidade deve atender a vários tipos de usuários, mesmo que cada um tenha interesses diferentes. A boa informação contábil deve atender a todos que dela necessitam, independente do interesse ou da decisão a ser tomada.

\subsection{CARACTERÍSTICAS DA INFORMAÇÃO CONTÁBIL}

A informação contábil possui várias características que em conjunto tornam-na útil e essencial para a tomada de decisão pelos gestores das empresas. As principais características das informações contábeis para que se tornem úteis e mais citadas na literatura estão descritas e comentadas a seguir.

Em sua publicação oficial, o Conselho Federal de Contabilidade (2011) cita a relevância na informação contábil como característica principal da mesma, pois sendo relevante a informação pode fazer a diferença em uma decisão. Outra característica é a fidedignidade dessas informações representadas nos relatórios, pois os fatos ali relatados devem ser verdadeiras.

Também vale destacar a característica de comparabilidade da informação, que segundo o Conselho Federal de Contabilidade (2011), aumenta-se a utilidade da informação quando se possibilita a comparação de relatórios entre diversos períodos. Outra qualidade a ser destacada é a verificabilidade, onde diferentes observadores podem chegar em um mesmo resultado sobre determinado fenômeno apresentado. Segundo Stroeher (2005, p. 34) a característica da verificabilidade representa a capacidade de 
assegurar que a informação representa o que quer representar.

No contexto contábil, uma característica muito importante a ser observada é a tempestividade, que significa que a informação deve estar disponível em tempo de poder influenciar na tomada das decisões, considerando ainda a sua compreensibilidade, onde a informação deve ter a possibilidade de ser compreendida pelos usuários. De nada adianta ser tempestiva se não for compreendida.

Em resumo, para Stroeher (2005, p. 61), as características das informações contábeis englobam a oportunidade, compreensibilidade, confiabilidade, comparabilidade e relevância.

Nesta visão, pode-se destacar que a informação contábil, para ser útil para a tomada de decisão deve conter pelo menos as seguintes características:

a) deve ter relevância para o decisor; sua representação deve ser fidedigna; possuir poder de comparabilidade; de verificabilidade; ser tempestiva na sua apresentação; ser compreensível para o usuário; deve ser neutra, não enviesada; ser oportuna e finalmente, ser confiável naquilo que transmite.

Gerar as informações contábeis com as características acima apresentadas é uma tarefa na maioria das vezes complexa, porém é uma meta que deve ser alcançada melhorando o processo de comunicação.

Conforme escrevem Favero et al.(2011, p. 5) "neste caminho [de aperfeiçoamento do processo de comunicação], a etapa mais significativa refere-se ao relacionamento do contador com os usuários". Estreitando este relacionamento, o contador poderá aperfeiçoar a linguagem utilizada e perceber de qual maneira as informações serão mais úteis para auxiliar no processo de tomada de decisões.

3 FLUXO DAS INFORMAÇÕES E DAS DECISÕES NO AMBIENTE GERENCIAL DAS EMPRESAS A PARTIR DAS AÇÕES A SEREM EXECUTADAS

Independente do tamanho, cada vez mais as organizações utilizam o sistema de informações para atender e reagir às necessidades que o próprio mercado cria no mundo dos negócios. Com base na evolução histórica dos sistemas de informações percebe-se que este mudou a maneira como as empresas conduzem os processos na produção de produtos e/ou serviços, dando às empresas e indivíduos novas ferramentas para melhorarem suas vidas e ambientes.

De acordo com Laudon \& Laudon (1999, p. 5):

Um sistema de informação é uma parte integrante de uma organização e é um produto de três componentes: tecnologia, organização e pessoas. Com base nos autores, cada componente tem sua característica específica e indispensável para entender o sistema de informações. Por exemplo, as organizações criam o sistema de informação para resolver problemas muitas vezes gerados pela própria cultura e valores da empresa. Já as pessoas em seus trabalhos usam as informações vindas do computador unindo-as entre os setores podendo executar as tarefas de forma mais eficiente. E a tecnologia é a maneira pela qual as organizações usam essas informações para uso das pessoas.

É necessário salientar que a informação, quando não utilizada e que não gera qualquer ação, acaba se transformando em um mero dado. Esse dado pode retornar ao sistema como retroalimentação deste para gerar uma nova informação ou ser descartado do processo.

Conforme observação de Schmidt (2002, p.86), no processo empresarial;Representada pelo nível operacional, as atividades e as decisões são de natureza estruturada e ou programada. Essas informações são bem analíticas, detalhadas, ricas na precisão e que, muitas vezes, constituem grande quantidade de dados em forma bruta ou primária, gerada pelas ações operacionais. Os dados sofrem processamentos mínimos necessários para manter sua integridade na respectiva base de dados.

A definição supracitada refere-se ao fluxo de informações, onde a informação gerada por um sistema causa uma ação, esta ação por sua vez gera mais informações, tornando-se úteis para a tomada de decisão.

As empresas cada vez mais se utilizam de meios informatizados para controlarem seus 
processos através de sistemas que contribuem para se manterem competitivas no mercado. Eles possibilitam o controle das atividades e principalmente se tornaram fonte de informações para os gestores.

Para evidenciar claramente o valor da informação para a empresa, pode-se dizer que ela se tornou atualmente mais um produto, pelo fato de que todos necessitam dela para diversos fins, como os de alavancar o seu negócio, manter e conquistar mais uma fatia de mercado, (market share), planejar, montar estratégias, cuidar da elaboração das informações com os mesmos critérios de elaboração dos produtos, como dos serviços.

Para obter informações adequadas e confiáveis através de sistemas, é extremamente importante o uso da tecnologia da informação, pois com isso tornam-se mais eficientes os processos operacionais e decisórios das organizações. Desta forma, investir em tecnologia significa melhoria na disseminação das informações e qualidade dos produtos ou serviços.

\subsection{ASPECTOS QUE FORTALECEM OS SISTEMAS DE INFORMAÇÃO GERENCIAL NAS EMPRESAS}

Os sistemas de informação gerenciais são instrumentos utilizados para gerar informação para o processo decisório. Por consequência, para que a empresa possa usufruir as vantagens básicas dos Sistemas de Informação Gerenciais, é necessário, segundo Rezende e Abreu (2000, p. 121), que alguns aspectos sejam observados. Entre estes, podem-se citar:

a) O envolvimento da alta e média gestão;

b) A competência por parte das pessoas envolvidas com o SIG;

c) uso de um plano mestre ou planejamento global;

d) A atenção específica ao fator humano da empresa;

e) A habilidade dos executivos para tomar decisões com base em informações;

f) $O$ apoio global dos vários planejamentos da empresa;

g) O apoio organizacional de adequada estrutura organizacional e das normas e procedimentos inerentes ao sistema; h) O conhecimento e confiança no SIG;

i) Existência de e/ou informações relevantes e atualizadas;

j) A adequação da relação custo $x$ benefício.

As mudanças nos processos empresariais são inevitáveis quando se opta por investir em inovação, principalmente com relação à tecnologia.

\subsection{RELATÓRIOS DO SISTEMA DE INFORMAÇÃO GERENCIAL}

Os relatórios do sistema de informação gerencial podem ajudar os administradores no que tange aos aspectos de desenvolvimento de planos para melhorar a administração, assim como obter melhor controle sobre as operações da empresa, e tomar decisões acertadas.

O processo de transformação de dados resulta em informações úteis, as quais podem ser observadas nos relatórios. STAIR (1998), escreve que os relatórios advindos do sistema de informação gerencial incluem relatórios programados, relatório indicador de pontos críticos, relatórios sob solicitação e relatórios de exceção. Os relatórios programados são aqueles produzidos periodicamente, por exemplo, em uma fábrica a produção de um determinado produto pode ser monitorado diariamente. O relatório de pontos críticos é um tipo especial de relatório programado emitido no começo de cada dia, resumindo as atividades do dia anterior.

Os administradores obtêm informações sobre as atividades críticas da empresa possibilitando ações corretivas. Os relatórios sob solicitação são produzidos somente quando o administrador quer saber sobre um item específico, por exemplo, total da venda de um determinado produto. Os relatórios de exceção são parametrizados para informar automaticamente critérios preestabelecidos pela empresa, por exemplo, para se ter um efetivo controle de estoque os administradores parametrizam o sistema para avisar quando determinado produto está com estoque abaixo do mínimo ideal.

Diante deste contexto, conclui-se que os relatórios produzidos pelo sistema de informação gerencial devem ser fornecidos de acordo com a necessidade dos gerentes. Eles podem ser diários, semanais, mensais e 
apresentar informações de cunho financeiro, administrativo, e contábil.

\subsection{CONDIÇÕES DE TOMADA DE DECISÃO}

As decisões são tomadas sob diversas condições. Podem ser sob condições de certeza, condições de incerteza e condições de risco. As decisões programadas normalmente oferecem um grau de risco menor do que as decisões não programadas.

Em se tratando das decisões tomadas sob certeza, o decisor tem conhecimento das consequências ou resultados de todas as alternativas, sendo assim, pode escolher a melhor dentre as alternativas propostas. Stephen e Coulter (1996, p. 126), enfatizam que "a situação ideal para a tomada de decisões é a de certeza, ou seja, o administrador pode tomar decisões precisas, pois o resultado de cada alternativa é conhecido". Com relação às decisões tomadas sob condições de incertezas, os resultados são desconhecidos e gerados sob probabilidades, onde o decisor tem pouco ou nenhum conhecimento das informações que formam as alternativas.

$\mathrm{Na}$ tomada de decisão com risco, todas as alternativas têm um resultado específico e são projetadas com base nas probabilidades conhecidas. É de se esperar que o tomador de decisão de uma empresa conheça todas as alternativas e saiba determinar a dimensão do risco a que a empresa estará sendo submetida.

Diante do exposto, observa-se que a tomada de decisão está diretamente relacionada ao potencial informativo do Sistema de Informação da empresa. Poder contar com a objetividade, clareza e, se não for possível mesmo eliminar, pelo menos contornar as ambiguidades muito comuns nas línguas usadas para as descrições das informações têm sido questões cruciais para o sucesso de qualquer empreendimento. Em nosso estudo, colocamos o foco do debate justamente nesse último item, qual seja a embiguidade lexical, e sobre seu impacto, trataremos na próxima seção.

\section{A AMBIGUIDADE LEXICAL NA GERAÇÃO DE INFORMAÇÕES CONTÁBEIS}

Os problemas da representação lexical têm se mostrado muito produtivos nas pesquisas atuais sobre a significação linguística. Contudo, as áreas de profissões regulamentadas pouco têm se preocupado com esses fatos. Depois de um longo período em que o léxico foi considerado assistemático e idiossincrático, a busca por regularidades e por relações semânticas sistemáticas no campo lexical passou a caracterizar as pesquisas nessa área, como afirma Moura (2002). Analisando por este prisma, um promissor campo de investigação se abre na medida em que o léxico, ao invés de ser representado como uma estrutura fixa e estável, passa a ser analisado em sua relação composicional no corpo da sentença e mesmo do texto e mais especificamente, nas diversas áreas profissionais. Representações mais flexíveis (e mais ricas) foram propostas para dar conta da imensa produtividade e variação dos sentidos lexicais em contexto. Fenômenos bastante tradicionais em semântica, como polissemia, ambiguidade e indeterminação entram em cena nessa tentativa de explicitar a riqueza do funcionamento do léxico e sua interação com a aplicabilidade prática da gramática. Nos casos de terminologia técnica, duas características semânticas têm sido alvo de aprofundamento de pesquisas, a polissemia e a homonímia. Essas duas manifestações fazem toda a diferença, principalmente quando aplicadas à terminologia de especialidades.

É interessante quando se analisa o processo decisório do ponto de vista da gestão, contudo, o que muitas vezes não se oberva é o aspecto linguístico que está sob o contexto de formação da informação.

$\mathrm{Na}$ formação da linguagem, alguns aspectos são temas de discussões e pesquisas para a área da linguística. A linguagem do homem, pelas próprias pesquisas, existe desde há muito tempo, e a curiosidade dessa linguagem pode ser facilmente observada pelas lendas, mitos, cantos, rituais, pela literatura, filosofia e até pela religião. No contexto de formação de língua, Barthes (1970, I.1.1), escreve que língua ..." é o conjunto sistemático das convenções necessárias para a comunicação, indiferente à matéria dos sinais que a compõem". Então, língua não é um sistema individual, - visto que 
é usado para comunicação, e isto subentende a participação de mais de uma pessoa, - mas um conjunto de sistemas que pertence a um grupo social ao qual determinado indivíduo pertence. Saussure (1972, pag. 37) complementa que... "a língua é um conceito social". Daí se extrai que cada língua se distingue das demais, pelos seus sons específicos e pela organização peculiar desses sons em formas funcionais".

Essa formação da língua é então direcionada aos grupos sociais, por exemplo, as áreas de conhecimento profissionais, como medicina, direito, economia, administração e a contabilidade. Cada grupo de pessoas de uma mesma área tem uma forma de conduta, e isto diz respeito também à forma de se comunicarem entre si. A esses fenômenos de estudos de linguagens denominamos de Terminologia de especialidades, que é uma área de pesquisa utilizada pela Linguística de Corpus, que utiliza-se de grande conjunto de dados (chamados de corpora - plural de corpus). Essa área ocupa-se em descrever o que cada termo significa em um contexto de uso exclusivo de uma determinada área de especialidade, que pode ser técnica ou científica.

Nos estudos da Terminologia, uma abordagem bastante significativa tem sido a questão semântica, que procura avaliar os problemas de ambiguidade. A ambiguidade é estudada em duas vertentes, a estrutural e a lexical (Câmara Jr. 1986) e pode se manifestar de diversas formas, tais como a polissemia, homonímia, sinonímia dentre outras formas. Para este estudo, apresentamos apenas um exemplo de polissemia, que está relacionado com o termo investimento. Para Silva (2006, p.10), polissemia "é a associação de dois ou mais sentidos relacionados entre si a uma única forma linguística". Vejamos a seguir este exemplo:

Para a contabilidade: Considera investimento como a aplicação de algum tipo de recurso com a expectativa de receber algum retorno futuro superior ao aplicado, compensando, inclusive, a perda de uso desse recurso durante o período de aplicação. Num sentido amplo, o termo investimento aplica-se tanto à compra de máquinas, equipamentos e imóveis para a instalação de unidades produtivas como à compra de títulos financeiros. Para Martins (1988; pg.25), "investimento é um gasto ativado em função de sua vida útil ou de benefícios atribuíveis a futuro(s) período(s)". No contexto legal da contabilidade, a Lei Federal no 6.404/76 no art. 179, item III assim classifica investimento:

I/I - em investimentos: as participações permanentes em outras sociedades e os direitos de qualquer natureza, não classificáveis no ativo circulante, e que não se destinem à manutenção da atividade da companhia ou da empresa.

Para a economia: Investimento significa a aplicação de capital em meios que levam ao crescimento da capacidade produtiva, os bens de capital. No contexto econômico, o investimento é a despesa das firmas na dotação de bens de capital. Em um exemplo clássico, aplicações financeiras para contadores, é investimento, para economistas é poupança.

Apesar de não ser objetivo deste estudo comparar duas áreas do conhecimento (contabilidade e economia), o exemplo trazido acima foi apenas para demonstrar que as questões terminológicas podem afetar profundamente as análises financeiras das empresas.

Assim como acontece com o termo investimento que provoca dificuldade de interpretação para os operadores da área, há outros tantos termos ambíguos que podem trazer também diversas interpretações.

Este problema de entendimento terminológico foi observado já em 1920, quando o Instituto Americano de Contadores Públicos Certificados - AICPA - constituiu o primeiro Comitê de Terminologia, com o objetivo de reunir um conjunto de palavras e expressões que eram comumente utilizadas pela contabilidade e fixar significados mais concisos para cada uma delas, bem como quando da atenção voltada a problemas de semântica e questões de uniformidade, até a grande evolução das evidenciações das companhias abertas brasileiras. Desde então, pôde-se constatar a necessidade crescente da realização de pesquisas contábeis que enfoquem a abordagem da Teoria da Comunicação. Observa-se nos últimos anos uma grande quantidade de pesquisas publicadas nos diversos meios de divulgação sobre a necessidade de uma Contabilidade como fonte eficaz de informação para tomada 
de decisões e fomentam a pesquisa na busca da diminuição dos ruídos que comprometem a harmonia da relação estabelecida entre os elementos de comunicação retromencionados. Apesar dessas inúmeras publicações (teses, dissertações e artigos), a abordagem tem sido normalmente com relação a necessidade de geração de uma boa informação, porém, nenhuma delas tem abordado os aspectos linguísticos que estão por trás da formação terminológica.

No processo de gestão empresarial, a Contabilidade é considerada pela Teoria da Comunicação como o Sistema de Informações da entidade e deve refletir com a máxima clareza todas as informações necessárias aos seus usuários, a fim de que possa cumprir adequadamente o seu papel na produção de informações e comunicação das mesmas. Os ruídos da comunicação contábil, a exemplo do uso demasiado de termos técnicos e estrangeirismos, dificultam a interpretação das informações e acabam por comprometer o feedback, a tomada de decisão dos seus usuários. Conforme Vasconcelos e Viana (2002, p. 21)

... de nada adianta a posse da tecnologia se a informação não é entendida, muito menos compartilhada, assim como se sabe que a informação não produzirá efeitos se não existir uma mentalidade focada na direção da informação...

Ainda neste mesmo caminho, Libonati e Souto Maior (1996, p. 247-48) elencaram alguns ruídos presentes no processo de comunicação contábil:

a) Terminologia contábil - a Contabilidade utiliza termos técnicos que não produzem uma adequada compreensão da informação pelos usuários;

b) Quantidade de informação divulgada como o limite de divulgação das informações contábeis é muito subjetivo, corre-se o risco de, ao sumarizar aquelas consideradas relevantes e úteis, omitir informações importantes e, ao mesmo tempo, prestar informações inúteis, que provocam a "diminuição da eficiência da análise" por parte dos usuários;

c) Capacidade de entendimento - o pouco conhecimento da matéria contábil por uma parcela de usuários provoca dificuldades na compreensão da mensagem.
Outro problema que pode ser considerado um ruído muito forte e não abordado pelos autores são os estrangeirismos - termos grafados em outros idiomas, normalmente em inglês - que às vezes não possuem uma tradução literal e são utilizados em relatórios contábeis sem o devido esclarecimento do significado aos usuários.

\section{CONCLUSÃO}

Conforme análise de inúmeros trabalhos sobre esse tema, concluímos que o processo de comunicação contábil ainda apresenta muitos ruídos que dificultam consideravelmente o entendimento das informações produzidas. Alguns dos problemas envolvem os usuários, que possuem restrições quanto ao entendimento especializado dos relatórios, pois não são profissionais da área, mas sim, leigos teoricamente, motivo pelo qual deve-se buscar cada vez mais a clareza na produção desses relatórios, para produzir menos ruídos e maior fidelidade.

Conforme discorrido nesse artigo, a quantidade de informação divulgada deve ser objeto de apreciação pelos órgãos de classe, através da normalização dos aspectos relevantes que devem ser divulgados nesses relatórios, cujo aperfeiçoamento destas normas contribui cada vez mais para a correta evidenciação. De nada adianta um contador elaborar uma grande quantidade de informações se estas não atendem às necessidades dos seus usuários.

Para que este processo comunicacional entre a contabilidade e os seus usuários seja mais adequado, é necessário ainda uma longa caminhada, visto que a linguagem contábil utilizada ainda necessita de maior clareza para que, ao considerar as dificuldades de entendimento por uma parcela dos usuários, as informações possam ser transmitidas de forma mais transparente.

Neste sentido, as características qualitativas da informação contábil recomendadas pelo Grupo de Empresas Transnacionais da ONU, servem de parâmetro para que a informação transmitida chegue ao usuário de forma compreensível, possa ser comparada, seja confiável e, principalmente, relevante para subsidiar as decisões. 
Para finalizar, o que se espera é que este trabalho possa suscitar, principalmente no meio acadêmico mais uma linha de pesquisa, que é a realização de estudos mais aprofundados sobre equivalência terminológica na contabilidade, visando assim confirmar que a comunicação contábil é de fato a linguagem dos negócios,

\section{REFERENCIAS}

[1] BARTHES, Roland, Elementos de Semiologia. In: La semiologia (Buenos Aires, Tiempo Contemporâneo). São Paulo, CulgtrixEditora da USP. 1971.

BATISTA, Emerson de Oliveira. Sistemas de informação: o uso consciente da tecnologia para o gerenciamento. São Paulo : Saraiva, 2004.

[3] BRASIL, Lei Federal 6.404 de 15 de Dezembro de 1976.

[4] CÂMARA JR., Joaquim Mattoso. Dicionário de linguística e gramática. Petrópolis: Vozes, 1986.

[5] CONSELHO FEDERAL DE CONTABILIDADE (CFC). Resolução 1374/11 - Dá nova redação à NBC TG estrutura conceitual: estrutura conceitual para elaboração e divulgação de relatório contábil-financeiro. Conselho Federal de Contabilidade. Disponível em: < http://www.crcsp.org.br >. Acesso em: 07/06/2012.

[6] DAVENPORT, Thomas H; PRUSAK, Laurence. Conhecimento empresarial. Tradução de Lenke Peres. Rio de Janeiro: Campus; São Paulo: Publifolha, 1999

[7] FAVERO, Hamilton Luiz et al. Contabilidade: teoria e prática. $6^{\underline{a}}$ ed. São Paulo: Atlas, 2011.

[8] LAUDON, K. C.; LAUDON, J. P. Sistema de Informação. 4a edição. Rio de Janeiro: LTCLivros Técnicos e Científicos Editora S.A., 1999.

[9] LIBONATI, Jeronymo José; SOUTO MAIOR, Verônica Cunha. O papel da comunicação na contabilidade. In: CONGRESSO BRASILEIRO DE CONTABILIDADE, 15, 1996, Fortaleza. Anais... Brasília: Conselho Federal de Contabilidade, 1996. v. 4. p. 230-254.

MARTINS. Eliseu. Contabilidade de Custos; São Paulo, Atlas. 1998.

[11] MOURA. Heronides Maurílio de MELO. POLISSEMIA E INDETERMINAÇÃO SEMÂNTICA. Revista DELTA, Vol. 18 - Especial - 2002.

[12] NIYAMA, Jorge Katsumi. Contabilidade Internacional. $2^{\underline{a}}$ ed. São Paulo: Atlas, 2010. principalmente após a convergência das normas contábeis para os padrões internacionais, onde os profissionais deverão conhecer a terminologia utilizada em qualquer país, a fim de que os esforços para publicação das informações não sejam perdidos por tê-las relegado à evidenciação de meros dados agregados.
[13] OLIVEIRA, Djalma de Pinho Rebouças. Sistemas, organização e métodos: uma abordagem gerencial. 13. ed. São Paulo: Atlas, 2002.

[14] OLIVEIRA, Edson. Contabilidade Informatizada: Teoria e prática. São Paulo, Atlas. 1997.

[15] PADOVEZE, Clóvis Luís. Manual de contabilidade básica: contabilidade introdutória e intermediária. 7aㅡ ed. $3^{\underline{\underline{a}}}$ reimpr. São Paulo: Atlas, 2011.

[16] REZENDE, D. A.; ABREU, A. F.. Tecnologia da Informação aplicada a sistemas de informação empresariais: o papel estratégico da informação e dos sistemas nas empresas. São Paulo: Atlas, 2000

[17] SAUSSURE, Ferdinand de, Curso de Linguística Geral, São Paulo, Cultrix-Editora da USP, 1972.

[18] SCHMIDT, Paulo (Organizador). Controladoria: agregando valor para a empresa. Porto Alegre: Bookman, 2002.

[19] SILVA, A. O Mundo dos Sentidos em Português - polissemia, semântica e cognição. Coimbra, Ed. Almedina, 2006.

[20] STAIR. Ralph M. Principios de Sistemas de Informação: Uma abordagem gerencial. LTC. Rio de Janeiro. 1998.

[21] STEPHEN P. Robbies.; COULTER, Mary. Administração. 5.ed. Prentice. Hall Interamericana, 1996.

[22] STROEHER, Angela Maria. Identificação das características das informações contábeis e a sua utilização para tomada de decisão organizacional de pequenas empresas. $160 \mathrm{f}$. Dissertação (Mestrado em Administração) Programa de Pós-Graduação em Administração, Universidade Federal do Rio Grande do Sul, Rio Grande do Sul, 2005. Disponível em: < http://www.ea.ufrgs.br >. Acesso em: 07/06/2012. [23] VASCONCELOS, Yumara Lúcia; VIANA, Aurelina Laurentina. Evidenciação: forma e qualidade. Revista Brasileira de Contabilidade, Brasília, ano 31, n. 134, p. 21-29,

[24] mar./abr. 2002. 


\section{Bapítulo 15}

\section{USO DO SISTEMA DE INFORMAÇÃO GERENCIAL PARA TOMADA DE DECISÕES NAS ORGANIZAÇÕES}

\section{Elias Garcia}

\section{Osmarina Pedro Garcia}

Udo Strassburg

Resumo: O presente artigo avalia a importância do Sistema de Informação Gerencial (SIG) na gestão empresarial para tomada de decisões. Em função do processo de mudanças aceleradas, principalmente no que diz respeito aos avanços da tecnologia atrelado a era da informação, um adequado sistema de informação será fator preponderante no auxilio à tomada de decisão. O desenvolvimento gerencial eficaz e eficiente pressupõe, em qualquer organização, a existência de infra-estrutura informacional para tomada de decisão, de forma ágil e segura. O sistema de informação gerencial fortalece o plano de atuação das empresas, a geração de informações rápidas, precisas e principalmente úteis, garantindo uma estruturação de gestão diferenciada. Isso tudo melhora o processo de tomada de decisões pelos gestores. Neste trabalho, buscou-se fazer uma revisão teórica do que existe de mais relevante em relação aos Sistemas de Informação Gerencial. Realizou-se uma pesquisa bibliográfica com a intenção de mostrar a importância que tem a utilização dos SIGs no apoio à gestão empresarial.

Palavras-chaves: Tecnologia de Informação, Tomada de Decisões, Sistema de informação. 


\section{INTRODUÇÃO}

$\mathrm{Na}$ atualidade vive-se na era da informação, exigindo das organizações uma gestão estratégica eficiente, que pode ser facilitada pela utilização de recursos inteligentes oriundos de tecnologias emergentes, oferecendo os recursos que suprirão as necessidades das empresas. A tecnologia de informação oferece recursos tecnológicos e computacionais para armazenamento, gerenciamento, garimpo e geração de informações. Os sistemas de informação estão cada vez mais sofisticados, propondo mudanças nos processos, estrutura e estratégia de negócios. Estes fatos abrem lacunas para que os gestores, com visão de competitividade busquem o aperfeiçoamento contínuo para suas empresas.

O desenvolvimento e a crescente evolução das organizações é fruto da evolução da tecnologia da informação e do conhecimento. Estes fatores têm transformado significativamente a sociedade. Para acompanhar essas transformações, tanto as pessoas quanto as organizações têm procurado se adequar e se atualizar para se inserir nesse modelo atual de mercado. Esse modelo é chamado 'Era da informação', que é necessário ter em mente a tecnologia de informação e os sistemas de informação como grandes precursores e responsáveis pelo valor adicionado às tomadas de decisões.

Nesse sentido, o presente artigo tem por objetivo discorrer sobre a importância e a utilização do sistema de informação gerencial na gestão empresarial para a tomada de decisões. Metodologicamente, a pesquisa é do tipo descritiva por meio de procedimento bibliográfico e com abordagem qualitativa.

\section{REFERENCIAL TEÓRICO}

\section{DADOS, CONHECIMENTO.}

\section{INFORMAÇÃO}

Inicialmente, torna-se necessário conceituar os elementos que conduzem as empresas nos seus negócios. Segundo Batista (2004, p. 20), "do ponto de vista da administração de empresas em concordância com a definição de sistemas, existem dois elementos fundamentais para a tomada de decisões: os canais de informação e as redes de comunicação". Através dos canais de informação as organizações definem de onde serão adquiridos os dados, e as redes de comunicação definem para onde os dados serão direcionados.

Para a formação dos sistemas e a conseqüente obtenção dos elementos fundamentais para a tomada de decisão é necessário o conhecimento dos conceitos de Dados, Informação e Conhecimento. Para Davenport e Prusak (1999), é essencial para a realização bem-sucedida dos trabalhos ligados ao conhecimento, que as organizações saibam definir o que são dados, informações e conhecimento, pois o sucesso ou o fracasso organizacional muitas vezes pode depender da aplicação desses elementos para solução de problemas e tomada de decisões.

Os dados apresentam-se como elementos em sua forma bruta, que não podem por si só sustentar a estruturação necessária para tomada de ação. Os dados precisam passar por análise e transformações para se tornarem úteis. Oliveira (2002, p.51), escreve que "dado é qualquer elemento identificado em sua forma bruta que, por si só, não conduz a uma compreensão de determinado fato ou situação". Assim, para a compreensão de determinado fato ou situação em uma organização é necessário que os dados se transformem em informação. Nakagawa (apud PADOVEZE 2000, p. 43), descreve que: "informação é o dado que foi processado e armazenado de forma compreensível para seu receptor e que apresenta valor real percebido para suas decisões correntes ou prospectivas".

Enquanto que Oliveira (1992), trata que a informação auxilia no processo decisório, pois quando devidamente estruturada é de crucial importância para a empresa, associa os diversos subsistemas e capacita a empresa a impetrar seus objetivos.

O valor atribuído pelos gestores às informações depende dos resultados alcançados pela empresa. Os benefícios oferecidos pelas decisões acertadas, baseadas em informações valiosas representam o sucesso da empresa.

O conceito de valor da informação segundo Padoveze (2000, p. 44), está relacionado com:

a) A redução da incerteza no processo de tomada de decisão. 
b) A relação do benefício gerado pela informação versus custo de produzi-la.

c) Aumento da qualidade da decisão.

Para que estes três elementos possam estar em sintonia com as necessidades da empresa, em termos de informação é necessário um adequado sistema de armazenamento de dados e um eficiente garimpador para os mesmos. Com a grande quantidade de dados que as empresas geram diariamente, fica difícil organizá-los, quanto mais encontrá-los. Estes sistemas são os responsáveis pela organização e estruturação dos dados na forma necessária para atender as necessidades das empresas.

As informações são criadas a partir da transformação dos dados, através da aplicação do conhecimento humano. Para Laudon e Laudon (1999, p. 10), "conhecimento é o conjunto de ferramentas conceituais e categorias usadas pelos seres humanos para criar, colecionar, armazenar e compartilhar a informação".

Para medir o valor da informação o gestor deve dispor da informação de forma que ela reduza as incertezas encontradas no decorrer do processo decisorial, e conseqüentemente, aumente a qualidade da decisão. A base do conhecimento facilita reconhecer quais dados e informações são úteis para se atingir os objetivos traçados pela organização.

\section{TECNOLOGIA DE INFORMAÇÃO (TI)}

O ambiente empresarial está mudando continuamente, tornando-se mais complexo e menos previsível, e cada vez mais dependente de informações e de toda a infraestrutura tecnológica que permite o gerenciamento de enormes quantidades de dados.

Para Pereira e Fonseca (1997, p. 239), "a tecnologia da informação surgiu da necessidade de se estabelecer estratégias e instrumentos de captação, organização, interpretação e uso das informações".

As informações com qualidade e apresentadas em tempo hábil à tomada de decisão são de vital importância para as empresas modernas. O uso adequado dos recursos da $\mathrm{TI}$ permite que sejam geradas informações oportunas e com qualidade.
Foina (2001, p. 31), conceitua TI como: "[...] um conjunto de métodos e ferramentas, mecanizadas ou não, que se propõe a garantir a qualidade e pontualidade das informações dentro da malha empresarial".

Batista (2004, p. 59), destaca que, "Tecnologia de Informação é todo e qualquer dispositivo que tenha a capacidade para tratar dados e/ou informações, tanto de forma sistêmica como esporádica, independentemente da maneira como é aplicada". A gestão estratégica das informações, resultante da TI é parte integrante de qualquer estrutura gerencial de sucesso.

\subsection{MELHORIA NOS PROCESSOS EMPRESARIAIS COM O USO DA TECNOLOGIA DA INFORMAÇÃO}

A Tecnologia da Informação transformou e ainda continua transformando o mundo dos negócios. Os processos empresariais precisam ser dotados de confiabilidade, versatilidade, eficiência e eficácia. Ela é utilizada para melhorar o desempenho das atividades da empresa, e por conseqüência, apoiar a reengenharia dos processos empresariais.

O'Brian (2002) descreve que um dos valores estratégicos da tecnologia da informação é proporcionar melhorias importantes nos processos empresariais. Os processos operacionais podem se tornar eficientes, e os processos gerenciais da empresa, eficazes. Com essas melhorias nos processos empresarias a empresa pode planejar adequadamente que tipo de informações são necessárias a cada setor, gerar as informações que realmente sejam úteis e otimizar os recursos destinados para este fim, podendo desta forma reduzir custos, melhorar a qualidade e o atendimento ao cliente e criar novos produtos e serviços.

Com as melhorias oferecidas pela Tecnologia de Informação, as empresas podem ter novas oportunidades comerciais, permitindo a expansão para novos mercados ou novos segmentos de mercados existentes. Ainda que isso signifique enfrentar muitas barreiras, principalmente no que tange ao custo elevado de investimento e complexidade da tecnologia de informação. 


\section{SISTEMA E SUA CLASSIFICAÇÃO}

A busca pela solução dos problemas conduz os gestores a unir as partes que compõem a organização para formar um sistema que the dará condições de organizar e administrar o todo.

Batista (2004, p. 22), define sistema como "[...] disposição das partes de um todo que, de maneira coordenada, formam a estrutura organizada, com a finalidade de executar uma ou mais atividades ou, ainda, um conjunto de eventos que repetem ciclicamente na realização de tarefas predefinidas". A formação de um sistema se dá pela união de diversas partes interdependentes que conjuntamente visam atingir um objetivo comum.

Os sistemas são classificados de várias maneiras, porém para este trabalho, classificam-se de duas maneiras principais: Sistemas Abertos e Sistemas Fechados. Padoveze (1997, p.36), afirma que "[...] os sistemas fechados não interagem com 0 ambiente externo, enquanto que os sistemas abertos caracterizam-se pela interação com o ambiente externo, suas entidades e variáveis". Para reforçar, a seguir está apresentada detalhadamente a classificação de sistema.

\subsubsection{SISTEMA ABERTO}

A interação da empresa com a sociedade e o ambiente onde ela atua caracteriza essencialmente o chamado sistema aberto. Bio (1985, p.19) propõe que "[...] os sistemas abertos envolvem a idéia que determinados inputs são traduzidos no sistema e, processados, geram certos outputs". Com efeito, a empresa vale-se de recursos materiais, humanos e tecnológicos, de cujo processamento resulta bens ou serviços a serem fornecidos ao mercado. A empresa busca recursos no ambiente, processa-os com ajuda dos recursos internos e devolve ao ambiente na forma de bens ou serviços. A relação de troca é natural no desenvolvimento de qualquer atividade, assim como a empresa busca no fornecedor a matéria-prima, precisa estar preparada internamente com recursos humanos e tecnológicos, para transformar essa matéria-prima e devolver à sociedade em forma de produto acabado.

\subsubsection{SISTEMA FECHADO}

O sistema fechado independe do meio externo para o desenvolvimento das suas funções. Cornachione (1998, p.25) afirma que "[...] os sistemas fechados são entendidos como os que não mantêm relação de interdependência com o ambiente externo". Neste mesmo sentido Padoveze (2000) cita como exemplo de sistema fechado o relógio, onde o seu mecanismo trabalha em conjunto sem precisar do meio externo para o seu funcionamento. A interação ocorre entre as partes que compõem o sistema, não se tornam menos importantes, têm seus benefícios, apenas não interagem com o meio externo.

\subsection{SISTEMA EMPRESA}

A empresa é um grande sistema aberto, em razão da sua interação com o meio ambiente externo. Ela capta no meio externo os recursos brutos, processa e devolve ao ambiente externo em forma de bens, serviços prestados, ou informações, atendendo as necessidades da sociedade. No decorrer desse processo podem ocorrer desvios e resultados insatisfatórios, que podem não ser aproveitados na forma como saíram. A retroalimentação permite a correção desses desvios, a fim de que se possam alcançar os objetivos satisfatoriamente. Chiavenato (2000, p. 49) escreve que "[...] a empresa é visualizada como um sistema aberto em um dinâmico relacionamento com seu ambiente, recebendo vários insumos (entradas), transformando esses insumos de diversas maneiras (processamento ou conversão) e exportando os resultados na forma de produtos ou serviços (saídas)". O planejamento estratégico é elaborado sob condições e variáveis ambientais. Esse fato só é possível por ser a empresa um sistema aberto e estar em constante interação com o ambiente.

\section{SISTEMAS DE INFORMAÇÃO - SI}

Os sistemas de informação têm por objetivo armazenar dados sobre o negócio da empresa, para que em momento oportuno esta possa garimpá-los, gerando informações para a tomada de decisões. Stair (1998, p. 11) afirma que os SI: "[...] são compostos por uma série de elementos ou componentes 
inter-relacionados que coletam (entrada), manipulam e armazenam (processo), disseminam (saída) os dados e informações e fornecem um mecanismo de feedback". Gil $(1999, \quad$ p.14) define que os SI "[...] compreendem um conjunto de recursos humanos, materiais, tecnológicos e financeiros agregados segundo uma seqüência lógica para o processamento dos dados e a correspondente tradução em informações".

Na visão de Pereira e Fonseca (1997, p. 241) "[...] os sistemas de informação (management information systems) são mecanismos de apoio à gestão", desenvolvidos baseados na TI atuando como condutores das informações visando facilitar, agilizar e aperfeiçoar o processo decisório nas empresas. A gestão empresarial precisa cada dia mais do apoio de SI, pois dão segurança, agilidade e versatilidade às empresa no momento em que processam as decisões.

\subsection{FINALIDADES DOS SISTEMAS DE INFORMAÇÃO - SI}

As empresas precisam estar preparadas para lidar com os problemas internos e externos do ambiente em que estão inseridas, para tanto buscam no desenvolvimento de SI, suporte para a resolução desses problemas. Laudon e Laudon (1999, p. 26), afirmam que "a razão mais forte pelas quais as empresas constroem os sistemas, então, é para auxiliar na resolução dos problemas organizacionais e para reagir às mudanças no ambiente". Os sistemas de informação objetivam a resolução de problemas organizacionais internos, e a conseqüente preparação para enfrentar as tendências da crescente competitividade de mercado.

Para Pereira e Fonseca (1997, p. 241) os sistemas de informação têm por finalidade "[...] a captura e/ou a recuperação de dados e sua análise em função de um processo de decisão. Envolvem, de modo geral, o decisor, o contexto, o objetivo da decisão e a estrutura de apresentação das informações".

De forma estruturada, os sistemas de informação oferecem possibilidades (informações) para que as empresas reajam às mutações do mercado e se sinta alicerçadas por um processo decisório forte o suficiente para garantir a resolução dos problemas.

\subsection{POR QUE UTILIZAR SISTEMAS DE INFORMAÇÃO?}

A necessidade de um Sistema de Informação (SI) nas empresas surgiu devido ao grande e crescente volume de informações que a organização possui. Com o Sistema de Informação estruturado, a apresentação das informações necessárias e também já propiciando uma visão das decisões, a empresa garante um grande diferencial em relação aos concorrentes, e os gestores podem tomar decisões mais rápidas, com base em fontes seguras.

A exigência do mercado competitivo, dinâmico e principalmente globalizado motiva as empresas a operarem com um sistema de informação eficiente, garantindo níveis mais elevados de produtividade e eficácia. Segundo Batista (2004, p. 39) "[...] o objetivo de usar os sistemas de informação é a criação de um ambiente empresarial em que as informações sejam confiáveis e possam fluir na estrutura organizacional".

$\mathrm{Na}$ era da informação, o diferencial das empresas e dos profissionais está diretamente ligado à valorização da informação e do conhecimento, proporcionando soluções e satisfação no desenvolvimento das atividades. Para serem efetivos, os sistemas de informação precisam, segundo Pereira e Fonseca (1997, p. 242), corresponder às seguintes expectativas:

a) Atender as reais necessidades dos usuários;

b) Estar centrados no usuário (cliente) e não no profissional que o criou;

c) Atender ao usuário com presteza;

d) Apresentar custos compatíveis;

e) Adaptar-se constantemente às novas tecnologias de informação;

f) Estar alinhados com as estratégias de negócios da empresa.

Ao visualizar um sistema que atenda os requisitos acima, a empresa se sente confiante no momento de utilizá-lo no processo decisório de seus negócios. 


\section{CLASSIFICAÇÃO DE SISTEMA DE INFORMAÇÃO}

Os sistemas, do ponto de vista empresarial, podem ser classificados de acordo com a sua forma de utilização e o tipo de retorno dado ao processo de tomada de decisões. Os sistemas podem ser de contexto operacional, gerencial e estratégico, abrangendo desde o chão de fábrica até questões de cunho estratégico para a empresa.

$\mathrm{Na}$ seqüência, estão apresentados os principais tipos de sistemas de informação, dando, porém, maior ênfase ao sistema de informação gerencial, estudo desse trabalho.

\subsection{SISTEMA DE APOIO ÀS OPERAÇÕES}

Os sistemas de Apoio às Operações de uma empresa têm por principais metas processar transações, controlar processos industriais e atualizar banco de dados, fornecendo informações de âmbito interno e externo. Apesar da sua importância para o desenvolvimento normal das atividades da empresa, não consegue desenvolver informações específicas, necessitando do apoio do sistema de informação gerencial.

\subsection{SISTEMA DE PROCESSAMENTO DE TRANSAÇÕES (SPT)}

Os sistemas de processamento de transações são utilizados no nível operacional. Afirmam Laudon e Laudon (2001, p. 31) que um SPT "[...] é um sistema computadorizado que executa e registra as transações rotineiras diárias necessárias para a condução dos negócios".

A automatização dos trabalhos repetitivos e rotineiros comuns aos negócios da empresa agiliza e facilita a realização dos trabalhos, além de oferecer uma gama maior de informações. Como exemplo, pode-se citar a transação das rotinas da folha de pagamento. A computadorização, além de produzir os cheques para pagamento dos colaboradores, pode fornecer relatórios exigidos pelos órgãos federais e estaduais. São também exemplos de SPT, a emissão de notas fiscais e o controle de estoque.

\subsection{SISTEMAS DE TRABALHO DO CONHECIMENTO E DE AUTOMAÇÃO DE ESCRITÓRIO (STC E SAE)}

A necessidade do nível de conhecimento da empresa é suprida pelos sistemas de trabalho do conhecimento e de automação de escritório. Segundo Batista (2004, p. 24) a definição que se aplica ao STC e SAE é descrita da seguinte forma: "[...] é toda e qualquer tecnologia de informação que possui como objetivo principal aumentar a produtividade pessoal dos trabalhadores que manipulam as informações de escritório".

Laudon e Laudon (2001, p. 33) também definem: "os sistemas de automação de escritório (SAE) são aplicações de informática projetadas para aumentar a produtividade dos trabalhadores de dados, dando suporte à coordenação e às atividades de comunicação de um escritório típico". Os aplicativos dos escritórios são projetados com base na necessidade de manipulação e gerenciamento de documentos, aumentando assim a produtividade dos envolvidos com a atividade, por exemplo, a editoração eletrônica, arquivamento digital, planilhas de cálculo e outros, que favorecem a qualidade e agilidade das tarefas. Os sistemas de trabalho do conhecimento exigem uma visão ampla das pessoas, pois além de saber usar os aplicativos dos escritórios, essas pessoas precisam saber utilizar o que o aplicativo oferece para criar informações novas.

\subsection{SISTEMA DE APOIO GERENCIAL}

Quando se fala em fornecer informações para a tomada de decisão, toda a empresa deve estar envolvida nesse processo. A complexa relação entre os diversos gerentes de uma organização deve ser facilitada pelos sistemas de apoio gerencial. O'Brien (2002, p.29) afirma que "quando os sistemas de informação se concentram em fornecer informação e apoio à tomada de decisão eficaz pelos gerentes, eles são chamados sistemas de apoio gerencial". Entre os vários tipos de sistemas de apoio gerencial, pode-se citar: Sistema de Suporte a Decisão (SSD), Sistema de Suporte Executivo (SSE) e Sistema de Informação Gerencial (SIG). 


\subsubsection{SISTEMA DE SUPORTE A DECISÃO (SSD)}

Os SSD são munidos de grande quantidade de dados e ferramentas de modelagem, permitindo uma flexibilidade, adaptabilidade e capacidade de resposta rápida ao nível gerencial da organização. Nessa contextualização, Batista (2004, p. 25) considera como SSD "[...] os sistemas que possuem interatividade com as ações do usuário, oferecendo dados e modelos para a solução de problemas semi-estruturados e focando a tomada de decisão". Os SSD oferecem recursos cruciais que viabilizam o suporte às decisões de nível gerencial.

\subsubsection{SISTEMA DE SUPORTE EXECUTIVO (SSE)}

Os sistemas de suporte executivo dão suporte ao nível estratégico da empresa e ajudam a definir os objetivos a serem estabelecidos, utilizando-se de tecnologia avançada para a elaboração de gráficos e relatórios. Os usuários desse sistema são os executivos seniores. Os SSE não são projetados para resolver problemas específicos, em vez disso, fornecem uma capacidade de computação e telecomunicações que pode mudar a estrutura dos problemas.

\subsubsection{SISTEMA DE INFORMAÇÃO GERENCIAL (SIG)}

O sistema de informação gerencial dá suporte às funções de planejamento, controle e organização de uma empresa, fornecendo informações seguras e em tempo hábil para tomada de decisão. Oliveira (2002, p. 59) define que "o sistema de informação gerencial é representado pelo conjunto de subsistemas, visualizados de forma integrada e capaz de gerar informações necessárias ao processo decisório". Polloni (apud GARCIA e GARCIA, 2003, p. 29), definem que SIG "[...] é qualquer sistema que produza posições atualizadas no âmbito corporativo, resultado da integração de vários grupos de sistemas de informação que utilizam recursos de consolidação e interligação de entidades dentro de uma organização".

Stair (1998, p. 278), escreve que "o propósito básico de um SIG é ajudar a empresa a alcançar suas metas, fornecendo a seus gerentes detalhes sobre as operações regulares da organização, de forma que possam controlar, organizar e planejar com mais efetividade e com maior eficiência".

Os executivos devem buscar projetar os SIGs inserindo dados de origem interna e externa, existindo portando, uma interação entre os meios, resultando na concretização dos objetivos preestabelecidos pela empresa. As fontes externas advêm do relacionamento com fornecedores, acionistas, clientes e concorrentes, facilitadas nas atuais circunstâncias pela evolução tecnológica. As fontes internas estão relacionadas aos bancos de dados mantidos pela organização. Os bancos de dados são atualizados pela captura e armazenamento dos dados resultantes da integração dos diversos sistemas que compõem a organização, entre eles, sistemas de finanças, sistemas de contabilidade, sistemas de recursos humanos, sistemas de venda e marketing. Oliveira (1992, p. 39) sobre SIG afirma que "é o processo de transformação de dados em informações que são utilizadas na estrutura decisória da empresa, proporcionando, ainda, a sustentação administrativa para otimizar os resultados esperados".

Os SIGs mudam constantemente para atender o dinamismo dos negócios, o que vai de encontro à necessidade de qualquer organização para sobreviver no mercado. Para Batista (2004, p. 22) sistema de informação gerencial;

É o conjunto de tecnologias que disponibilizam os meios necessários à operação do processamento dos dados disponíveis. È um sistema voltado para a coleta, armazenagem, recuperação e processamento de informações usadas ou desejadas por um ou mais executivos no desempenho de suas atividades. È o processo de transformação de dados em informações que são utilizadas na estrutura decisória da empresa proporcionam a sustentação administrativa para otimizar os resultados esperados.

A estrutura decisória da empresa, no contexto de processos gerenciais, classifica os sistemas de acordo com o problema organizacional que ajuda a resolver. Batista (2004) escreve que os sistemas são classificados em: sistema de nível estratégico, de conhecimento, tático e operacional. As informações geradas pelos sistemas de nível estratégico são utilizadas na definição do 
planejamento estratégico, que influencia na tomada de decisão. Os sistemas de nível tático são usados no controle dos planejamentos operacionais, define as táticas ou metas a serem cumpridas. Os sistemas de conhecimento envolvem a transmissão de conhecimento e informação entre os departamentos. Os sistemas de nível operacional são utilizados para o desenvolvimento das tarefas diárias da empresa, como exemplo, o sistema de compra/venda.

\subsubsection{IMPORTÂNCIA DOS SISTEMAS DE INFORMAÇÃO GERENCIAL PARA AS EMPRESAS}

Tem-se dificuldade em avaliar quantitativamente os benefícios oferecidos por um SIG, porém Oliveira (2002, p.54) afirma que o SIG pode, sob determinadas condições, trazer os seguintes benefícios para as empresas:

- Redução dos custos das operações;

- Melhoria no acesso às informações, proporcionando relatórios mais precisos e rápidos, com menor esforço;

- Melhoria na produtividade;

- Melhoria nos serviços realizados e oferecidos;

- Melhoria na tomada de decisões, por meio do fornecimento de informações mais rápidas e precisas;

- Estímulo de maior interação dos tomadores de decisão:

- Fornecimento de melhores projeções dos efeitos das decisões;

- Melhoria na estrutura organizacional, para facilitar o fluxo de informações;

- Melhoria na estrutura de poder, proporcionando maior poder para aqueles que entendem e controlam os sistemas;

- Redução do grau de centralização de decisões na empresa; e

- Melhoria na adaptação da empresa para enfrentar os acontecimentos não previstos.

Essas premissas permitem que as empresas definam possíveis fortalecimentos do processo de gestão, garantindo o diferencial de atuação e por conseqüência, vantagem competitiva.

Os SIGs, segundo Stair (1998) resulta em vantagem competitiva para a empresa, pois um SIG deve ser desenvolvido de forma a dar apoio para alcance das metas da organização. Por exemplo, os executivos de nível superior usam relatórios do SIG no desenvolvimento de estratégias para o sucesso dos negócios, os gestores de nível médio usam os relatórios de SIG para comparar as metas estabelecidas da empresa com os resultados reais.

Dessa forma, a empresa justifica o cumprimento de suas metas com a ajuda dos sistemas de informação gerencial.

\subsubsection{ASPECTOS QUE FORTALECEM O SISTEMA DE INFORMAÇÃO GERENCIAL NAS EMPRESAS}

Os SIGs são instrumentos para o processo decisório. Por conseqüência, para que a empresa possa usufruir as vantagens básicas dos SIGs, é necessário, segundo Rezende e Abreu (2000, p. 121) que alguns aspectos sejam observados. Entre estes podem ser citados:

- O envolvimento da alta e média gestão;

- A competência por parte das pessoas envolvidas com o SIG;

- O uso de um plano mestre ou planejamento global;

- A atenção específica ao fator humano da empresa;

- A habilidade dos executivos para tomar decisões com base em informações

- O apoio global dos vários planejamentos da empresa;

- O apoio organizacional de adequada estrutura organizacional e das normas e procedimentos inerentes ao sistema:

- O conhecimento e confiança no SIG;

- Existência de e/ou informações relevantes e atualizadas;

- A adequação da relação custobenefício.

As mudanças nos processos empresariais são inevitáveis quando se opta por investir em 
inovação, principalmente com relação à tecnologia.

\subsubsection{RELATÓRIOS DO SISTEMA DE INFORMAÇÃO GERENCIAL}

Os relatórios do sistema de informação gerencial podem ajudar os administradores no que tange aos aspectos de desenvolvimento de planos para melhorar a administração, assim como obter melhor controle sobre as operações da empresa, e tomar decisões acertadas.

O processo de transformação de dados resulta em informações úteis, as quais podem ser observadas nos relatórios. Stair (1998) escreve que os relatórios advindos do sistema de informação gerencial incluem relatórios programados, relatório indicador de pontos críticos, relatórios sob solicitação e relatórios de exceção. Os relatórios programados são aqueles produzidos periodicamente, por exemplo, em uma fábrica, a produção de um determinado produto pode ser monitorada diariamente. O relatório de pontos críticos é um tipo especial de relatório programado emitido no começo de cada dia, resumindo as atividades do dia anterior.

Os administradores obtêm informações sobre as atividades críticas da empresa possibilitando ações corretivas. Os relatórios sob solicitação são produzidos somente quando o administrador quer saber sobre um item específico, por exemplo, total da venda de um determinado produto. Os relatórios de exceção são parametrizados para informar automaticamente critérios preestabelecidos pela empresa, por exemplo, para se ter um efetivo controle de estoque, os administradores parametrizam o sistema para avisar quando determinado produto está com estoque chegando no mínimo ideal.

Neste contexto, conclui-se que os relatórios produzidos pelo sistema de informação gerencial deveriam ser fornecidos de acordo com a necessidade dos gerentes. Eles podem ser diários, semanais, mensais e apresentar informações de cunho financeiro, administrativo, e contábil.

\section{ENTERPRISE RESOURSE PLANNING - ERP}

Também chamado de Planejamento de Recursos Empresariais, é um programa de gestão empresarial destinado ao controle e gerenciamento dos recursos colocados à disposição dos gestores do negócio. É um recurso que possibilita a integração de todas as funções e processos empresariais. Conforme Rezende \& Abreu (2000, p. 209) "A tecnologia ERP e seus recursos podem contribuir muito com o funcionamento dos modelos de Sistemas de Informação Gerencial (SIG) e Estratégico (SIE), desde que bem implantado, porque, ao contrário, ela causará muitos danos à empresa, sejam financeiros ou comportamentais". Os sistemas de informações empresariais tentam absorver a totalidade das questões que envolvem as empresas, tendo como objetivos principais torná-las competitivas; reduzir os seus gastos; economizar dinheiro e atingir maior eficiência em seu ramo de negócios.

\section{INTELIGÊNCIA ARTIFICIAL}

A inteligência artificial utiliza os recursos do conhecimento, e é o que não está estruturado nos sistemas de informações tradicionais, pois eles possuem dados do que ocorreu na empresa e não fazem um relacionamento com outras ocorrências do negócio. Ex.: conforme as reações em função do que já ocorreu - as vendas caíram este mês em função do aumento do juro. Conforme afirmações do acontecimento do momento - as vendas estão fracas hoje. São afirmações que o sistema não tem condições de tomar ou sugerir atitudes, relacionando dados históricos e sim os gestores que terão condições de fazê-lo, e é neste sentido que os estudiosos estão se aprofundando na inteligência artificial.

\section{SISTEMA ESPECIALISTA}

Também são chamados de Expert Systems (ES). Eles são considerados especialistas pelo fato de que as suas soluções são oriundas de uma especialidade do conhecimento humano e que somente um especialista na área, poderia resolver sem os recursos do computador.

De acordo com Stair, (apud REZENDE \& ABREU, 2000, p. 214);

Sistema especialista é um agrupamento organizado de pessoas, procedimentos, banco de dados e dispositivos usados para gerar um parecer especializado ou 
sugerir uma decisão em uma área, dominio ou disciplina. Ele atua como um profissional especializado (expert) com muita experiência em determinado domínio. E é desenvolvido em partes por meio de exaustivas entrevistas e observações de tais profissionais, buscando extrair dos experts seu profundo conhecimento do referido domínio especializado.

Portanto, sistemas especialistas possuem alta dependência de profissionais especializados. São importantes no contexto empresarial como ramo de assessoria.

\section{SISTEMA DE COMUNICAÇÃO}

O sistema de telecomunicações migrou a pouco tempo do sistema analógico para o sistema digital, possibilitando a junção dos recursos da informática com os da comunicação, passando a compartilhar dados, voz, textos, imagens e mensagens ao mesmo tempo. Este compartilhamento se processa através de cabos, interligados a redes e também por intermédio da internet, intranet e extranet.

Para as empresas, o sistema de telecomunicações deve ser estabelecido para a interligação entre os diversos computadores existentes em seu domínio, estejam eles próximos ou distantes, com o objetivo de estabelecer um vínculo entre os diversos setores do empreendimento e, desta forma, executar a integração, compartilhando e transferindo informações, estabelecendo um canal de comunicação entre todos os subsistemas da empresa.

\section{DATA WAREHOUSE}

O Data Warehause também é conhecido como "armazém de dados". Ele armazena os dados obtidos de todos os sistemas de informação da empresa, dando condições para que, com esta junção de dados, se consiga verificar tendências para o negócio e também enxergar novas estratégias empresariais. Para Jamil (2001, p. 280) "os Data Warehause podem ser compreendidos numa abordagem superficial, como um conjunto de componentes tecnológicos que permite o agrupamento de dados de diversas fontes".

Os Data Warehause são implantados nas empresas como forma de ampliar a capacidade de gerenciamento das mesmas, através das informações fornecidas por ele. Desta forma, ele não terá a função simples de um banco de dados, que receberá os inputs dos sistemas, transformando-os em dados mais consistentes e armazenando-os, permitindo que seja feita análise nesses dados.

\section{DATAMINING}

O Datamining é uma ferramenta que auxiliará - Data Warehouse na mineração de dados, buscando padrões e relações que venham auxiliar na busca de informações completas para a solução dos problemas. Carvalho (2001, p. 4) destaca que Datamining é "descobrir conhecimento novo escondido em grande massa de dados".

Assim como o Data Warehouse é considerado a memória da empresa, o Datamining é taxado como a inteligência dela, buscando a junção de dados comuns ou que tenham afinidade entre si, para uma melhor análise dos mesmos.

\section{CONDIÇÕES DE TOMADA DE DECISÃO}

As decisões empresariais são tomadas sob diversas situações, sob condições de certeza, de incerteza e de risco. As decisões programadas normalmente oferecem um grau de risco menor do que as decisões não programadas. Em se tratando das decisões tomadas sob certeza, o gestor tem conhecimento das conseqüências ou resultados de todas as alternativas possíveis, sendo assim, pode escolher a melhor dentre elas. Stephen e Coulter (1996, p. 126), enfatizam que "a situação ideal para a tomada de decisões é a de certeza, ou seja, o administrador pode tomar decisões precisas, pois o resultado de cada alternativa é conhecido". Com relação às decisões tomadas sob condições de incertezas, os resultados são desconhecidos e gerados sob probabilidades, onde o gestor tem pouco ou nenhum conhecimento das informações que formam as alternativas. 
Na tomada de decisão com risco, todas as alternativas têm um resultado específico e são projetadas sob probabilidades conhecidas. $\mathrm{O}$ tomador de decisão conhece todas as alternativas e sabe que o risco é inevitável. Diante do exposto, observa-se que a tomada de decisão está diretamente relacionada ao potencial informativo do Sistema de Informação da empresa, e este deve ser o mais útil possível na geração da melhor informação no auxilio ao gestor.

\section{CONCLUSÃO}

Nos cenários da era da informação é de vital importância compreender as melhores práticas e aplicações das áreas de sistemas e tecnologia da informação nas empresas. O propósito básico da informação é o de habilitar a empresa a alcançar seus objetivos pelo uso eficiente dos recursos disponíveis, portanto, a posse das informações pode decidir o futuro da organização. Na corrida para atender às demandas do mercado, as empresas buscam soluções que as diferenciem aumentando a sua competitividade. Decisões rápidas e corretas são fundamentais para a empresa alcançar bons resultados. Faz-se necessário otimizar o planejamento e execução das atividades, sincronizar a cadeia de suprimentos e reduzir os custos operacionais, aumentar a satisfação dos seus clientes e a lucratividade do negócio.
A utilização de tecnologias de última geração e a melhor prática em software possibilita a construção e aplicações superiores em prazos bastante agressivos, capazes de atender desde pequenos até grandes volumes de utilização. O sucesso é garantido pela velocidade em que as informações são assimiladas e pela rapidez nas tomadas de decisões. Quando a empresa tem uma estrutura organizacional sólida, um futuro traçado, sabe utilizar os recursos oferecidos pela Tecnologia de Informação e têm como aliado os sistemas de informação gerencial, viabilizando a geração de relatórios, este só tem a agregar benefícios à gestão empresarial na tomada de decisões.

O sistema de informação gerencial possibilita fazer um acompanhamento das rotinas econômico-financeiras, proporcionando um panorama seguro da organização e uma melhor alocação de investimentos, constituindo um grande diferencial para a empresa, garantindo, também, o gerenciamento das informações para geração de relatórios rápidos e precisos, agilizando o processo de tomada de decisões. Os sistemas de informação gerenciais fortalecem o plano de atuação das empresas. A geração de informações rápidas, precisas e principalmente úteis para o processo de tomada de decisão garante uma estruturação de gestão diferenciada, resultando em vantagem competitiva sobre as demais empresas.

\section{REFERÊNCIAS}

[1] BATISTA, Emerson de Oliveira. Sistema de Informação: o uso consciente da tecnologia para o gerenciamento. São Paulo: Saraiva, 2004.

[2] BIO, Sérgio Rodrigues. Sistemas de informação: um enfoque empresarial. São Paulo: Atlas, 1985.

CARVALHO, L. A. V. de. Datamining, a mineração de dados no marketing, medicina, economia, engenharia e administração. São Paulo: Érica, 2001.

CORNACHIONE Jr., Edgard B. Informática aplicada às áreas de contabilidade, administração e economia. 2. ed. São Paulo: Atlas, 1998.

CHIAVENATO, Idalberto. Administração: Teoria, Processo e Prática. 3. ed. São Paulo: Pearson Education do Brasil, 2000.
[6] DAVENPORT, Thomas $\mathrm{H}$; PRUSAK, Laurence. Conhecimento empresarial. Tradução de Lenke Peres. Rio de Janeiro: Campus; São Paulo: Publifolha, 1999.

[7] FOINA, Paulo Sérgio. Tecnologia de Informação: planejamento e gestão. São Paulo: Atlas, 2001.

[8] GARCIA, Elias; GARCIA, Osmarina Pedro Garcia. A importância do sistema de informação gerencial para a gestão empresarial. Revista Ciências Sociais em Perspectiva, do Centro de Ciências Sociais Aplicadas de Cascavel, Cascavel, v. 2 , n. 1, p. 21-32, 1 sem. 2003.

[9] GIL, Antônio de Loureiro. Sistema de Informações Contábil/Financeiros. 3. ed. São Paulo: Atlas, 1999

[10] JAMIL, G. L. Repensando a TI na empresa moderna. Rio de Janeiro: Axel Books, 2001. 
[11] LAUDON, Kenneth C.; LAUDON, Jane Price. Sistemas de informação. 4. ed. Rio de Janeiro: LTC, 1999.

[12] Gerenciamento de sistemas de informação. 3. ed. Rio de Janeiro: LTC, 2001.

[13] O’BRIEN, James A. Sistemas de informação e as decisões gerenciais na era da internet. Tradução de Cid Knipel Moreira. São Paulo: Saraiva, 2002.

[14] OLIVEIRA, Djalma de Pinho Rebouças de. Sistemas de informação gerenciais: estratégias, táticas, operacionais. 8. ed., São Paulo: Atlas, 1992.

[15] Sistemas, organizações e métodos: uma abordagem gerencial. 13. ed. São Paulo, 2002

[16] PADOVEZE, Clóvis Luís. Contabilidade gerencial: um enfoque e sistemas de informação contábil. São Paulo: Atlas, 1997.
[17] Sistemas de Informações Contábeis: fundamentos e análise. 2. ed., São Paulo: Atlas, 2000.

[18] PEREIRA, Maria José Lara de Bretãs; FONSECA, João Gabriel Marques. Faces da Decisão: as mudanças de paradigmas e o poder da decisão. São Paulo: Makron Books, 1997.

[19] REZENDE, Denis Alcides; ABREU, Aline França de. Tecnologia da informação aplicada a sistemas de informação empresariais: o papel estratégico da informação e dos sistemas de informação nas empresas. São Paulo: Atlas, 2000.

[20] STAIR, Ralph M. Princípios de sistemas de informação. Rio de Janeiro: LTC, 1998.

[21] STEPHEN P. Robbies.; COULTER, Mary. Administração. 5.ed. Prentice. Hall Interamericana, 1996. 


\section{Bapítulo 16}

CONSTRUÇÃO DE UM DATA WAREHOUSE UTILIZANDO FERRAMENTA OPEN SOURCE NO PROCESSO DE GESTÃO DA INFORMAÇÃO GERENCIAL

\section{Emanoély Fernanda Gura}

Larissa Lourenço Nunes Benck

Simone de Almeida

Resumo: Na maioria das organizações, há problemática na correta interpretação das informações e a dificuldade de agrupá-las, para obter um novo conhecimento. Assim, a tecnologia de Data Warehouse é uma solução que procura de maneira flexível e eficiente tratar um grande volume de dados e obter informações que auxiliem no processo de tomada de decisão. Baseado nisso, este artigo descreve o processo de construção de uma aplicação que explora a tecnologia de Data Warehouse, usando dados coletados em uma farmácia magistral localizada na região de Ponta Grossa - Paraná. Para implementação do estudo de caso foi utilizada a ferramenta Pentaho, que oferece suporte para o processo de Data Warehouse o que contribuiu com o desenvolvimento do projeto. A abordagem metodológica utilizada é a pesquisa qualitativa, por meio de um estudo de caso. O estudo da teoria foi essencial para realização dos processos e a etapa da procura por uma ferramenta ideal fez a equipe conhecer possibilidades distintas, auxiliando na melhor escolha para o estudo de caso. As respostas das questões levantadas na etapa de brainstorming, e que deveriam ser respondidas com o projeto, foram obtidas com sucesso.

Palavraschave: Data Warehouse, Gestão da Informação, Business Intelligence. 


\section{INTRODUÇÃO}

É comum originar polêmicas sobre a capacidade de interpretação e compreensão de palavras; interpretar não somente em um contexto qualquer e sim de uma maneira que o objeto analisado possa ser utilizado para auxiliar em seus problemas ou pensamentos. Percebe-se que quem desenvolve essa capacidade obtém uma grande vantagem sobre suas atitudes e comportamento. Isso não é diferente em uma organização, que nada mais é do que uma junção de pessoas e funções que gira em torno de informações. É indiscutível que a informação é considerada a melhor forma de negociação atualmente, pois é um requisito relevante para manter a vantagem competitiva, auxiliando no processo de tomada de decisão.

Hoje as empresas não trabalham mais para gerar e implantar informações nos sistemas, mas sim, para obter informações gerenciais executivas para melhor agir e mais rápido decidir, ao que denomina-se de Gestão da Informação. Faz-se necessário organizar, controlar e filtrar os dados para melhor apoiar os executivos, gerentes e analistas, em um processo automatizado, surgindo, então, a área de Business Intelligence.

Como a maioria dos sistemas não são modelados e preparados para armazenar informações decisórias ou estratégicas nas empresas, surge a necessidade de uma base histórica para as tomadas de decisões, denominado Data Warehouse (DW) ou Armazém de Dados. O DW integra os dados internos e externos de uma organização, proporcionando assim, a conectividade do mundo virtual com o dos negócios. Com esse agrupamento de dados é possível gerar relatórios com novas visões, ou seja, transformar o conhecimento antes tácito em tangível.

Ainda assim, percebe-se a grande dificuldade encontrada pelas organizações na tomada de decisão rápida. Muitas organizações não sabem como trabalhar com os dados coletados ao longo dos anos, perdendo a sua essencialidade e diferenciação no mundo dos negócios, o que é meritório em um mercado altamente competitivo.

Faz-se mister, portanto, um estudo mais abrangente desse problema, permitindo obter maior domínio do processo de construção DW e aplicá-lo em um estudo de caso, identificando suas fases e utilizando os conceitos e princípios necessários na geração de conhecimento.

Dessa forma, este artigo utiliza a tecnologia de DW para apoiar a tomada de decisão, onde se apresenta uma breve revisão bibliográfica sobre DW, focando especialmente em suas principais características e no processo de implementação.

$\mathrm{Na}$ estrutura deste, inicialmente é apresentado um estudo sobre as diferenças entre Gestão do Conhecimento e Gestão da Informação elencando o Sistemas de Informação Gerencial com a Tomada de Decisão. Também tem-se o conceito, a caracterização e a classificação do DW. Posteriormente, aborda-se a metodologia e o projeto de pesquisa, descrevendo-a e apresentando a ferramenta Pentaho como apoio ao desenvolvimento do DW. Por último, mostram-se os resultados das pesquisas e suas respectivas discussões.

\section{DIFERENÇAS ENTRE GESTÃO DO CONHECIMENTO E GESTÃO DA INFORMAÇÃO}

Muitos se perguntam por que está havendo esse súbito interesse em conhecimento. E duas afirmações colocam discussão ao tema. Primeira: não é um súbito interesse, uma vez que a busca pelo conhecimento vem crescendo consideravelmente, mas hoje o apelo é digital e aguçado em tecnologia; e a segunda é sustentada por Davenport\& Prusak (1998, p.15): "Numa economia global, o conhecimento pode ser a maior vantagem competitiva da empresa".

Atribuir essa busca acelerada por conhecimento às tecnologias dá uma falsa visão de que aqueles que dispõem de equipamentos sofisticados obtêm a melhor informação. Como explica Rossetti (2007), o potencial de contribuição da Tecnologia da Informação ( $\mathrm{TI})$ não chega a ser um destaque, restringe-se ao desenvolvimento e uso dos registros dos ativos intelectuais e dos sistemas de processamento. A tecnologia ajuda a reunir valores e transformar dados em informação, o que não significa que um conjunto de dados armazenado será útil. É necessário que eles sejam transformados em informação e esta em conhecimento. Segundo OLIVEIRA (2008, p.73) "a eficácia empresarial está sendo seriamente 
prejudicada por sistemas que, simplesmente, produzem grandes quantidades de dados e informações que não são trabalhados e utilizados". Percebe-se, então, que dados diferem de informação, assim como informação difere-se de conhecimento.

Para identificar essa diferença, surge técnicas adquiridas através da Gestão de Conhecimento e da Gestão da Informação. De acordo com Valentim (2004), Gestão de Informação é um conjunto de estratégias que visam identificar as necessidades informacionais, mapear os fluxos formais de informação nos diferentes ambientes da organização. Por outro lado, a Gestão do Conhecimento é o conjunto de estratégias para criar, adquirir, compartilhar e utiliza alvos de conhecimento, bem como estabelece fluxos que garantam a informação necessária no tempo e formato adequados, a fim de auxiliar na geração de ideia.

Além disso, existem algumas vertentes que fundem os dois modelos de gestão. Ambos modelos focam para o fato de que pretendem apoiar as atividades desenvolvidas no dia a dia e na tomada de decisão, mas focam em fluxos informacionais diferenciados, sendo a Gestão de Informação nos fluxos formais (conhecimento explícito - do latim explicitus, quando o conhecimento está declarado, mostrado, explicado) e a Gestão de Conhecimento nos fluxos informais (conhecimento tácito - do latim tacitus, quando o conhecimento não pode ser exteriorizado por palavras; como: construção individual de conhecimento, valores, crenças e comportamento organizacional).

Os sistemas de informação buscam pela tradução do conhecimento tácito, como afirma GIL (1999) explicando que eles devem compreender um conjunto de recursos humanos, materiais, tecnológicos e financeiros agregados segundo uma sequência lógica para o processamento dos dados e a correspondente tradução em informações. Traduzindo-se em Sistema de Informação Gerencial (SIG), ele é projetado para oferecer aos administradores informações seguras para a tomada de decisão, sendo esse o ponto de interesse do estudo da informática nas organizações.

"Um Sistema de Informações Gerencial (SIG) abrange uma coleção organizada de pessoas, procedimentos, software, banco de dados e dispositivos que fornecem informação rotineira aos gerentes e aos tomadores de decisão. O foco de um SIG é, principalmente, a eficiência operacional. Marketing, produção, finanças e outras áreas funcionais recebem suporte dos sistemas de informação gerencial e estão ligados através de um banco de dados comum" (STAIR \& REYNOLDS, 2002, p. 18).

Percebe-se através das definições que um SIG nada mais é que ferramentas que auxiliem e permitam aos gestores de forma dinâmica e prática embasar as informações necessárias para as decisões que norteiam as empresas. As tomadas de decisões envolvem um ciclo e é fundamental a existência de informações apropriadas a cada uma das fases do ciclo sendo elas de implantação, avaliação da decisão, recomendações de mudanças e tomada de decisão.

Cabe aos analistas e desenvolvedores de tais sistemas adaptá-los e implementá-los quanto aos pontos inerentes ao cenário analisado. Essa área de estratégia empresarial é conhecida como Business Intelligence, ou Negócio Inteligente, que tem por finalidade auxiliar as organizações por meio da automatização dos processos empresariais.

\section{DATA WAREHOUSE}

O Data Warehouse (DW) consiste em reunir todos os dados de relevância da organização em um único lugar, para retirar uma informação mais precisa e consistente nos relatórios. A constante expansão das empresas, por conseguinte suas informações, necessitam de um tratamento adequado a esse volume de dados para que possam ser melhor interpretados e gerenciados. Segundo Inmon (1999), como características de um DW observam-se:

- Orientado a assunto: seria o principal assunto a ser tratado pelo DW, ou seja, a principal informação da organização.

- Variação de Tempo: são dados precisos em relação ao tempo, chamados de snapshots, ou fotos instantâneas; após retirar os dados corretos eles são inalteráveis.

- Não volátil: os dados carregados no DW não podem mais ser alterados, gerando apenas duas operações sobre eles: a carga e o acesso a esses dados 
(consulta).

- Integração: os dados necessitam ser armazenadas de forma única, quando são movidos do ambiente operacional para o ambiente analítico, convencionando nomes, variáveis de medidas e assim sucessivamente. Além da não normalização dos dados.

Data Mart (DM) é um subconjunto de DW, que contém dados para um setor específico da empresa. Um DW é composto por DMs. Conforme Machado (2004), a principal vantagem do seu emprego é o retorno rápido de informações, o que garante maior comprometimento do usuário final.

Para a implantação de um DW, deve se utilizar a modelagem denominada Modelagem Multidimensional, auxiliando o processo de tomada de decisão diária. A Modelagem de um modelo multidimensional é dividida em:

- Fatos: Segundo Machado (2004), varia ao longo do tempo, possuem valores numéricos de avaliação, seu histórico pode ser mantido e cresce com o passar do tempo.

- Dimensões: Para se obter as dimensões dos fatos, têm-se quatro elementos participantes: quando foi realizada, onde, quem e o que foi realizado. Obtendo essas respostas realiza-se a análise dimensional, podendo ser compostas e com hierarquias.

- Medidas: são os atributos numéricos que representam um fato, ou seja, representam o desempenho de um indicador de negócio relativo às dimensões que participam desse fato.

Metadados são considerados dados sobre dados, isto é, os dados sobre os sistemas que operam com estes dados. Um repositório de metadados é uma ferramenta essencial para o gerenciamento de um DW no momento de converter dados em informações para o negócio. Deve conter informações como a origem dos dados, regras de transformação, nomes e apelidos e formatos de dados.

Segundo Inmon (1999), a granularidade é o mais importante aspecto do projeto de um DW. Trata-se do nível de detalhe exigido dos dados. "Quanto mais detalhado os dados forem, mais baixo é o nível de granularidade" (GRAY, 1998, p. 01). O baixo nível de granularidade aumenta o volume de dados armazenados no DW e o alto nível limita as pesquisas, com poucos detalhes. As fases de um DW podem ser sintetizadas em quatro:

- Sistemas Operacionais de Origem: são bases operacionais transacionais, podendo ser dados de web, ERP, externo entre outros.

- Área de Trabalho: a área de armazenamento onde ocorre o conjunto de processos de extração, transformação e carregamento, ou seja, ETL (Extract, Transformation, Load).

- Data Warehouse/Data Mart: local onde os dados ficam organizados esperando para serem consultados. Machado (2004, p. 44) exemplifica: "o Data Warehouse é um armazém de dados e os Data Marts são as prateleiras".

- Ferramenta de acesso a dados: componente principal do DW é a ferramenta de acesso aos dados, o sistema está pronto para consultas.

Para gerir o sistema de DW faz-se necessário a busca de ferramentas adequadas, isto é, um conjunto de tecnologias que ofereçam suporte ao ambiente de informação. Existe no mercado, um volume enorme de ferramentas que tem o foco deBusiness Intelligence e que a falta de padronização, tanto estrutural quanto operacional, dificulta o processo de comparação.

A partir dessa informação e após estudo sobre as ferramentas do mercado, foi escolhidaa ferramentaPentaho®. Fundada em 2004, baseia-se em tecnologia Java, sendo de código aberto e gratuito. Com ela pode-se realizar consultas, relatórios, análise de informações (OLAP), ETL e mineração de dados.

\section{APLICAÇÃO DA TECNOLOGIA DW EM UM ESTUDO DE CASO}

A Ionsfarma, farmácia de manipulação e homeopatia, está localizada em Ponta Grossa - Paraná desde 1999 é responsável por vendas de produtos comerciais e 
manipulados. Medicamentos manipulados são preparados em uma farmácia magistral autorizada pela Vigilância Sanitária e contém o princípio ativo e a dose prescrita pelo médico. Estes medicamentos são apresentados pelas farmácias de manipulação como alternativas às doses padrões disponibilizadas pela indústria, ou seja, a produção de medicamentos é personalizada em relação à dose, como também a combinação de princípios ativos em uma mesma cápsula ou outras formas de apresentação do medicamento (ANVISA, 2007).

Para se manter competitiva no mercado, as empresas desse ramo de atuação necessitam de informações que possibilitem maior conhecimento de seu negócio, auxiliando em sua tomada de decisão. O objetivo geral é combinar as necessidades de informação da comunidade de usuários com os dados que realmente estão disponíveis, compondo o repositório de dados.

\subsection{PRÉ-PROCESSO}

Inicialmente é feito o processo de extração de subsídios frente a frente com o usuário, uma atividade indispensável para recolhimento de informações relevantes que a organização necessite obter. Uma maneira para realizar esse processo é por meio de técnicas como o brainstorming, entrevistas com o cliente, entre outras.

A coleta de dados foi realizada junto à proprietária e administradora da empresa, requerendo informações vitais para gerar o DW. Foram identificadas as seguintes questões que o DW deverá responder:
Após definidos os questionamentos, é realizada a análise para dar início ao processo de modelagem. A Figura 1 mostra o ciclo de vida do DW em que inicialmente é realizado o planejamento do projeto, definindo as necessidades do negócio. Segue-se com os processos sequenciais mostrados no diagrama, sendo esses o projeto técnico de arquitetura, a seleção e instalação da ferramenta, a modelagem multidimensional, o projeto físico, a preparação de dados, a aplicação analítica e o desenvolvimento da aplicação. Após o término dessas fases, é feita a implementação e a manutenção do DW. 
Figura 1 - Ciclo de vida do Data Warehouse

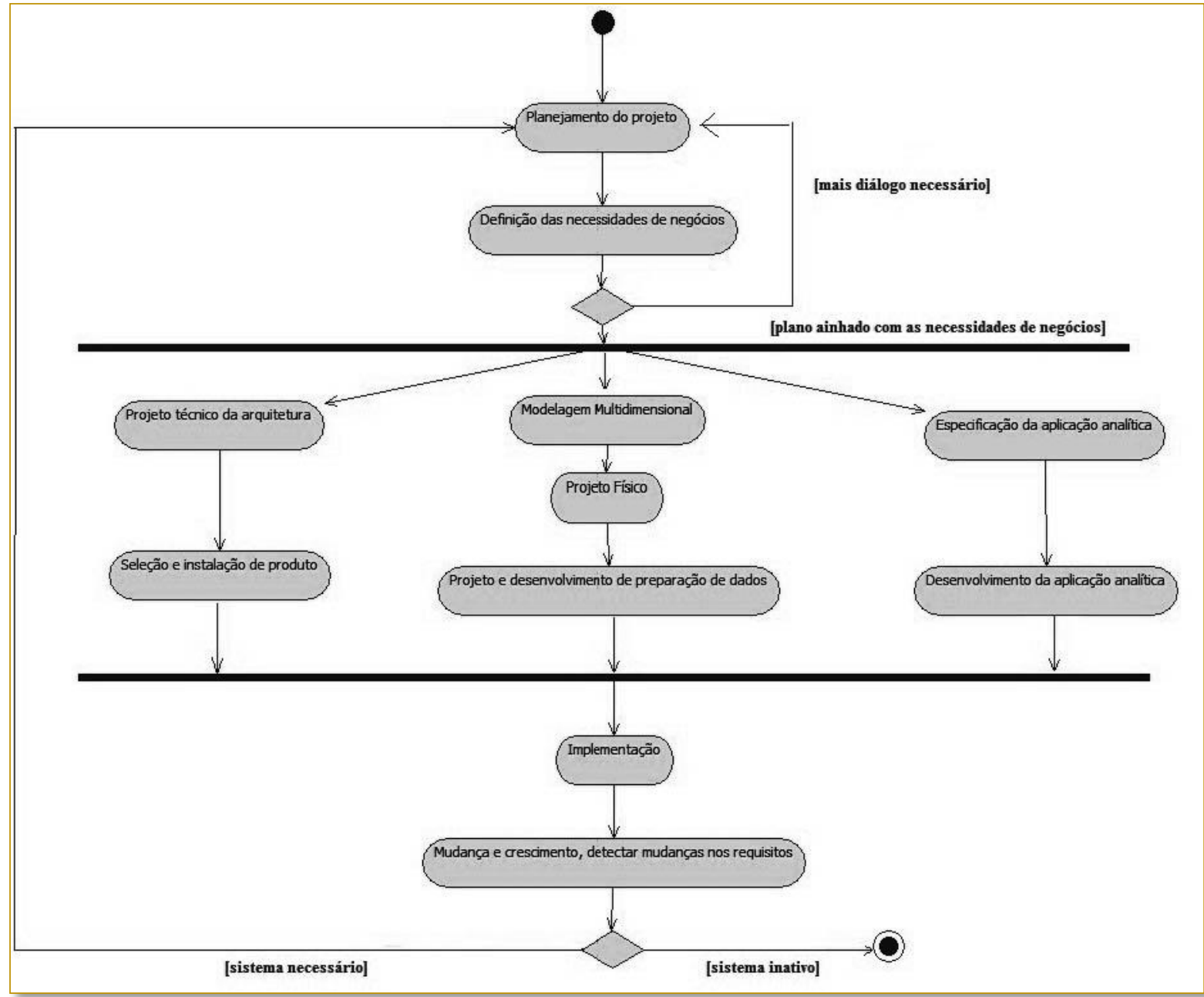

Fonte: Teorey, et al. (2006, p. 157)

\subsection{PROJETO LÓGICO}

Para dar início ao projeto lógico foi realizada uma análise minuciosa do Modelo de Entidade e Relacionamento do banco de dados da empresa, definindo assim o Modelo Multidimensional ilustrado na Figura 2. Foram definidas as seguintes dimensões: Cliente, Médico, Especialidade, Componente,
Produto, Venda e Tempo. E o fato foi definido como: Venda.

Foi escolhido o processo de modelagem departamental, ou seja, um Data Mart, focando assim em um único problema da empresa. Diante das pesquisas, concluiu-se que o departamento propício seria vendas, com foco no faturamento. 
Figura 2 - Modelagem Multidimensional

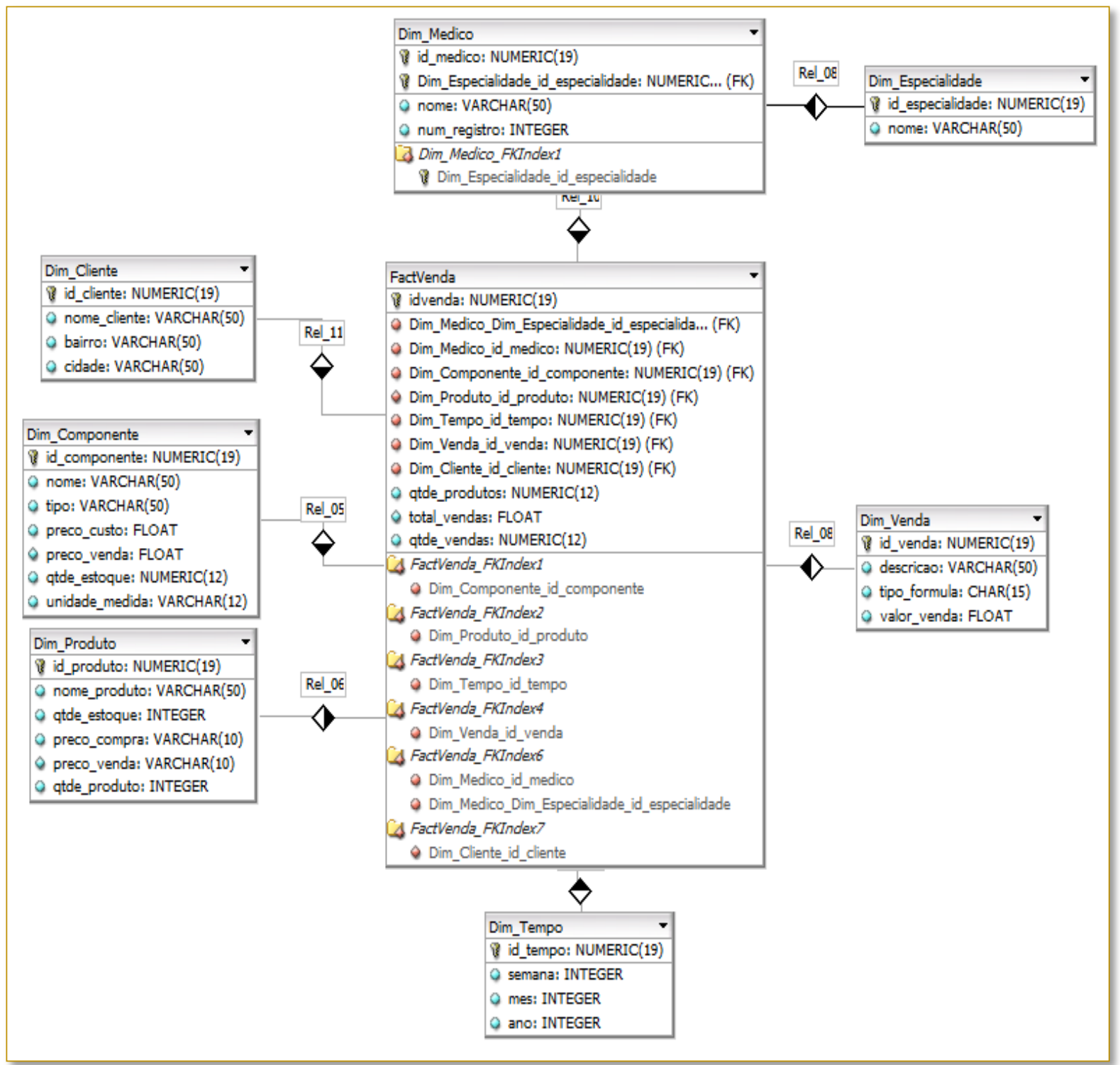

Fonte: Autoria própria.

\subsection{CRIAÇÃO DO DW PARA O ESTUDO DE CASO}

Após entender as requisições do cliente através do brainstorming, compreender o banco de dados do sistema pela análise do Modelo Entidade Relacionamento e definir as métricas do projeto de DW com o projeto lógico, além de configurar as ferramentas da suíte Pentaho, inicia-se a criação do DW para o estudo de caso. Essa etapa será dividida em: criação da base de dados, geração do modelo multidimensional e processo de ETL.

Com o auxílio da ferramenta SQLDbx - um IDE para desenvolvimento SQL focado em ambientes de servidores heterogêneos - e utilizando o driver do banco de dados MySQL, criou-se o repositório de dados baseado na modelagem multidimensional apresentada na fase do estudo de caso.

$\mathrm{Na}$ etapa de geração do modelo multidimensional, realizou-se a conexão da base de dados nas ferramentas de administração: administration-console e biserver-ce. Dependendo do banco de dados (BD) a ser utilizado, mudam-se as configurações, devendo atentar-se a detalhes de driverespecífico para cada ferramenta e o caminho do repositório. 
Utilizando a ferramenta Schema Workbench da Pentaho, criam-se as tabelas, juntamente com seus atributos, diferenciando fatos de dimensões. Pode-se, agora, gerar o XML (Extensible Markup Language)-Linguagem Padronizada de Marcação Genérica capaz de descrever diversos tipos de dados que facilitao compartilhamento de informações através da internet - da modelagem multidimensional. Para isso é feita a transformação do modelo multidimensional que se foi criado, em XML e a sua publicação na web.

Para extrair, transformar e carregar a base de dados utilizou-se o pacote data-integration, em que é realizado o processo de ETL, ou seja, a extração, a transformação e o carregamento dos dados no repositório.

Figura 3 - Transformação da dimensão Cliente

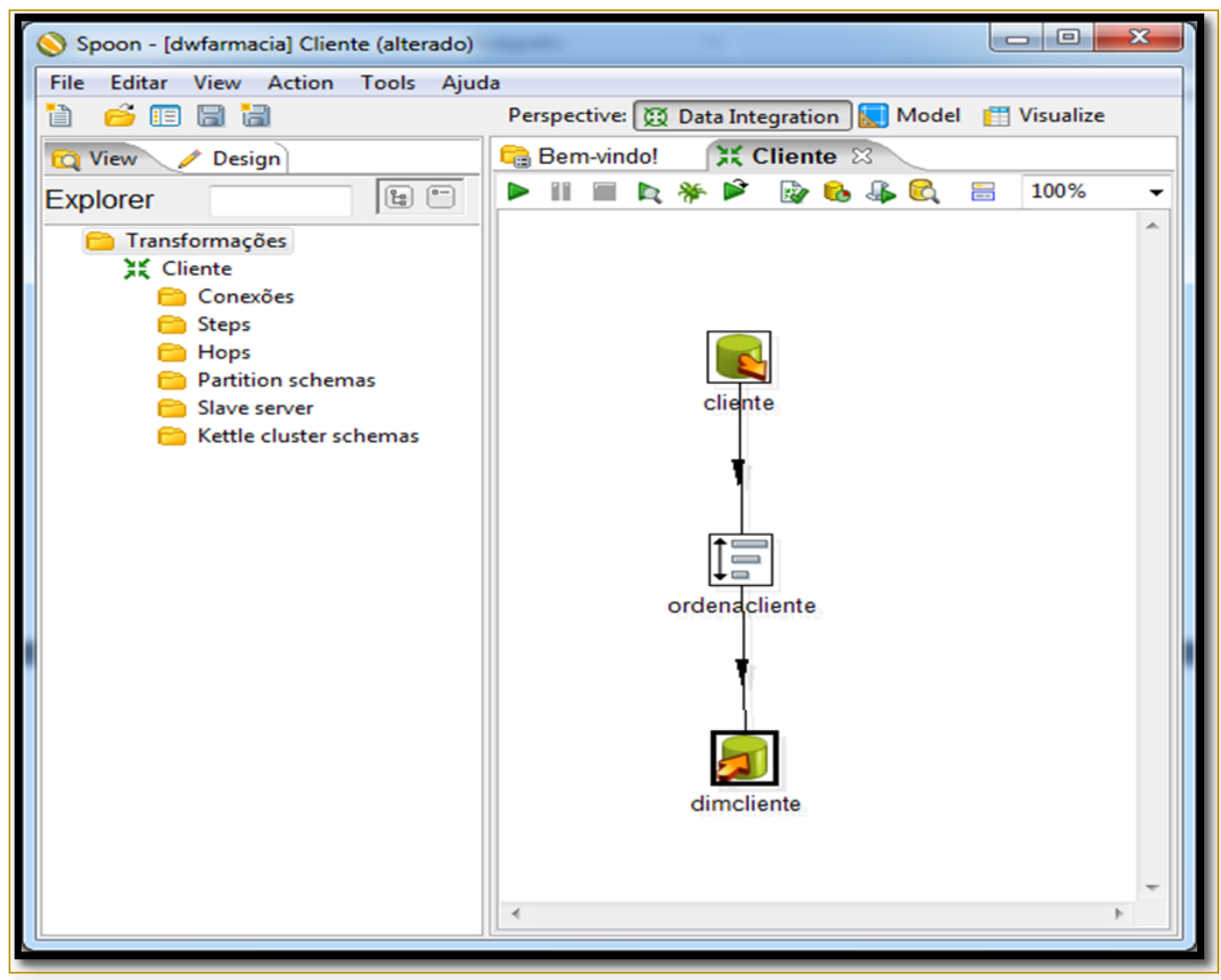

Fonte: Autoria própria

No estudo de caso, o desenvolvimento do DW foi realizado por etapas, isto é, cada dimensão passou pelo processo de transformação separadamente, isso é uma particularidade dos analistas, que necessitavam observar separadamente cada fase do processo, porém não há restrições para gerar as transformações em mais de uma dimensão em um mesmo processo.

Os processos de transformação, na maioria dos casos, consistem na ordenação dos dados e logo em seguida, é realizada a carga deles no repositório. Adicionalmente em alguns processos de transformação foram feitos joins para inserir duas tabelas em uma única dimensão. Como exemplo, na Figura 3 mostra-se a transformação juntamente com a carga dos dados na dimensão Cliente.

Após finalizar o processo de ETL nas dimensões, faz-se necessário passar pelo processo o fato. A Figura 4 representa o fato venda, onde são realizados os joins de todas as dimensões e algumas tabelas necessárias para a composição do mesmo. Após a finalização da fase de ETL, as tabelas estão carregadas com os dados e prontas para serem analisadas, ou seja, os relatórios já podem ser gerados. 
Figura 4 - Transformação Fato Venda

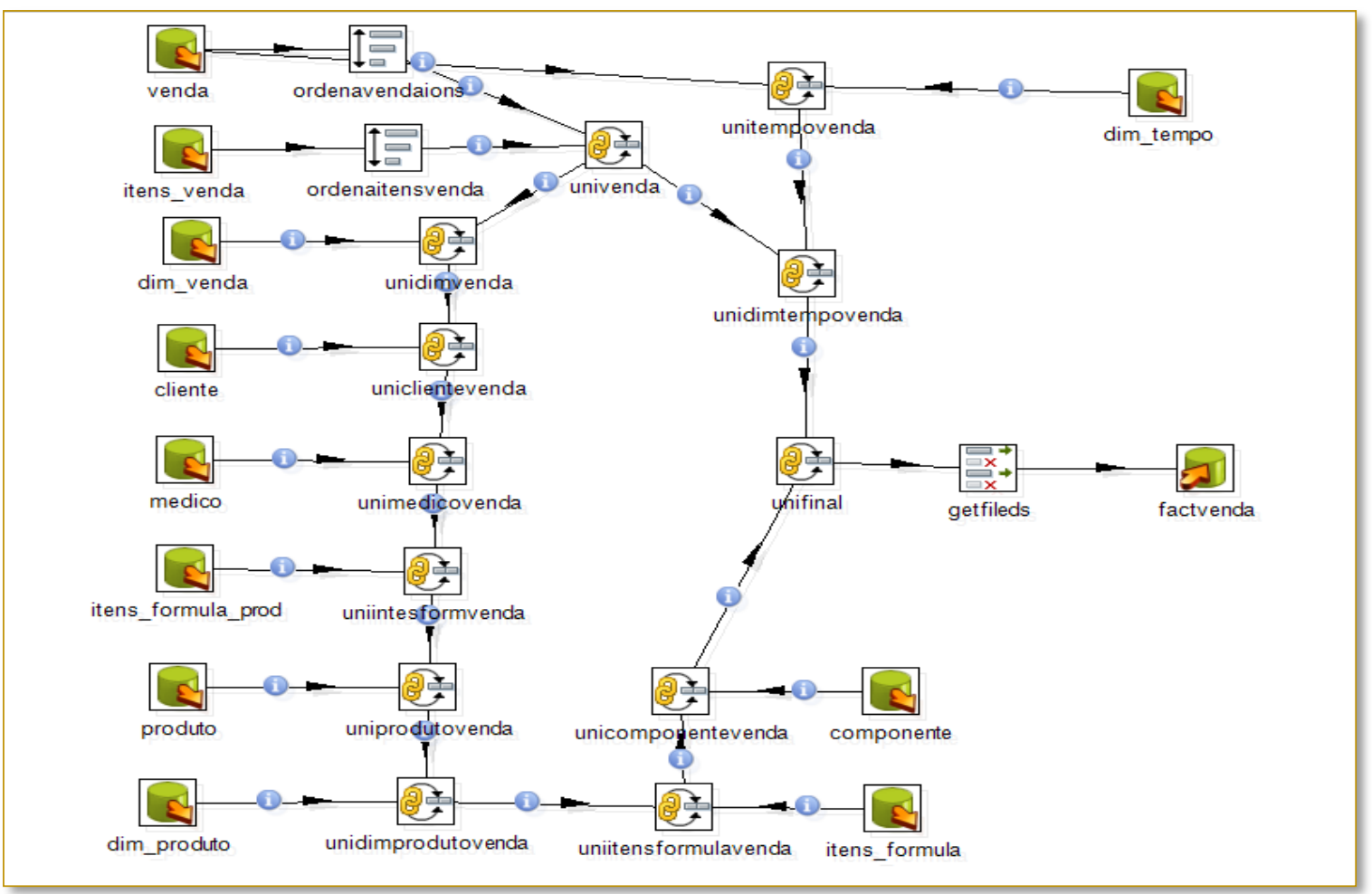

Fonte: Autoria própria

\section{CONCLUSÃO}

Com o estudo da gestão da informação e do conhecimento foi possível visualizar a diferença e a essencialidade de cada uma e além disso, a necessidade de como os tomadores de decisão precisam de um conhecimento detalhado da informação. Isso para poder gerar o conhecimento adequado para uma tomada de decisão mais eficiente, portanto, correlaciona-se o estudo da tecnologia de DW, para que esta auxilie os gestores.

Após a fase de estudo da tecnologia, é possível concluir que a melhor implementação do DW está diretamente relacionada com o entendimento e compreensão de cada fase do processo, bem como associá-las com as ferramentas de desenvolvimento. Caso o analista não esteja familiarizado com o seu processo na teoria, dificilmente conseguirá colocá-lo em prática e assim, atingir suas metas.

Um grande desafio encontrado foi na implementação do DW e do estudo de caso, uma vez que cada organização tem suas particularidades e faz-se necessário a integração total do analista com o processo empresarial. No caso apresentado, esse estudo do ambiente corporativo foi possível graças ao Modelo de Entidade e Relacionamento disponibilizado pela empresa, que teve de ser minuciosamente compreendido, além da realização do brainstorming para obter questões a serem resolvidas com o estudo.

Vale ressaltar que a Pentaho engloba todas as tarefas do processo de Business Intelligence e ainda com a possibilidade de utilizar qualquer banco de dados. Com esta vasta gama de recursos, para se obter um resultado positivo, é necessário muito estudo de suas inúmeras funcionalidades.

Em geral, as expectativas com o desenvolvimento do DW foram alcançadas. O estudo da teoria foi essencial para realização dos processos. A busca pela ferramenta ideal permitiu que a equipe tivesse contato com distintas ferramentas o que auxiliou na melhor escolha para o estudo de caso. A Pentaho 
supriu as necessidades para realizar os processos, apesar de todo o esforço para trabalhar com esta vasta gama de recursos.

Conclui-se que a utilização dos recursos de DW processo pode ser considerada um grande passo para facilitar a gestão empresarial. Sendo possível a geração de relatórios opcionais e de fácil acesso e modificação própria dos gestores de acordo com o gosto e a vontade de cada um, podendo atingir sua meta mais rapidamente e permitindo uma constante análise gerencial.

\section{REFERÊNCIAS}

[1] ANVISA - Agência Nacional de Vigilância Sanitária. Resolução RDC № 214, de 9 de fevereiro de 2007. Brasília (DF): Diário Oficial [da] República Federativa do Brasil; 9 fev. 2007.

[2] BARQUIN, R.; EDELSTEIN, S. Planning and Designing the Data Warehouse. Prentice Hall, 1997.

[3] DAVENPORT, T. H.; PRUSAK, L. Conhecimento Empresarial: como as organizações gerenciam seu capital intelectual. Tradução de Lenke Peres - Rio de Janeiro: Elsevier, 2003.

[4] GIL, A. L. Sistema de Informações Contábil/Financeiros. 3aㅡ Ed. São Paulo: Atlas, 1999.

[5] GRAY, P; WATSON, H. J. Decision Support in the Data Warehouse. New Jersey: Prentice Hall, 1998.

[6] INMON, W. H.; WELCH, J. D.; GLASSEY, K. L. Gerenciando data warehouse. São Paulo: Makron, 1999.

[7] MACHADO, F. N R. Tecnologia e Projeto de Data Warehouse Uma Visão Multidimensional.São Paulo: Editora Érica, 2004.
[8] OLIVEIRA, W. J. Data warehouse. Florianópolis: Visual Books, 2002.

[9] OLIVEIRA, Djalma de Pinho Rebouças de. Sistemas de Informações Gerenciais: Estratégicas Táticas Operacionais. 12a Ed. São Paulo: Editora Atlas, 2008, 299 páginas.

[10] PENTAHO, Disponível em <http://www.pentaho.com/>. Acesso em: 14/09/ 2011.

[11] ROSSETTI, A. G.; MORALES, A. B. T. O papel da tecnologia da informação na gestão do conhecimento. Brasília, 2007. Disponível em: < http://www.scielo.br/pdf/ci/v36n1/a09v36n1.pdf > Acesso em: 15/10/2011.

[12] SQL Server Analysis Services. Dados Multidimensionais. Disponível em $<$ http://msdn.microsoft.com/ptbr/library/bb522607.aspx> Acesso em: 22/09/ 2011.

[13] STAIR, R. M.; REYNOLDS G. W. Princípios de Sistemas de Informações: Uma abordagem Gerencial. 4ํed. São Paulo: LTC, 2002.

[14] VALENTIM, Marta L.P. Gestão da informação e gestão do conhecimento. Marília, 2004. Artigo, Info Home. Disponível em: < http://www.ofaj.com.br/colunas_conteudo.php? cod $=88$ > . Acesso em: 15/10/2011. 


$$
\text { Alutary }
$$




\section{Brenner Lopes (Organizador)}

Possui graduação em Ciências Econômicas pela Pontifícia Universidade Católica de Minas Gerais (1995) e mestrado em Administração pela Faculdade Novos Horizontes (2010). Possui especialização em Altos Estudos de Política e Estratégia; Especialização em Estudos Superiores de Planejamento Estratégico; Especialização em Gestão Estratégica da Informação; Especialização em MBA Finanças e Controladoria; Especialização em Programa Alta Dirección en un Entorno Globalizado. Atualmente é diretor - Nous SenseMaking, consultoria em estratégia e diretor regional da Cortex Intelligence, consultoria em inteligência competitiva., atuando principalmente nos seguintes temas: inteligência competitiva, estratégia, processo decisório e redes.

\section{Alcione Dias da Silva}

Possui graduação em Administração pela Faculdade de Ciências Contábeis e Administrativas de Cachoeiro de Itapemirim - FACCACI. Atuou como professor do Centro Universitário São Camilo-ES. Atua desde 1990, no setor público e privado, na área de Ciência da Computação, com ênfase em sistemas de informação, banco de dados e gerenciamento de projetos. Trabalha atualmente na empresa pública de tecnologia da informação e comunicação DATACI, onde atua como diretor de tecnologia da informação, atua também como Tutor à distância do IFES. Possui pós graduação em Comércio Internacional, Análise de Sistemas e Gerenciamento de Projetos pela Fundação Getúlio Vargas - FGV. É mestre em Pesquisa Operacional e Inteligência Computacional pela UCAM..

\section{Ana Cristina da Costa Piletti}

Doutoranda em Ciências da Comunicação pela Escola de Comunicações e Artes da Universidade de São Paulo (ECA/USP). Bacharel em Comunicação Social/ Relações Públicas pela Fundação Armando Álvares Penteado(2002), licenciada em Pedagogia pela Faculdade Paulista de Educação e Comunicação (2009), MBA Executivo em Marketing e Comunicação pela Escola Superior de Propaganda e Marketing (2005) e mestre em Educação pela Universidade de Sorocaba (2012).

\section{André Irazoqui de Lima}

Engenheiro de Produção pela Fundação Universidade Federal do Pampa com MBA em Gestão Empresarial pela Fundação Getúlio Vargas (FGV). Possui experiência nas áreas de automação industrial, programação (VBA - Excel, C e Ladder), aquisição de suprimentos, planejamento e controle da produção, gestão de contratos e manutenção. Como membro da Pampa's Engineering Solutions foi vencedor do 1ํㅡㄹ Desafio Startup Campanha no ano de 2015. 


\section{Antônio de Souza Silva Junior}

Graduado em Administração de Empresas pela Universidade de Pernambuco (2006). Mestre em Administração pela PROPAD/UFPE(2009). Doutor em Administração pelo PROPAD/UFPE (2014). Professor da Universidade Federal de Pernambuco Campus Recife, Departamento de Ciência da Informação.

\section{Bruno Missi Xavier}

Possui graduação em Sistemas de Informação pelo União Social Camiliana (ES)(2004) e mestrado em Pesquisa Operacional e Inteligência Computacional pela Universidade Candido Mendes(2012). Atualmente é Professor do Instituto Federal de Educação, Ciência e Tecnologia do Espírito Santo. Tem experiência na área de Ciência da Computação, com ênfase em Sistemas de Computação. Atuando principalmente nos seguintes temas:Mineração de Texto, Descoberta de Conhecimento.

\section{Carolina Yukari Veludo Watanabe.}

Bacharel em Matemática Aplicada e Computação Científica (2006), Mestre (2007) e Doutora (2013) em Ciência da Computação e Matemática Computacional pela Universidade de São Paulo (ICMC-USP São Carlos). Desde 2015 atua como docente e pesquisadora no Programa de Pós-Graduação Mestrado em Administração na Universidade Federal de Rondônia, na linha de pesquisa Estratégia, Gestão e Tecnologia em Organizações. Suas pesquisas na área de Administração incluem Estratégia e processo decisório, Aprendizagem em Organizações e Inovação e Tecnologia em Organizações.

\section{Claudio Sonaglio Albano}

Graduação Administração Empresas/URCAMP, 1986. Especialista em Ciências da Computação, PUC/RS - Porto Alegre, 1992. Mestre em Administração de Empresas, área Sistemas de Informação UFRGS, 2001 e Doutor em Administração pela FEAIUSP em 2014, com estágio sanduíche na Universidade Estadual de Nova York (EUA), no Centro Tecnologia para Governo (CTG, Albany). Professor da Universidade Federal do Pampa, campus Bagé. Tem experiência na área de Ciência da Informação, com ênfase em Teoria Geral da Informação, atuando principalmente nos seguintes temas: estratégia organizacional; tecnologia da informação e sistemas de informação, em especial, relacionados com governos. Professor nos cursos de graduação de Engenharias no Campus Bage. Professor e orientador na especialização latu sensu de Engenharia econômica, campus de Alegrete. Professor e 
orientador do mestrado acadêmico de Administração de Empresas, campus de Santana do Livramento.

\section{Daisy Campos Alvim}

"Doutora em Administração de Empresas pela UNaM (Universidad Nacional de Misiones), Argentina. Mestre em Administração de Empresas pela Fundação Getulio Vargas (FGV). Pós Graduada em Gestão de Negócios e Tecnologia pela Fundação Getúlio Vargas (FGV). Administradora de Empresas pela Faculdade Moraes Junior - Rio de Janeiro. Docente nos cursos de educação continuada da FGV.

Consultora de empresas do setor público e privado em modernização organizacional, com aplicação dos conceitos de, modelagem estratégica, gestão de projetos e gestão por processos de negócio. Projetos desenvolvidos para o setor financeiro, industrial, público, saúde, previdência privada, e telecomunicações."

\section{Daniel Arruda Coronel}

Professor Adjunto do Departamento de Economia e Relações Internacionais e dos Programas de Pós-Graduação em Gestão de Organizações Públicas e de Agronegócios da Universidade Federal de Santa Maria (UFSM). Atualmente é bolsista de produtividade do Conselho Nacional de Desenvolvimento Científico e Tecnológico (CNPq), diretor da Editora UFSM; editor associado da Revista Ciência Rural (Qualis B1 em Administração) e da Revista Práticas em Administração Pública (ISSN:2526-6292); acadêmico da Academia Santa-Mariense de Letras (ASL); membro do Comitê Assessor da área de Economia e Administração da Fundação de Amparo à Pesquisa do Estado do Rio Grande do Sul (FAPERGS); membro do Conselho Científico Permanente da Editora CRV; membro do Conselho Fiscal da Câmara do Livro de Santa Maria; parecerista de periódicos internacionais e nacionais. Foi coordenador substituto do Curso de Administração da UFSM (2011-2012); diretor da Sociedade Brasileira de Economia, Administração e Sociologia Rural (2013-2015) e secretário do Conselho Municipal de Cultura de Santa Maria (2016). É doutor em Economia Aplicada pela Universidade Federal de Viçosa (UFV); mestre em Agronegócios pela Universidade Federal do Rio Grande do Sul (UFRGS); bacharel em Administração pela Universidade do Vale do Rio dos Sinos (UNISINOS) (CRA-RS, Registro: 047444) e em Ciências Econômicas pela UFSM (CORECON-RS, Registro: 7811). 


\section{Délvio Venanzi}

Possui Doutorado em Educação - Universidade de Sorocaba (2016), graduação em Engenharia Elétrica pela Universidade de Mogi das Cruzes (1986),Mestrado em Administração de Empresas pelo Centro Universitário Santana (SP) (2000) e Mestrado em Engenharia de Produção pela Universidade Estadual Paulista Júlio de Mesquita Filho (2008). Atualmente é professor titular da Universidade de Sorocaba, Coordenador do Curso de Engenharia de Produção. Professor de Logística e Supply Chain da Faculdade de Tecnologia de Sorocaba (FATEC).

\section{Elias Garcia}

Graduação em Ciências Contábeis pela Unioeste (1988); Mestrado em Contabilidade pelo UNICS (1999); doutorado em Ciências Empresariais pela UMSA (Buenos Aires - Registrado no Brasil pela UFPR - 2008); doutorado em Letras/Linguística pela Unioeste (2016); Cursos de Especialização em Business Management pela Saint Johns University (NY); curso de aperfeiçoamento em Auditoria Contínua na Rutgers University (Newark - NJ - 2010); professor da graduação em Ciências Contábeis e do Mestrado em Gestão e Desenvolvimento Regional da Unioeste; Perito Judicial na Justiça Estadual e Federal na Comarca de Cascavel PR.; consultor do MEC para avaliação de cursos e de Instituições de Ensino; consultor de empresas públicas e privadas; palestrante nas áreas de Educação Corporativa e Acadêmica; Acadêmico Imortal da Academia de Ciências Contábeis do Paraná (Cadeira 07); no ensino, atua nas áreas de Sistemas de Informação; Tecnologia da Informação; Gestão de Custos e Perícia Contábil; na pesquisa, atua também na Linguística com foco na Ambiguidade Lexical; diversos artigos científicos publicados no Brasil e no exterior, bem como livro e capítulos de livros.

\section{Emanoély Fernanda Gura Vieira}

Especialista em Gestão de Projetos de Tecnologia da Informação pela PUCPR, com projeto na área de Gestão da Qualidade de Software e Tecnóloga em Análise e Desenvolvimento de Sistemas pela UTFPR Ponta Grossa, concluindo com trabalho na linha de Gestão da Informação. Atualmente atua como Desenvolvedora JAVA Pleno e TeamLeader na área cartorária." 


\section{Fernanda Mosseline Josende Coan}

Doutoranda do Programa de Ciências Contábeis da UNISINOS, possui mestrado em Ciências Sociais pela UNISINOS, graduação em Ciências Contábeis pela UFMT.

\section{Fernando Ribeiro dos Santos}

Doutor em Administração de Empresas pela Universidade Presbiteriana Mackenzie (2015), Mestre em Gestão de Negócios pela Universidade Católica de Santos (UniSantos - 2006), Pós-graduado em Modelos Organizacionais pelo Centro Universitário Monte Serrat (Unimonte - 2003), MBA em Marketing pela Fundação Getúlio Vargas (FGV - 2000) e Bacharel em Administração pela Associação de Ensino Unificado do Distrito Federal (AEUDF - 1997). Atualmente é professor efetivo (concursado) do IFSP - Campus Cubatão; da FATEC/PG e da Unimes Virtual, trabalhando em Ensino a Distância (EAD) desde 2008 como Professor Tutor nos Bacharelados e nos Tecnólogos e desde 2007 como Professor Autor (conteudista).

\section{Flávio de São Pedro Filho}

Pós-Doutor em Gestão e Economia na Universidade da Beira Interior (UBI), Covilhã, Portugal (2017), com o Projeto de Pesquisa aprovado intitulado "Estratégia de gestão para inovação e sustentabilidade". É Doutor em Administração (2010), pela Universidade de São Paulo (USP), conforme Apostila de revalidação de título. Doutor em Gestão de Empresas (2009), laureado Magna cum Laude pela Universidad Autónoma de Asunción (UAA). É Mestre em Engenharia de Produção (2004), na área de Gestão de Negócio, pela Universidade Federal de Santa Catarina. É Bacharel em Administração (1982) pela EAUFBA. Professor de Inovação e Sustentabilidade no PPGMAD/UNIR e Pesquisador na Universidade Federal de Rondônia.

\section{Geórgia Regina Rodrigues Gomes}

Possui graduação em Licenciatura em Ciências com habilitação em Matemática pela Faculdade de Filosofia de Itaperuna (1989), Análise de Sistemas pela PUC-Rio (1991), mestrado em Informática pela Pontifícia Universidade Católica do Rio de Janeiro (1999) e doutorado em Informática pela Pontifícia Universidade Católica do Rio de Janeiro(2006). Atuou como Analista de Sistemas de 1992 a 2003 na PUC-Rio, trabalhando em desenvolvimento e na manutenção de sistemas de informação corporativos e como coordenadora de desenvolvimento de sistemas. Atua no magistério desde 2000 e no superior desde 2006. Trabalhou como professora Adjunta da Universidade Candido Mendes e como Professora/Diretora de Ensino do IFF-Itaperuna. Atualmente é vice_diretora e professora 
adjunta da Universidade Federal Fluminense/INFES e professora colaboradora do mestrado da Universidade Candido Mendes. Tem experiência na área de Ciência da Computação, com ênfase em Sistemas de Computação, atuando principalmente nos seguintes temas: Mineração de Dados, Mineração de Texto, Integração de Banco de Dados, Bibliotecas Digitais, Metadados, Recuperação da Informação, Educação a Distância, Sistemas de Informação.

\section{Haroldo Lhou Hasegawa}

Possui graduação em Engenharia de Materiais pela Universidade Federal de São Carlos (2000), mestrado em Ciência e Engenharia dos Materiais pela Universidade Federal de São Carlos (2004) e doutorado em Programa de Pós Graduação em Ciência e Engenharia de Materiais pela Universidade Federal de São Carlos (2007) também é especialista em Engenharia de Produção pelo Curso de Especialização em Engenharia de Produção pela UNESP (2010). Atualmente é professor adjunto-a da Universidade Federal de Itajubá.

\section{Henrique Rego Monteiro Da Hora}

Graduado em Tecnologia em Informática pelo então CEFET-Campos (2004), mestre em Engenharia de Produção pela Universidade Estadual do Norte Fluminense Darcy Ribeiro (2007) e doutor em Engenharia de Produção pela Universidade Federal Fluminense (2013). Atualmente é Diretor de Internacionalização e Inovação do IFFluminense e coordenador Adjunto do Mestrado em Sistemas Aplicados à Engenharia e Gestão do IFFluminense, e leciona e orienta no Mestrado em Pesquisa Operacional e Inteligência Computacional da UCAM-Campos. Atua na área de otimização discreta, principalmente com métodos multicritério.

\section{Janaina Wohlenberg}

Graduada em Administração de Empresas, pela Universidade de Passo Fundo, Mestre e Doutoranda do curso de Tecnologia Ambiental, pela Universidade de Santa Cruz do Sul. Docente na Universidade Federal do Pampa (UNIPAMPA), atuando junto aos Programas de Graduação de Tecnologia em Agronegócio, Enologia e Zootecnia e no Programa de Pós Graduação em Agronegócio. Tem experiência na área de Administração de Empresas, com ênfase em Gestão Estratégica Organizacional, Gestão Orçamentária e Contábil e Gestão Ambiental. 


\section{João Pedro Albino}

Possui graduação em Tecnologia em Processamento de Dados pela Fundação Educacional de Bauru (1978), graduação em Bacharelado em Ciências da Computação pela Universidade Estadual Paulista Júlio de Mesquita Filho - UNESP (1989), mestrado em Ciência da Computação pela Universidade Federal de São Carlos - UFSCar (1993) e doutorado em Administração, área Métodos Quantitativos e Informática, pela Faculdade de Economia, Administração e Contabilidade - FEA, da Universidade de São Paulo - USP (1999). Fez PósDoutorado na FEA-USP (2008), em Inovação e Gestão Tecnológica e Estágio de Pósdoutoramento na Universidade de Aveiro, em Portugal (2006-2007), na área de Gestão do Conhecimento.

\section{Jorge Bidarra}

Bacharelado Ciência da Computação ( UFRJ, 1980), Mestrado Engenharia de Sistemas e Computação (UFRJ, 1988), Doutorado Linguística Computacional (UNICAMP, 2001) e PósDoutorado Processamento da Linguagem Natural (UFSC/University of Sheffield)/Bolsista CAPES-Fund. Araucária. Professor Associado C UNIOESTE (cursos Ciência da Computação, Mestrado/Doutorado Linguística (linha de pesquisa: mecanismos da linguagem, lexicologia/lexicografia, extração de informação em bases de textos). Grupos de Inteligência Aplicada e Pesquisa Linguagem e Sociedade (UNIOESTE/CNPq). Experiência profissional: Empresas e Docência. Áreas de Interesse/Pesquisa: Tecnologias Assistivas, Interface Humano-Computador e PLN/Linguística Computacional. Pesquisa em Andamento: Sistema Bilíngue de tradução automática Português-LIBRAS (PORLIBRAS).

\section{Jose Eduardo Pecora Jr}

Professor do Departamento de Adminstração Geral e Aplicada da UFPR, Ph.D. em Administração de Empresas, pela Université Laval no Canadá, Mestre e Bacharel em Matemática Aplicada e Computacional pela Universidade Estadual de Campinas. Membro colaborador do Centre interuniversitaire de recherche sur les reseaux d'entreprise, la logistique et le transport (CIRRELT). Tem experiência na área de Pesquisa Operacional, com ênfase em Matemática Discreta e Combinatória, atuando principalmente nos seguintes temas: otimização combinatória e aplicações das técnicas de pesquisa operacional à problemas industriais reais, redes logísticas, supply chain, administração da produção e gestão de projetos. 


\section{Larissa Lourenço Nunes Benck}

"Graduação em Tecnologia em Análise e Desenvolvimento de Sistemas em 2011 pela Universidade Tecnológica Federal do Paraná, UTFPR, Ponta Grossa, Brasil

MBA em Gestão de Tecnologia da Informação em 2014 pelo Instituto Döll, Faculdade Santana, Ponta Grossa, Brasil. Tem atuado como Programador Java,Framework (Grails ,JasperReports) e Openreports. Otimização de query. Modelagem de dados utilizando o Power Designer. Análise e Planejamento de Sistemas."

\section{Laura Melo Barros Bona Miranda}

outora em Administração de Empresas pela Universidade Presbiteriana Mackenzie na Linha de Recursos e Desenvolvimento Empresarial, com bolsa CAPES-PROSUP, modalidade II. Mestre também em Administração pela Universidade de Fortaleza - Unifor. Graduada em Administração de Empresas e Bacharel em Comunicação Social com habilitação em Publicidade e Propaganda. Atuando na área da docência desde 2005, com cursos de extensão, graduação e especialização, além de participações em congressos como palestrante.

\section{Luciane Ines Matte}

Mestra em Gestão de Organizações Públicas do Programa de Pós-Graduação em Administração da UFSM - 2014. Bacharel em Ciências Contábeis pela Fundação Universidade Federal do Rio Grande - FURG - 2006. Possui experiência na área de Administração e Ciências Contábeis. Já atuou em atividades relacionadas a Gestão de Patrimônio, Recrutamento, Seleção, Treinamento/Instrutoria e Folha de Pagamento. Atualmente é contadora na Pró Reitoria de Administração, da Universidade Federal de Santa Maria/UFSM.

\section{Luiz Gabriel Pereira Herzog}

Bacharel em Engenharia de Produção pelo Instituto Federal de Educação, Ciência e Tecnologia do Espírito Santo (IFES). 


\section{Marcelo Elias dos Santos}

Doutorando do Programa de Administração de Organizações da FEA-RP/USP, possui mestrado em Administração de Organizações pela FEA-RP/USP, graduação em Ciências Contábeis pela Unemat, graduação em Administração de Empresas pela UFMT e MBA em Gestão Estratégica de Pessoas e Organizações Sustentáveis pela Fundace/USP.

\section{Marcelo Tadeu Monteiro Freitas}

Possui graduação em Administração pela FACCACI (1995), Pós-Graduação em Análise de Sistemas (1997) e Tecnologia e Projetos de Redes (2000) pela Estácio de Sá, MBA em Gerenciamento de Projetos pela FGV (2008) e Mestrado em Pesquisa Operacional e Inteligência Computacional pela UCAM (2007). Atualmente é professor titular da FACCACI nas disciplinas de Sistemas de Informações Gerenciais, Informática Aplicada e Gerenciamento de Projetos. Também exerce o cargo de Analista de TI na Companhia de Tecnologia da Informação de Cachoeiro de Itapemirim (DATACI), desde 1990, onde atua nas áreas de Desenvolvimento de Sistemas, Administração de Banco de Dados e Gerenciamento de Projetos.

\section{Maria Eugenia S.S. Vasconcelos}

Mestre em Pesquisa Operacional e Inteligência Computacional pela Universidade Cândido Mendes(2017), possui graduação em Engenharia de Produção pelo Instituto Tecnológico e das Ciências Sociais Aplicadas e da Saúde (2009) assim como em Licenciatura em Ciências da Natureza pelo Instituto Federal Fluminense (2005). Atualmente é professor da Prefeitura Municipal de Campos dos Goytacazes, da Secretaria de Educação do Estado do Rio de Janeiro (SEEDUC) e do Instituto Tecnológico e das Ciências Sociais Aplicadas e da Saúde (ISECENSA). Possui experiência na área de Engenharia de Produção, com ênfase em Garantia de Controle de Qualidade. É Pesquisadora nas áreas de gestão da qualidade, métodos de auxílio multicritério a decisão, mineração de dados e mineração de texto.

\section{Marilyn de Souza Cyganczuk}

É mestre em Engenharia de Produção pela Universidade Federal do Paraná (2017). Possui graduação em Administração pela Universidade Federal do Paraná (2014). Atua na área administrativa na Universidade Federal do Paraná. Tem experiência profissional com atuação nas áreas Administrativa, Contábil e Financeira. 


\section{Michel Stein Barbosa}

Bacharel em Engenharia de Produção pela Universidade Federal do Pampa com Especialização em controladoria e Finanças pela Universidade Católica de Pelotas. Trabalhando na área de gestão bancária.

\section{Munir de Sá Mussa}

Graduado em Sistemas de Informação pelo Instituto Federal Fluminense (2012) e mestrando em Sistemas Aplicados à Engenharia e Gestão pelo Instituto Federal Fluminense. Atualmente é professor substituto na área de informática no Instituto Federal Fluminense. Possui experiência na área de Tecnologia da Informação. Atua em pesquisas na área de gestão de TI.

\section{Murilo Gonçalves Almeida}

Acadêmico do oitavo período em Administração da Fundação Universidade Federal de Rondônia. Servidor Público do Estado de Rondônia.

\section{Osmarina Pedro Garcia Garcia}

Graduação em Ciências Contábeis pela Unioeste (1987); Especialização em Contabilidade e Gestão Estratégica pela Unioeste (1999); Especialização em Auditoria e Perícia Contábil pela Unioeste (2001); Mestrado em Gestão e Desenvolvimento Regional pela Unioeste (2015); perita contábil na Justiça Estadual na comarca de Cascavel PR; consultora de empresas na área de gestão de pessoas e gestão do conhecimento; diversos artigos científicos publicados em periódicos e eventos científicos bem como capítulo de livros.

\section{Pablo de Lima}

Bacharel em Ciências Contábeis pela Universidade do Estado de Mato Grosso 


\section{Rafael Leite de Freitas}

Tecnólogo em Desenvolvimento de Software (2009) e especialista em Análise, Projeto e Gerência de Sistemas de Informação (2015) pelo Instituto Federal Fluminense. Mestrando em Sistemas Aplicados a Engenharia e Gestão, também pelo Instituto Federal Fluminense. Atualmente é Tecnólogo em Informática e Comunicação do Instituto Federal Fluminense, atuando no desenvolvimento de sistemas para a instituição. Realiza pesquisas em derivação de requisitos de software a partir de modelos de processo de negócio melhorados.

\section{Renata Gomes Cordeiro}

Bacharela em Ciência da Computação (2014) pela Universidade Estadual do Norte Fluminense Darcy Ribeiro. Pós-graduada em Engenharia de Sistemas (2016) pela Escola Superior Aberta do Brasil. Mestranda em Sistemas Aplicados à Engenharia e Gestão pelo Instituto Federal Fluminense. Analista de Tecnologia da Informação no Instituto Federal Fluminense desde 2015, atuando na área de desenvolvimento de software. Atualmente realizando pesquisas na área de Mineração de Dados Educacionais.

\section{Ricardo Mendes Junior}

Graduado em Engenharia Civil pela Universidade Federal do Paraná, doutorado em Engenharia de Produção e Sistemas pela Universidade Federal de Santa Catarina, e pósdoutorado em Tecnologia da Informação na Construção (2014). Foi sócio diretor de empresas de tecnologia e consultoria em Curitiba. É professor da Universidade Federal do Paraná desde 1981, onde atuou no curso de Engenharia Civil e desde 2008 atua no curso de Engenharia de Produção. Desde 2000 atua em cursos de pós-graduação e pesquisa, desenvolvimento e inovação nas áreas gerenciamento de projetos, gestão da informação, planejamento da produção na construção e BIM.

\section{Rodolfo de Amorim Paulo}

Possui graduação em Engenharia de Produção pelo Instituto Federal de Educação, Ciência e Tecnologia do Espírito Santo(2016), curso-tecnico-profissionalizante em Técnico em Edificações pelo Instituto Federal de Educação, Ciência e Tecnologia do Espírito Santo(2009) e ensino-medio-segundo-graupelo Colégio Castro Alves(2007). Tem experiência na área de Engenharia de Produção 


\section{Silvio Luiz de Paula}

Possui doutorado, mestrado e graduação em administração pela Universidade Federal de Pernambuco-UFPE. Atualmente é professor de Gestão da Informação no Departamento de Ciência da Informação na Universidade Federal de Pernambuco-UFPE. Tem experiência na área de administração, com ênfase em gestão de pessoas, comunicação organizacional, responsabilidade social, comportamento organizacional, pesquisando atualmente as temáticas competência informacional e mediação da informação.

\section{Simone de Almeida}

Bacharel em Processamento de Dados pela Universidade Estadual de Ponta Grossa (1991), Especialista em Ciência da Computação pela Universidade Estadual de Ponta Grossa (1992), Mestre em Engenharia de Produção pela Universidade Tecnológica Federal do Paraná (2005) e Doutora em Engenharia de Produção na Universidade Federal de Pernambuco (2012). Atualmente é professora da Universidade Tecnológica Federal do Paraná. Tem experiência na área de Engenharia de Software, Banco de Dados, Gerenciamento de Projetos e Análise e Desempenho de Processos atuando principalmente nos seguintes temas: Desenvolvimento de Sistemas de Informação, Tomadas de Decisão, Avaliação de Desempenho.

\section{Simone Vasconcelos Silva}

Doutora em Computação pela Universidade Federal Fluminense (UFF). Mestre em Engenharia de Produção pela Universidade Estadual do Norte Fluminense (UENF). Diretora de PósGraduação do Instituto Federal Fluminense (IFFluminense). Coordenadora do Curso de Mestrado Profissional de Sistemas Aplicados à Engenharia de Gestão e docente nos cursos na área de Informática do IFFluminense desde 1997. Coordenadora dos núcleos de pesquisa NES - Núcleo de Engenharia de Software e do GProQS - Gestão de Processos e Qualidade de Serviços. Diretora de Gestão de Projetos no Pólo de Inovação Campos dos Goytacazes do IFFluminense. Profissional certificada na área de Gerência de Projetos e Processos, com mais de 15 anos de experiência e atuando em diversos projetos.

\section{Stephany Pereira dos Santos}

Graduanda em Engenharia de Produção pelo Instituto Federal do Espírito Santo, Campus Cariacica. 


\section{Thiago José Barbosa Dantas.}

Graduando do Curso de Administração de Empresas da Fundação Universidade Federal de Rondônia - UNIR, Técnico em Radiologia pela Faculdade Paulista de Tecnologia - FAPTEC. Atualmente Servidor Público na Secretaria de Estado da Saúde de Rondônia.

\section{Tiberius Mariano Medeiros}

Graduado em Gestão da Informação pela Universidade Federal de Pernambuco-UFPE e pósgraduado em Planejamento e Gestão organizacional pela Universidade de Pernambuco-UPE, possui experiência profissional em planejamento e gestão do conhecimento no âmbito da Gestão Pública Estadual.

\section{Tomás Daniel Menendez Rodriguez}

Possui Doutorado em Matemática na Saint Petersburg State University (1992). Pós-Doutorado em Matemáticas na Associação Instituto de Matemática Pura e Aplicada - IMPA, Rio de Janeiro em 2004. Atualmente é professor titular da Universidade Federal de Rondônia. Tem experiência docente e de pesquisa nas áreas de Matemática (Análise Funcional e Equações Diferenciais), Matemática Aplicada e Modelagem, Matemática Financeira, Matemática Computacional, Pesquisa Operacional, Construção de Índices e Indicadores . É Professor de Análises Estatísticas e de Métodos Quantitativos de Pesquisa do Mestrado de Administração da UNIR e Professor do Mestrado Profissional de Matemática em Rede Nacional - PROFMAT.

\section{Udo Strassburg}

Possui graduação em Ciências Contábeis pela Universidade Estadual do Oeste do Paraná (1987), mestrado em Ciências Contábeis pela Fundação Alvares Penteado - FECAP - SP (2001) e doutorado em Desenvolvimento Regional e Agronegócio pela UNIOESTE (2016). É professor da graduação e do Programa de Mestrado em Contabilidade da UNIOESTE, perito do juízo - JUSTIÇA ESTADUAL CÍvEL, consultor do MEC. Tem experiência na área de Ciências Contábeis com ênfase em Teoria da Contabilidade Perícia Contábil, atuando principalmente nos seguintes temas: contabilidade, finanças e evidenciação, sistema de informação, avaliação de desempenho, tecnologia da informação, custos e perícia contábil. É membro da Academia de Ciências Contábeis do Paraná. Publicou um livro e 9 capítulos de livros e mais de 100 artigos em Revistas e Congressos Nacionais e Internacionais. 


\section{Valderez Ferreira Fraga}

Doutora em Educação pela UFRJ. Mestre em Education and Human Development pela GWUWashington DC. Especialização em Metodologia do Ensino de Terceiro Grau pela UNESP. Graduação em Ciências Jurídicas e Sociais pela UFP/UniCeub . Experiência em coordenação em GRH no ITA. Docente convidada Mestrado e Doutorado FGV-EBAPE e UFRJ-IE- ECEX. Artigos em periódicos e jornais, livros em Fenomenologia/Gestão e Tansculturalidade. Consultora de organizações públicas e privadas, nacionais e multinacionais pela Valore-RH.

\section{Vaneska Tavares Rangel Prestes}

Possui Mestrado em Engenharia de Produção pela Universidade Candido Mendes (2017) e graduação em Direito pela mesma Universidade (2003). Exerceu o cargo de Controladora Geral do Município de Campos dos Goytacazes por 2 anos (2013-2014), tendo trabalhado neste órgão pelo período de 11 anos. Atualmente exerce o cargo de Auditora no Instituto Federal Fluminense. Tem experiência na área de Direito Público, com ênfase em Controladoria da Gestão Fiscal e Auditoria. É Pesquisadora nas áreas de auditoria, métodos de auxílio multicritério a decisão, mineração de dados e mineração de texto.

\section{Vidal Dias da Mota Junior}

Graduado em Ciências Sociais pela Universidade Estadual Paulista Júlio de Mesquita Filho (UNESP,1999), Especialista em Gestão Pública e Gerência de Cidades (UNESP, 2002), Mestre em Ciências Sociais pela Universidade Federal de São Carlos (UFSCar,2002) e Doutor em Ciências Sociais pela Universidade Estadual de Campinas (UNICAMP,2006). Diretor de Operações do Parque Tecnológico de Sorocaba (2015-2017). Secretário Adjunto de Habitação e Regularização Fundiária de Sorocaba-SP (2017). Professor Titular da Universidade de Sorocaba (Uniso).

\section{Willen Borges Coelho}

Possui título de mestre em Pesquisa Operacional e Inteligência Computacional pela Universidade Cândido Mendes (2013), pós graduação em Gestão Educacional com Ênfase em Administração, Orientação e Supervisão Escolar na Faculdade de Educação da Serra FASE (2009) e graduação em Sistemas de Informação pelo Centro Universitário São Camilo (2005). Atualmente é Analista de Tecnologia da Informação do Instituto Federal de Educação, Ciência e Tecnologia do Espírito Santo. Tem experiência na área de Ciência da Computação, com ênfase em Ciência da Computação, atuando principalmente nos seguintes temas: linux, software livre e infraestrutura de rede. 


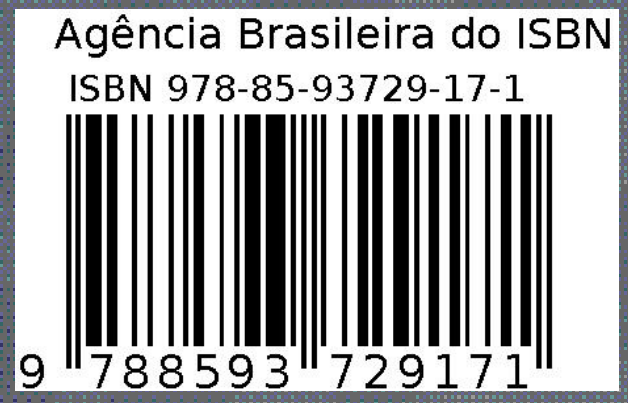

